NBSIR 79-1759R

\title{
Low Velocity Performance of Anemometers
}

L P Purtell

Natic ial Bureau of Standards

Fluid Engineerıng Division

Washıngton, D.C. 20234

May 1979

Final Report

on

Contract No. H0166198

Evaluation of the Behavior of Mine Anemometers in the NBS Low Velocity Calibration Facility

Prepared for

United States Department of the Interior Bureau of Mines 

NBS-114A (REV. 0-76)

\begin{tabular}{|c|c|c|}
\hline $\begin{array}{l}\text { U.S. DEPT. OF COMM. } \\
\text { BIBLIOGRAPHIC DATA } \\
\text { SHEET }\end{array}$ & $\begin{array}{l}\text { 1. PUBLICATION OR REPORT NO. } \\
\text { NBSIR } 79-1759 /\end{array}$ & 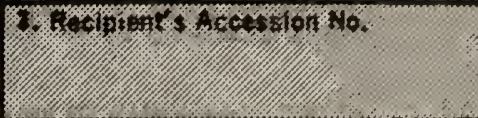 \\
\hline \multicolumn{2}{|l|}{ 4. TITLE AND SUBTITLE } & $\begin{array}{l}\text { 5. Publication Date } \\
\text { May } 1979\end{array}$ \\
\hline \multicolumn{2}{|c|}{ LOW VELOCITY PERFORMANCE OF ANEMOMETERS } & 3. Poriving Ormaization Code \\
\hline \multicolumn{2}{|l|}{$\begin{array}{l}\text { 7. AUTHOR(S) } \\
\text { L.P. Purtell }\end{array}$} & $\begin{array}{l}\text { 8. Performing Organ. Report No. } \\
\text { NBSIR 79-1759/ }\end{array}$ \\
\hline \multicolumn{2}{|c|}{ 9. PERFORMING ORGANIZATION NAME AND ADDRESS } & Ie polpeertaknork Unit No. \\
\hline \multicolumn{2}{|c|}{$\begin{array}{l}\text { NATIONAL BUREAU OF STANDARDS } \\
\text { DEPARTMENT OF COMMERCE } \\
\text { WASHINGTON, DC } 20234\end{array}$} & $\begin{array}{l}\text { 11. Contract/Grant No. } \\
\text { H0166198 }\end{array}$ \\
\hline \multirow{2}{*}{\multicolumn{2}{|c|}{$\begin{array}{l}\text { 12. SPONSORING ORGANIZATION NAME AND COMPLETE ADDRESS (stroot, CIty, stalo, zIP) } \\
\text { Office of the Assistant Director - Mining } \\
\text { Bureau of Mines } \\
\text { United States Department of the Interior } \\
\text { Washington, D. C. } 20241\end{array}$}} & $\begin{array}{l}\text { 13. Type of Report \& Period Covered } \\
\text { Dec. } 1,1976 \text {-Fina1-- } \\
\text { Nov. } 30,1978\end{array}$ \\
\hline & & 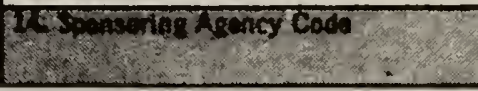 \\
\hline
\end{tabular}

15. SUPPLEMENTARY NOTES

Document describes a computer program; SF-185, FIPS Software Summary, is attached.

16. ABSTRACT (A 200-word or loso tactual aummary of moot elgnilicant information. Il documont includos a signilicant bibliography or literature survey, montion it here.)

The performance of ten anemometers of several types has been measured at low air speeds. Multiple calibration runs provided sufficient clata for measuring random error about the mean calibration curve in addition to the difference between indicated and true speeds. Measurements were also performed of the minimum operating speeds of the anemometers.

17. KEY WORDS (oix to twolve ontries; alphabetical order; capitalize only the firet lotter of the firat key word unloee a propor name; -oparated by somicolons)

Airflow; anemometer; laser velocimeter; low velocity; mine ventilation; wind tunnel.

18. AVAILABILITY

$\square$ Unlimited

[X] For Official Distribution. Do Not Release to NTIS

Order From Sup. of Doc., U.S. Government Printing Office, Washington, DC 20402, SD Stock No. SNOO03-003-

Order From National Technical Information Service (NTIS), Springfield, VA. 22161

\begin{tabular}{|l|l|}
$\begin{array}{l}\text { 19. SECURITY CLASS } \\
\text { (THIS REPORT) }\end{array}$ & $\begin{array}{l}\text { 21. NO. OF } \\
\text { PRINTED PAGES } \\
\text { UNCLASSIFIED }\end{array}$ \\
\hline $\begin{array}{l}\text { 20. SECURITY CLASS } \\
\text { (THIS PAGE) } \\
\text { UNCLASSIFIED }\end{array}$ & 22. Price \\
\hline
\end{tabular}


This report was prepared by the National Bureau of Standards, Fluid Engineering Division, Washington, D. C. 20234, under USBM Contract Number H0166198. The contract was initiated under the Coal Mine Health and Safety Program. It was administered under the technical direction of PM\&SRC, with Dr. George H. Schnakenberg, Jr., acting as the Technical Project Officer. Mr. H. R. Eveland was the contract administrator for the Bureau of Mines. This report is a summary of the work recently completed as part of this contract during the period December 1, 1976, and November 30, 1978. This report was submitted by the author May 1979 . 


\section{LOW VELOCITY PERFORMANCE OF}

\section{ANEMOMETERS}

L. P. Purtell

Fluid Engineering Division

Center for Mechanical Engineering and Process Technology

National Engineering Laboratory

National Bureau of Standards

Washington, D.C. 20234

May 1979

Final Report

Prepared for

United States Department of the Interior

Bureau of Mines

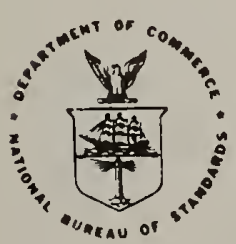

U.S. DEPARTMENT OF COMMERCE, Juanita M. Kreps, Secretary Jordan J. Baruch, Assistant Secretary for Science and Technology NATIONAL BUREAU OF STANDARDS, Ernest Ambler. Director 



\section{NOMENCLATURE}

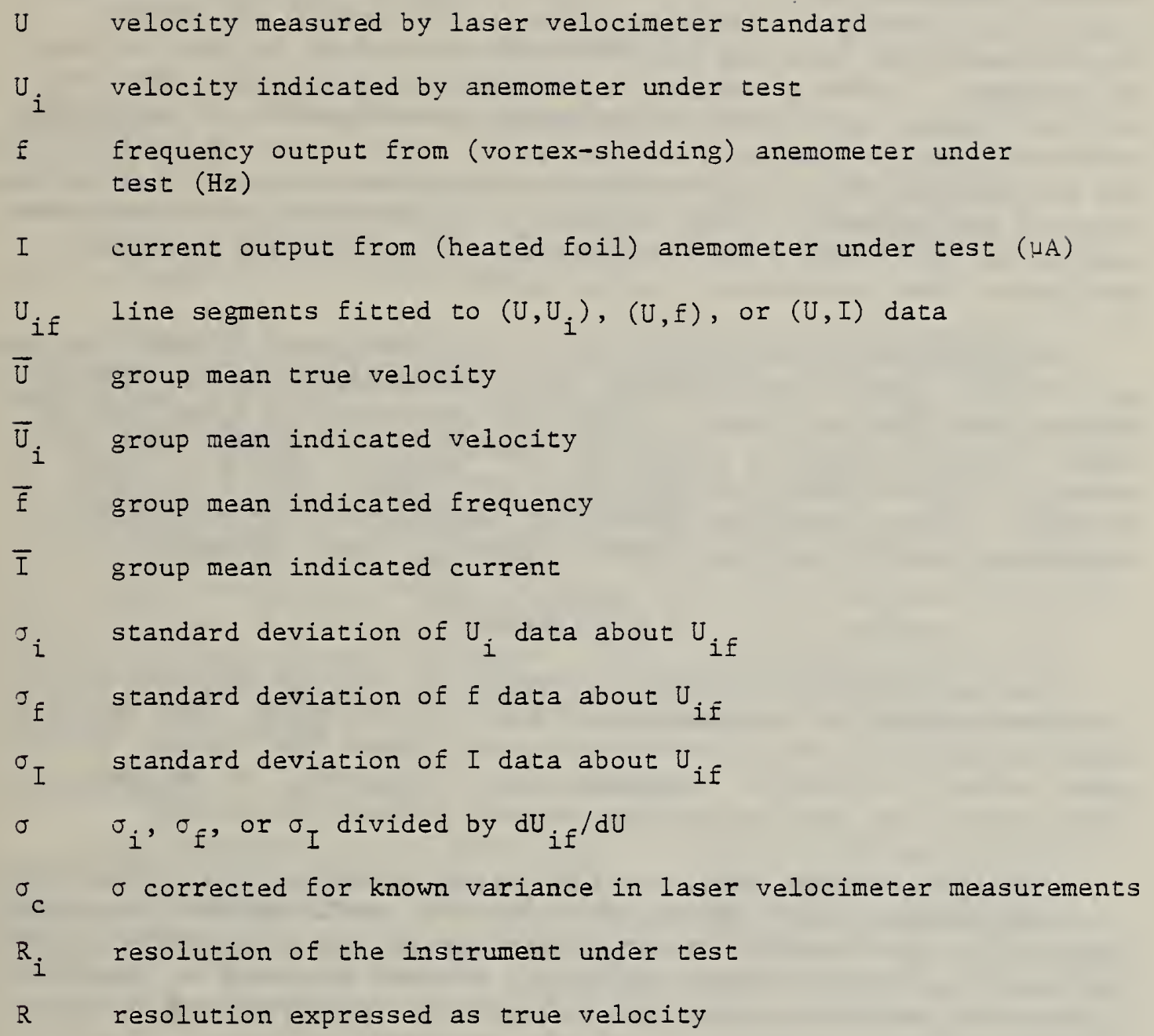




\section{INTRODUCTION}

The National Bureau of Standards in order to meet the need for a calibration capability with adequate accuracy at low air velocities, i.e., below 2.5 meters per second, undertook the development of a lowvelocity calibration facility for wind speed measuring instruments which would provide a capability down to 0.05 meters per second (approximately 10 feet per minute) with an accuracy of plus or minus one percent. It was a natural consequence therefore that when said facility became operational to undertake an evaluation of the stateof-the-art and to provide the information needed as to the reliability and performance of instrumentation for such measurement. Thus various types of instruments for low velocity air measurement have undergone testing at NBS. This report summarizes the results and presents analyses of the instruments' performance.

Performance is measured in terms of a comparison between indicated and true air speed, the variation in repeated measurements, and the minimum operating air speed. Since the indicated air speed may be easily corrected using a chart, for instance, to find the true air speed, the latter two measurements of performance are of primary interest. Thus a detailed handling of random error is presented including the effect of instrument resolution where necessary.

\section{THE FACILITY}

The data reported here were measured in the Low Velocity Airflow Facility [1] at the National Bureau of Standards. The facility consists primarily of a low velocity wind tunnel and a laser velocimeter velocity standard. The wind tunnel (Figure 1) is an open return type with the fan pulling the air through the tunnel.

The test section, $6.1 \mathrm{~m}$ in length and nominally $0.91 \mathrm{~m}$ by $0.91 \mathrm{~m}$ in cross-section, is constructed of acrylic panels mounted in a steel frame. The test section is supported from above by I-beams to allow the laser velocimeter traversing gear, mounted on rails on the floor of the room parallel to the test section, to be positioned at any location along the length of the test section.

The performance of the wind tunnel in terms of steadiness, flatness of mean velocity profiles, and turbulence level is extremely satisfactory. No drift in air velocity during a test was detected. The mean velocity profiles outside of the wall boundary layers are flat to within $0.5 \%$ even as close as 1 meter from the entrance to the test section. The residual turbulence intensity is less than $0.05 \%$.

A laser velocimeter is used as the velocity standard. It is linear with velocity from first principles and does not suffer a 
severe loss of resolution at very low velocities as does, for instance, the Pitot-static tube. Furthermore, it is nonintrusive and has good spatial resolution. Adequate sensitivity is obtained in the facility without the artificial seeding of scattering particles. Thus the difficulties and inconvenience associated with seeding and the possible effect of such seeding on the performance of the device under test are avoided.

\section{THE INSTRUMENTS}

Instrument A -- Bronze bearing vane anemometer.

A11 of the vane anemometers tested have flat vanes without camber or twist as opposed to helicoidal types. All but one (instrument $E$ below) are entirely mechanical and require only a timer (stopwatch) for operation.

Instrument $A$ is a commercially available instrument (Davis Instrument Manufacturing Company, Incorporated, 4-Inch Low Speed Anemometer, S/N 22889). I It was supplied for test by the U. S. Mining Enforcement and Safety Administration (MESA) at the request of the U. S. Bureau of Mines. The housing is 4 inches $(10.2 \mathrm{~cm})$ in diameter and $1-3 / 4$ inches $(4.4 \mathrm{~cm}$ ) deep (Figure 2). Thin metal vanes without camber or twist mounted on arms drive a rotor linked to a dial indicator by a gear train. The bearings in this particular instrument are standard bronze bearings (as opposed to ball bearings). One revolution on the dial represents an indicated passage of 100 feet of air through the instrument. Thus an external timer (not a part of the anemometer) is required to complete a measurement of velocity (an average velocity for the duration of the measurement).

Instrument $B$ - Ball bearing vane anemometer.

This anemometer is a commercially available instrument (Davis Instrument Manufacturing Company, Incorporated, 4-Inch Low Speed Anemometer, S/N 24323 B). It was supplied for test by the $U$. S. Mining Enforcement and Safety Administration (MESA) at the request of the U. S. Bureau of Mines. As may be seen in Figure 3, it is identical to instrument $A$ except that the bearings are ball bearings instead of bronze bearings.

Instrument $C$ - Jewel bearing vane anemometer.

This anemometer is a commercially available instrument (Sybron/ Taylor Corporation, 4-Inch Anemometer, S/N H873). It was supplied for test by the U. S. Mining Enforcement and Safety Administration (MESA) at the request of the U. S. Bureau of Mines. It is very

\footnotetext{
These particular instruments were selected as being representative of the type of anemometer and their selection does not represent an endorsement.
} 
similar in appearance (Figure 4) to instruments $A$ and $B$ though the dimensions of the hub and shroud are slightly different. The bearings, however, are jewel instead of bronze or ball bearing.

Instrument D - High speed vane anemometer.

This anemometer is a commercially available instrument (Davis Instrument Manufacturing Company, Incorporated, 4-Inch High Speed Anemometer, S/N 31125B). It was supplied for test by the U. S. Mining Enforcement and Safety Administration (MESA) at the request of the U.S. Bureau of Mines. This anemometer (Figure 5) is dimensionally identical to instrument $B$, including ball bearings, but has four vanes instead of eight, thus permitting operation at higher air speeds.

Instrument E -- Magnetic pick-up vane anemometer.

This anemometer is a commercially available instrument (Abbirko Instruments, Limited, Flowmaster, $S / N$ 6184). It was supplied for test by the U. S. Mining Enforcement and Safety Administration at the request of the U.S. Bureau of Mines. The instrument's vane housing is approximately 2.75 inches $(7.0 \mathrm{~cm}$ ) in diameter (see Figure 6) with an attached block for the magnetic pick-up, or proximity transducer, and a handle projecting down from the block. The magnetic pick-up detects the passage of the metal vanes, and the resulting electrical signal is converted to a deflection of a meter connected to the probe by a cable. The meter was located outside the tunnel during the tests and was oriented horizontally. Three ranges of operation are selectable: $10 \mathrm{w}-0$ to $300 \mathrm{fpm}$, medium - 0 to $1000 \mathrm{fpm}$, and high - 0 to $3000 \mathrm{fpm}$. The anemometer requires a 9 volt battery for operation.

Instrument F - Full size impact-deflection anemometer.

This type of anemometer operates from the dynamic pressure of the air stream. This pressure is converted to a deflection of a dial indicator by impacting a small vane linked to the meter. The operation is thus entirely mechanical.

Instrument $F$ is a commercially available instrument (Alnor Instrument Company, Velometer, Series 6000-P). It was supplied for test by the U.S. Mining Enforcement and Safety Administration at the request of the U.S. Bureau of Mines. The instrument (Figure 7) consists of a main body meter (approximately $15 \times 17 \times 6 \mathrm{~cm}$ ) with connections for one of several probes. The Pitot probe is composed of a cylinder 0.5 inches $(1.27 \mathrm{~cm})$ in diameter and 13 inches $(33 \mathrm{~cm})$ long which mounts in a range selector unit connected to the main body by hoses. The cylinder has ports to admit the airflow and must be properly oriented in the airstream to obtain a reading. The range selector may be set to one of two ranges, 100-1250 fpm (1ow range) and 100-2500 fpm (high range). Other range selectors are available, 
but were not tested herein.

The diffuser probe (Figure 8 ) is similar to the Pitot probe except that only impact pressure is utilized in the diffuser probe thus requiring a vent to be opened in the range selector for operation. It operates over the same ranges as the Pitot probe.

The low velocity probe (Figure 9) attaches directly to the main body and operates like the Pitot probe except over a range of $30-300$ fpm. Note that all the probes and the main body were mounted entirely within the wind tunnel since the flow is slightly below atmospheric pressure.

Instrument G -- Compact impact-defection anemometer.

This anemometer is a commercially available instrument (Alnor Instrument Company, Velometer Jr., Type 8100). It was supplied for test by the U. S. Mining Enforcement and Safety Administration at the request of the U. S. Bureau of Mines. The instrument is approximately $8.2 \times 10.2 \times 3.8 \mathrm{~cm}$ in size (see Figure 10) and contains entrance and exit ports for the air on the upstream and downstream surfaces, respectively. The entrance port is adjustable (two sizes) providing two ranges of velocity measurement, 50 to $200 \mathrm{fpm}$ and 100 to $800 \mathrm{fpm}$. The instrument is a one piece, self-contained unit.

Instruments $\mathrm{H}$ and $\mathrm{I}-$ - Vortex-Shedding Anemometers.

This type of instrument measures velocity by detecting the frequency of a vortex street shed from a bluff, two-dimensional object such as a cylinder. This frequency will be well-defined if the shedding body is properly matched to the air speed.

These anemometers (two units, serial numbers 49 and 48 , respectively, are commercially available instruments (J-TEC Associates, Incorporated, VA-216 Air Draft Sensor) ${ }^{l}$ supplied for test by the U. S. Bureau of Mines. The instruments are approximately $30 \times 10 \times 14 \mathrm{~cm}$ in size (see Figure 11) and include probe heads and the necessary electronics for operation. The probe head consists of a rod approximately $6.4 \mathrm{~mm}$ in diameter and $35 \mathrm{~mm}$ in length supported at the ends and oriented normal to the air stream. An ultrasonic transmitter and receiver pair located downstream of the cylinder detect the vortex street shed by the cylinder as an amplitude modulation of the ultrasonic signal. This modulation is converted by the electronics section to a pulse train (approximately a square wave signal) as an output. A frequency-to-voltage converter section also provides an analog output. Since the frequency of shedding of a vortex street is roughly proportional to velocity, the output signals can be used to measure the air velocity. A separate power supply is necessary to operate the instrument.

Instrument J - Heated foil anemometer.

This anemometer is a prototype instrument (Thermogage, Inc., 
Air Velocity Meter) supplied for test by the U. S. Bureau of Mines. It consists of a tube approximately $9.5 \mathrm{~mm}$ in diameter and $10.2 \mathrm{~cm}$ in length aligned with the flow, and a $15.9 \mathrm{~m}$ diameter handle attached normal to the tube midway along its length (see Figure 12). A part of the wall of the tube is composed of a heat-conducting foil which has an electrically heated spot flanked upstream and downstream by temperature sensors. As air passes through the tube, the upstream sensor experiences a lower temperature than the downstream sensor, and this difference, converted to an electrical signal, is related to velocity. The instrument thus consists of this thermal transducer and an electronics module containing a line-voltage operated power supply, the necessary circuitry, and a micro-ammeter.

\section{THE TESTS}

\subsection{General Description}

Many types of tests can be performed on various aspects of an instrument's performance, such as its response to turbulent flow, shock and vibration, dirt, moisture, or orientation to velocity and gravity vectors, but the results of such tests require comparison with a base level of performance. This base level should be obtained under conditions closely approximating the ideal environment, which, in the case of anemometers is a steady, uniform flow field of large dimensions. The Low Velocity Airflow Facility has been found to provide a good approximation to these conditions for the instruments reported on here.

The performance is measured in terms of the mean error, the random error, and minimum operating air speed. The mean error, for the purposes of this report, is defined simply to be the mean difference between the air speed indicated by the anemometer under test and the air speed indicated by the velocity standard. Random error is defined as usual in terms of a root-mean-square deviation of the indicated air speed from an appropriate mean value (see section 5 for more details). To permit evaluation of these characteristics, multiple calibration tests and minimum operating speed determinations were performed.

\subsection{Calibration tests}

These tests consisted of measuring the response of the anemometer undergoing testing to an air flow of a speed measured by the laser velocimeter velocity standard. (See tables A-I through $\mathrm{J}-5$ ). Each instrument was tested at a number of air speeds over the range of operation below about $4 \mathrm{~m} / \mathrm{s}$. Five such tests were conducted for each instrument with an attempt made to repeat the air speeds for each test. (The effects of not exactly repeating the air speeds are discussed in the analysis of section 5). The particular test set-up for the calibrations varied somewhat from instrument to instrument, but in general consisted of mounting the anemometer on or near the centerline of the test-section, I m from its upstream end, locating the laser velocimeter probe volume at a position where disturbance of the flow due to the presence of the anemometer is negligible, and measuring the air speed with both the 
anemometer under test and the laser velocimeter standard. The details which varied from instrument to instrument are described in the following paragraphs.

Four of the vane anemometers, A, B, C, and D, are so similar in dimension and function that the tests were nearly identical for them. The location of the probe volume $(30 \mathrm{~cm}$ upstream of the anemometer) was the same for each and was determined from a series of velocity measurements upstream of instrument $A$. These are presented in Figure 13 as the ratio of the local velocity to the freestream velocity. These measurements were performed at two freestream speeds, 3.6 and $0.36 \mathrm{~m} / \mathrm{s}$ to verify independence of freestream speed as predicted by potential flow theory. With no anemometer in the tunnel, variation in velocity along the centerline is imperceptible over the distance traversed.

The same four anemometers, A, B, C, and D, also require a timer to determine the indicated airspeed. This was computed from initial and final readings of the dial and of the associated time interval (around two minutes). The anemometer runs continuously in the tunnel since it cannot be accessed while the tunnel is in operation without disturbing the flow. Thus the readings of the anemometer were performed with the anemometer in operation. The laser velocimeter measurement of the air velocity was performed during the time interval for reading the vane anemometer.

The remaining vane anemometer, instrument $E$, has an electronic read-out, thus not requiring a separate time measurement. It is smaller in dimension than $A$ through $D$ and will disturb the airflow less. Consequently the probe volume could be located as for instruments A through D. As with the others, the laser velocimeter measurement of the air velocity was performed during the time interval for reading the vane anemometer.

The full size impact deflection anemometer, instrument $F$, has three velocity probes which were tested on all ranges. The Pitot probe and diffuser probes are essentially slender $(1.27 \mathrm{~cm}$ diameter) cylinders presenting little disturbance to the flow. Thus they were tested with the probe volume located $30 \mathrm{~cm}$ upstream of the probe as with the vane anemometers. The meter body and hoses were located downstream of the probes. The low velocity probe, however, attaches directly to the meter body rather than by hoses, thus requiring the meter body and probe to be placed together at the calibration position. Thus the velocity upstream of this combination was measured to again find a location for the probe volume. However, $30 \mathrm{~cm}$ upstream was found to be quite sufficient (Figure 14).

The velocity upstream of the compact impact-deflection anemometer, instrument $G$, was also measured to find a location for the probe volume, and again $30 \mathrm{~cm}$ was found to be sufficient. 
The vortex-shedding anemometers, instruments $H$ and $I$, are larger than the others and disturb the flow proportionately more. However, it was found that by placing the measuring head on the centerline (thus with the bulk of the instrument off the centerline) that the laser velocimeter probe volume could be located $35 \mathrm{~cm}$ upstream of the instruments. Since the outputs of $H$ and $I$ are an analog voltage and a pulse train, separate instrumentation consisting of a digital volt meter and a frequency counter were required for the tests. These measurements were recorded during the time interval required for measurement by the laser velocimeter standard.

The remaining instrument, the heated foil anemometer, instrument $J$, has a very small probe head and was thus tested with the probe volume again at $30 \mathrm{~cm}$ upstream. The output is an analog meter reading in microamps.

\subsection{Minimum Operating Speed}

Determination of the minimum air speed at which operation of an instrument is possible varies with the type of instrument under test. The instruments may be separated into two categories for this purpose: instruments that entirely cease to function below some speed, and instruments that lose sufficient resolution in their output (or read zero) below some speed.

The vane anemometers, A through $E$, all fit in the first category, but here two minimum operating speeds may be defined, a starting speed, the speed at which the instrument starts from rest as the air speed is slowly increased, and a stopping speed, the speed at which the anemometer ceases to turn as the air speed is slowly decreased.

To determine the starting speeds of the instruments, the velocity in the tunnel was increased from below the starting speed at a smooth acceleration of approximately $0.15 \mathrm{~m} / \mathrm{s} / \mathrm{min}$ until movement of the vanes could be detected by eye. At that moment the air velocity would be fixed and the laser velocimeter measurements initiated. If the anemometer continued rotating for at least thirty seconds and did not decelerate, the measurement of velocity by the laser velocimeter was recorded as the starting speed.

Because of the anemometer's angular momentum, stopping speed is more difficult to determine than starting speed. Some preliminary runs indicated that a two minute interval between reductions in air velocity of approximately $1 \mathrm{~cm} / \mathrm{s}$ was sufficient for the anemometer to come to rest if the stopping speed had been reached.

The only other instruments having minimum speeds of functioning are the vortex-shedding anemometers, instruments $H$ and $I$. As the air speed is reduced the depth of modulation of the ultrasonic signal is reduced until at some speed it can no longer be detected by the instruments. 
Since neither friction nor angular momentum is involved, as opposed to the vane anemometers, the minimum operating speed was easily determined by simply observing the pulse train from the instruments as the air speed was slowly reduced. When the pulses disappeared (which occurred rather abruptly) the air speed was recorded as the minimum operating speed.

The other instruments, the impact pressure anemometers, $F$ and $G$, and the heated foil anemometer, $J$, all fit in the second category of instruments which lose sufficient resolution below some speed. This minimum operating speed is defined here to be that at which the anemometer under test indicates a speed of one-half the lowest marked division on the dial above zero. This was chosen because at that indicated speed the resolution is at least as large as the reading.

\section{RESULTS AND DISCUSSION}

\subsection{Methods of data analysis}

As may be observed in Figures 16 through 32, the data for the calibration curves are in groups because of attempts to repeat the true air speeds from run to run. The mean calibration data are defined to be the pairs of values consisting of the mean true velocity for a group and the mean indicated velocity (or frequency, etc.) of that group. Plots of these pairs (connected by solid lines in Figures 16 through 32), give an indication of linearity of the instrument's response and serve in determining the random error of that response. Furthermore, the mean data may be used to define calibration curves for correcting an indicated reading in the field. Figures 33 through 59 (odd numbered) are especially valuable in this respect.

Random error is frequently defined as the standard deviation (about the mean) of repeated measurements. This is only useful, however, if the true or reference value is fixed or has negligible variation from measurement to measurement. Precise repetition of wind tunnel speeds, though, is extremely difficult at the low speeds required for these tests. The random error here, then is defined in terms of the root-mean-square deviation of the data in a group from an appropriate curve through that group. This is illustrated in Figure 15 where $\bar{U}$ is the group mean true velocity and $\bar{U}_{j}$ is the group mean indicated velocity. An ideal calibration curve, $U_{i}(U)$, Is approximated within the group by a straight line segment, $U_{\text {, }}$, passing through $\left(\overline{\mathrm{U}}, \overline{\mathrm{U}}_{i}\right)$. The root-mean-square deviation, curve, $\tilde{U}^{i}(U)$, is approximated within the group by a straight line segment, $U_{i}^{i}$, passing through $\left(\bar{U}_{,}, \bar{U}_{i}\right)$. The root-mean-square deviation, $\sigma_{i}$, of the data, ( $U_{,}, U_{i r}$ ) from $\tilde{U}^{*}{ }_{(U)}{ }^{\dagger}$ is thus approximated by the root-mean-square deviation from the line segment, U ${ }^{\cdot}$. More specifically:

$$
\sigma_{i}^{2} \simeq \frac{1}{N} \sum_{r=1}^{N}\left[U_{i r}-U_{i f}\left(U_{i r}\right)\right]^{2}
$$

The slope of the line segment, $U_{\text {if }}$, is computed as the average of the slopes of line segments connecting the $\left(\bar{U}_{,}, \bar{U}_{i}\right)$ of interest with the ( $\left.\bar{U}_{,}, \bar{U}_{i}\right)$ 's of the neighboring group(s). 
The standard deviation, $\sigma_{i}$, is a measure of the scatter in the data in terms of indicated air speed (or frequency, etc., depending on the measurement). To compare instruments, however, this must be converted to an equivalent scatter in true air speed. An approach consistent with the above approximations for $\sigma_{i}$ is to divide $\sigma_{i}$ by the local slope of $\mathrm{U}_{\text {if }}$, namely ( $\left.\mathrm{dU}_{i f} / \mathrm{dU}\right)$. The result, $\sigma$, is now Eaken to be a measure of the random errorf of the instrument in terms of true velocity, subject to the corrections and limitations discussed below.

Computing $\sigma_{i}$ from measurements by an instrument having a scale with a resolution, $R_{i}$, much smaller than $\sigma_{i}$ is an accepted procedure for determining repeatability of the instrument. However, if the resolution is large (poor) compared to $\sigma_{\text {. }}$ (where $\sigma_{\text {i }}$ is presumed known by some means independent of the scale being considered, say by a second scale with better resolution), the indicated $\sigma$ may be much smaller than it should be. For a Gaussian distribution of errors it is assumed that $\sigma_{i}$ may be adequately computed if the resolution is at most approximately twice $\sigma_{i}$.

As with the computed values of $\sigma_{i}$, these values of resolution, $R_{i}$, were converted to equivalent values, $\dot{i}$, in terms of true velocity by dividing by the slope ( $\mathrm{dU} / \mathrm{dU}$ ). These latter values, divided by two, were then included in the figures where applicable in units of velocity or as percentage of $\bar{U}$. As will be seen, $R / 2$ does indeed exceed $\sigma$ for several of the instruments. Thus these particular values of $\sigma$ should be taken with reservation and perhaps replaced by the values $R / 2$. The performance of the instrument in these instances in terms of random error may exceed the quality of its resolution.

The above analysis presumes that the contribution to the random errors from the laser velocimeter is negligible, and indeed this is true for most of the tests. The random uncertainty of the laser velocimeter (random error) may be estimated from repeated measurements at a particular fan setting, thus also including any unsteadiness in the air speed. The value of this uncertainty was reduced as improvements were made to the laser system and varied from $0.005 \mathrm{U}$ for instruments $A$ and $B$ to $0.002 \mathrm{U}$ for instrument $C$ to $0.001 U$ for all the others. A corrected standard deviation for the tested instruments, $\sigma_{c}$, may thus be computed from, for instance,

$$
\sigma_{c}^{2}=\sigma^{2}-(0.001 U)^{2}
$$

for any given $U$. Values of $\sigma$ are included in the figures where they differ perceptibly from the values of $\sigma$. Since $\pm 2 \sigma$ is close to the 95 percent confidence interval for one measurement, curves of $\pm 2 \sigma_{c}$ are also included in the figures of $U_{i}$ against $U$.

\subsection{Calibration Data}

The calibration data is presented in three forms for those instruments (A through $G$ ) that read directly in velocity: indicated versus true velocity, the deviation of indicated from true velocity against indicated velocity, and the percent deviation against true 
velocity (Figures 16 through 60). Instruments $\mathrm{H}, \mathrm{I}$, and $\mathrm{J}$ have only plots of indicated output (frequency for $\mathrm{H}$ and $\mathrm{I}$; current for $\mathrm{J}$ ) against true velocity, Figures 30,31 , and 32 . The primary function of the figures showing indicated velocity or output against true velocity is to illustrate the overall character of the response and the $95 \%$ confidence intervals. The other types of figures detail the features of most interest: the linearity, the range of scatter, and the deviation of indicated from the true velocity.

Vane anemometers $A, B$, and $D$ are nearly identical in dimension and also have very similar calibration curves (see Figures 16, 18, 19,33 through 36,39 , and 40). The rapid rise in the curve of Figure 33 as the velocity is reduced below 100 feet per minute $(0.5 \mathrm{~m} / \mathrm{s})$ is almost certainly due to the appearance of friction effects since this instrument, $A$, has bronze bearings rather than ball bearings as do instruments $B$ and $D$.

Instrument $C$, though a vane anemometer similar in appearance to $A, B$, and $D$, does differ somewhat from them, especially in the size and shape of the hub. This may explain the somewhat different character of the calibration data as presented in Figures 18, 37 , and 38 , though the instruments $A, B, C$, and $D$ really all have quite similar calibration characteristics.

The magnetic pick-up transducer and associated electronics of instrument $E$ may be the fundamental cause of the somewhat different character of its calibration data (figures 20, 21, 22, and 41 through 46) as compared to $A$ through $D$. This is evidenced by the change in the data between ranges on the instrument (e.g., Figures 41 and 43). This cannot be caused by the dynamics of the vane since mechanically and aerodynamically the instrument is unchanged when compared at the same speed but on different ranges. The overall character of the calibrations though is not significantly different from those of A through $D$.

The characteristics of the calibration data for the impactdeflection type instruments, $F$ and $G$, are determined by the aerodynamic characteristics of the probes and flow passages in the instruments as well as the meter characteristics. The different responses in the data of Figures 23 through 29 , and 47 through 60 show the effect of various probes and ranges. The only major conclusion to be drawn at this point is that at the lower velocities it is usually very important because of large errors to use a good calibration correction method (chart or table, etc.) when making a measurement. This is true for all the instruments, A through $G$.

There is little to comment upon concerning the calibration curves for the vortex-shedding and heated film anemometers ( $H$, I, and $\mathrm{J}$ ) since the output is not "velocity." Both the principle of vortex street frequency-to-velocity relationship and the temperatureto-velocity relationship have long been known. These particular instruments have utilized these principles so that sufficient 
sensitivity to velocity changes is produced. Both the near linearity of the vortex frequency with velocity and the usual nonlinearity of the heat transfer to velocity are apparent in the data (Figures 30,31, and 32).

\subsection{Random Error}

The random error, defined in Section 5.1, is presented in essentially two forms: in units of velocity, and as percent of group mean true velocity. The exceptions are instruments $H$, $I$, and $J$ which do not read out in velocity and thus also have plots of random error in units of their read-out (frequency or current). As was discussed in Section 5.1, the measure of random error, $\sigma$, is in terms of true velocity which was produced by dividing $\sigma$ by $\left(\mathrm{d} \bar{U}_{i} / \mathrm{d} \bar{U}\right)$. The random error for the instruments not having diract read-out in velocity was also expressed in this manner by dividing the random error in terms of the readout ( $f$ or $I$ ) by the group mean slope of the calibration curve ( $d \bar{f} / d \bar{U}$ or $d \bar{I} / d \bar{U})$.

The rather small sample size, five runs, causes a sizeable uncertainty in any one value of the random error. This is ameliorated somewhat though by the many values of velocity at which the random error was computed, thus permitting a smoothing of the data and effective reduction in the uncertainty. The data as presented, however, have not been smoothed but are the values computed according to the procedures presented in Section 5.1 .

The data for vane anemometers A, B, C, and D (Figures 61 and 62 for $A, 63$ and 64 for B, 65 and 66 for $C$, and 67 and 68 for D) all show the same trends of $\sigma$ and $\sigma / \overline{\mathrm{U}}$ with $\overline{\mathrm{U}}$ differing only in magnitude. The quite different character of the random error for instrument $E$, the only one with a magnetic pick-up transducer, Figures 69 and 74 , is most likely associated with the effects of resolution as discussed in section 5.1. As noted in the figures, the computed $\sigma$ is frequently less than the value $R / 2$. The other vane anemometers did not have random errors the same order as the resolution. For evaluation, as noted in Section 5.1, instrument $E$ should perhaps have $\sigma$ replaced by $R / 2$ for those values of $\sigma$ less than $R / 2$.

The impact-deflection type anemometers, instruments $F$ and $G$, likewise have random errors exceeded by the values $R / 2$ at some air speeds (Figures 75 through 88 ). None of $E, F$, or $G$, however, show any adverse or highly unusual characteristics in the trends of the random error with velocity.

The effect of resolution on the vortex-shedding anemometers, instruments $H$ and $I$, was eliminated by selecting instrumentation for reading the frequency which had far better resolution than required. This was possible in the laboratory because of the unprocessed signals, a pulse train and a voltage, available from 
the instruments under test. The only slightly unusual feature of the results (Figures 89 through 96) was that for instrument $\mathrm{H}$, $\sigma_{f} / \bar{f}$ or $\sigma / \bar{U}$ were nearly constant with velocity. Instrument $I$, though, gave values which increased somewhat as velocity was decreased. Since the instruments are nominally identical, no explanation is apparent for the (slight) variation.

The heated foil anemometer, instrument $\mathrm{J}$, showed trends with velocity similar to A through $D$, but had resolution almost perfectly matched to the random error (Figures 97 through 100).

\subsection{Minimum Operating Speed}

As discussed in Section 4.3, the minimum operating speed is determined in different ways for different instruments. The vane anemometers and the vortex-shedding anemometers all have minimum operating speeds determined by a complete ceasing of operation. The others simply lose resolution below some air speed. The various minimum operating speeds are summarized in Table $\mathrm{K}$.

The difference in starting and stopoing speeds for the vane anemometers, $A$ through $E$, is due to the difference in static and dynamic friction factors for the bearings. Both speeds, though, are lower for the instruments with the more friction-free bearings, such as $B$ and $D$. Instrument $D$, having fewer vanes than $B$, can operate at higher air speeds, but this advantage is offset somewhat by a decreased torque at lower speeds and thus a higher minimum operating speed.

Since the minimum operating speed of the vortex-shedding anemometers, instruments $H$ and $I$, depends on the level of detection of the ultrasonic modulation, the difference in the speeds for these two instruments is probably due to slightly differing adjustments of the electronic detection circuits rather than a physical or aerodynamic difference. As noted in Section 4.3, these instruments ceased operating rather abruptly as speed was reduced, thus giving a well-defined minimum operating speed.

For the instruments having a minimum operating speed defined by resolution, namely $F, G$, and $J$, the procedure for specifying the speed is defined in Section 4.3, and the results are summarized in Table $k$. The only comment on the results is that the resolution as discussed in Section 4.3 is $R_{i}$, the indicated resolution, whereas the minimum operating speeds (for all the instruments) are true speeds.

\section{SUMMARY}

Performance of ten anemometers of several different types has been measured at low air speeds in a wind tunnel which provides a steady air flow of low turbulence. Multiple calibration runs on 
each instrument provided sufficient data for measuring performance in terms of random error about the mean calibration curve as well as the difference between the indicated and true speeds. Measurements were also performed of the minimum operating speeds of the anemometers.

The results are presented in both tabular and graphical form. A detailed description is included of the tests, the results, and the methods of analysis.

\section{REFERENCES}

1. L. P. Purtell and P. S. Klebanoff, A Low Velocity Airflow Calibration and Research Facility, NBS TN 989, 1979. 


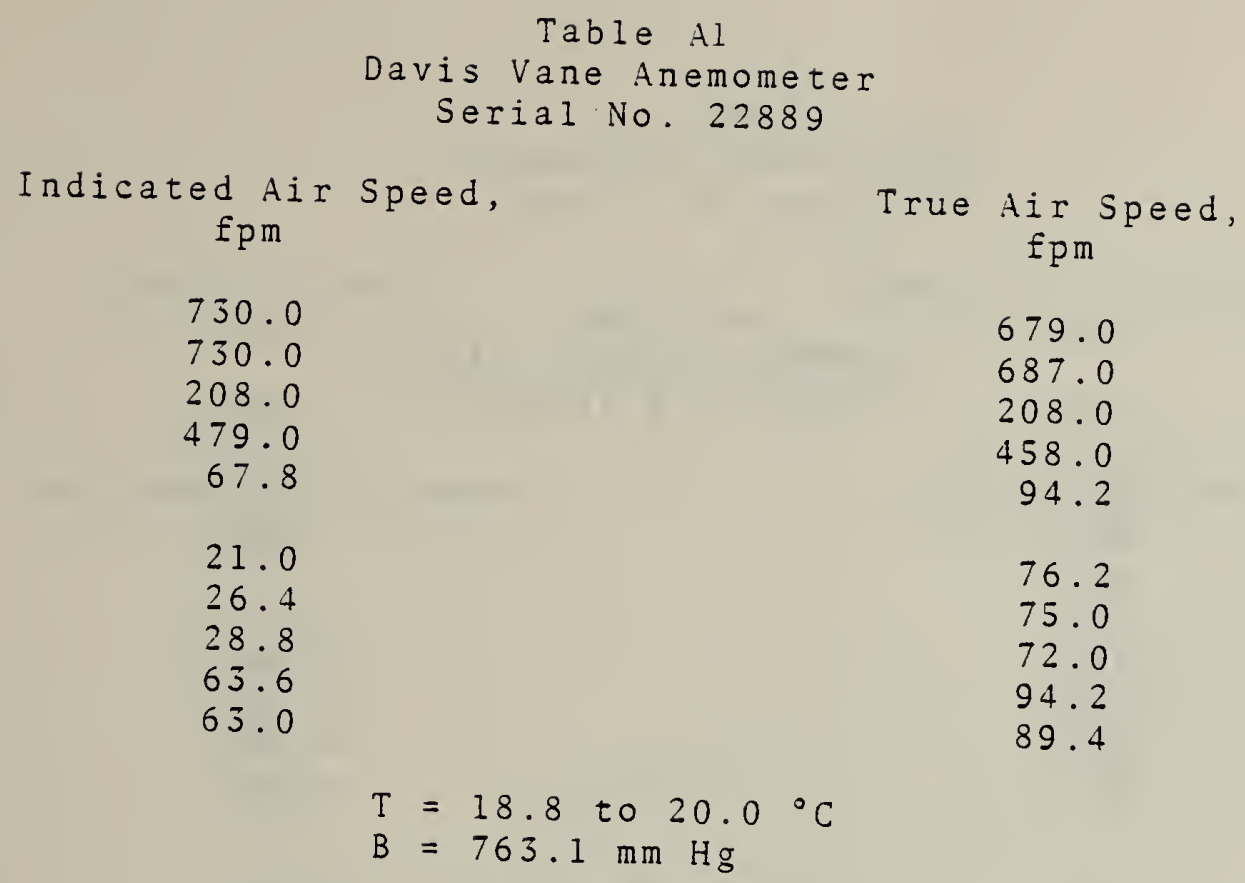

$$
\begin{aligned}
& T=20.1 \text { to } 21.0{ }^{\circ} \mathrm{C} \\
& B=763.1 \mathrm{~mm} \mathrm{Hg}
\end{aligned}
$$


Table Aj

Davis Vane Anemometer

Serial No. 22889

Indicated Air Speed, fpm

732.0

211.0

482.0

70.2

39.3

36.5

29.6

69.6

68.4
True Air speed, fpm

690.0 207.0

458.0

94.8

72.0

73.2

76.2

96.0

96.6

$$
\begin{aligned}
& T=21.0{ }^{\circ} \mathrm{C} \\
& B=755.0 \mathrm{~mm} \mathrm{Hg}
\end{aligned}
$$

Table A4

Davis Vane Anemometer

Serial No. 22889

Indicated Air Speed, fpm

735.0

210.0

481.0

69.6

39.1

44.0

45.3

70.8

70.8
True Air Speed, fpm

687.0 214.0 460.0 94.2 75.6

76.8

75.6

96.6

96.6

$$
\begin{aligned}
& T=21.6{ }^{\circ} \mathrm{C} \\
& B=764.0 \mathrm{~mm} \mathrm{Hg}
\end{aligned}
$$


Table A5

Davis Vane Anemometer

Serial No. 22889

Indicated Air speed, fpm

$$
\begin{array}{r}
710.0 \\
208.0 \\
479.0 \\
67.8 \\
25.8 \\
\\
39.1 \\
40.9 \\
64.8
\end{array}
$$

True Air Speed,

$$
\text { fpm }
$$$$
688.0
$$

215.0

458.0

95.4

74.4

74.4

75.0

94.2

$$
\begin{aligned}
& T=21.6{ }^{\circ} \mathrm{C} \\
& B=764.0 \mathrm{~mm} \mathrm{Hg}
\end{aligned}
$$




\section{Table $B J$}

Davis Vane Anemometer

Serial No. 24323 B

Indicated Air Speed,
fpm
717
206
468
80.5
57.5
35.0
12.2
22.7
8.1
144

Table B4

Davis Vane Anemometer

Serial No. 24323 B

$$
\begin{aligned}
& \mathrm{T}=21.3 \quad{ }^{\circ} \mathrm{C} \\
& \mathrm{B}=747.1 \mathrm{~mm} \mathrm{Hg}
\end{aligned}
$$

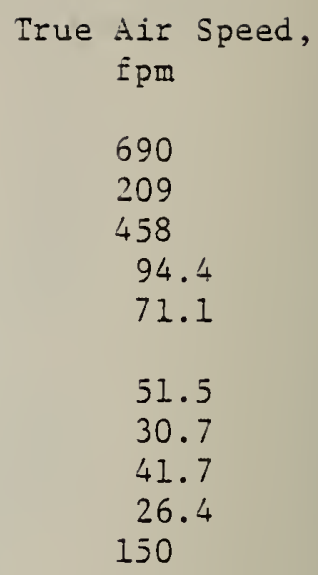

True Air Speed, fpm

696

215

466

96.0

72.0

50.4

31.2

41.4

25.2

152

$$
\begin{aligned}
& \mathrm{T}=22.1 \mathrm{\circ}^{\circ} \mathrm{C} \\
& B=750.5 \mathrm{~mm} \mathrm{Hg}
\end{aligned}
$$


Table B5

Davis Vane Anemometer

Serial No. 24323 B
Indicated Air Speed, fpm

718

207

471

78.8

56.0

33.8

13.6

26.9

11.5

114
True Air Speed, Epm

682

212

461

97.2

70.8

50.4

32.2

43.4

29.5

153

$$
\begin{aligned}
& T=22.5{ }^{\circ} \mathrm{C} \\
& B=750.5 \mathrm{~mm} \mathrm{Hg}
\end{aligned}
$$


Table Cl

Taylor Vane Anemometer

Serial No. 4873

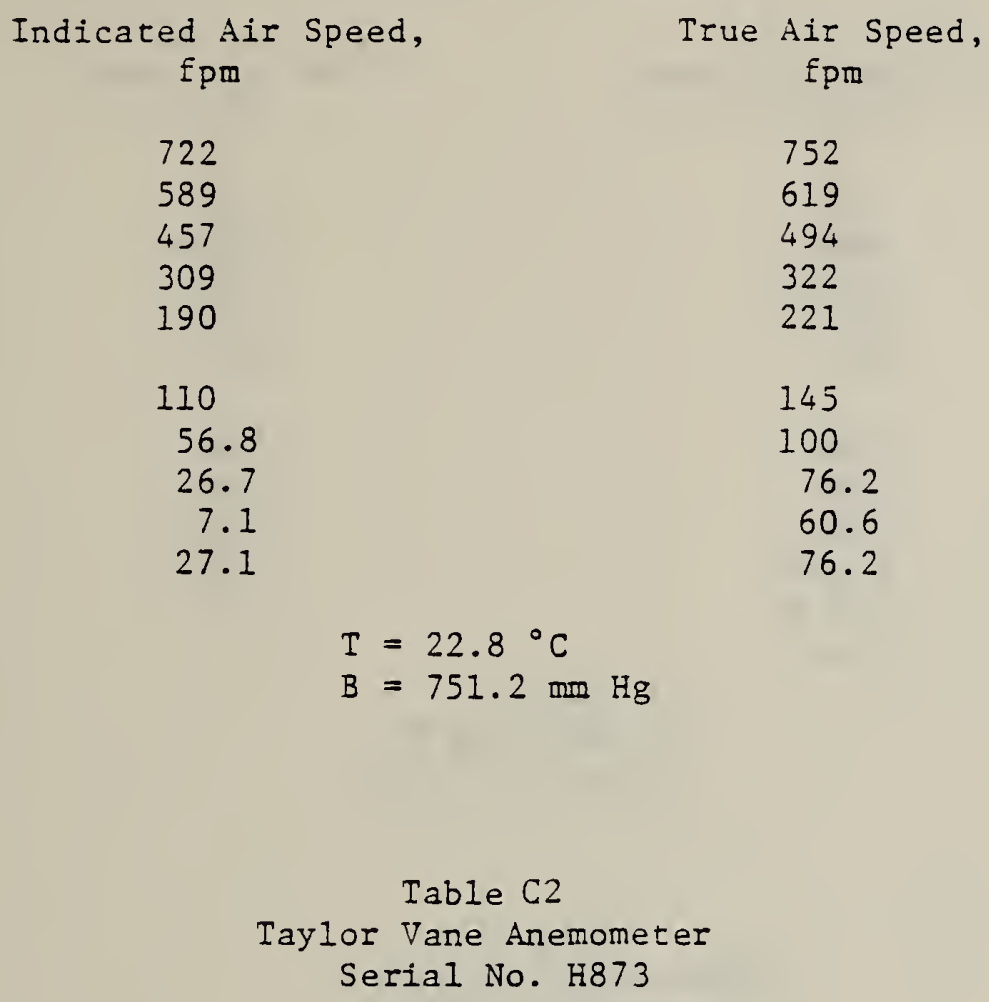

56.8

26.7

7.1

27.1

145

100

76.2

60.6

76.2

$\mathrm{T}=22.8^{\circ} \mathrm{C}$

$\mathrm{B}=751.2 \mathrm{~mm} \mathrm{Hg}$

Table C2

Taylor Vane Anemometer

Serial No. 4873

\section{Indicated Air Speed, fpm}

719

589

454

324

190

109

55.8

25.1

8.4

25.7
True Air Speed, epm

746

623

498

360

222

142

98.0

74.6

64.8

76.0

$$
\begin{aligned}
& \mathrm{T}=22.6{ }^{\circ} \mathrm{C} \\
& B=753.5 \mathrm{Hg}
\end{aligned}
$$


Table C3

Taylor Vane Anemometer

Serial No. H873

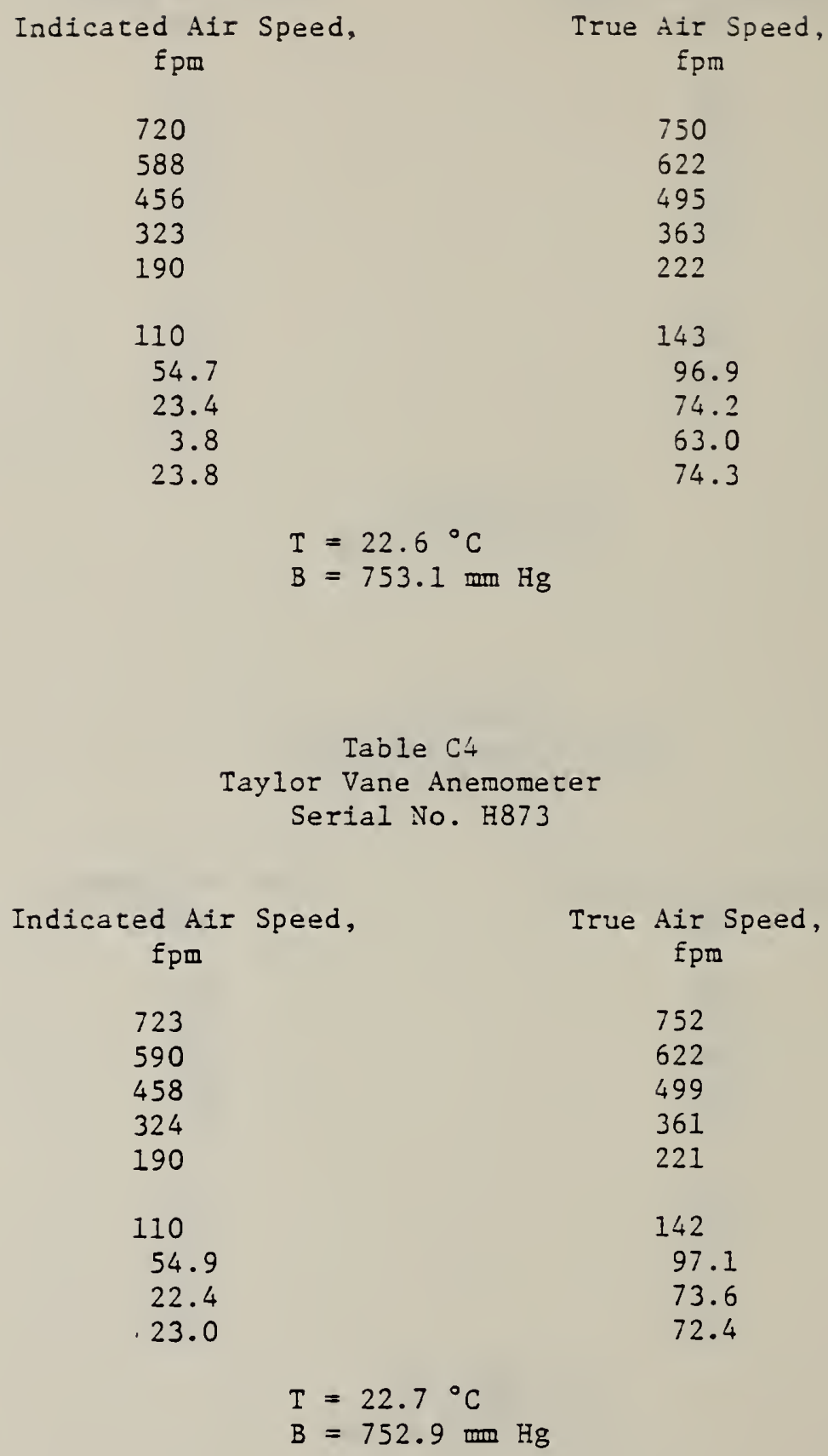


Table C5

Taylor Vane Anemometer

Serial No. H873

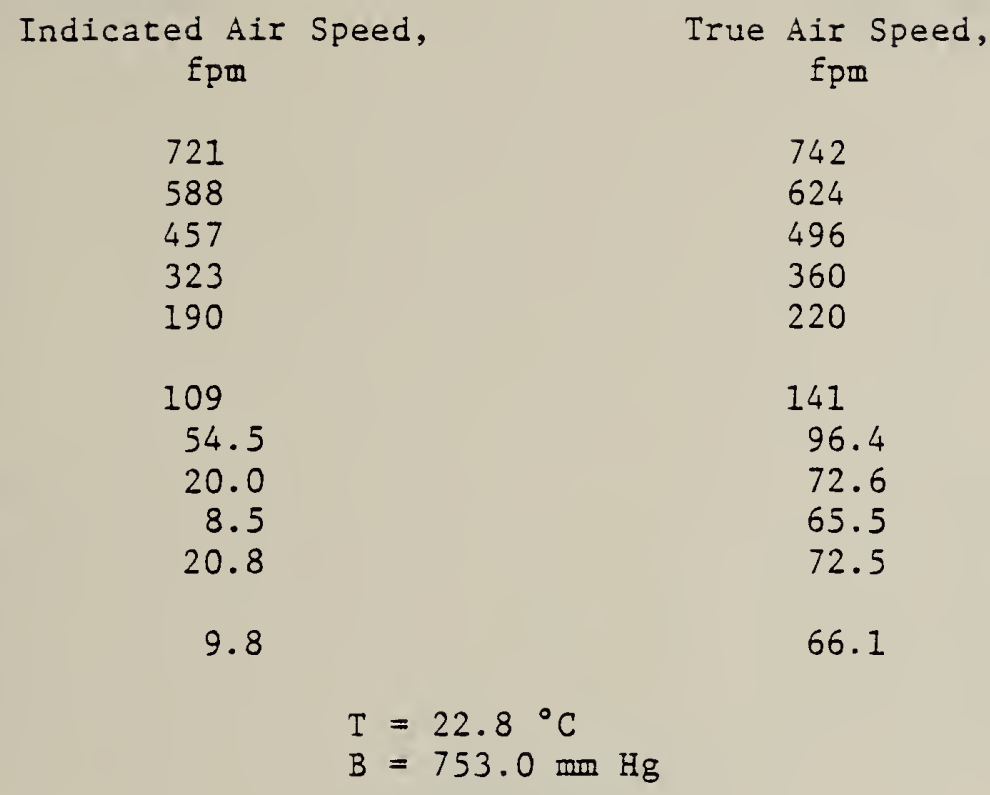



Table D 1

Davis Vane Anemometer

Serial No. 31125B
Indicated Air Speed,

fpm

785

639

496

359

219

136.4

80.2

53.7

38.9

28.6

Table D2

Davis Vane Anemometer

Serial No. 31125B

$$
\begin{aligned}
& T=23.6{ }^{\circ} \mathrm{C} \\
& B=753.8 \mathrm{~mm} \mathrm{Hg}
\end{aligned}
$$

True Air Speed,

fpm

736

606

478

347

217

141.2

92.1

68.2

56.6

47.7
Indicated Air Speed, fpm

786

640

497

358

219

137.3

81.8

56.1

41.8

26.4
True Air Speed, Epm

741

608

477

348

218

141.7

93.1

70.2

58.8

47.3

$$
\begin{aligned}
& T=23.8{ }^{\circ} \mathrm{C} \\
& B=753.8 \mathrm{~mm} \mathrm{Hg}
\end{aligned}
$$


Table D3

Davis Vane Anemometer

Serial No. 31I25B
Indicated Air speed,
fpm

786

641

498

358

218

135.5

81.1

53.7

38.9

24.5

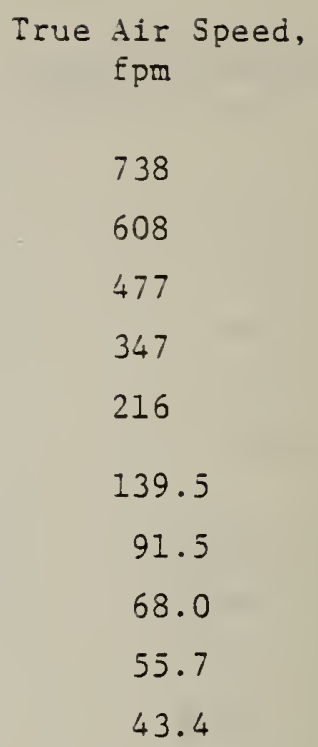

Irue Air Speed, fpm

738

608

477

347

216

139.5

91.5

68.0

55.7

43.4

$$
\begin{gathered}
T=24.2{ }^{\circ} \mathrm{C} \\
B=753.8 \mathrm{~mm} \text { Hg } \\
\text { Table D4 } \\
\text { Davis Vane Anemometer } \\
\text { Serial No. 31125B }
\end{gathered}
$$

Indicated Air Speed,
fpm

787

641

498

359

220

135.6

80.6

53.0

37.8

24.8
True Air Speed, fpm

738

608

477

347

217

140.5

91.4

67.7

55.4

44.6

$$
\begin{aligned}
& T=24.6{ }^{\circ} \mathrm{C} \\
& B=753.8 \mathrm{Hg}
\end{aligned}
$$


Table D5

Davis Vane Anemometer

Serial No. 31125B

\section{Indicated Air Speed, fpm}

True Air Speed, fpm

740

608

476

347

217

140.0

91.4

67.1

55.3

46.3

$T=24.7{ }^{\circ} \mathrm{C}$

$B=753.2 \mathrm{~mm} \mathrm{Hg}$ 

Table El

Abbirko Flowmaster

$S /$ iv 6184

Low Range
Indicated Air Speed, fpm

$$
\begin{array}{r}
50 \\
52 \\
64 \\
74 \\
86 \\
\\
96 \\
144 \\
184 \\
228 \\
272
\end{array}
$$

True Air Speed, Epm

59.9

64.1

74.5

86.1

97.2

108.4

157

200

248

300

$$
\begin{aligned}
& T=20.8^{\circ} \mathrm{C} \\
& B=758.4 \mathrm{~mm} \mathrm{Hg}
\end{aligned}
$$

$$
\begin{gathered}
\text { Table E2 } \\
\text { Abbirko Flowmaster } \\
\text { S/N } 6184 \\
\text { Low Range }
\end{gathered}
$$

Indicated Air Speed, fpm

True Air Speed, Ip̣

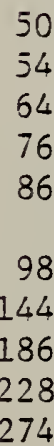

59.6

64.0

74.0

86.4

97.1

108.8

157

200

250

299 


\section{Table E3 \\ Abbirko Flowmaster \\ $\mathrm{S} / \mathrm{N} 6184$ \\ Low Range}

Indicated Air Speed, fpm

52
54
64
76
86

98
144
184
230
274
True Air Speed, fpm

59.8

64.1

74.3

86.2

96.7

107.8

157

199

249

298

$T=20.9^{\circ} \mathrm{C}$

$B=758.4 \mathrm{~mm} \mathrm{Hg}$

Table 54

Abbirko Flownaster

$\mathrm{S} / \mathrm{N} 6184$

Low Range

Indicated Air Speed, fpm

True Air Speed, fpm

48

50

60

74

84

98

142

184

228

272

54.9

60.0

72.1

82.8

94.4

106.8

155

198

248

299

$T=22.2^{\circ} \mathrm{C}$

$B=750.3$ inn $\mathrm{Hg}$ 
Table E5

Abbirko Flowmaster

$\mathrm{S} / \mathrm{N} 6184$

Low Range
Indicated Air Speed, fpm

50

52

60

76

84

98

142

182

228

272

$\mathrm{T}=22.3^{\circ} \mathrm{C}$

$B=751.1 \mathrm{~mm} \mathrm{Hg}$

Table E6

Abbirko Flowmaster

$\mathrm{S} / \mathrm{N} 6184$

Medium Range
True Air Speed, fpm

56.6

60.7

72.1

84.2

95.3

106.4

155

199

249

298
Indicated Air Speed, fpm

30

55

75

170

265

370

475

585

685
True Air Speed, fpm

63.4

86.1

108.1

199

299

402

507

611

716

$T=20.8^{\circ} \mathrm{C}$

$B=758.4 \mathrm{~mm} \mathrm{Hg}$ 
Table E7

Abbirko Flowmaster

$\mathrm{S} / \mathrm{N} 6184$

Medium Range

Indicated Air Speed, fpm

$$
\begin{array}{r}
25 \\
55 \\
80 \\
170 \\
270 \\
\\
375 \\
480 \\
585 \\
685
\end{array}
$$

True Air Speed, fpm

$$
\begin{array}{r}
64.4 \\
86.1 \\
108.2 \\
200 \\
298
\end{array}
$$

401

507

612

716

$$
\begin{aligned}
& T=20.9^{\circ} \mathrm{C} \\
& B=758.4 \text { tum } \mathrm{Hg}
\end{aligned}
$$

Indicated Air Speed, fpm

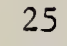

50

75

165

265

370

475

580

685
True Air Speed, fpm

59.9

82.8

106.2

199

298

402

506

611

714

$\mathrm{T}=22.2^{\circ} \mathrm{C}$

$B=750.0 \mathrm{mmg}$ 


\section{Table E9 \\ Abbirko Flowmaster \\ $S / N 6184$ \\ Medium Range}

Indicated Air Speed, fpm

25

50

80

170

265

375

485

585

690
True Air Speed, fpm

61.1

8.3 .6

107.5

199

299

402

506

611

716

$\mathrm{T}=22.3^{\circ} \mathrm{C}$

$\mathrm{B}=750.8 \mathrm{Hg}$

\author{
Table E10 \\ Abbirko Flowmaster \\ $S / N 6184$ \\ Medium Range
}

Indicated Air Speed, fpm

25

50

75

170

265

375

480

585

685
True Air Speed, fpm
61.2
83.0
106.8
199
299
402
506
611
717

$$
\begin{aligned}
& T=22.4^{\circ} \mathrm{C} \\
& B=751.2 \mathrm{~mm}
\end{aligned}
$$


Table Ell

Abbizko Elowaster

$S / \mathrm{N} 5 I 3 L$

Hign Range
Indivazed Ain Speed, Ip=

80

170

270

370

430

580

690
Irue Air Speed,

107.4

109

298

401

506

612

711

$$
\begin{aligned}
& I=20.6^{\circ} \mathrm{C} \\
& 3=758.4 \mathrm{Hg}
\end{aligned}
$$

Table E12

dooirko Elowwaster

$S / N 5184$

Eigh Range
Indisared Air Speed, =̄pa

90

170

270

380

480

590

590
True Air speed, Epm

108.6

190

299

403

507

613

715

$I=20.9^{\circ} \mathrm{C}$

$3=758.4=\mathrm{Hg}$ 


\section{Table E13 \\ Abbirko Flowmaster \\ S/N 6184 \\ High Range}

Indicated Air Speed, İpm

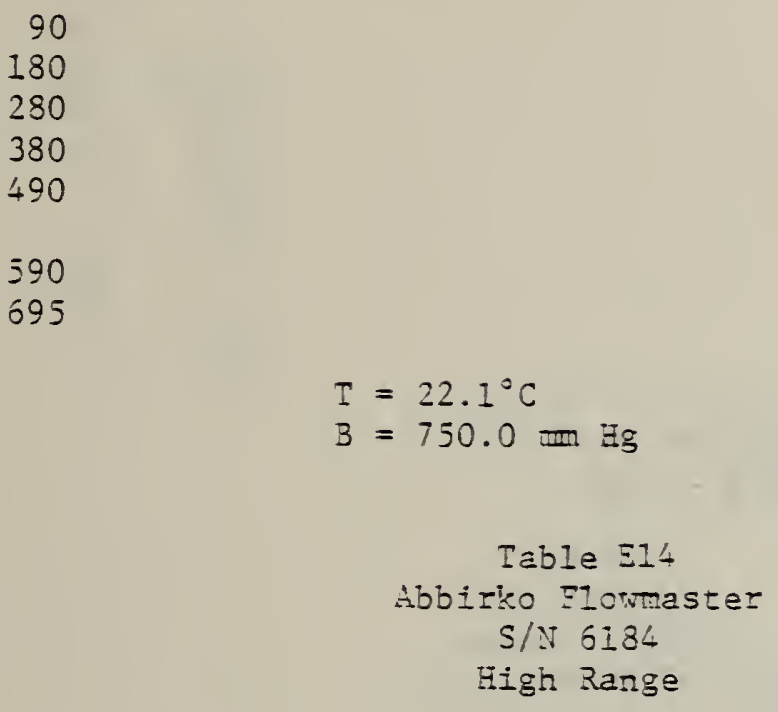

$T=22.1^{\circ} \mathrm{C}$

$B=750.0 \mathrm{dm}$

Indicated Air Speed, fpm

True Air Speed, fou

90

180

280

380

490

590

695
True Air Speed, 三pณ

106.3

198

299

401

505

612

712
106.7

199

299

403

507

611

715 


\section{Table E15 \\ Abbirko Flowmaster \\ S/N 6184 \\ High Range}

True Air Speed, fpm

107.9

200

299

403

506

612

715

$$
\begin{aligned}
& T=22.4^{\circ} \mathrm{C} \\
& B=751.2 \mathrm{~mm} \mathrm{Hg}
\end{aligned}
$$




\section{Table FI \\ Alnor Velometer \\ Series 6000-P \\ Pitot probe-1250 Scale}

Indicated Air Speed, fpm

100

140

190

285

380

468

560

645

$T=21.1{ }^{\circ} \mathrm{C}$

$B=739.5 \mathrm{~mm} \mathrm{Hg}$

Table E2

Alnor Velometer Series 6000-P

Pitot probe-1250 Scale

True Air Speed,

fpm

102

154

199

297

400

499

604

705

645

$$
\begin{aligned}
& T=21.1{ }^{\circ} \mathrm{C} \\
& B=739.5 \text { ing } \mathrm{Hg}
\end{aligned}
$$




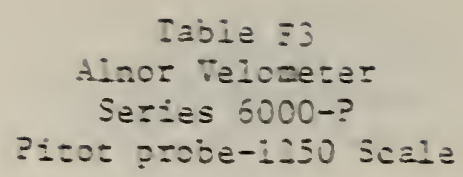

zou
zodicated Air speved,

Irue Air speed. zop

100

$2-0$

190

250

380

$-70$

¿50

$5-5$

102

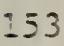

208

297

$-01$

$-98$

505

706

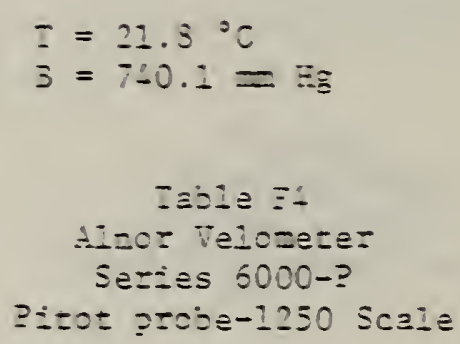

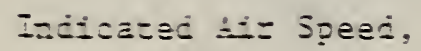
Ẽ=

True dir Speed. 宓

100

$1-0$

153

188

198

297

295

$\leftarrow 01$

425

498

550

503

$5-5$

704

$I=21.5=\mathrm{C}$

$\mathrm{s}=740.1=\mathrm{Eg}$ 


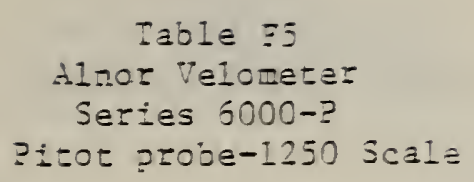

Indicated Air Speed, Eิㄸ

100

140

192

285

378

470

560

648
Indicated Ai= Speed, fpm

75

125

190

300

410

540

645

760

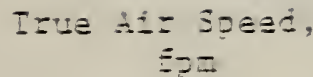

102

İ3

198

297

402

497

50:

709
$I=21.8{ }^{\circ} \mathrm{C}$

$3=741.0=\mathrm{Eg}$

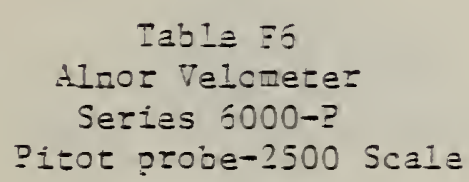

Izue $\therefore$ iz Speed, EDE

103

149

201

300

399

502

604

705

$$
\begin{aligned}
& I=21.1{ }^{\circ} \mathrm{C} \\
& B=749.2 \mathrm{Hg}
\end{aligned}
$$




\section{Table ET \\ Anor Velometer \\ Series 6000-? \\ Pitot probe-2500 Scale}

\section{Indicared Air Speed, Epm}

75

130

190

295

420

540

655

755
Irue Air Speed,
三p̣n

103

149

200

299

399

503

604

707

$I=21.1{ }^{\circ} \mathrm{C}$

$B=749.2 \mathrm{~mm} \mathrm{Hg}$

\author{
Table FB \\ Alnor Velometer \\ Series 6000-? \\ Pitot probe-2500 Scale
}

Indicated Air Speed,
fpm

80

130

195

300

435

540

650

755
True dir Speed, Epm

149

200

300

399

503

606

706

$T=21.1{ }^{\circ} \mathrm{C}$

$\mathrm{B}=749.3 \mathrm{~mm} \mathrm{Hg}$ 


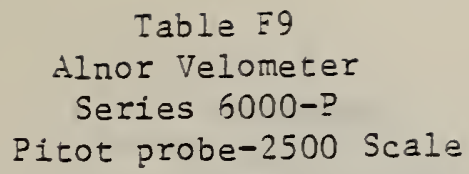

Indicated Air Speed, Epm

80

135

185

305

425

540

645

750

$T=21.1{ }^{\circ} \mathrm{C}$

$B=749.3 \mathrm{~mm} \mathrm{Hg}$
True Air Speed, Epm

103

149

200

300

399

503

605

704

\author{
Table E10 \\ Alnor Velometer \\ Series 6000-? \\ Pitot probe-2500 Scale
}
Indicated Air Speed, fpm

75

125

190

300

420

540

650

755
True Air Speed, Epm

103

149

200

300

398

503

605

705

$I=21.1{ }^{\circ} \mathrm{C}$

$B=749.3 \mathrm{Hg}$ 


\section{Table Ell \\ Alnor Velometer \\ Series 6000-? \\ Diffuser probe-2500 Scale}

Indicated Air Speed,

75

145

230

395

540

675

820

940

Indicated Air Speed, epm

545

680

815

940

\author{
$\mathrm{T}=21.1{ }^{\circ} \mathrm{C}$ \\ $B=747.8 \mathrm{~mm} \mathrm{Hg}$ \\ Table $\mathrm{E} 12$ \\ Alnor Velometer \\ Series 6000-? \\ Diffuser probe-2500 Scale
} Irue Air Speed,
fpm

101

148

201

301

401

501

602

701
True Air Speed, fpm

101

149

200

301

401

503

602

698

$T=21.1{ }^{\circ} \mathrm{C}$

$B=747.8$ ing $\mathrm{Hg}$ 


\section{Table F13 \\ Alnor Velometer \\ Series 6000-? \\ Diffuser probe-2500 Scale}

Indicated Air Speed,
Ipm

80

145

245

400

540

680

820

940

$\Gamma=21.1{ }^{\circ} \mathrm{C}$

$\mathrm{B}=747.5 \mathrm{~mm} \mathrm{Hg}$

Table F14

Alnor Velometer

Series 6000-P

Diffuser probe-2500 Scale
True Air Speed, zpm.

101

149

200

301

401

499

601

699

\section{Indicated Air Speed, fpm}

True Air Speed, fpm

945 


\section{Table $=15$ \\ Alnor Velometer \\ Series 6000-P \\ Diffuser probe-2500 Scale}

Indicated Air Speed,
fpm $_{\mathrm{pm}}$

90

150

245

395

540

680

815

940

$\mathrm{T}=21.1{ }^{\circ} \mathrm{C}$

$B=747.3 \mathrm{~mm} \mathrm{Hg}$ Indicated Air Speed,
fpm

135

195

280

395

510

620

735

840

\section{Table F16
or Velometer \\ Table F16
Alnor Velometer \\ Series 6000-P \\ Diffuser probe-1250 Scale}

Irue Air Speed, Epm

101

148

200

301

400

500

599

698
True Air Speed, fpm

101

149

199

300

401

498

601

698

$\mathrm{T}=21.1{ }^{\circ} \mathrm{C}$

$B=746.0 \mathrm{mg}$ 
Table Fli

Alnor Velometer

Series 6000-P

Diffuser probe-1250 Scale

\section{Indicated Air Speed, fpm}

130

200

278

398

515

620

738

840
True dir Speed, fpm

101

148

198

299

399

498

599

699

$$
\begin{aligned}
& T=21.1{ }^{\circ} \mathrm{C} \\
& B=746.0 \mathrm{Hg}
\end{aligned}
$$

\author{
Table F18 \\ Alnor Velometer \\ Series 6000-? \\ Diffuser probe-1250 Scale
}

\title{
Indicated Air Speed,
} fpm

True Air Speed, fpm

130

102

200

149

278

199

400

300

515

401

620

500

740

602

840

697

$\mathrm{T}=21.1{ }^{\circ} \mathrm{C}$

$B=745.4 \mathrm{~mm} \mathrm{Hg}$ 


\section{Table F19 \\ Alnor Velometer \\ Series 6000-? \\ Diffuser probe-1250 Scale}

Indicated Air Speed,
fpm

135

200

278

398

515

618

738

843

\author{
Table F20 \\ Alnor Velometer \\ Series 6000-P \\ Diffuser probe-1250 Scale
}

$$
\begin{aligned}
& T=21.1{ }^{\circ} \mathrm{C} \\
& B=745.4 \mathrm{~mm} \mathrm{Hg}
\end{aligned}
$$

True Air Speed,
fpm

101

149

200

301

402

501

601

701
Indicated Air Speed, fpm

138

200

275

395

518

620

738

840
True Air Speed, f pm

101

148

199

301

401

499

603

696

$\mathrm{T}=20.6{ }^{\circ} \mathrm{C}$

$\mathrm{B}=744.3 \mathrm{~mm} \mathrm{Hg}$ 


\author{
Table F21 \\ Alnor Velometer \\ Series 6000-P \\ Low Velocity probe
}

\section{Indicated Air Speed, fpm}

33

47

68

93

145

207

297 True Air speed,
fpm

43.0
56.5
77.6
102
150
199
271

$$
\begin{aligned}
& T=20.6{ }^{\circ} \mathrm{C} \\
& B=742.5 \mathrm{~mm} \mathrm{Hg}
\end{aligned}
$$

Table F22

Alnor Velometer

Series 6000-P

Low Velocity probe

True Air Speed, fpm

$$
42.9
$$

56.5

77.4

101

150

199

272

207

296

$$
\begin{aligned}
& T=20.6{ }^{\circ} \mathrm{C} \\
& B=742.5 \mathrm{~mm} \mathrm{Hg}
\end{aligned}
$$




\section{Tabie $\equiv 23$ \\ Alnor Velomerer \\ Series 5000-? \\ Iow Velocity probe}

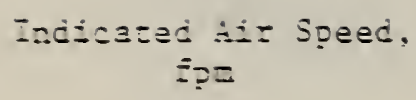

$I=20.0^{\circ} \mathrm{C}$

$3=7-2.0=\mathrm{Hg}$

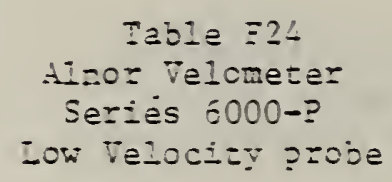

Irue Aiz Speed, हरा

\section{6}

36.1

77.6

101

149

199

270
Irue Air Speed, ipe

42.9

55.8

77.3

101

I 49

198

271

$$
\begin{aligned}
& I=20.0^{\circ} \mathrm{C} \\
& 3=742.0 \mathrm{E}=\mathrm{Eg}
\end{aligned}
$$




$$
\begin{gathered}
\text { Table } \overrightarrow{2} 25 \\
\text { Alnor Velomete } \\
\text { Series 6000-? } \\
\text { Low Velocity probe }
\end{gathered}
$$

Indicated dir Speed, Epm

33

48

68

94

144

207

296
Irue ir Speed,

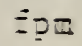

42.3

56.9

77.6

102

149

199

272

$$
\begin{aligned}
& I=20.0^{\circ} \mathrm{C} \\
& 3=740.3^{\mathrm{N}} \mathrm{Eg}
\end{aligned}
$$





\section{Table GI \\ Alnor Velometer Jr. \\ Low Range}

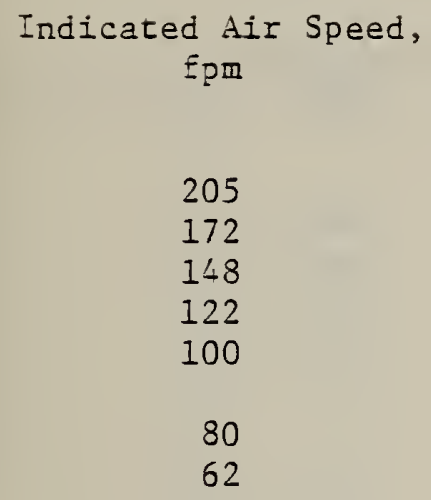
Indicated Air Speed,

205

170

146

122

100

78

60
True Air Speed, fpm

204.7

166.4

141.1

116.3

93.0

70.6

53.0

$$
\begin{aligned}
& T=26.9^{\circ} \mathrm{C} \\
& B=747.5 \mathrm{~mm} \mathrm{Hg}
\end{aligned}
$$

\section{Table G2 Alnor Velometer $\mathrm{Jr}$. Low Range}

True Air Speed, fpm 204.6 165.8 141.6 118.0 94.9 70.3 53.2

$$
\begin{aligned}
& T=26.9{ }^{\circ} \mathrm{C} \\
& B=747.5 \text { tim } \mathrm{Hg}
\end{aligned}
$$




\section{Tabla G3 \\ Alco: Melowezar JI. \\ Low Ra=ge}

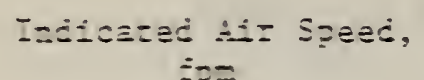

200

170

$1-3$

$\because 20$

$=00$

80

52
Izue Aiz speed, छo=

204.2

156.5

142.1

117.0

92.7

70.7

53.3
$z=25.9^{\circ} 0$
$3=7.7 . \Sigma= \pm \xi$
$Z a b l \equiv G:$

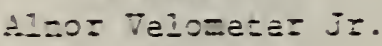
Iow Range

Irue Ai= Speed,

立二

204.7

156.3

141.1

116.4

$? 2.9$

59.5

53.4

$I=25.9^{\circ} \mathrm{C}$

$3=747.5=\mathrm{Eg}$ 


\section{TajIきG5 \\ Hicor Veloweter J". \\ Low Rasge}

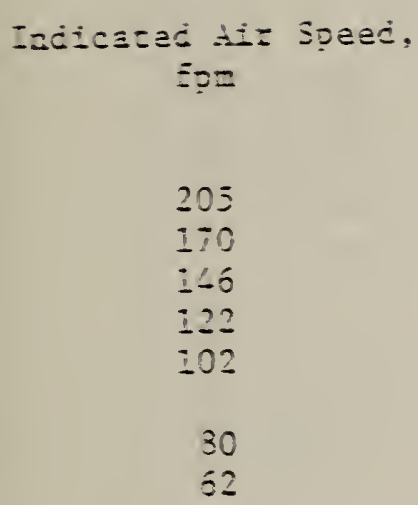

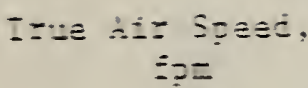

$20-.6$

165.2

141.3

1:7.5

ఏ. 3

72.2

इอ.

$I=27.0^{\circ} \mathrm{C}$

$3=74.5=\Xi \varepsilon$

Iñ
Inะ

ize

775

600

525

480

420

300

230

195

150

i०0
712.3

508.5

503.1

390.0

296.1

1:2.2

$14=.0$

117.2

93.5

5). 3

$$
\begin{aligned}
& I=26.9^{\circ} \mathrm{C} \\
& 3=727.5^{\circ}= \pm \Xi
\end{aligned}
$$




\section{Table GT \\ Alnor Velomerer Jr. \\ Eigh Range}

Indicared Air Speed, Epx

800

610

525

485

$\div 20$

300

230

195

160

105

$I=26.9^{\circ} \mathrm{C}$

$3=747.5 \mathrm{mg}$

Tabie G8

Alnor Velomerer Jr.

Hign Range

Indicated fir Speed,
三pl

800

610

530

480

420

300

210

180

150

100
Irue Air Speed, Epm

714.7

608.8

504.2

400.0

296.5

192.4

141.7

117.4

93.3

52.5
Irue Air Speed, fpm

714.2

609.7

504.9

399.3

296.9

191.8

140.3

117.4

93.0

53.3

$I=26.9^{\circ} \mathrm{C}$

$3=747.5 \mathrm{~mm} \mathrm{Eg}$ 


\section{Tabie G9 \\ Hlnor Velometer Jr. \\ High Range}

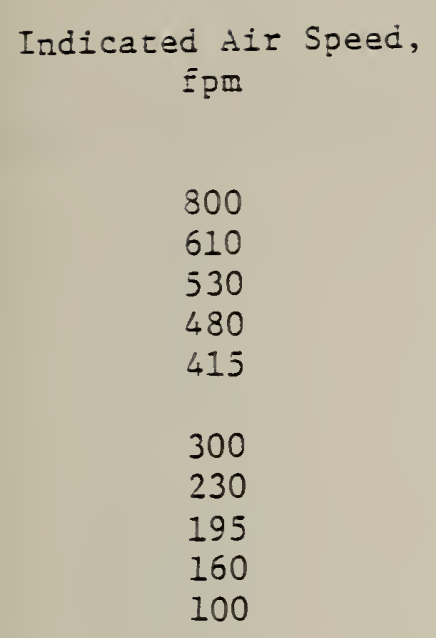

Irue tir Speed, 三?

715.9

609.4

501.4

400.2

296.9

192.5

141.5

116.9

93.4

52.8

$$
\begin{aligned}
& T=26.9{ }^{\circ} \mathrm{C} \\
& B=747.5 \mathrm{mg}
\end{aligned}
$$

\section{Table G10 \\ Alnor Velometer Jr. Hign Range}

\section{Indicated Air Speed,} f?m

800

625

530

480

420

300

225

195

160

100
True tir Speed, धрm

715.7

610.6

504.6

399.0

296.3

191.5

141.0

115.4

92.3

54.4

$$
\begin{aligned}
& T=27.0^{\circ} \mathrm{C} \\
& B=747.5 \mathrm{Hg}
\end{aligned}
$$



Table HI

J-Tec Type VA-216

$S / N 49$

Instrument Output Frequency $\mathrm{Hz}$

$$
\begin{array}{r}
8.68 \\
10.9 \\
12.6 \\
14.6 \\
16.5 \\
22.7 \\
32.5 \\
46.9 \\
65.4 \\
83.2
\end{array}
$$

110

147

187

242

278

318

$\begin{array}{cc}\text { Instrument Output Voltage } \\ \text { volts } \\ .132 & \begin{array}{c}\text { True Air Speed } \\ \text { fpm }\end{array} \\ .160 & 60.3 \\ .182 & 72.2 \\ .208 & 81.0 \\ .233 & 91.4 \\ & 100.6 \\ .312 & \\ .44 & 128 \\ .62 & 170 \\ .88 & 219 \\ 1.12 & 284 \\ 1.48 & 374 \\ 1.95 & 492 \\ 2.45 & 649 \\ 3.20 & 835 \\ 3.70 & 1103 \\ 4.20 & 1290 \\ & \\ & \end{array}$

$T=21.3$ to $21.6^{\circ} \mathrm{C}$

$B=752.4 \mathrm{~mm} \mathrm{Hg}$ 
Table H2

J-Tec Type VA-216

$S / N 49$

Instrument Output Frequency $\mathrm{Hz}$

8.63

10.5

12.3

15.0

16.6

22.9

32.6

46.9

66.2

84.0

112

148

186

245

276

320
Instrument Output Voltage
volts

.126

.154

.175

.209

.229

.308

.44

.62

.86

1.13

1.49

1.95

2.50

3.20

3.65

4.15

$T=22.5^{\circ} \mathrm{C}$

$B=752.7$
True Air Speed

fpm

60.8

72.5

81.6

92.9

100.8

130

172

220

284

375

492

647

833

1109

1293

1502 


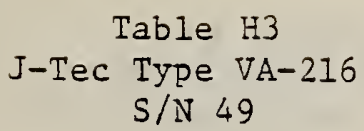

Instrument Output Frequency

$\mathrm{Hz}$

$$
\begin{aligned}
& 8.70 \\
& 10.8 \\
& 12.7 \\
& 14.9 \\
& 16.3 \\
& \\
& 23.0 \\
& 32.6 \\
& 47.4 \\
& 65.4 \\
& 84.0
\end{aligned}
$$

112

147

186

245

282

318

$\begin{array}{cc}\text { Instrument } \begin{array}{c}\text { Output Voltage } \\ \text { volts }\end{array} & \begin{array}{c}\text { True Air Speed } \\ \text { Ipm }\end{array} \\ & \\ .130 & 61.6 \\ .154 & 72.5 \\ .180 & 81.6 \\ .210 & 92.5 \\ .226 & 100.2 \\ & \\ .311 & 131 \\ .43 & 171 \\ .60 & 219 \\ .86 & 285 \\ 1.13 & 375 \\ 1.48 & 492 \\ 1.96 & 648 \\ 2.47 & 834 \\ 3.21 & 1110 \\ 3.68 & 1298 \\ 4.16 & 1497\end{array}$

$T=22.5$ to $22.8{ }^{\circ} \mathrm{C}$

$B=752.8 \mathrm{~mm} \mathrm{Hg}$ 
Table $\mathrm{H} 4$
J-Tec Type VA-216
S/N 49

Instrument Output Frequency $\mathrm{Hz}$
8.59
10.6
12.6
14.8
16.3

22.7

32.7

46.7

64.9

82.6

110

148

189

243

279

316

.126

\section{Instrument Output Voltage volts}

.154

.175

.209

.227

.308

.43

.60

.86

1.12

1.48

1.97

2.46

3.20

3.65

4.19
True Air Speed

59.8

71.1

80.5

91.9

100.4

131

171

219

286

374

493

648

835

1106

1286

1505

$$
\begin{aligned}
& T=22.8 \text { to } 23.0{ }^{\circ} \mathrm{C} \\
& B=752.8 \mathrm{~mm} \mathrm{Hg}
\end{aligned}
$$




$$
\begin{aligned}
& \text { Table H5 } \\
& \text { J-Tec Type VA-216 } \\
& \text { S/N } 49
\end{aligned}
$$

Instrument Output Frequency $\mathrm{Hz}$

8.50

10.8

12.6

14.9

16.4

23.3

32.8

46.5

65.4

83.3

110

147

188

244

279

320

\section{Instrument Output Voltage volts}

.126

.152

.177

.207

.226

.313

.43

.61

.84

1.12

1.48

1.96

2.47

3.20

3.65

4.12

$T=23.2$ to $23.4{ }^{\circ} \mathrm{C}$

$\mathrm{B}=751.3 \mathrm{~mm} \mathrm{Hg}$
True Air Speed

fpm

59.5

71.5

80.9

92.1

100.2

130

172

220

284

375

490

648

836

1111

1292

1502 

Table II

J-Tec Type VA-216

$S / N 48$

\section{Instrument Output Frequency, $\mathrm{Hz}$
Instrument Output Voltage, volts \\ True Air Speed,}

8.61

10.8

12.6

14.7

16.3

.118

.146

.168

.195

.216

59.6

71.0

80.4

92.0

100.5

22.2

30.8

.29

.40

.60

.78

59.5

82.6 .

1.09

130

172

220

286

375

106.8

145.6

1.43

1.91

494

650

2.44

832

$\mathrm{T}=23.1^{\circ} \mathrm{C}$

$B=751.0 \mathrm{~mm} \mathrm{Hg}$ 


\section{Table I2 \\ J-Tec Type VA-216 \\ $\mathrm{S} / \mathrm{N} 48$}

Instrument Output Frequency, $\mathrm{Hz}$

Instrument Output Voltage,
volts

True Air Speed, fpm

58.1

70.3

80.2

93.0

99.5

22.2

29.7

46.1

57.5

82.0

105.7

144.5

186.2
.116

.144

.166

.215

130

170

219

285

375

1.42

1.92

2.45

494

649

835

$$
\begin{aligned}
& T=23.4^{\circ} \mathrm{C} \\
& B=751.2 \mathrm{Hg}
\end{aligned}
$$


Table I3

J-Tec Type VA-216

$\mathrm{S} / \mathrm{N} 48$

Instrument Output Frequency, $\mathrm{Hz}$
Instrument Output Voltage, volts
True Air Speed, Epm

$$
\begin{gathered}
8.65 \\
10.9 \\
12.7 \\
15.0 \\
16.4 \\
\\
23.0 \\
29.2 \\
45.7 \\
57.8 \\
80.0 \\
106.4 \\
143.7 \\
184.8
\end{gathered}
$$

.117

.147

.169

.198

.218

.29

.38

.60

.77

1.07

1.49

1.91

2.45
59.6

71.9

81.0

92.9

100.9

130

171

220

285

375

492

650

836

$$
\begin{aligned}
& T=23.7^{\circ} \mathrm{C} \\
& B=750.8 \text { m } \mathrm{Hg}
\end{aligned}
$$


Table I4

J-Tec Type VA-216

$S / N 48$

Instrument Output Frequency,
$\mathrm{Hz}$

8.50

10.6

12.5

14.7

15.3

21.5

28.8

45.2

59.9

78.1

107.0

143.5

186.2

\author{
Instrument Output Voltage, \\ volts
}
True Air Speed, Epm

63.5

71.2

80.1

91.8

100.2

.196

.28

.38

.59

.78

1.04

130

170

220

284

375

1.40

1.90

492

547

2.44

834

$$
\begin{aligned}
& T=23.9^{\circ} \mathrm{C} \\
& B=750.2 \mathrm{~mm} \mathrm{Hg}
\end{aligned}
$$


Table I5

J-Tec Type VA-216

$S / N 48$

Instrument Output Frequency, $\mathrm{Hz}$

$$
8.40
$$

10.6

12.4

14.6

16.2

22.7

27.9

44.8

60.2

78.1

103.7

142.9

184.8
Instrument Output Voltage, volts

.06

.142

.165

.195

.215

.30

.37

.59

.77

1.04

1.58

1.88

2.43
True dir Speed, Epm

63.6

70.4

80.0

91.1

99.4

130

170

219

283

375

489

642

834

$$
\begin{aligned}
& \mathrm{T}=24.2^{\circ} \mathrm{C} \\
& \mathrm{B}=750.2 \mathrm{mg} \mathrm{Hg}
\end{aligned}
$$





\section{Table JI}

Thermogage Air Velocity Meter

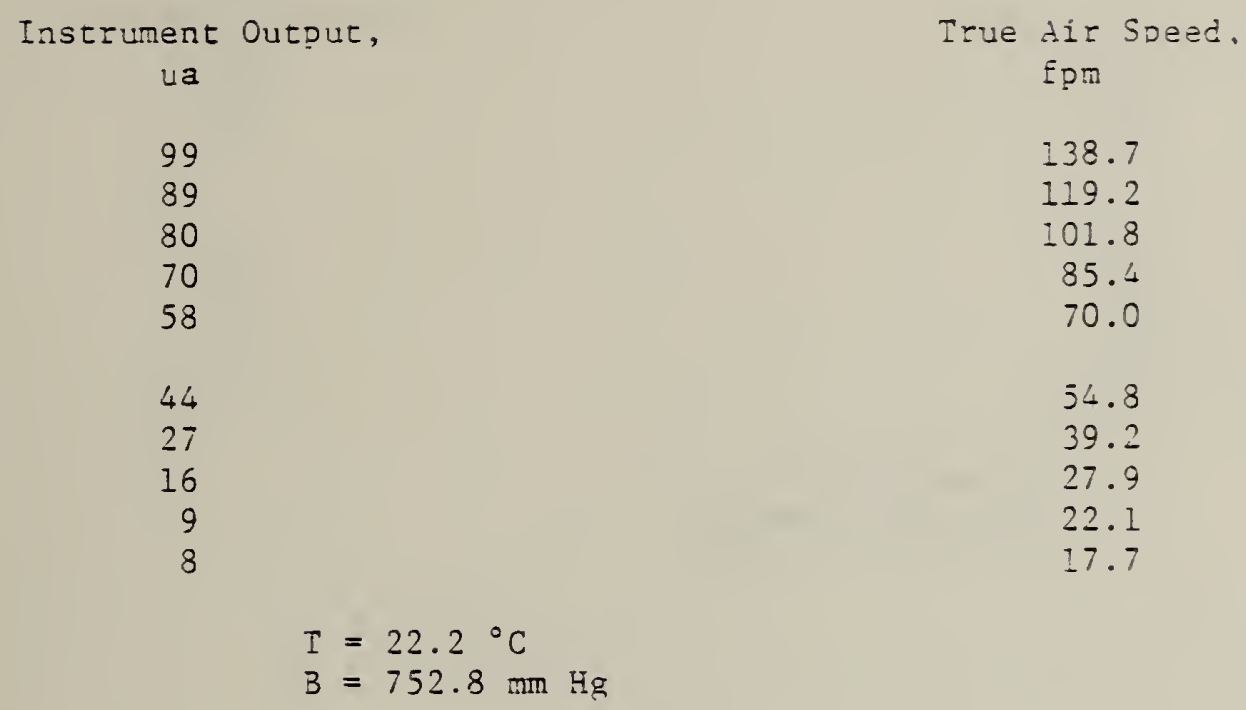

Table J2

Thermogage Air Velocity Meter

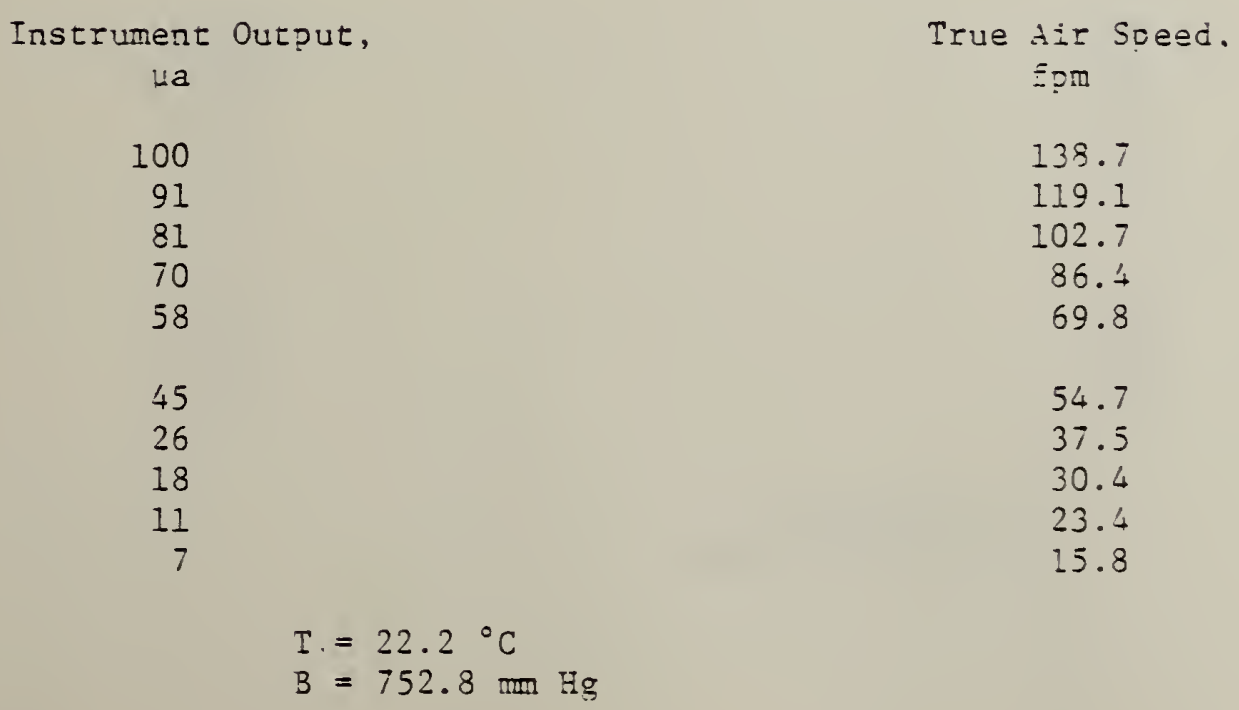


Fable J3

Thermogage Air Velocity Meter

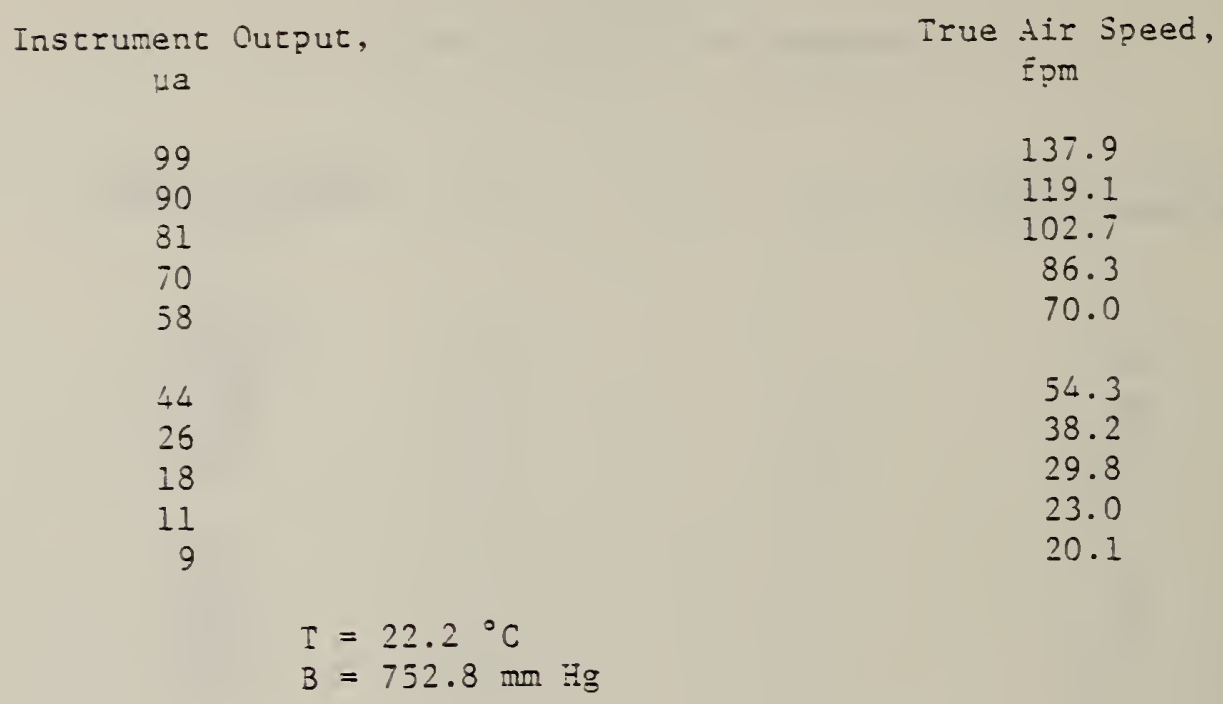

TabIe J4

Thermogage Air Velocity Meter

Instrument Output,

ua

100

90

81

71

58

43

24

17

12
True Air Speed, ipm

138.6

118.9

101.8

86.5

69.5

53.6

35.6

28.7

23.6

19.4

$$
\begin{aligned}
& I=22.2{ }^{\circ} \mathrm{C} \\
& B=752.8 \mathrm{~mm} \mathrm{Hg}
\end{aligned}
$$


Table J5

Thermogage Air Velocity Meter

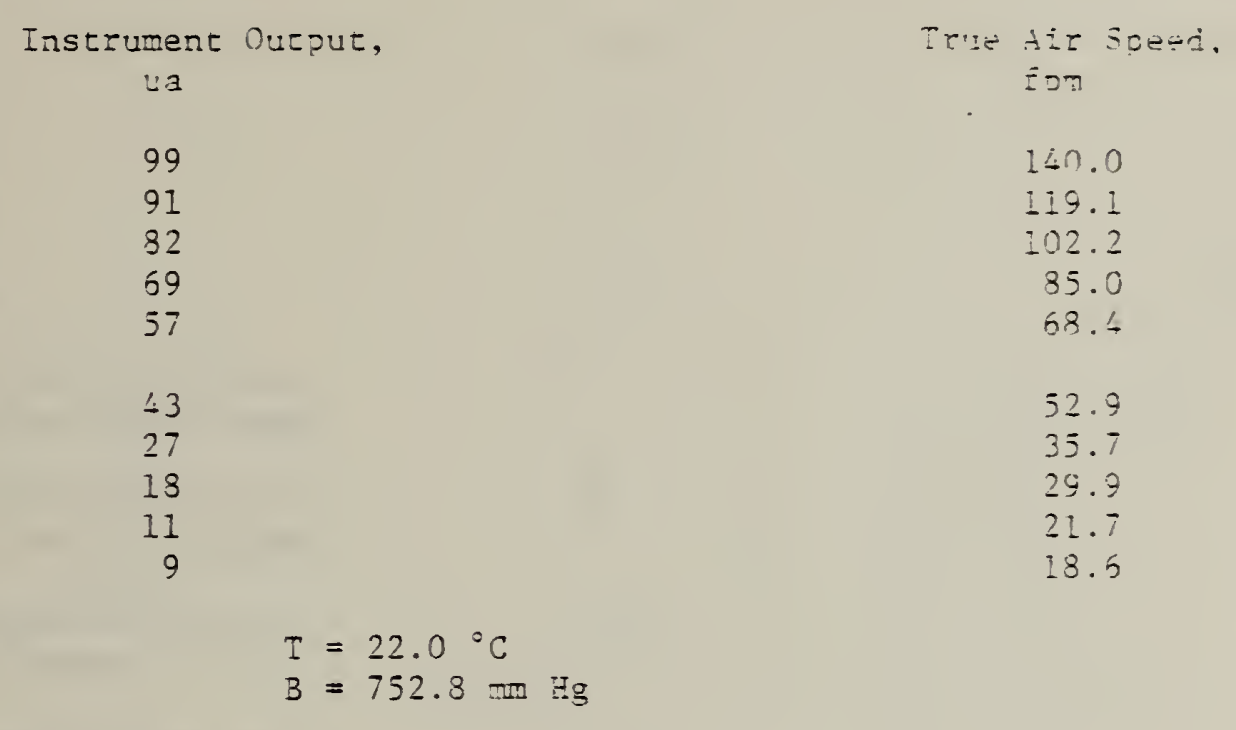



Table K

Minimun Operating Speeds

\section{INSTRLMENT}

A, vane

$B$, vane

C, vane

D, vane

E, vane

F, * impact-deflection, low and high ranges

F, * impact-deflection, low velocity probe

$G$, * impact-deflection, low range

$G, *$ impact-deflection, high range

H, vortex-shedding

I, vortex-shedding

$\mathrm{J}$, * heated-foil
STOPPING SPEED (fpm)

54

18.2

60.6

31.7

39.5

100

40

53.0

50.8

54.1

58.8

16
STARTING SPEED (EPM)

63.3

23.3

66.6

47.8

59.6 



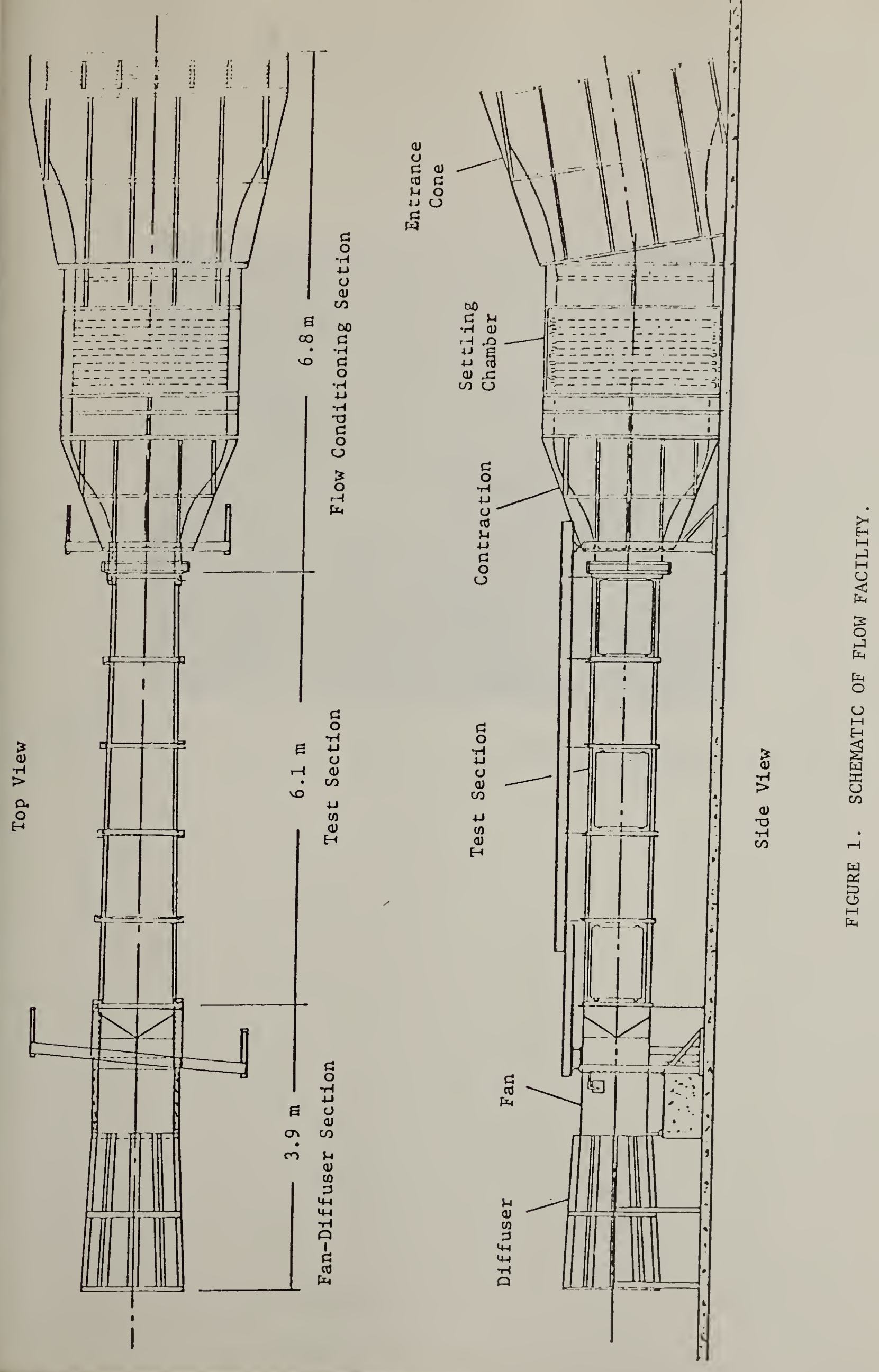




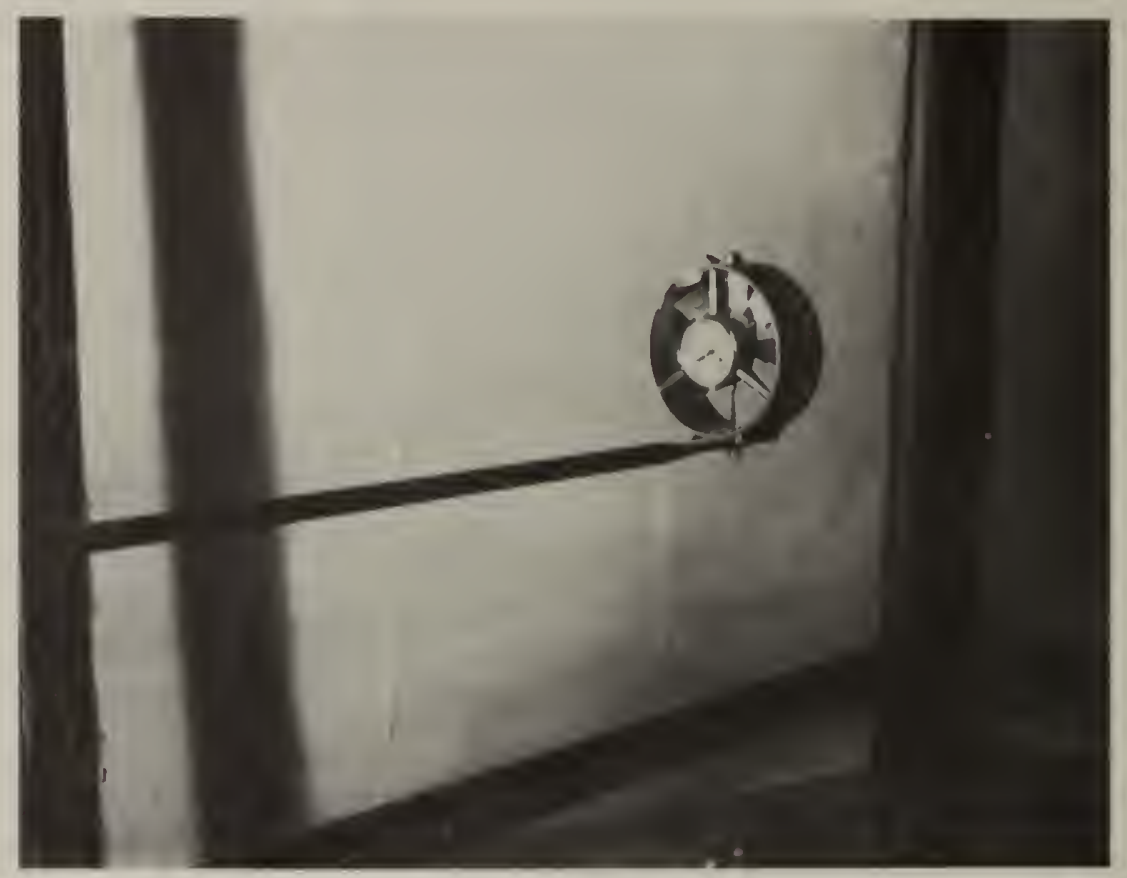

FIGURE 2. INSTRUMENT A MOUNTED IN THE TUNNEL, SHOWING METHOD OF SUPPORT. 


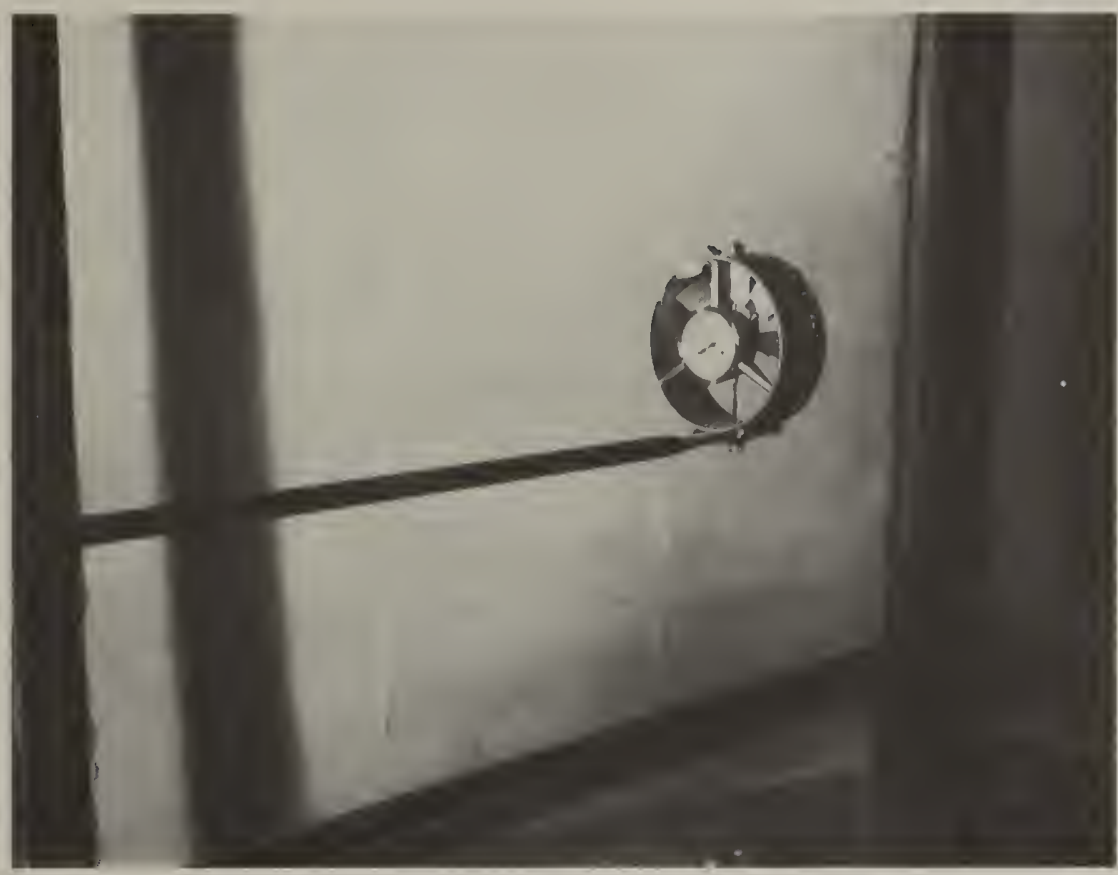

FIGURE 3. INSTRUMENT B MOUNTED IN THE TUNNEL, SHOWING METHOD OF SUPPORT. 


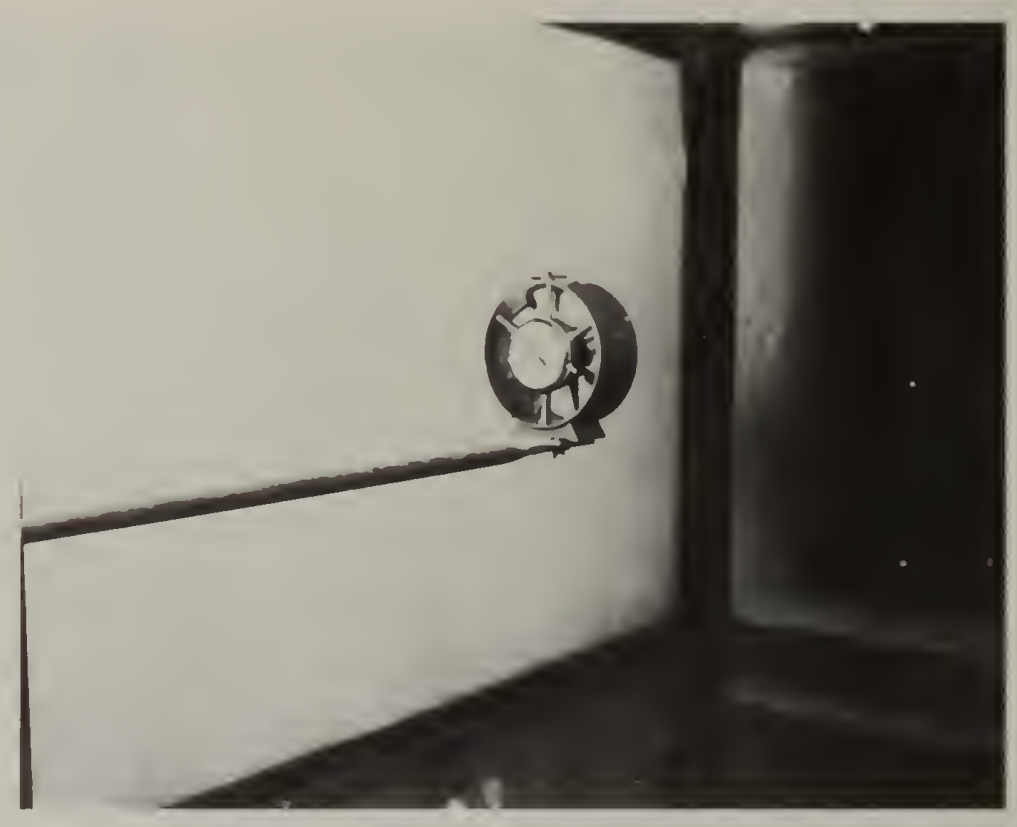

FIGURE 4. INSTRUMENT C MOUNTED IN THE TUNNEL, SHOWING METHOD OF SUPPORT. 


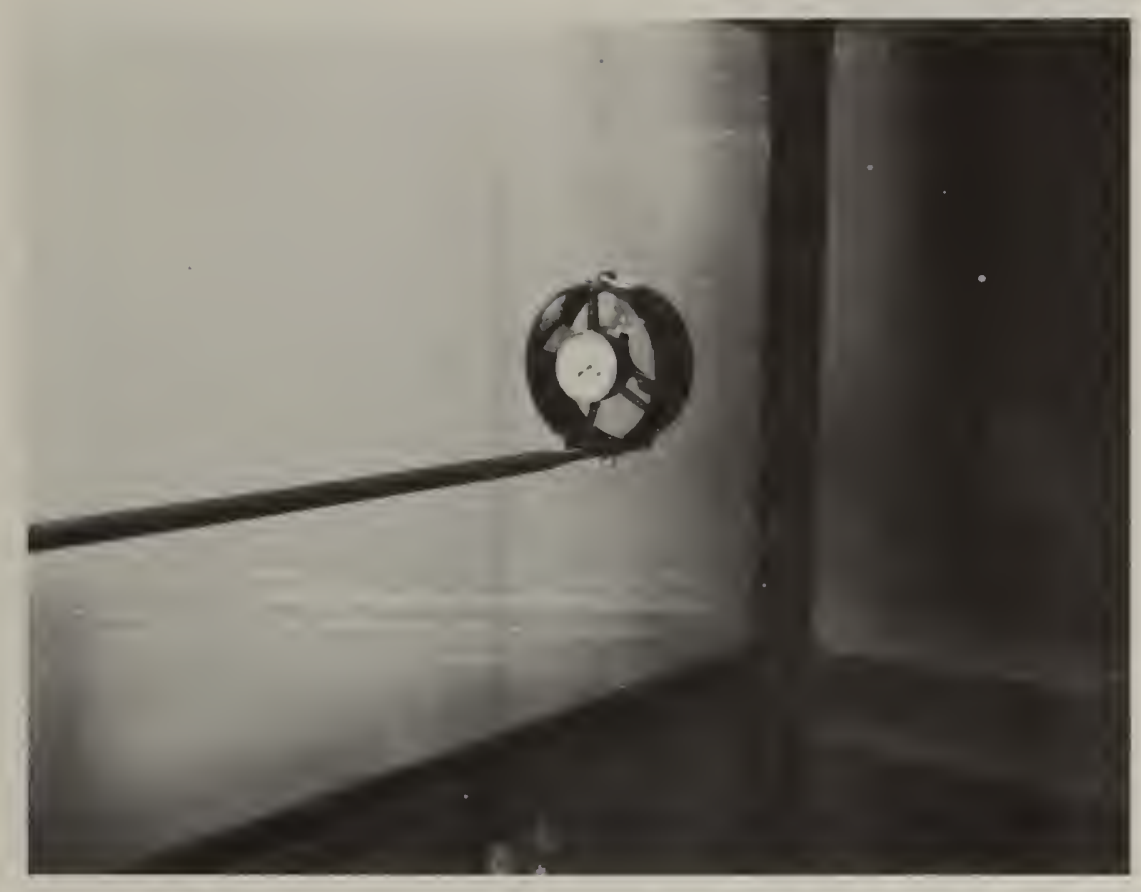

FIGURE 5. INSTRUMENT D MOUNTED IN THE TUNNEL, SHOWING METHOD OF SUPPORT. 


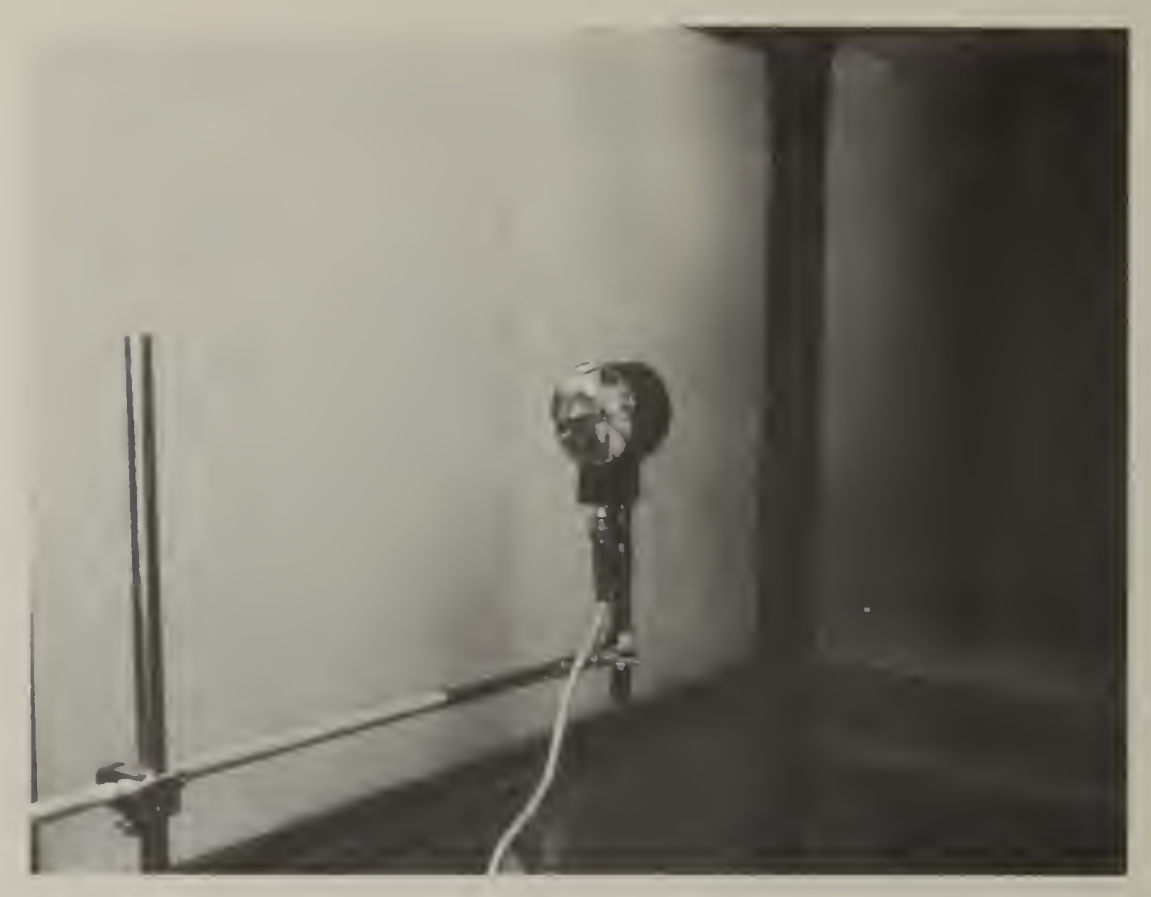

FIGURE 6. INSTRUMENT E MOUNTED IN THE TUNNEL, SHOWING METHOD OF SUPPORT. 


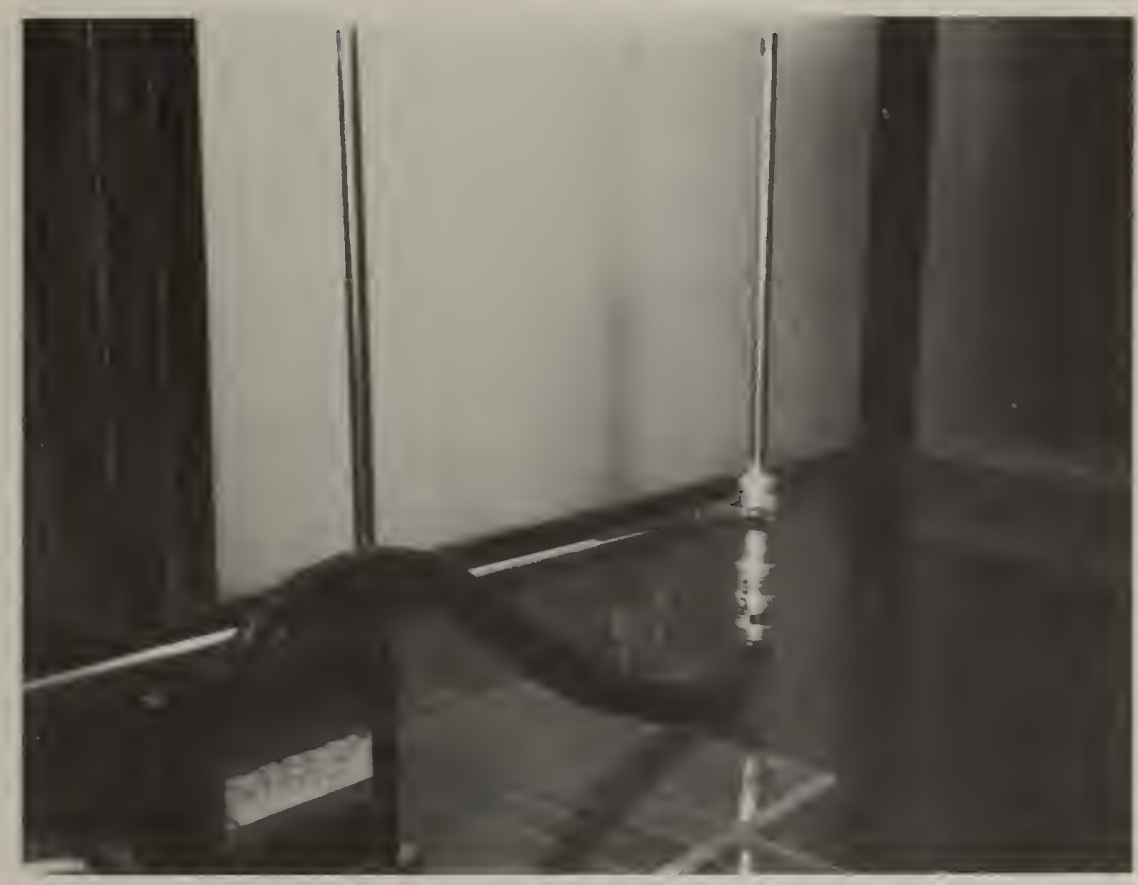

FIGURE 7. INSTRUMENT F. WITH PITOT PROBE MOUNTED IN TUNNEL SHOWING METHOD OF SUPPORT. 


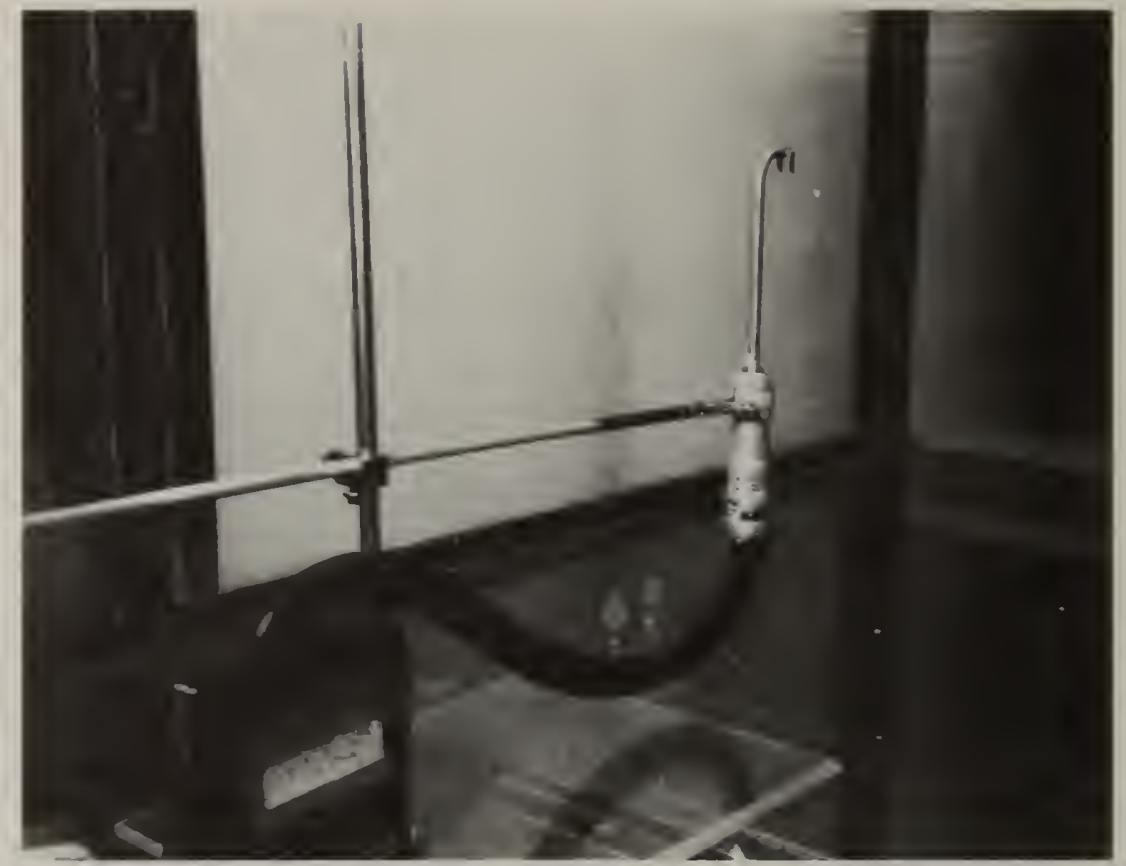

FIGURE 8. INSTRUNENT $F$ WITH DIFFUSER PROBE MOUNTED IN TUNNEL SHOWING METHOD OF SUPPORT. 


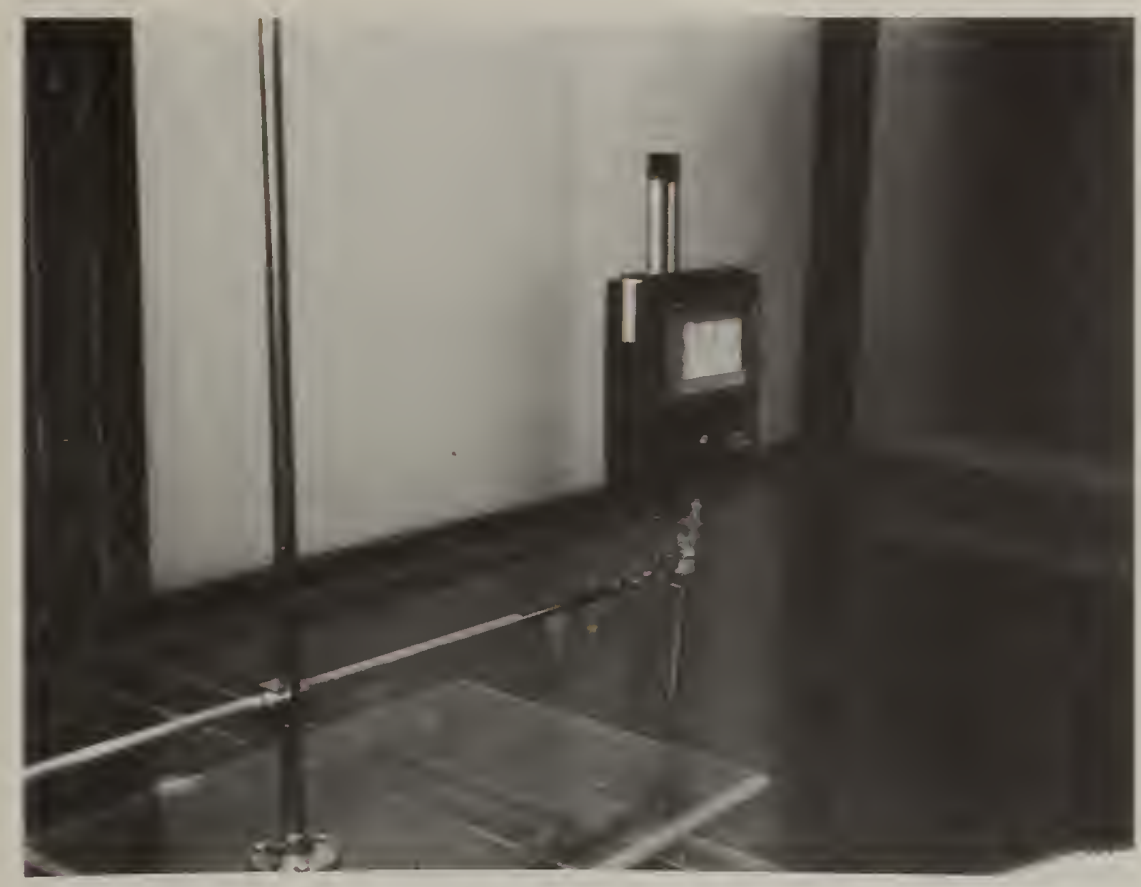

FIGURE 9. INSTRUMENT F WITH LOW-VELOCITY PROBE MOUNTED IN TUNNEL SHOWING METHOD OF SUPPORT. 


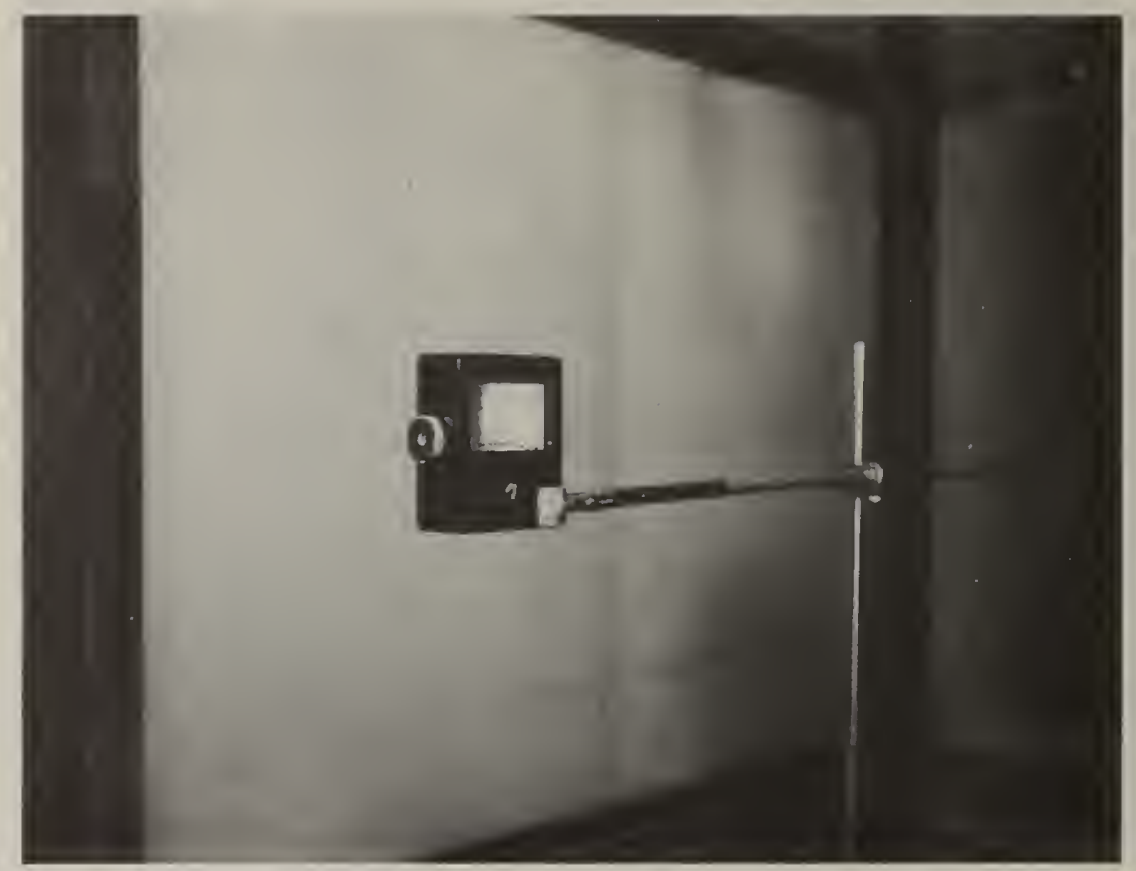

FIGURE 10. INSTRUMENT G MOUNTED IN THE TUNNEL, SHOWING METHOD OF SUPPORT (VIEWED LOOKING DOWNSTREAM). 


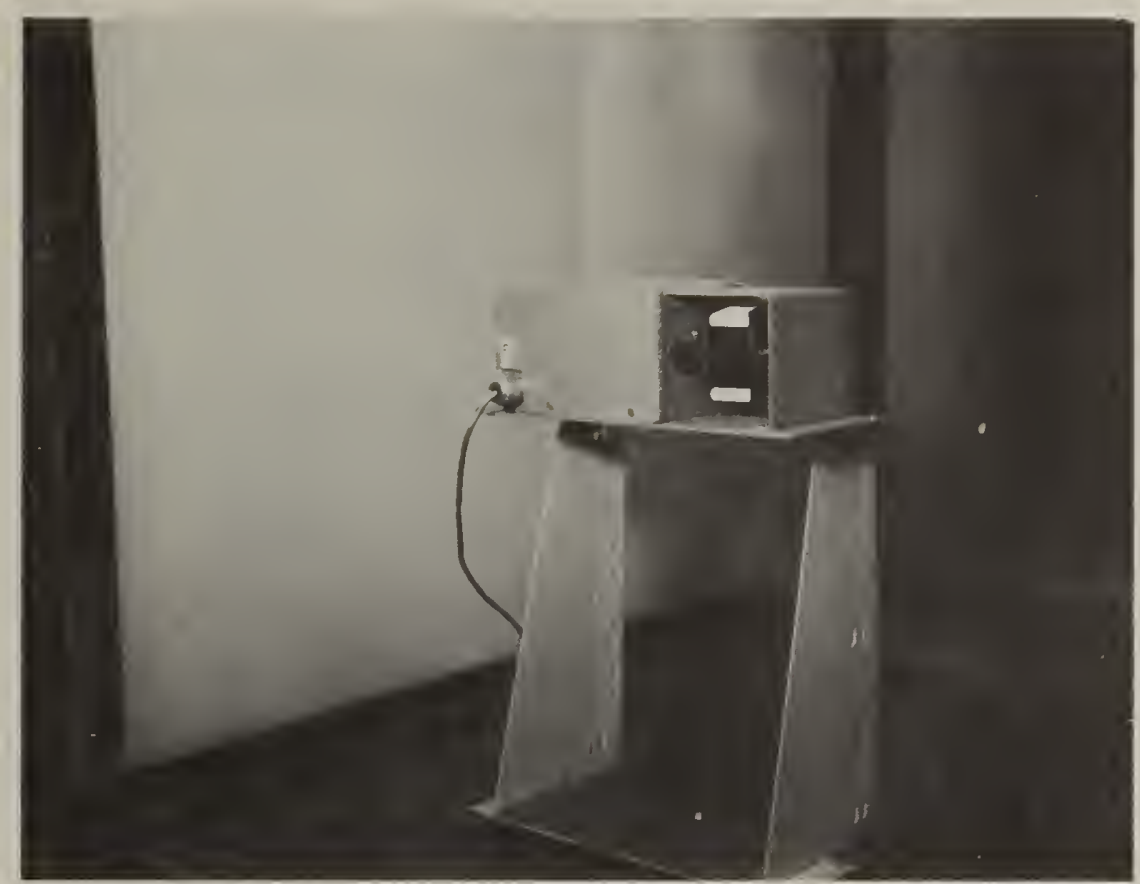

FIGURE 11. INSTRUMENTS H AND I MOUNTED IN TUNNEL, SHOWING METHOD OF SUPPORT (VIEWED LOOKING DOWNSTREAM). 


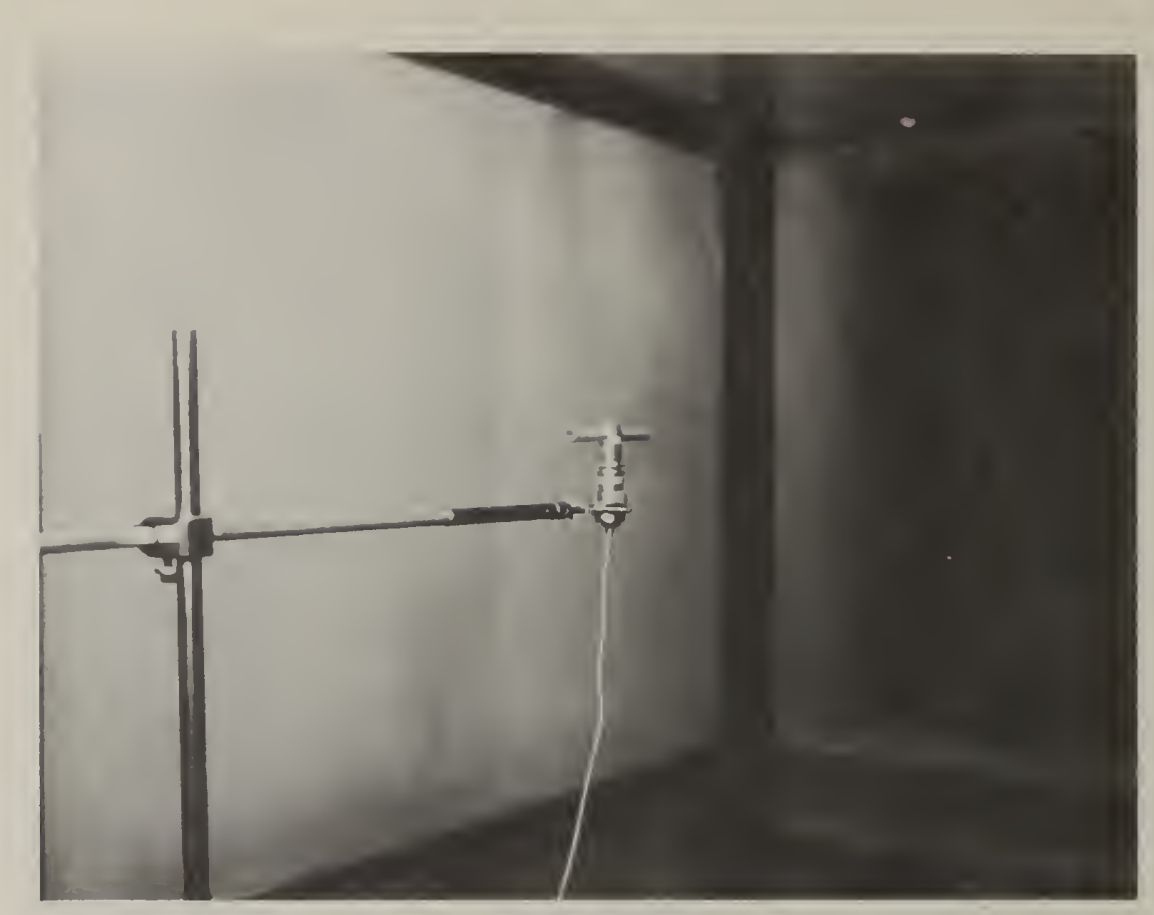

FIGURE 12. INSTRUMENT J MOUNTED IN TUNNEL, SHOWING METHOD OF SUPPORT. 


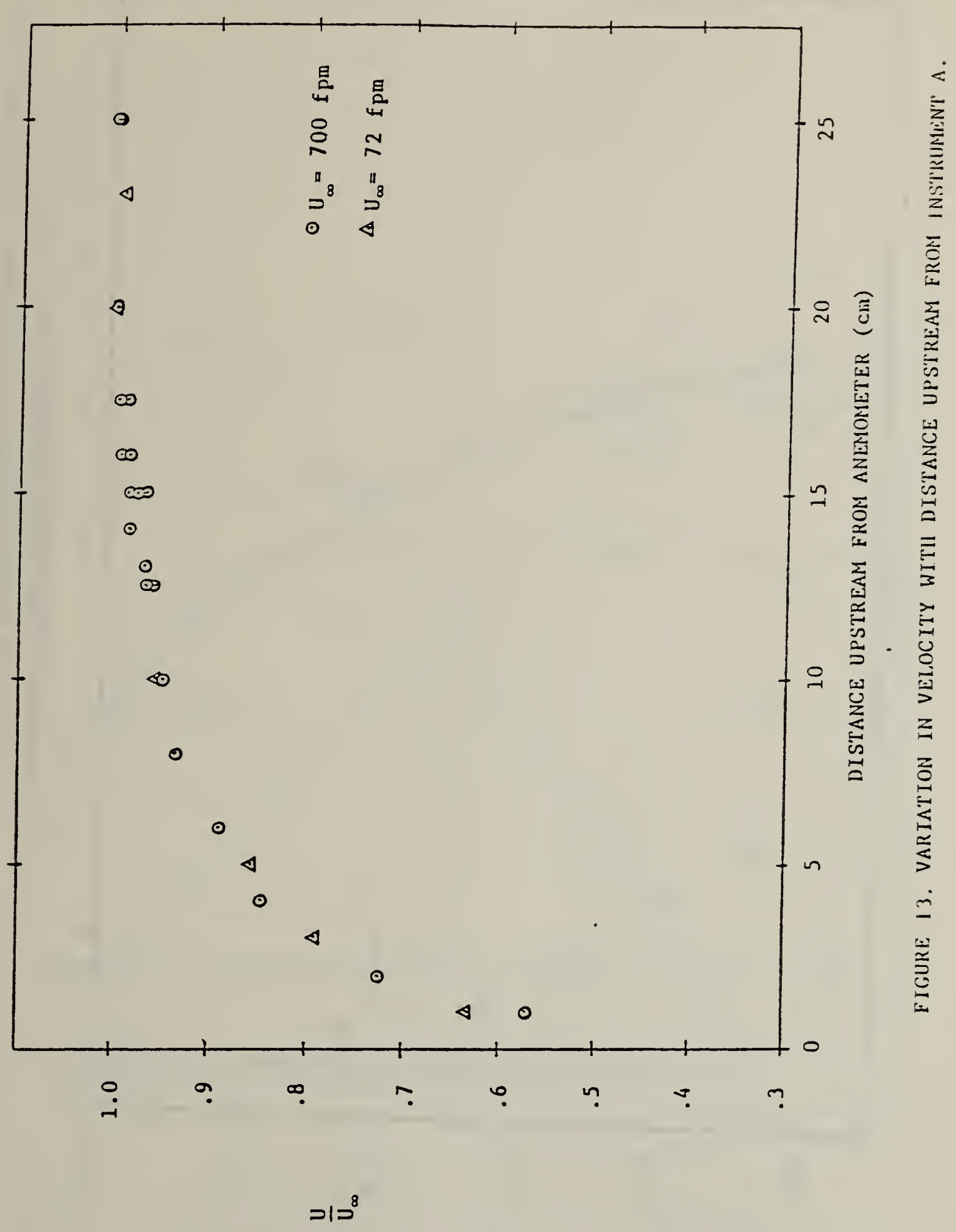




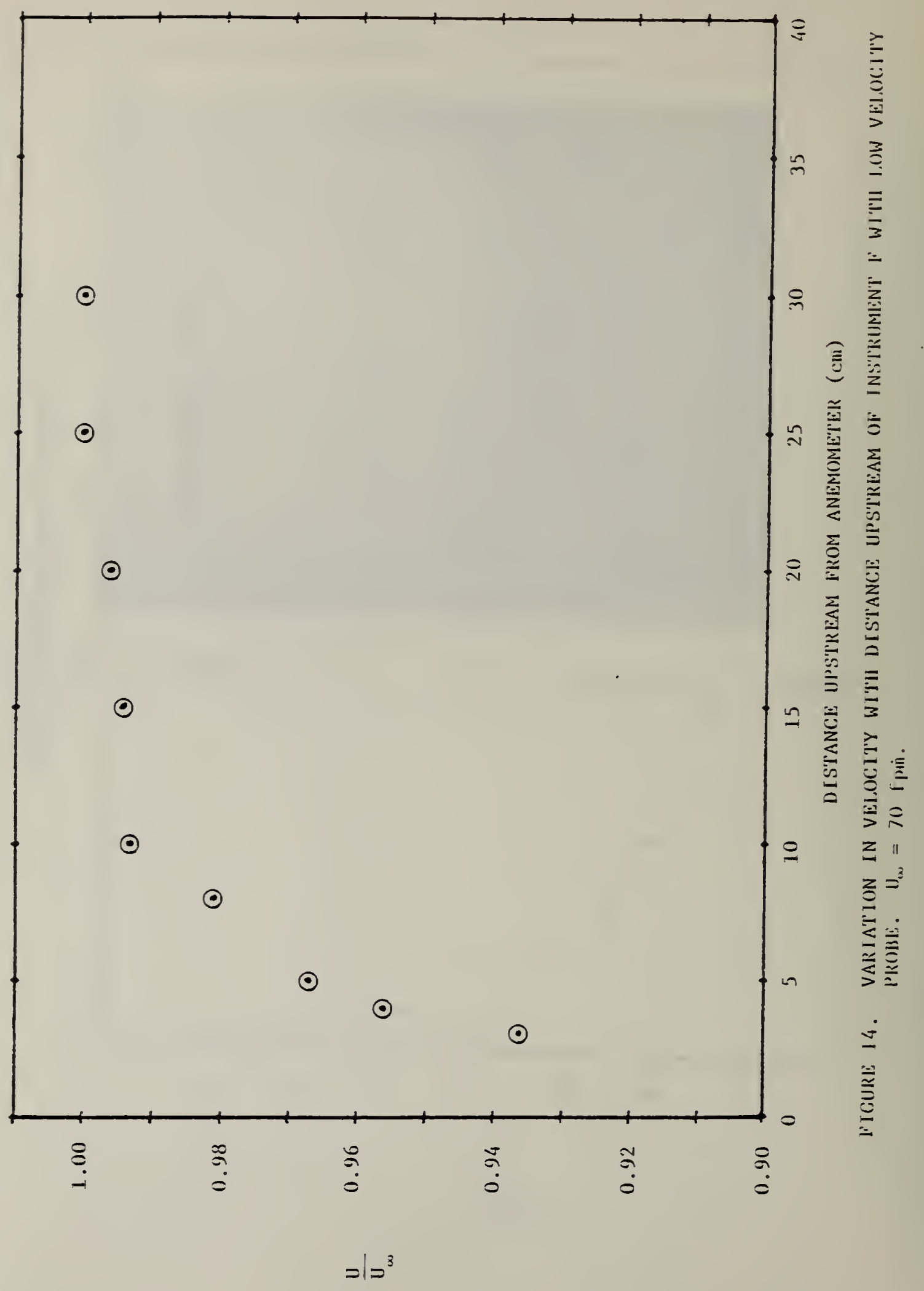




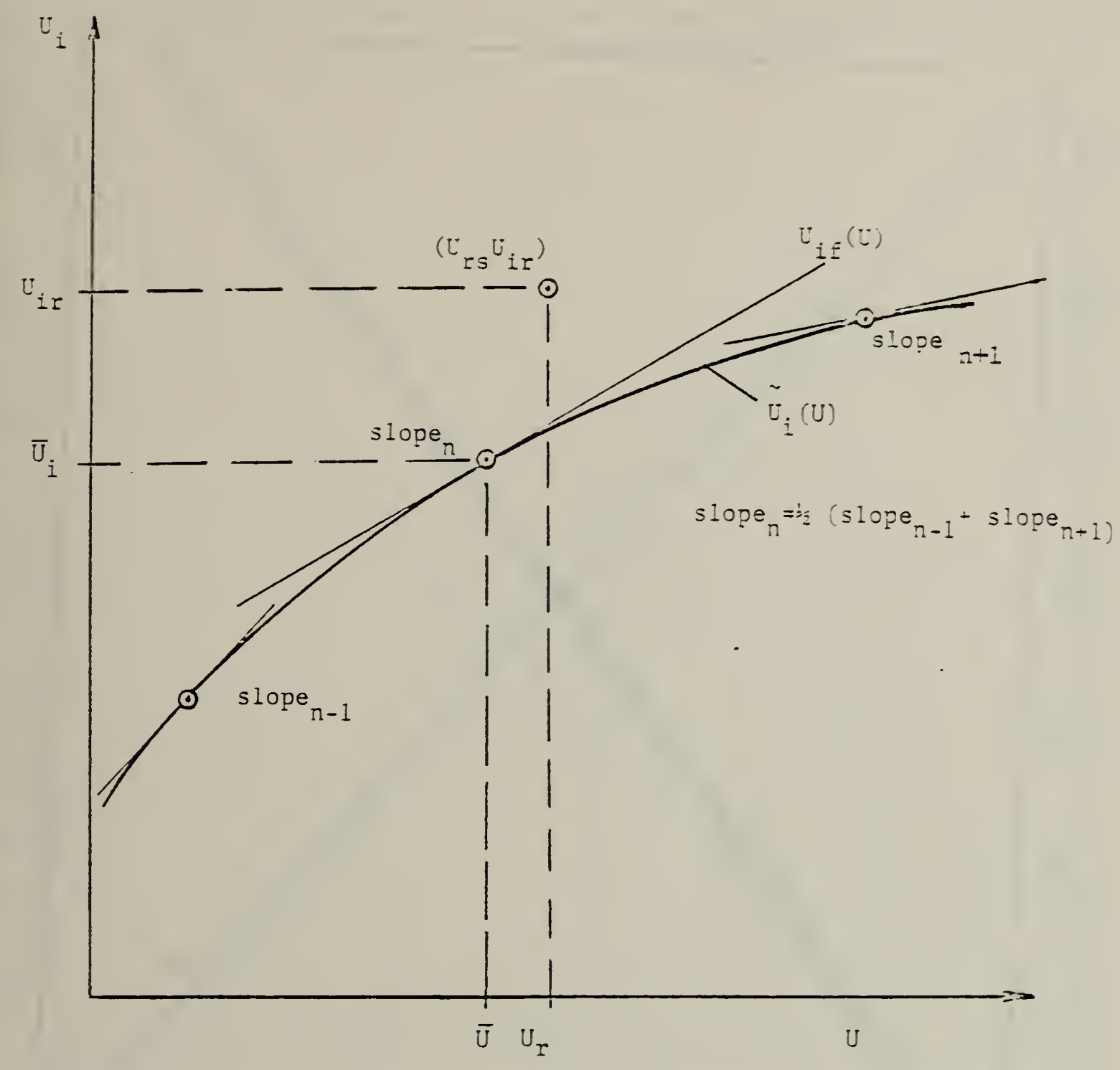

FIGURE 15. DEFINITION OF TERMS FOR CALCULATION OF $\sigma_{i}$. 


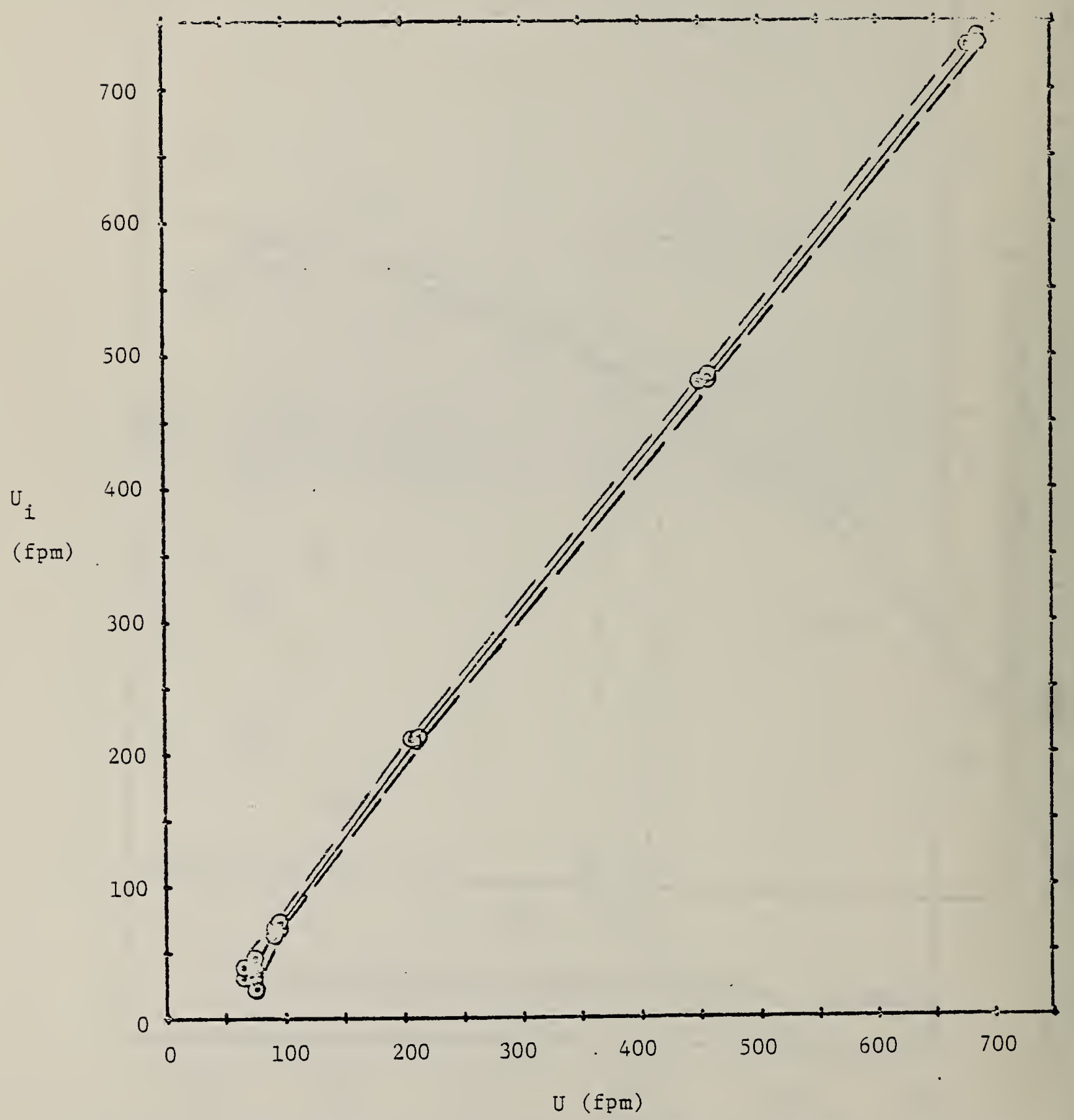

FIGURE 16. INDICATED VERSUS TRUE VELOCITY WITH $\pm 2 \sigma$ CURVES. INSTRUMENT A. 


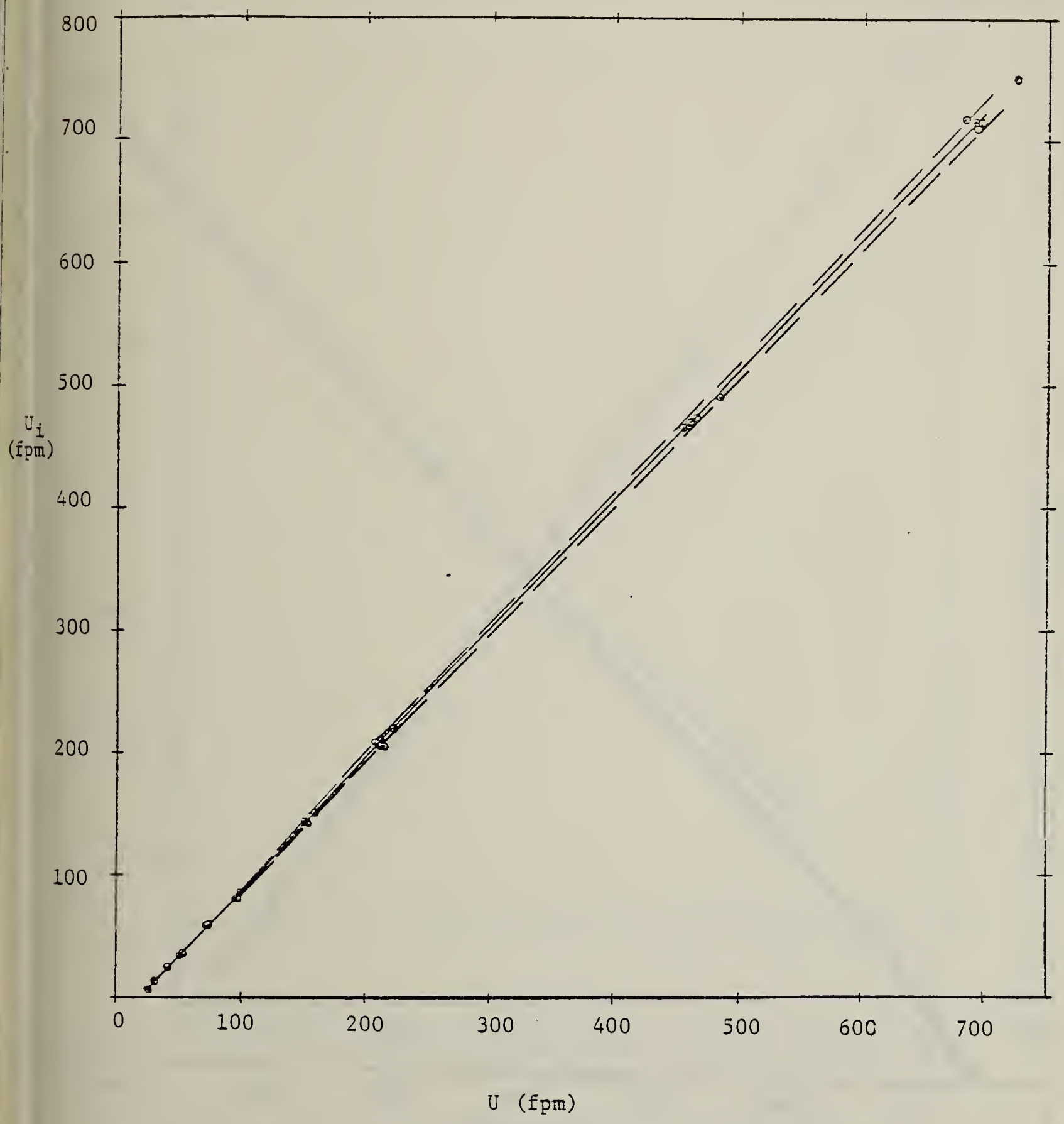

FIGURE 17. INDICATED VERSUS TRUE VELOCITY WITH $\pm 2 \sigma$ CURVES. INSTRUMENT $B$. 


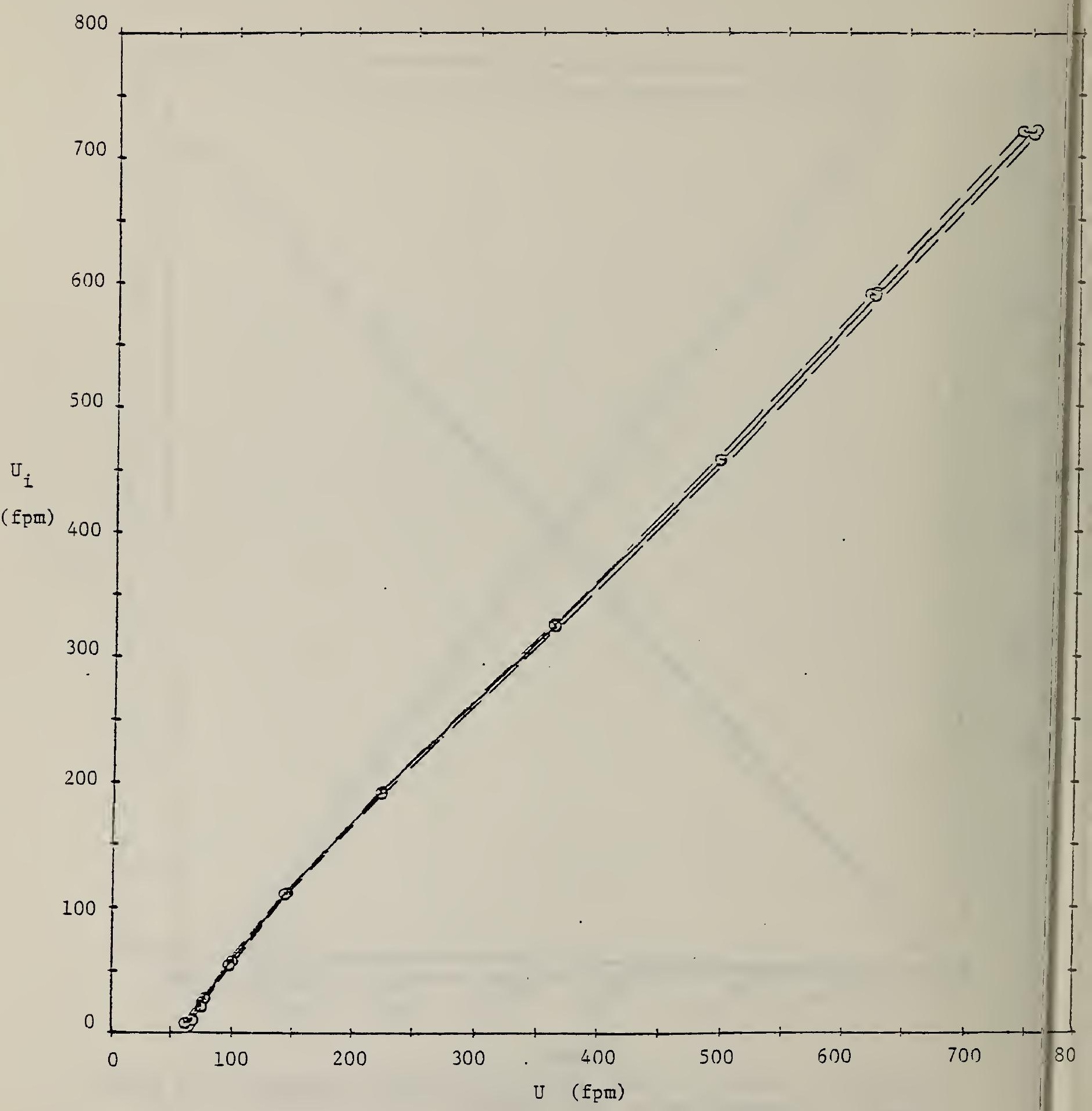

FIGURE 18. INDICATED VERSUS TRUE VELOCITY WITH \pm CURVES. INSTRUMENT $C$. 


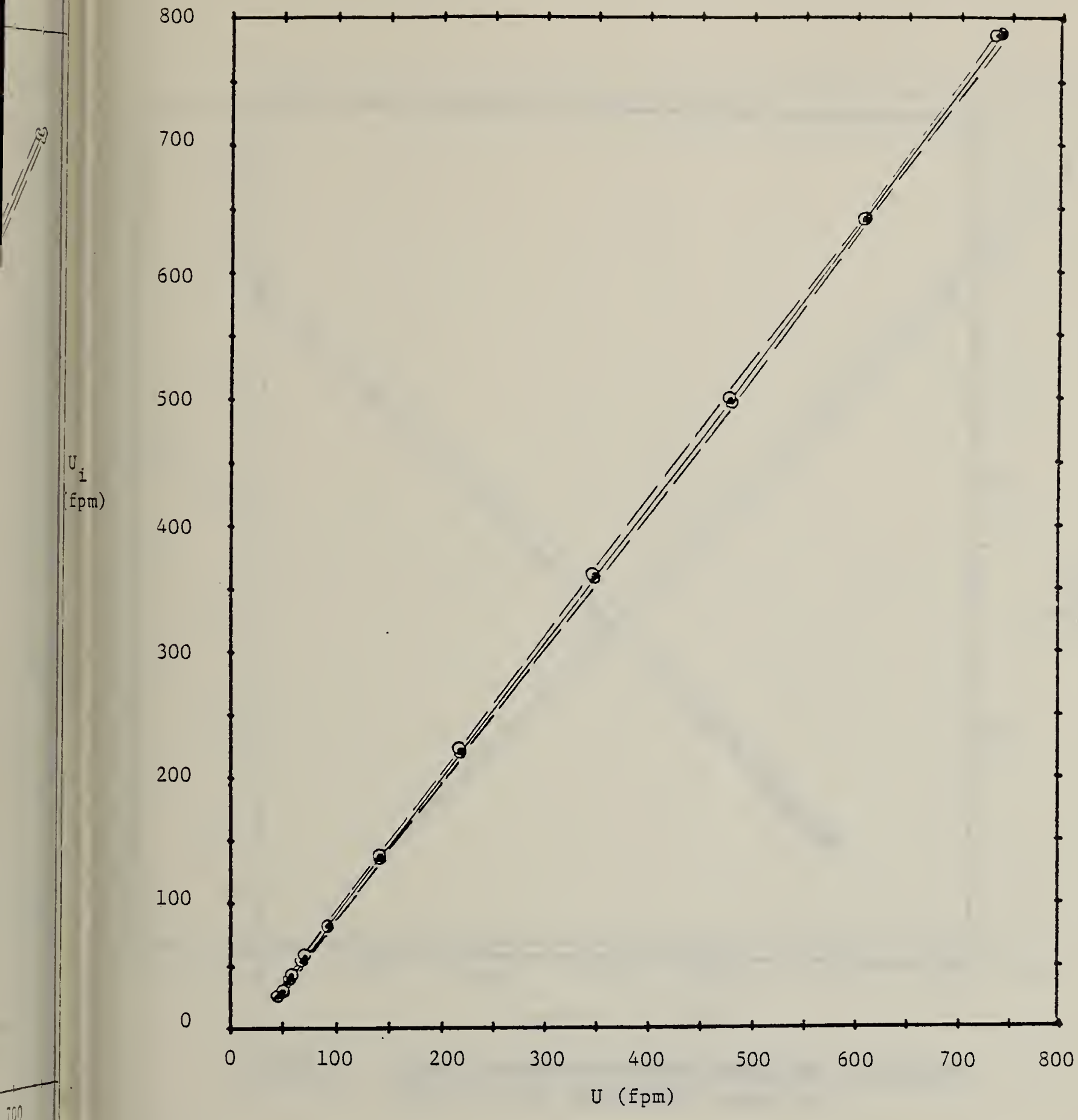

FIGURE 19. INDICATED VERSUS TRUE VELOCITY WITH $\pm 2 \sigma$ CURVES. INSTRUMENT D. 


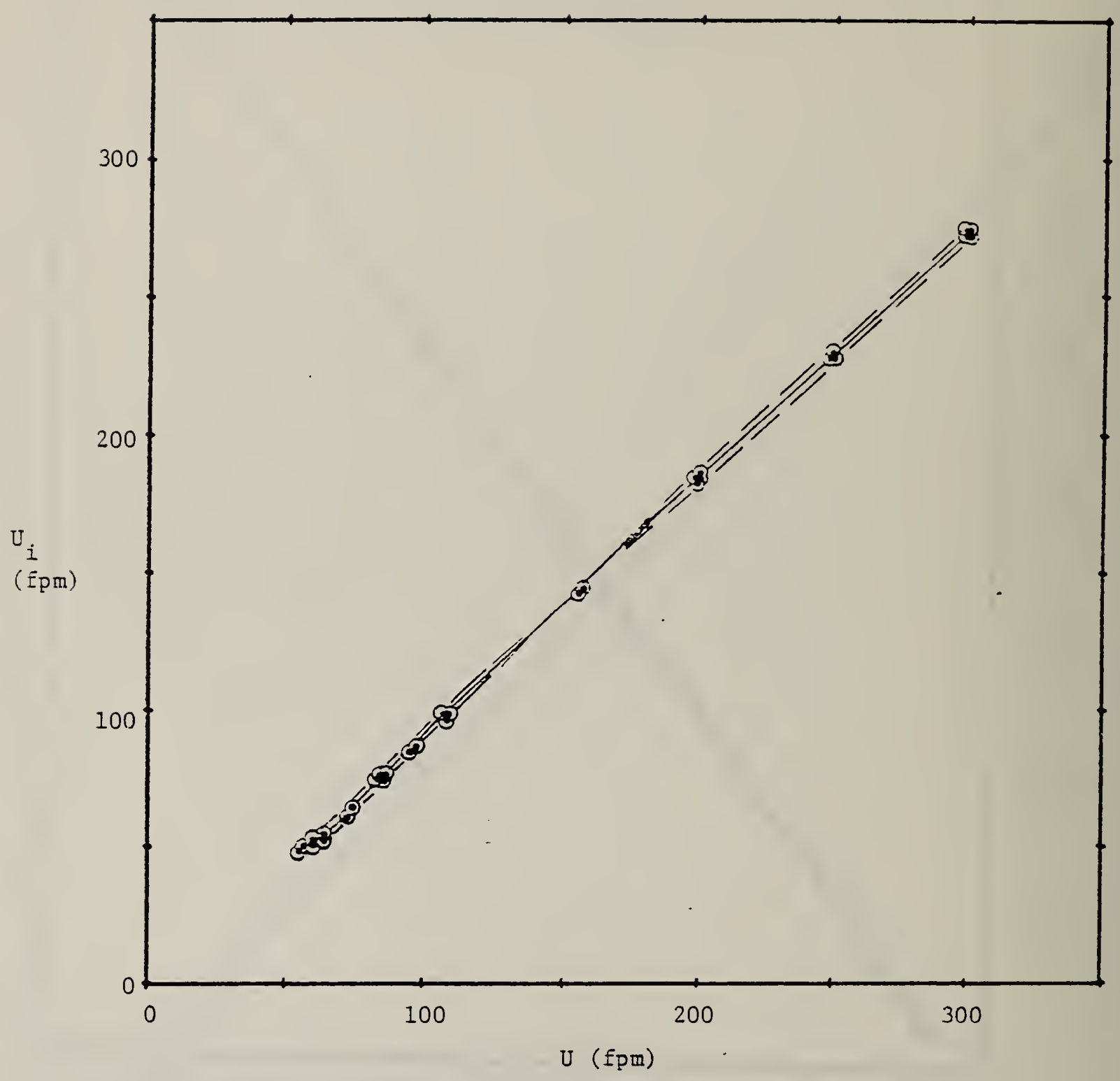

FIGURE 20. INDICATED VERSUS TRUE VELOCITY WITH $\pm 2 \sigma$ CURVES, LOW RANGE. INSTRUMENT E. 


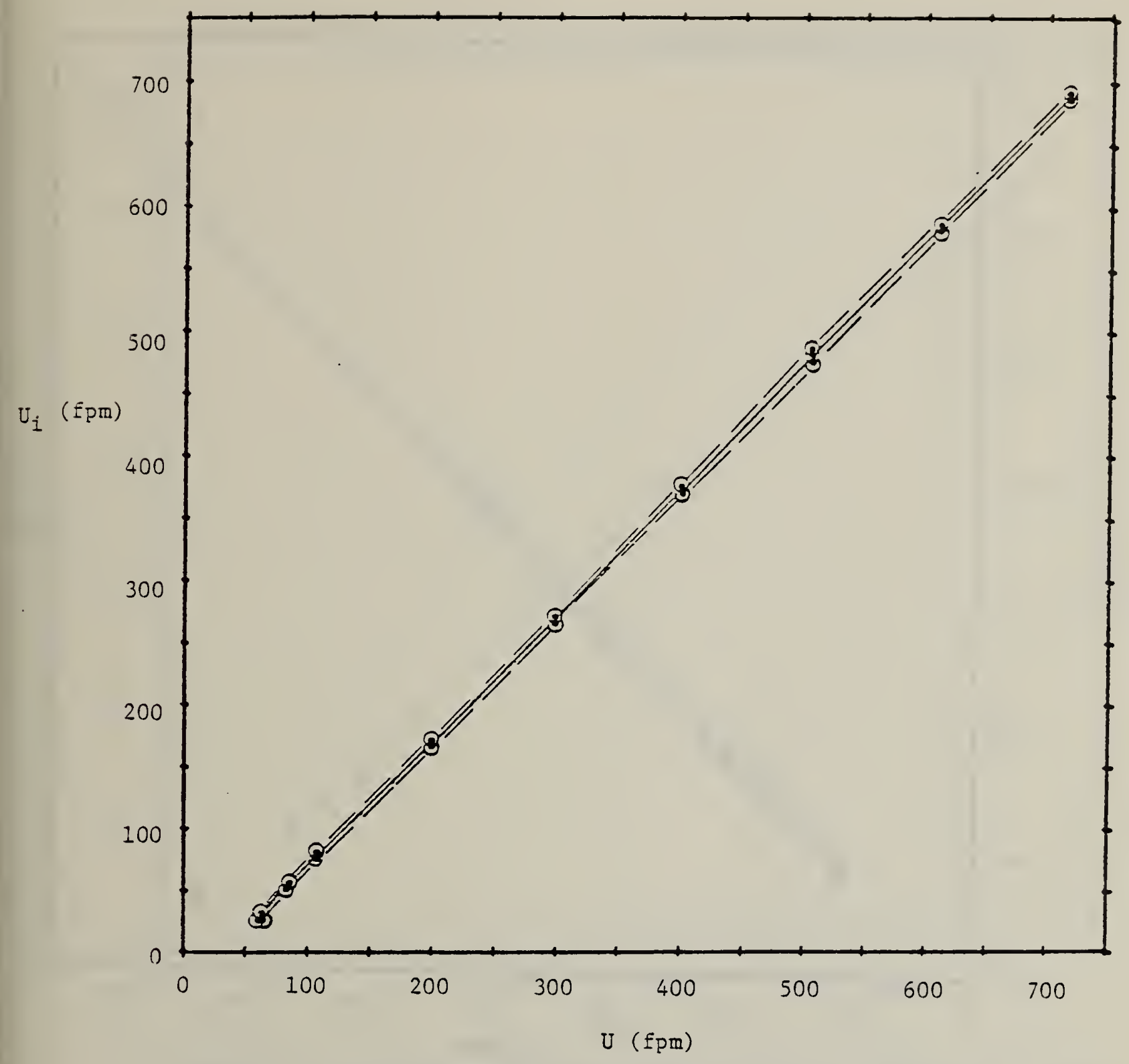

FIGURE 21. INDICATED VERSUS TRUE VELOCITY WITH $\pm 2 \sigma$ CURVES, MEDIUM RANGE. INSTRUMENT E. 


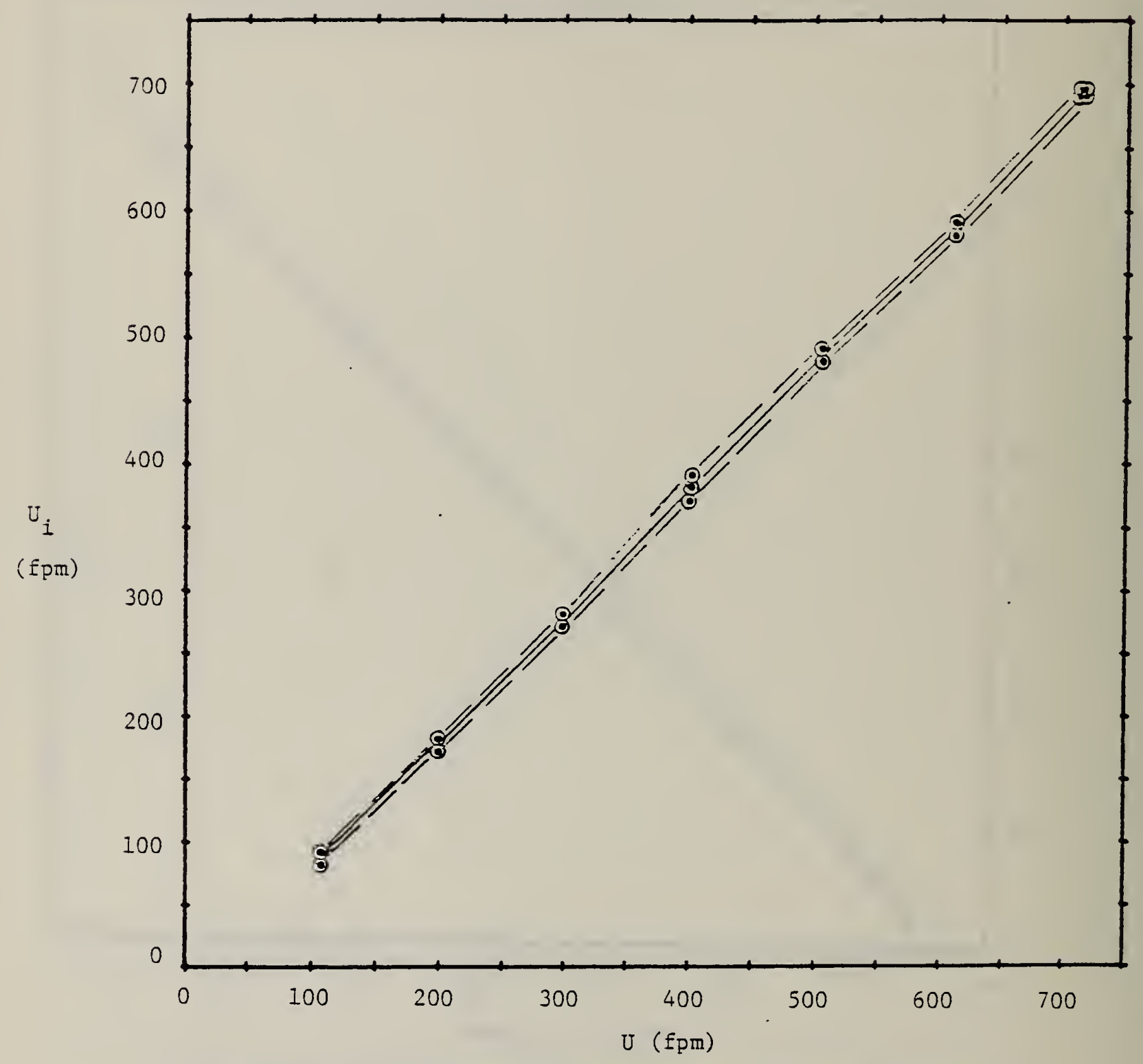

FIGURE 22. INDICATED VERSUS TRUE VELOCITY WITH $\pm 2 \sigma$ CURVES, HIGH RANGE. INSTRUMENT E. 


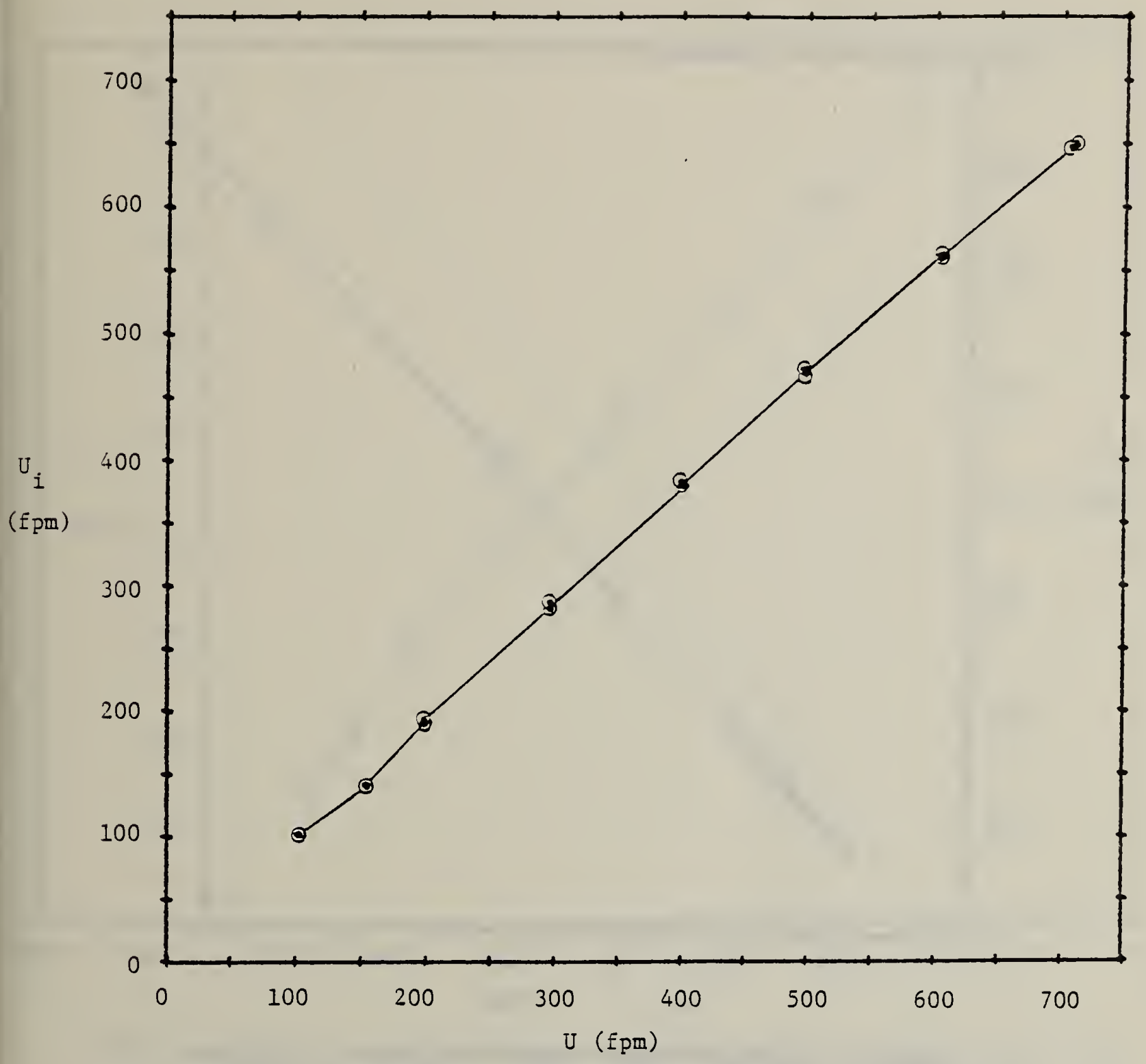

FIGURE 23. INDICATED VERSUS TRUE VELOCITY FOR PITOT PROBE, LOW RANGE. INSTRUMENT F. 


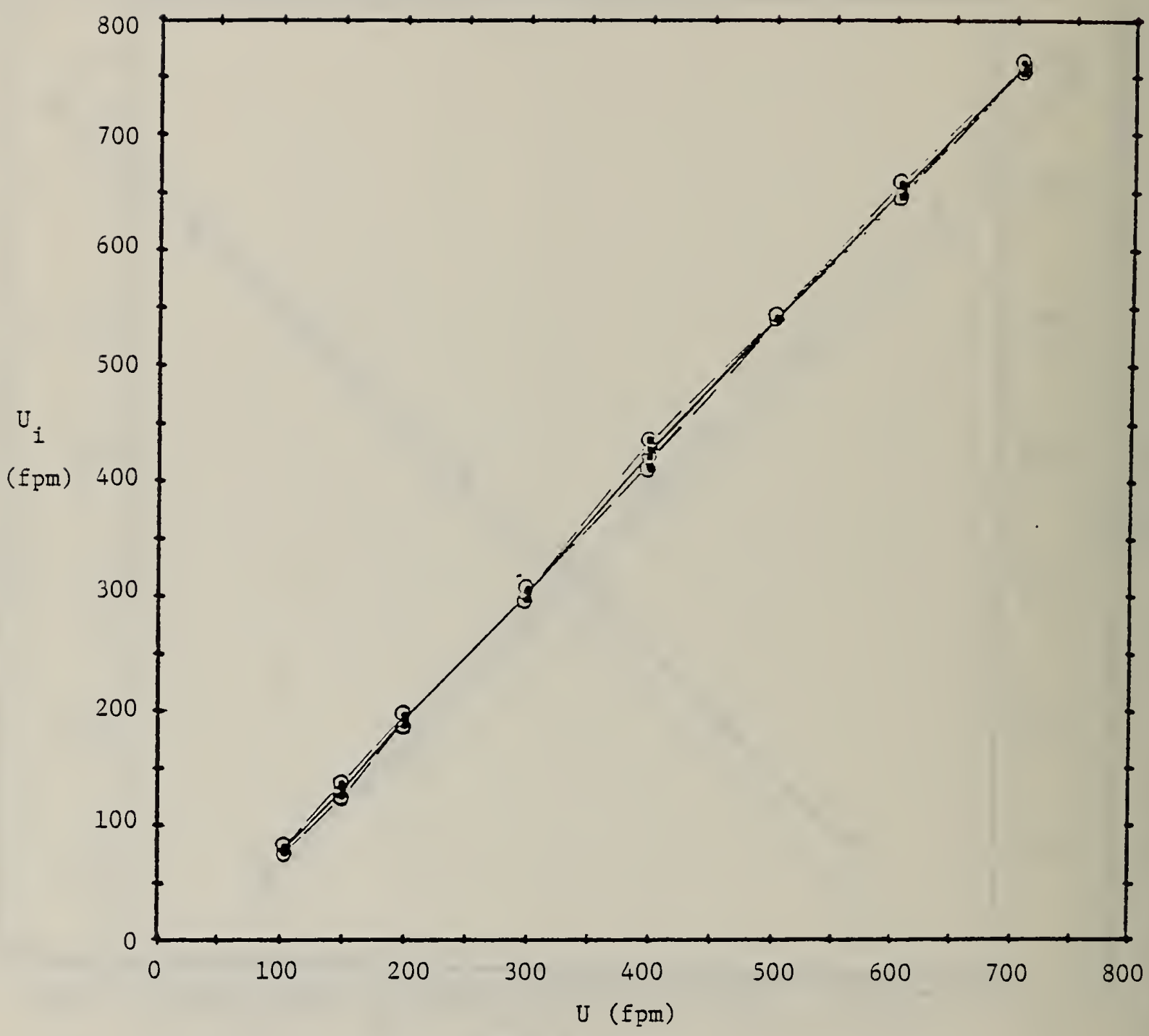

FIGURE 24. INDICATED VERSUS TRUE VELOCITY FOR PITOT PROBE, HIGH RANGE. INSTRUMENT F. 


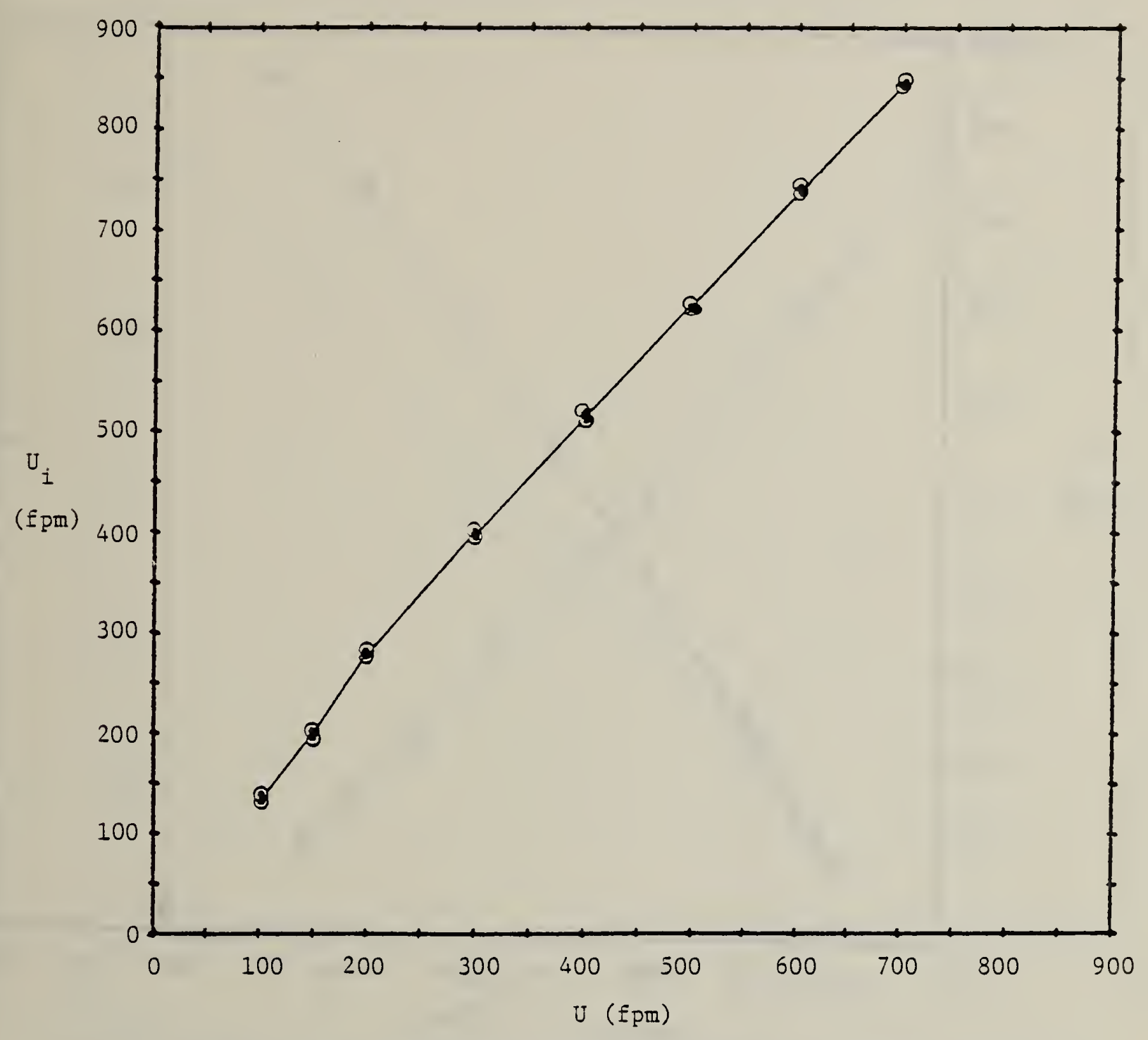

FIGURE 25. INDICATED VERSUS TRUE VELOCITY FOR DIFFUSER PROBE, LOW RANGE. INSTRUMENT F. 


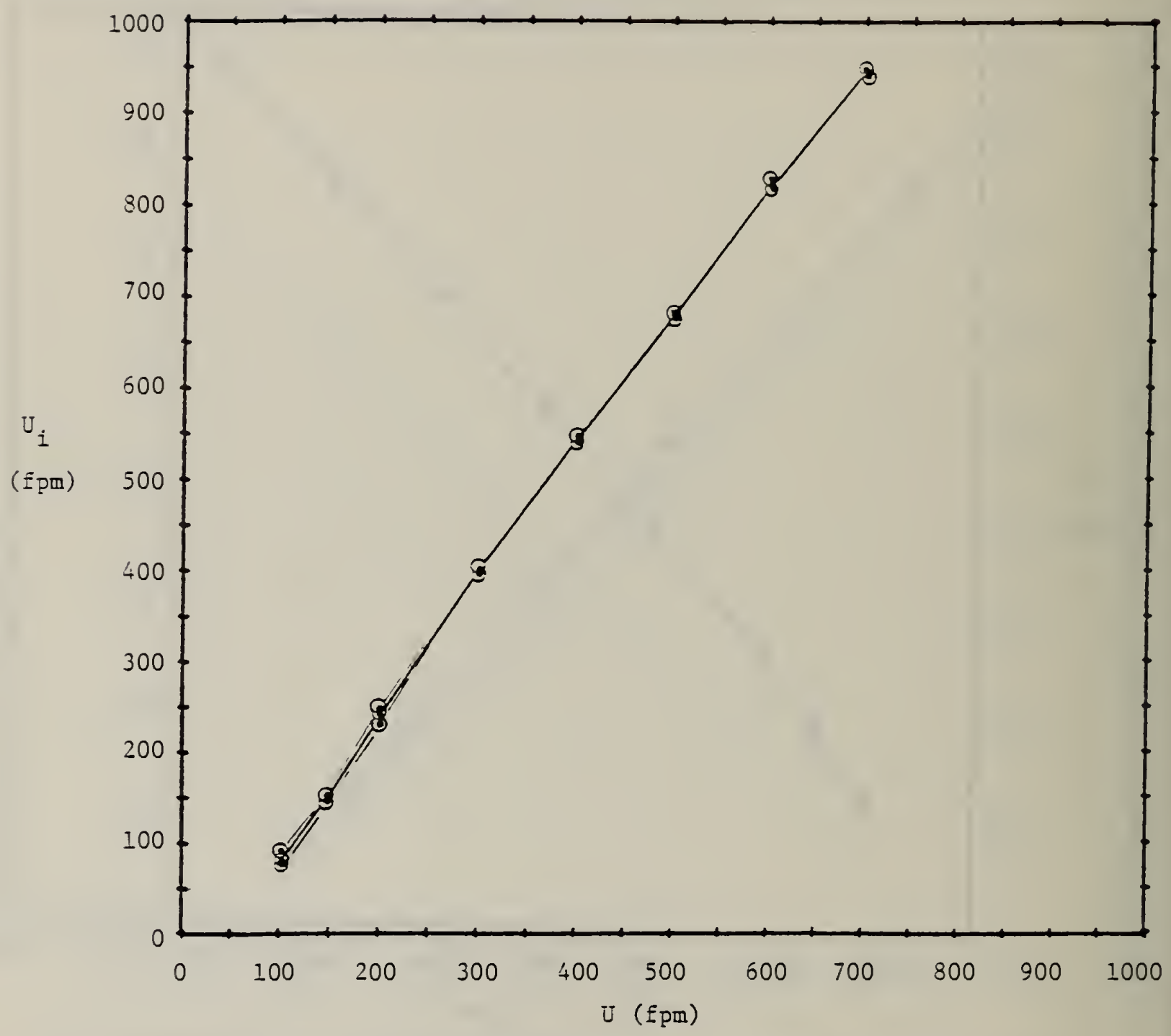

FIGURE 26. INDICATED VERSUS TRUE VELOCITY FOR DIFFUSER PROBE, HIGH RANGE. INSTRUMENT F. 


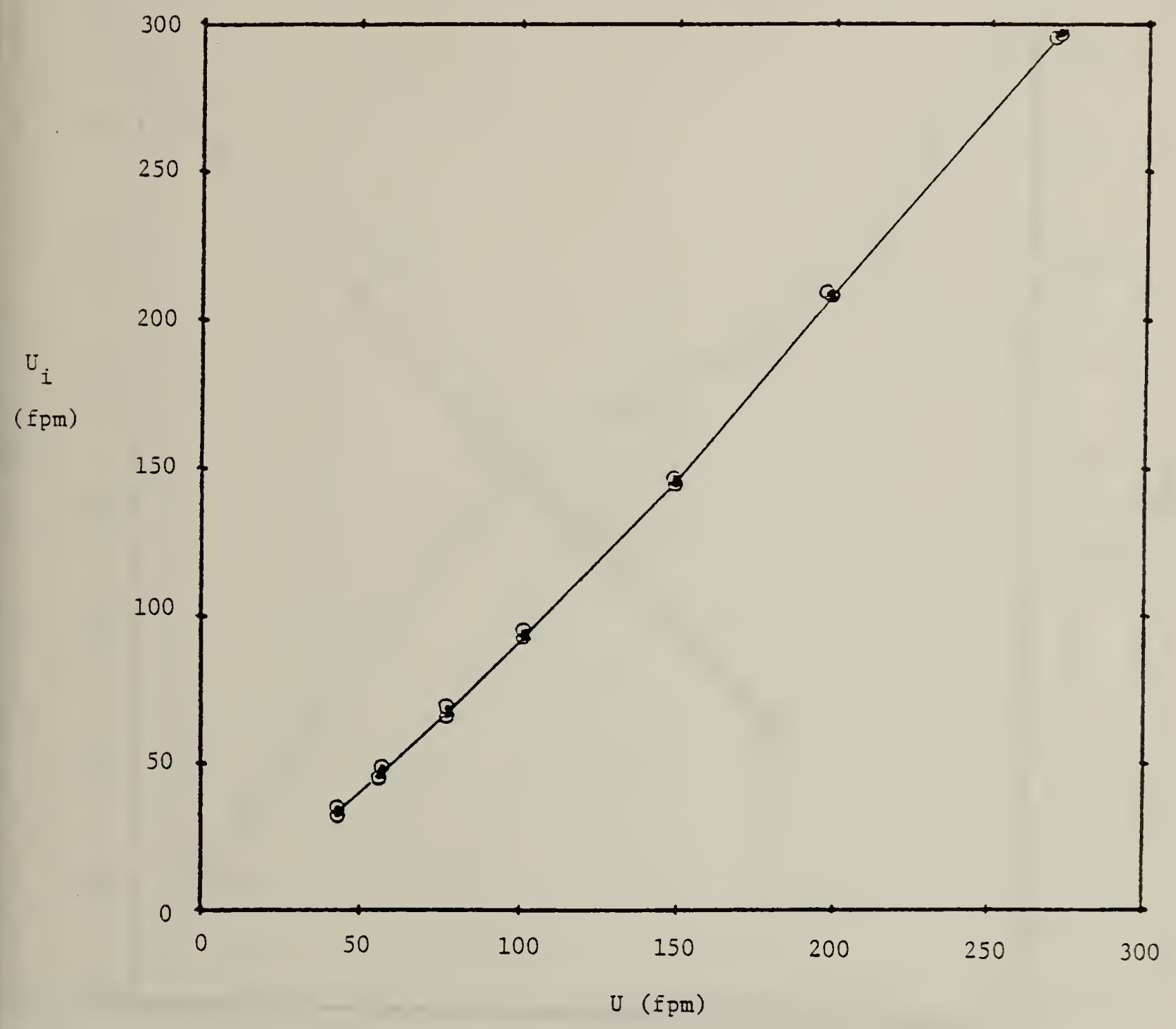

FIGURE 27. INDICATED VERSUS TRUE VELOCITY FOR LOW VELOCITY PROBE. INSTRUMENT F. 


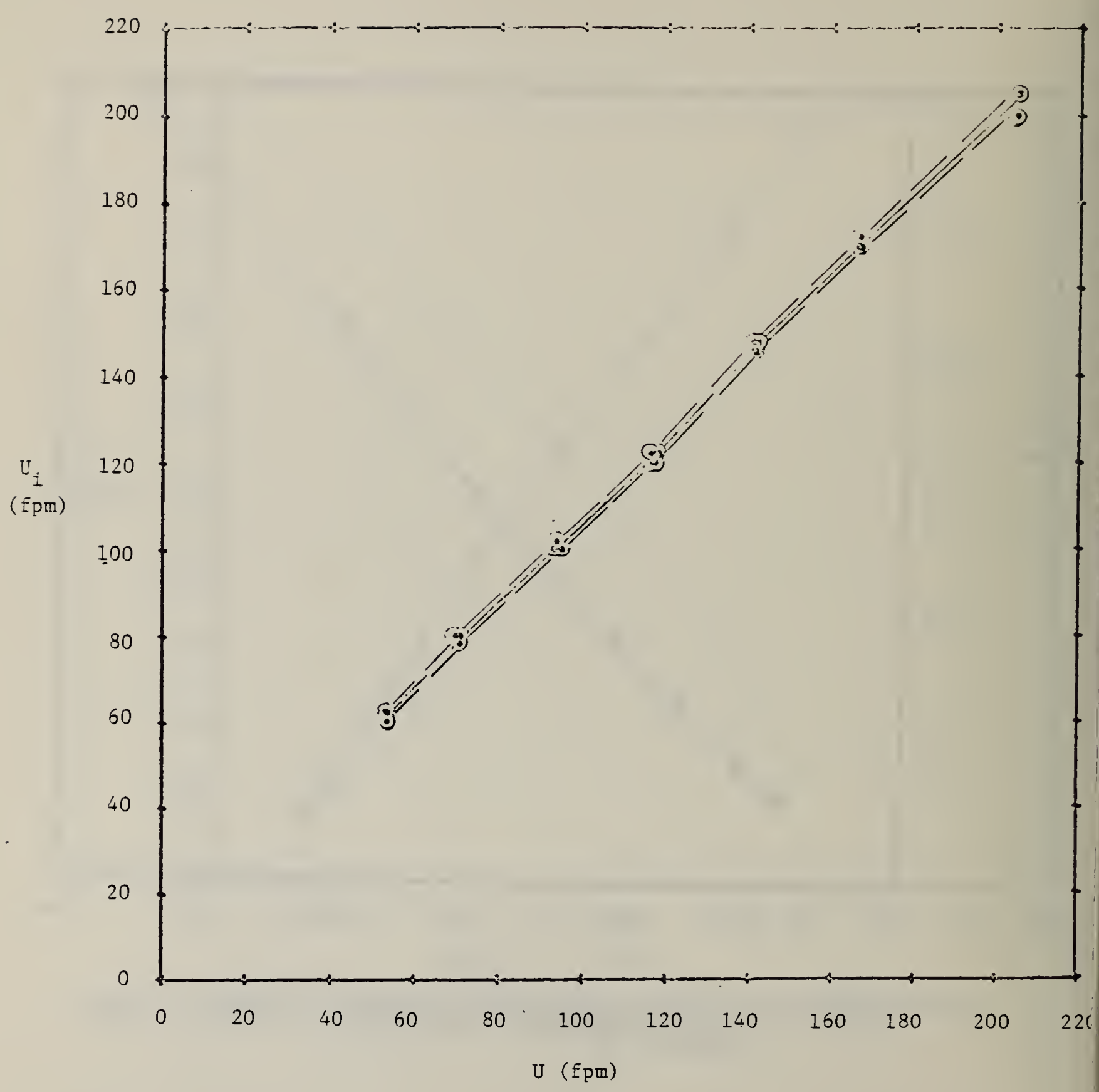

FIGURE 28. INDICATED VERSUS TRUE VELOCITY WITH $\pm 2 \sigma$ CURVES, LOW RANGE. INSTRUMENT G. 


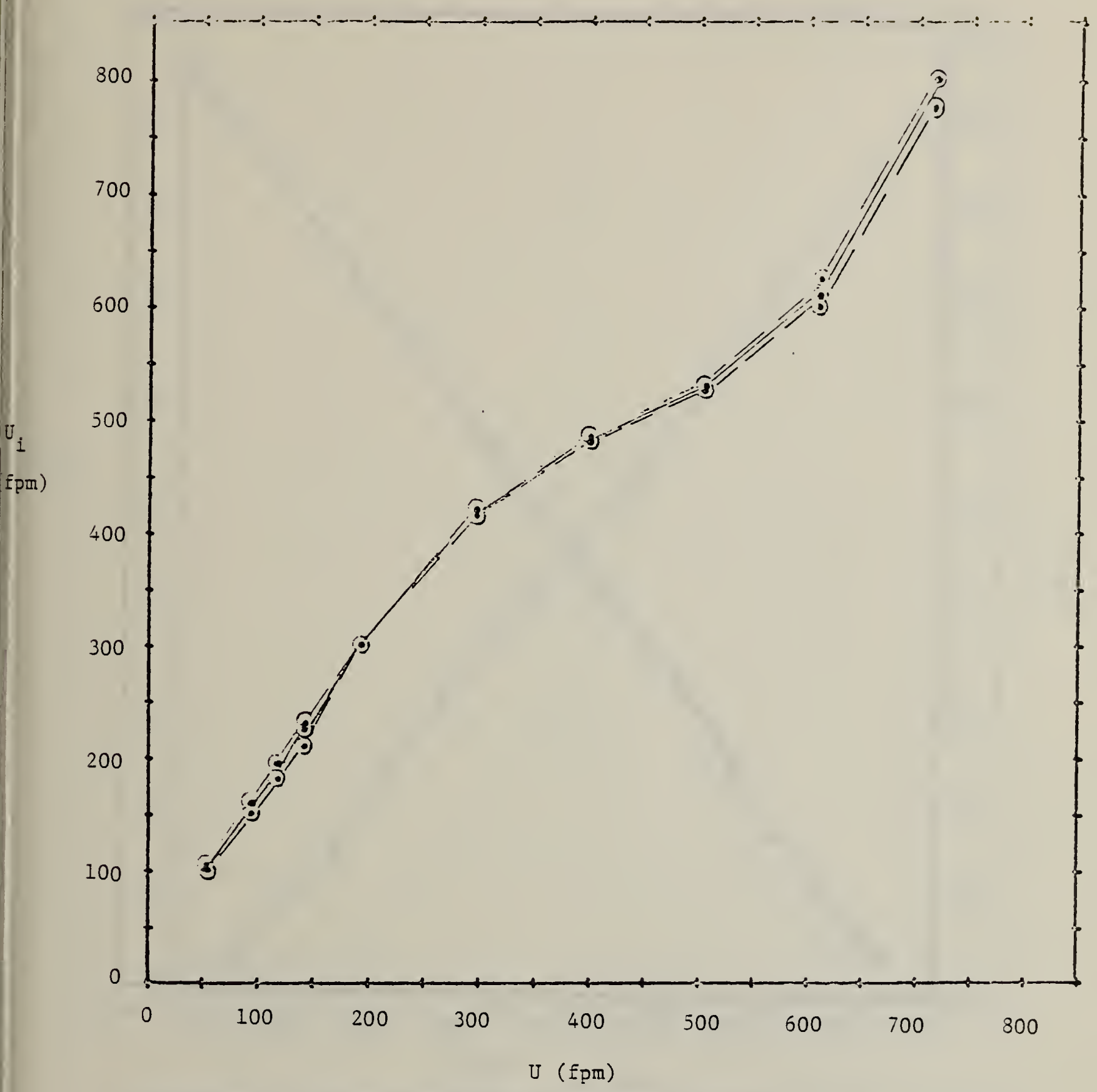

FIGURE 29. INDICATED VERSUS TRUE VELOCITY WITH $\pm 2 \sigma$ CURVES, HIGH RANGE. INSTRUMENT $G$. 


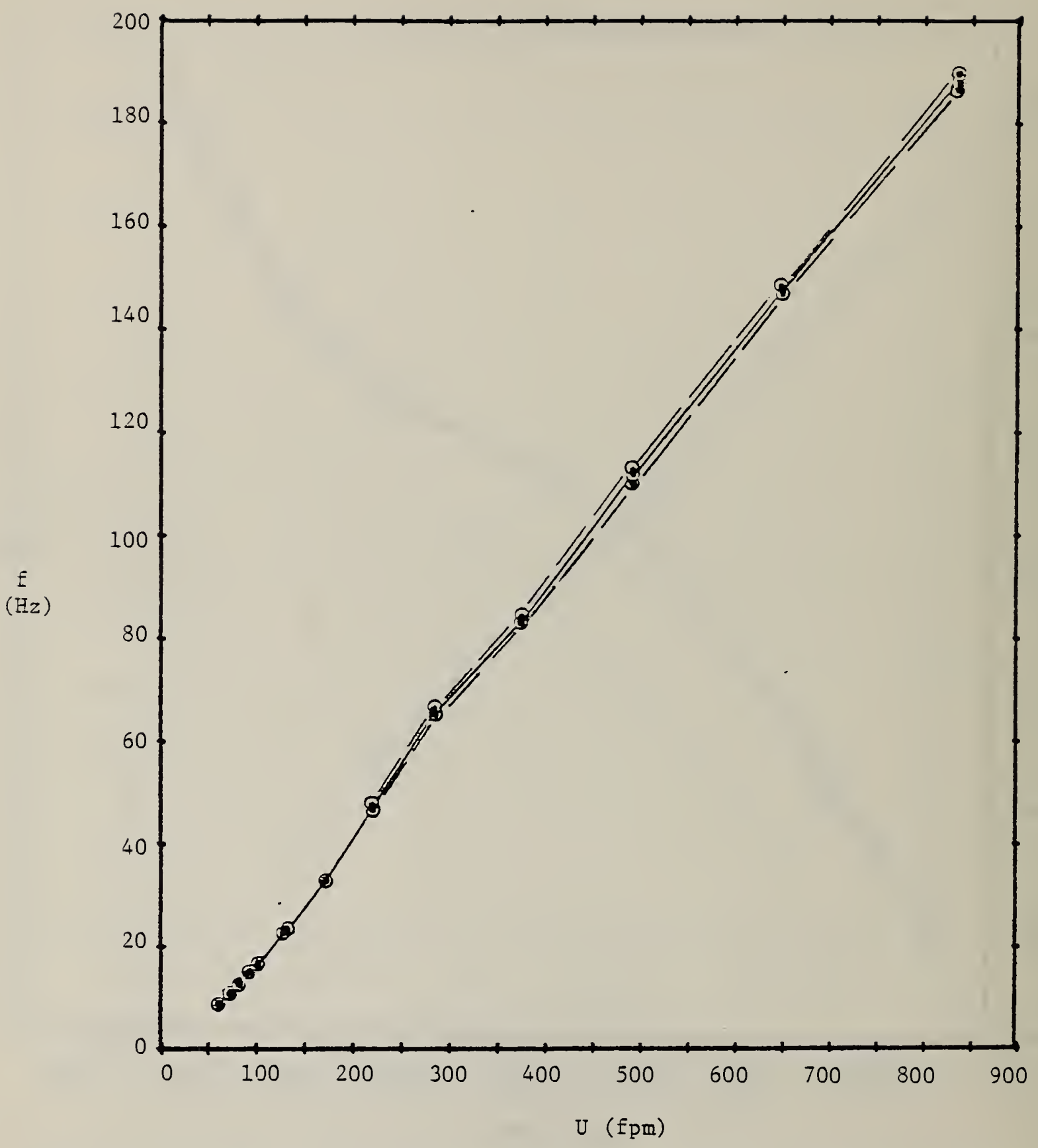

FIGURE 30. PULSE FREQUENCY VERSUS TRUE VELOCITY WITH $\pm 2 \sigma_{f}$ CURVES.
INSTRUMENT 


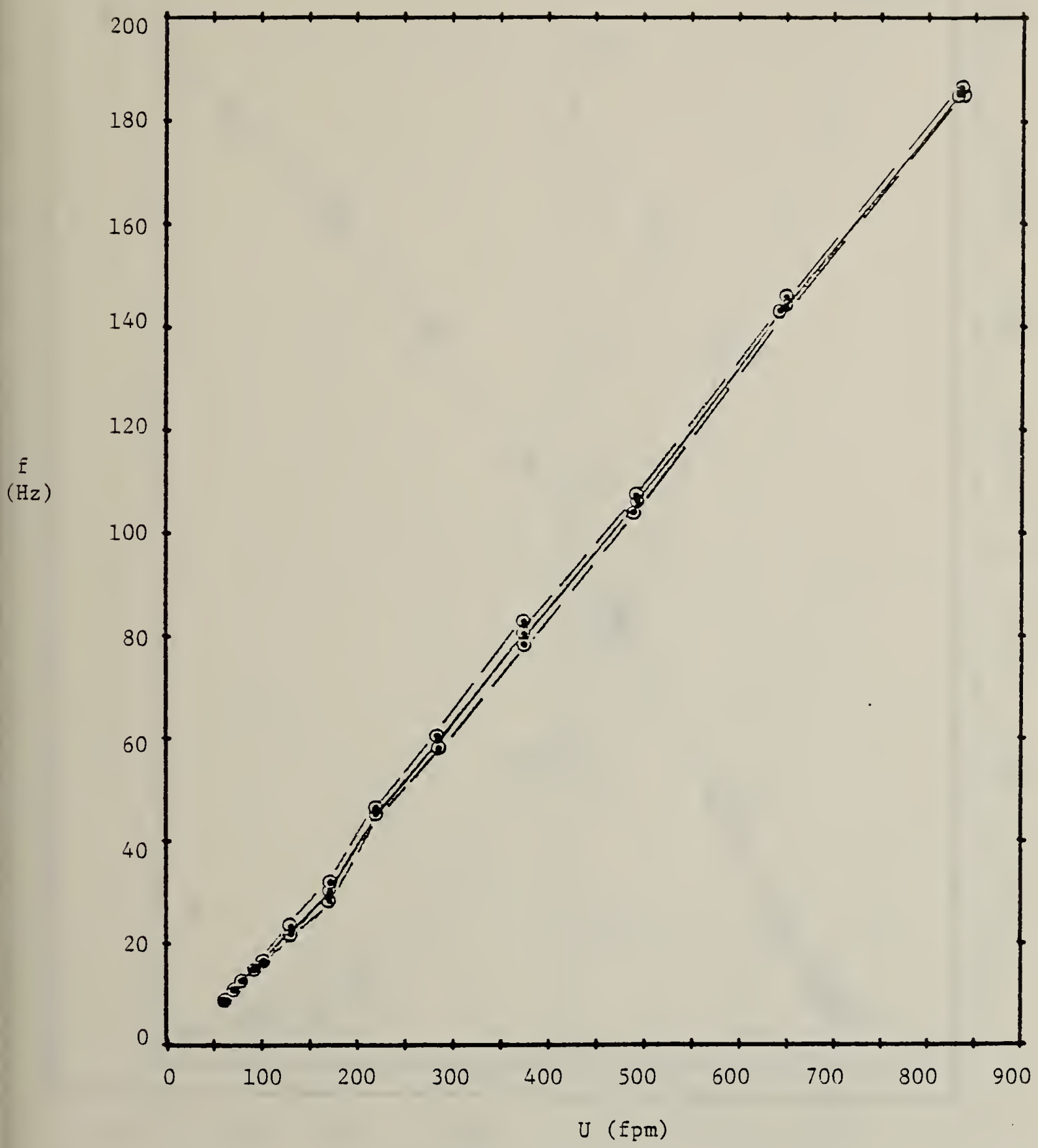

FIGURE 31. PULSE FREQUENCY VERSUS TRUE VELOCITY WITH $\pm 2 \sigma_{£}$ CURVES. INSTRUMENT I. 


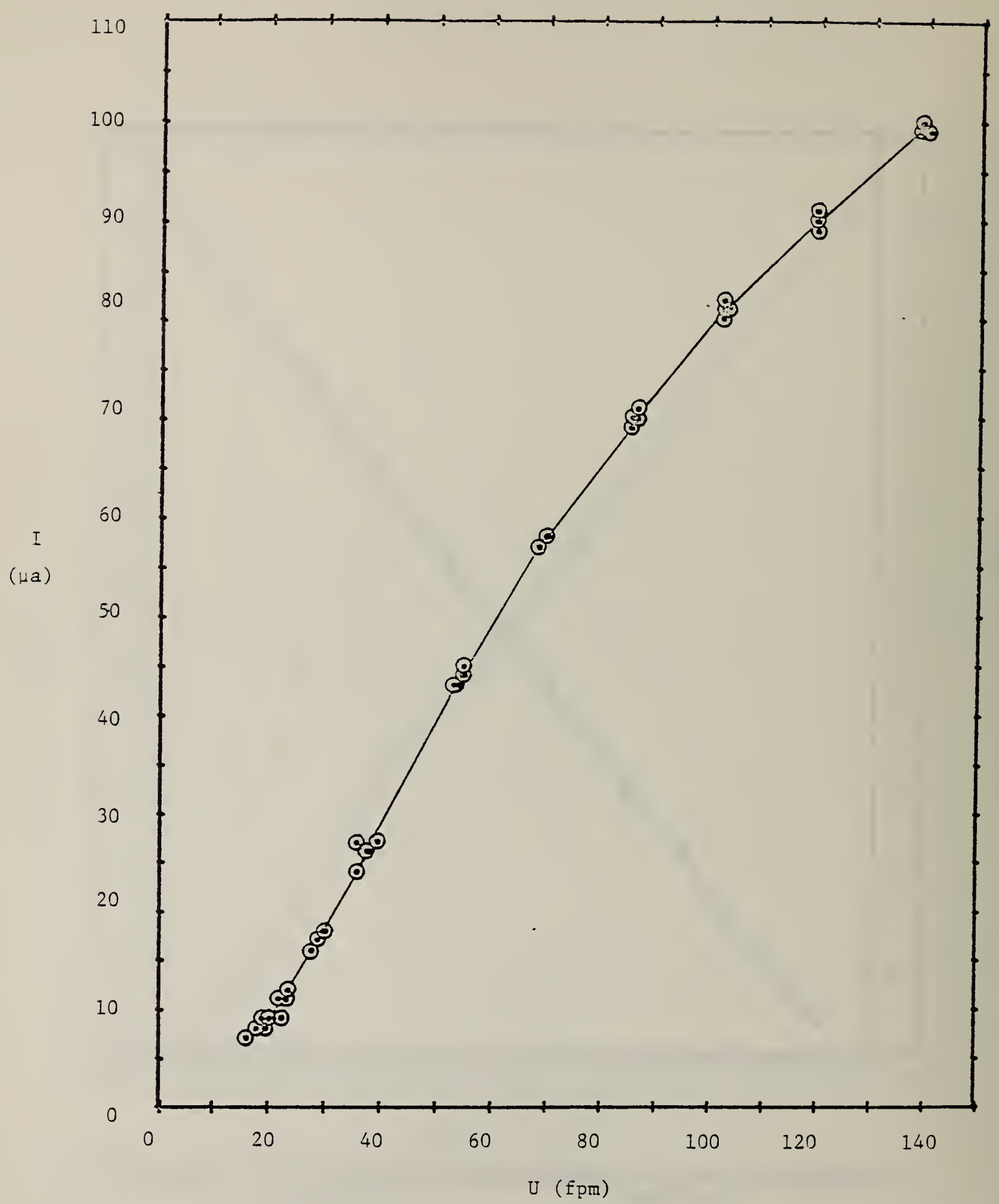

FIGURE 32. OUTPUT OF INSTRUMENT J AGAINST VELOCTTY. 


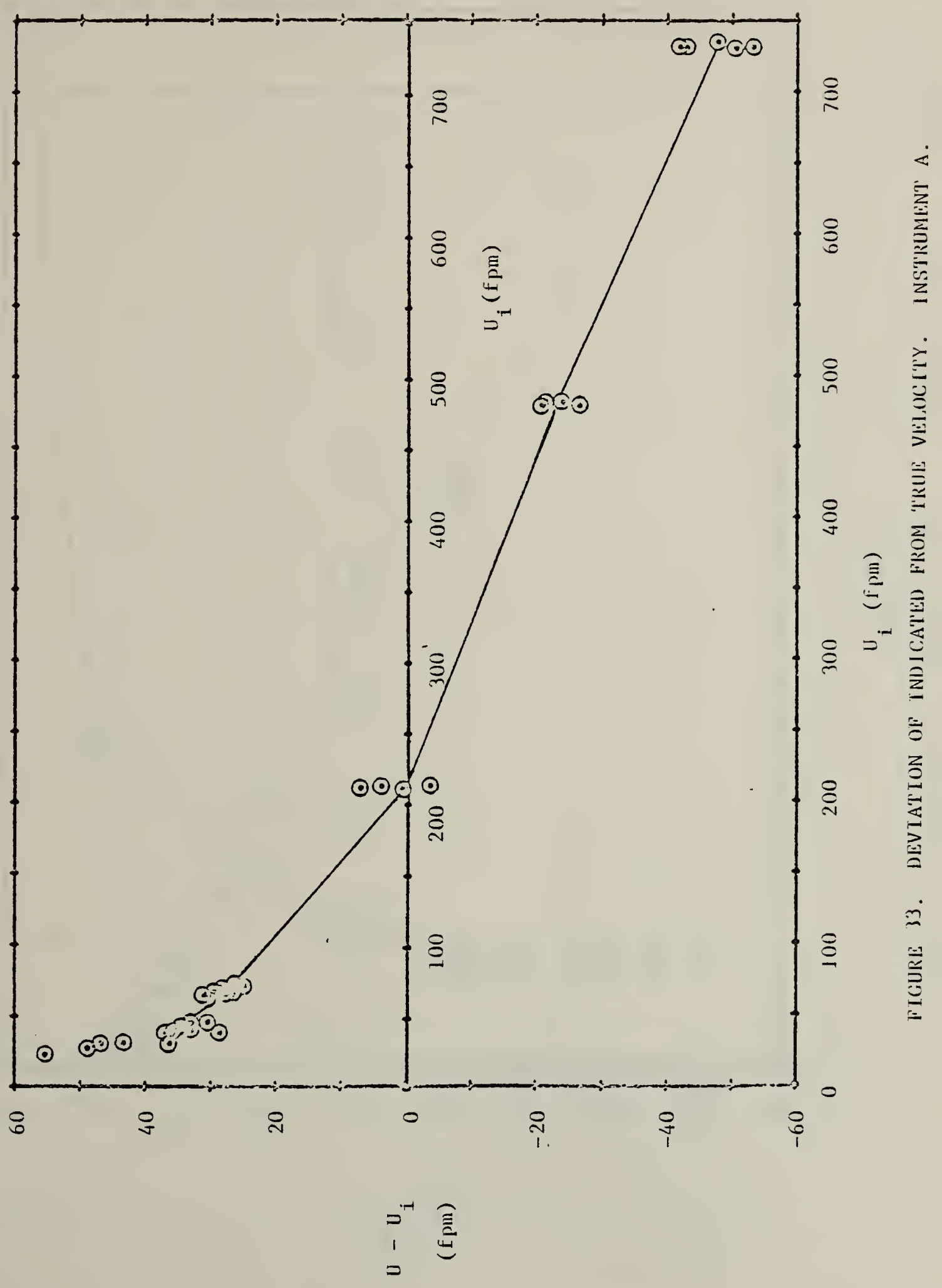




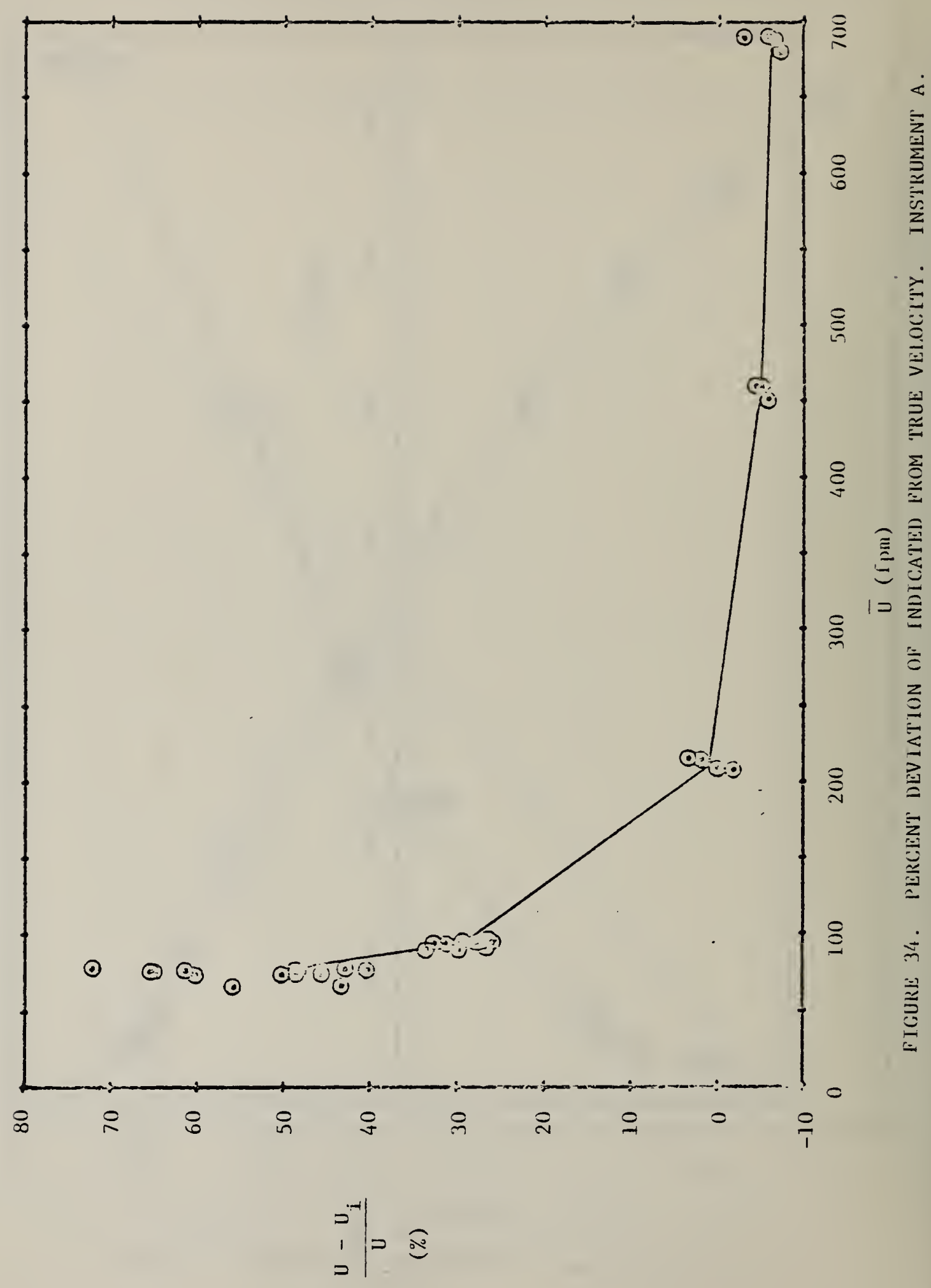




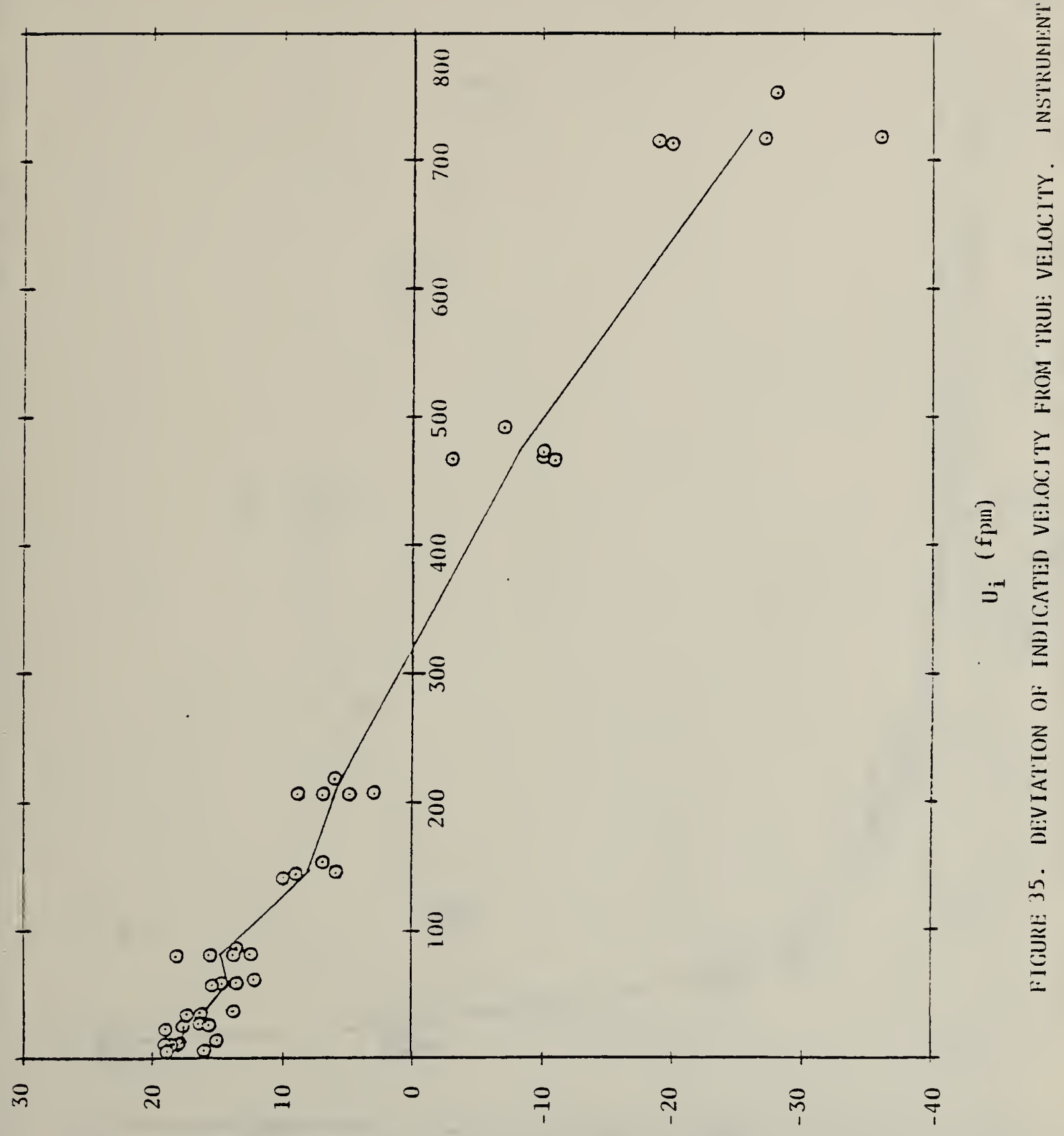

$$
\begin{aligned}
& \sum^{-1} \\
& \vdots \\
& =
\end{aligned}
$$




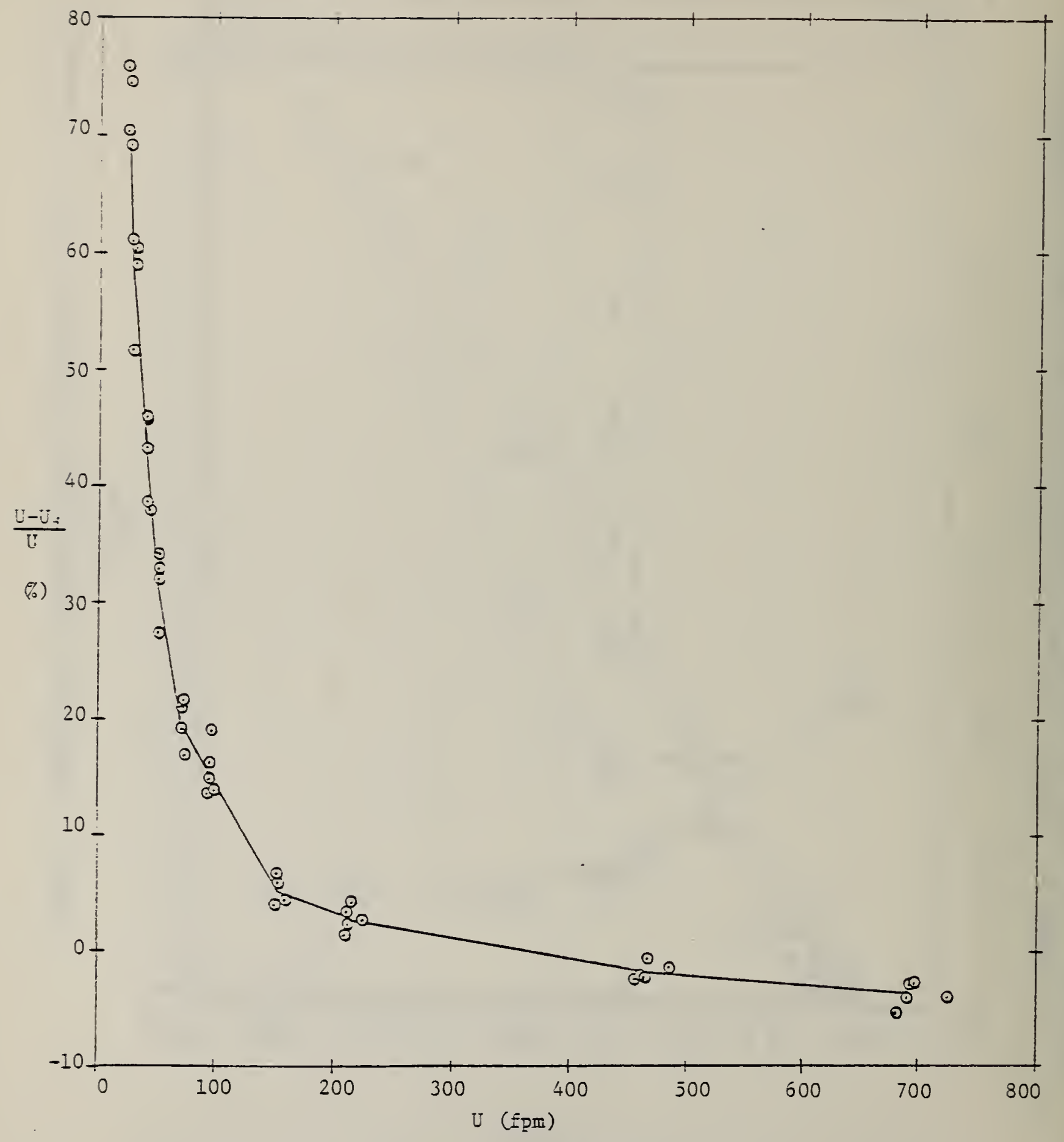

EIGURE 36. PERCENT DEVIATICN GF INDICATED VELOCITY FROM TRUE VELOCITY. INSTRUMENT 3. 


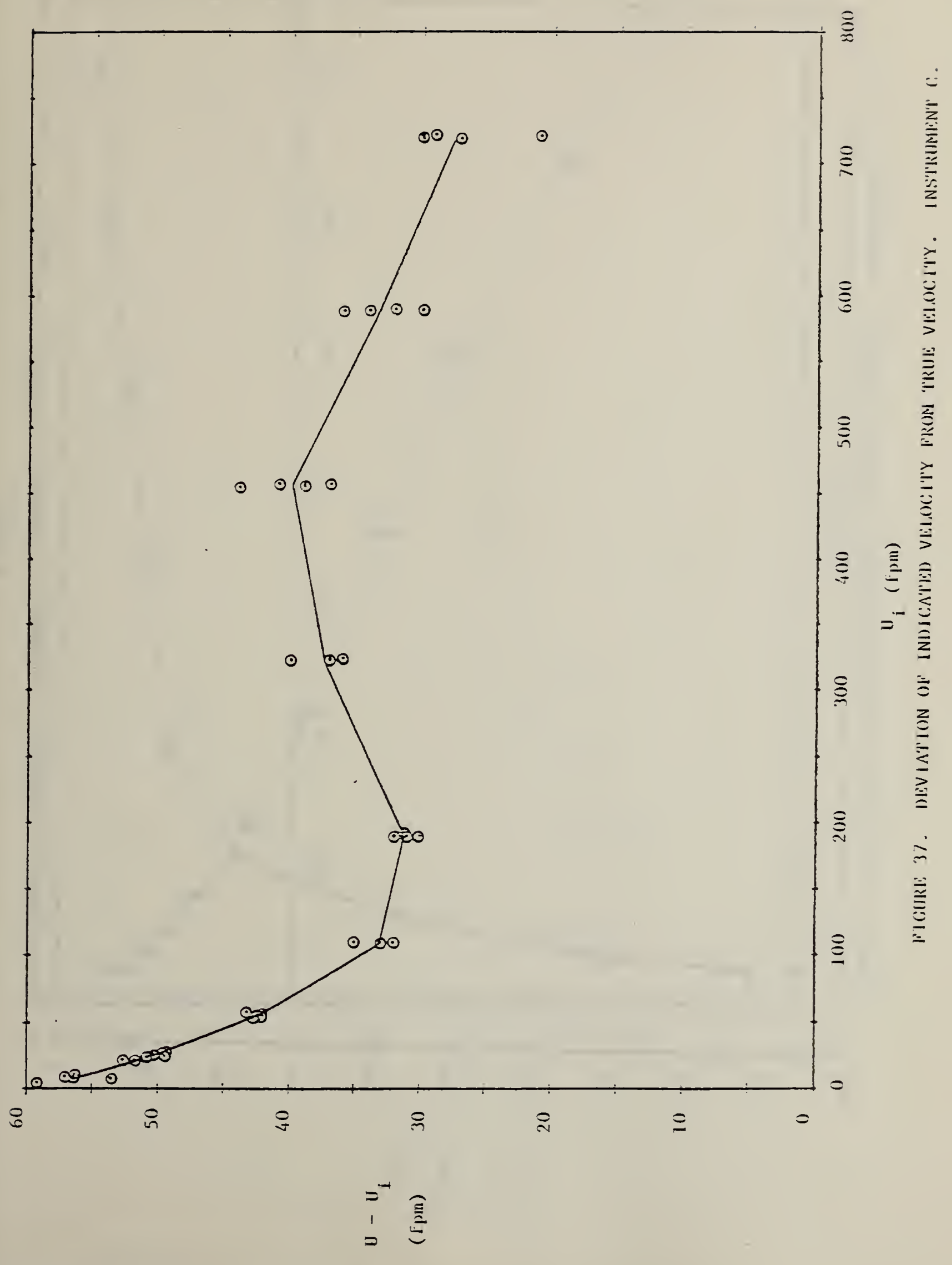




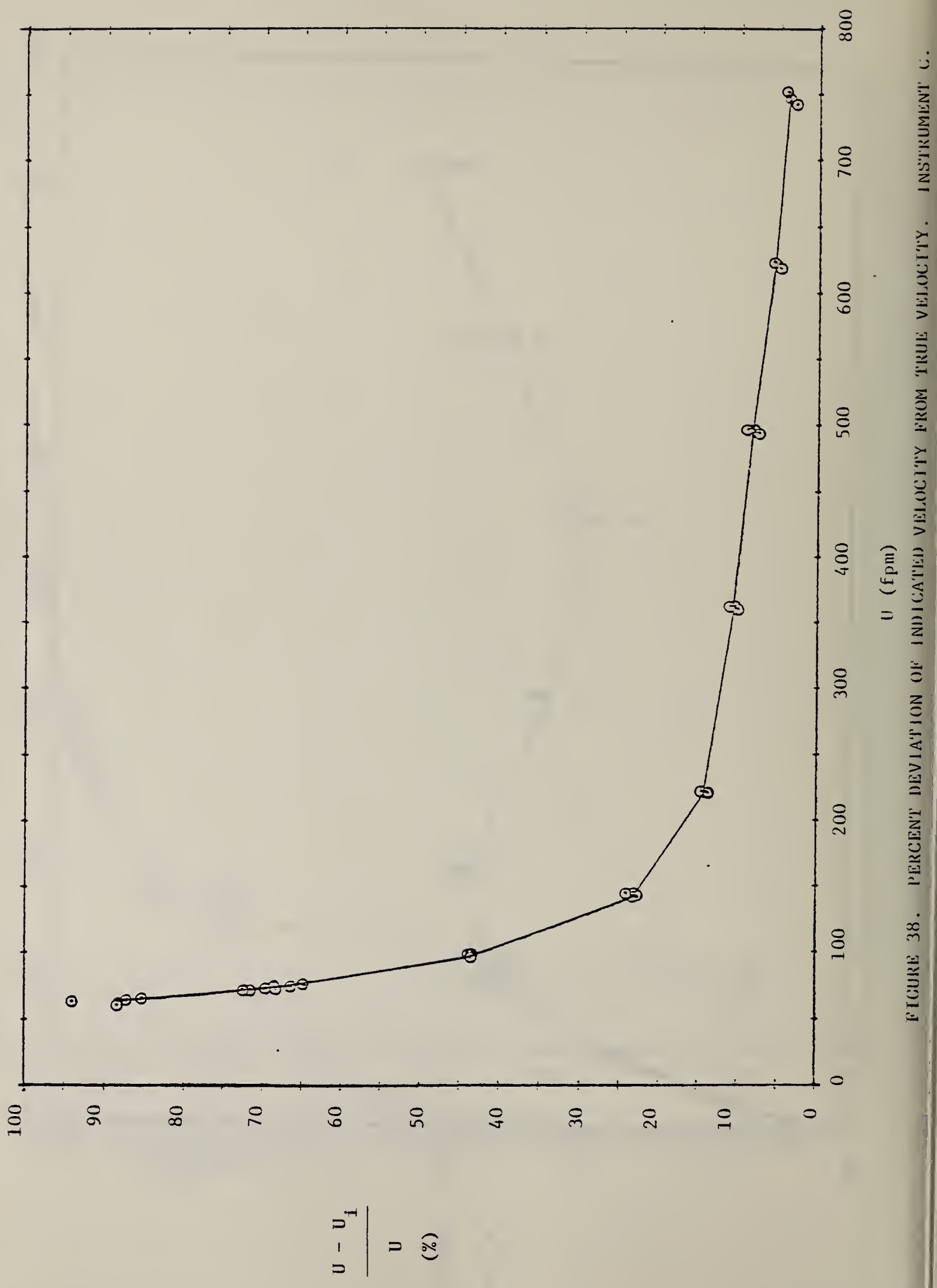




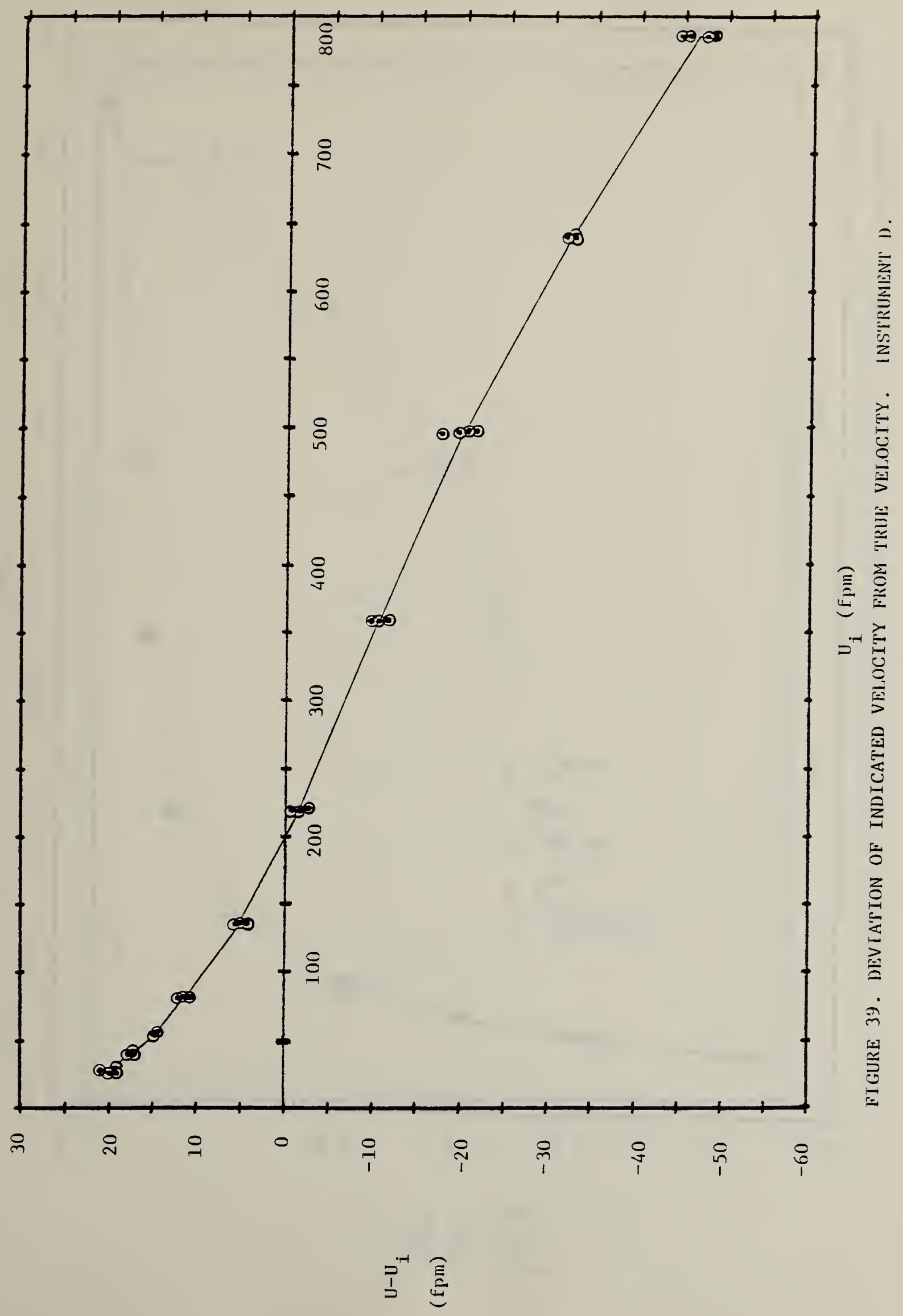




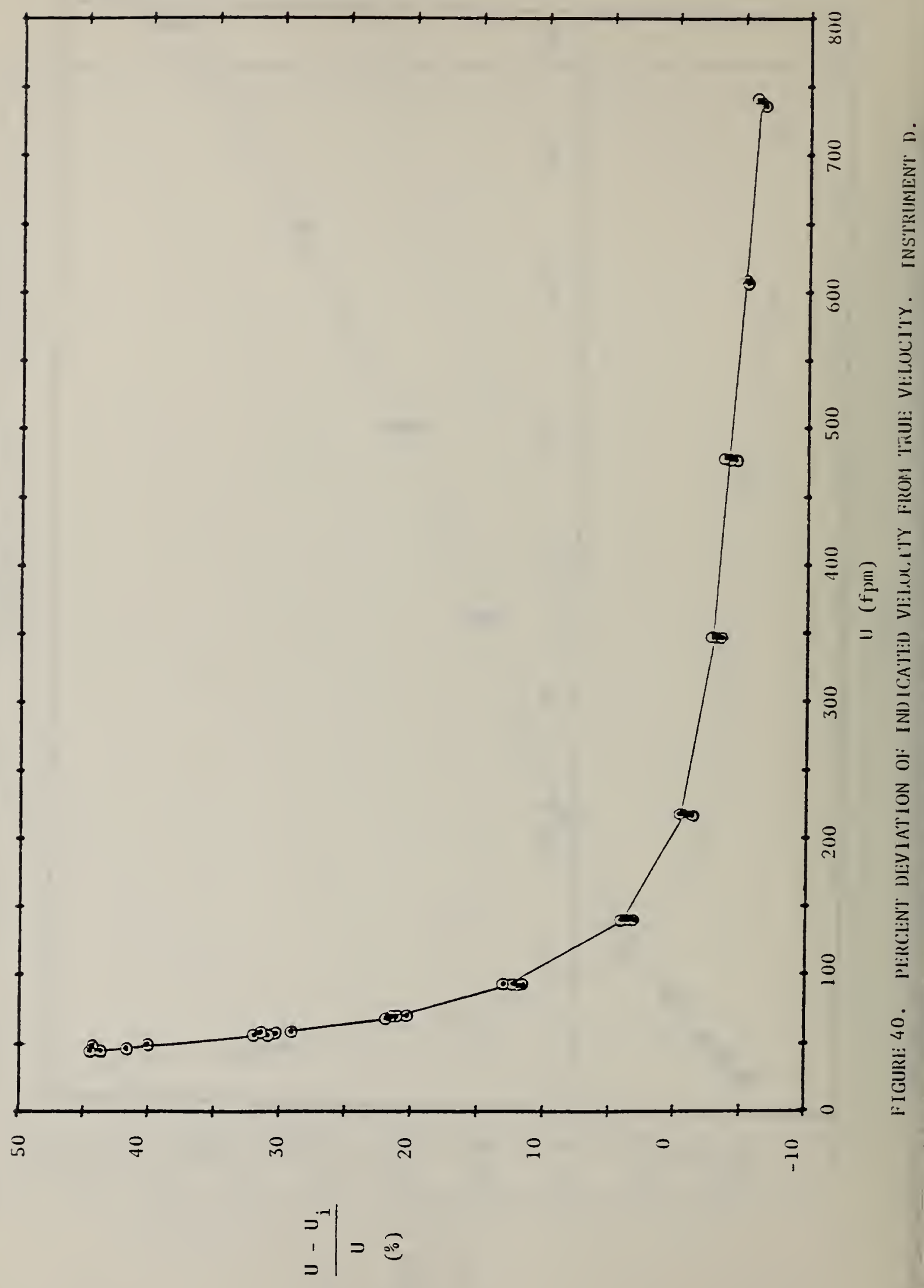




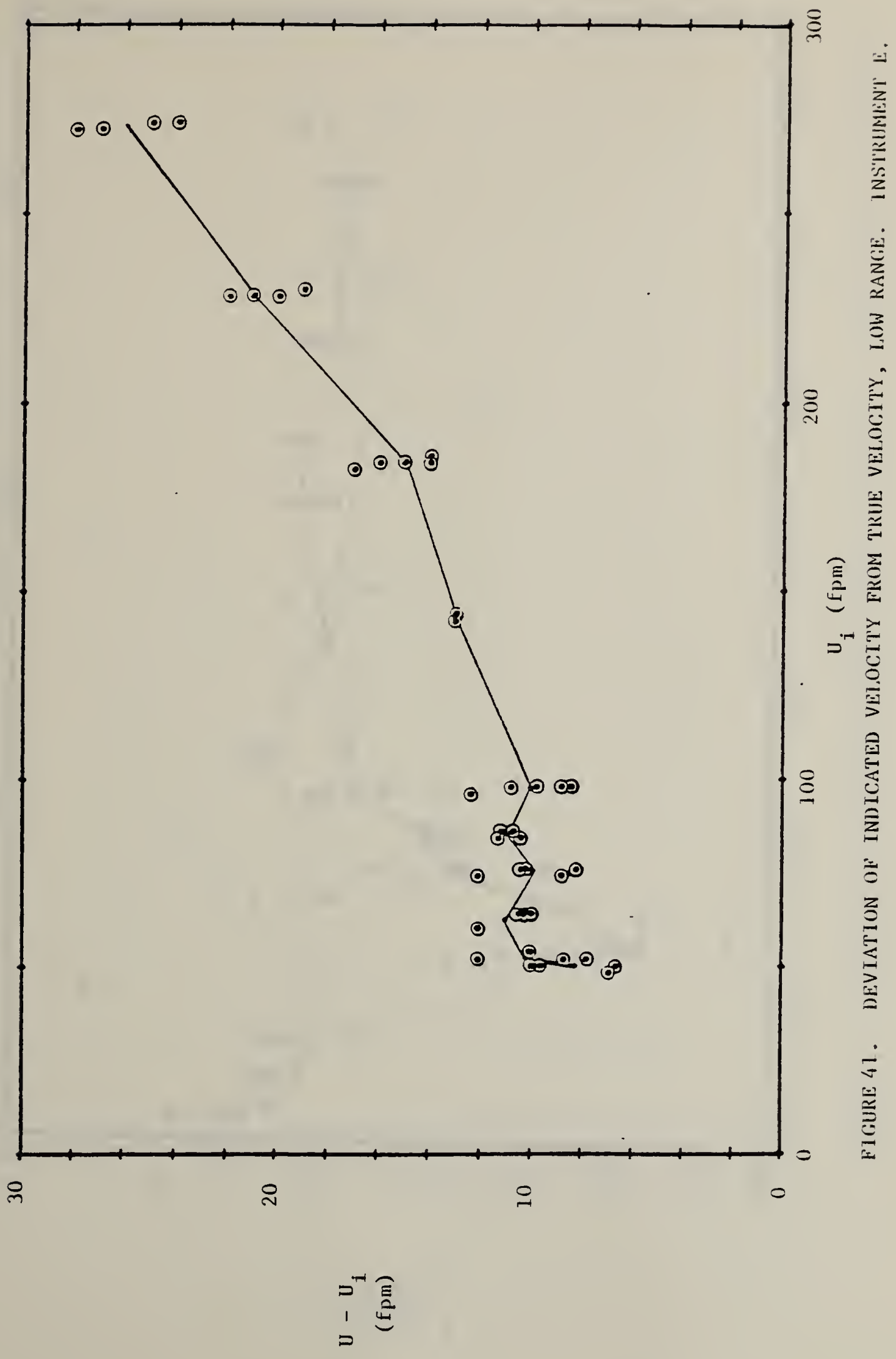




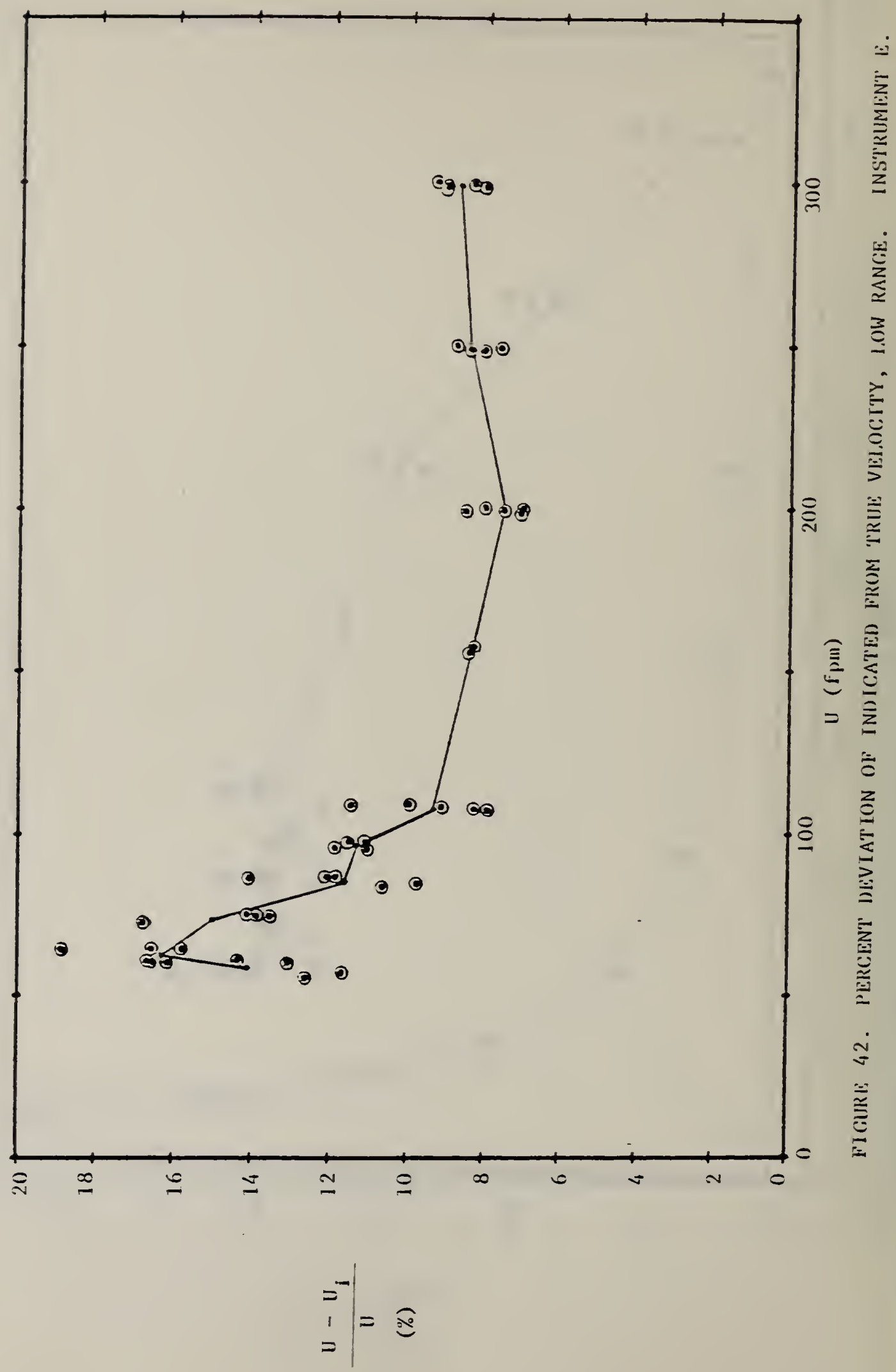




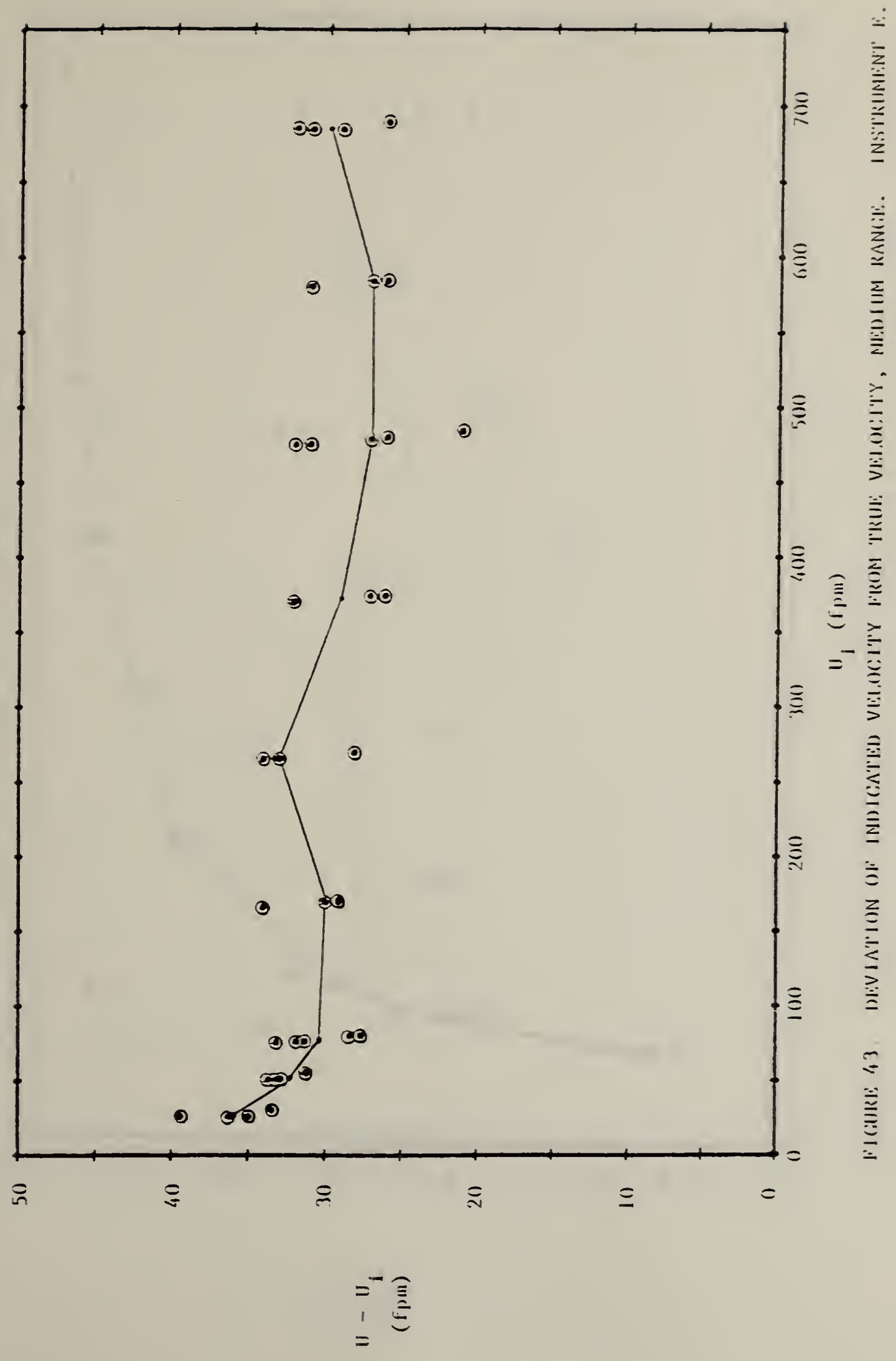




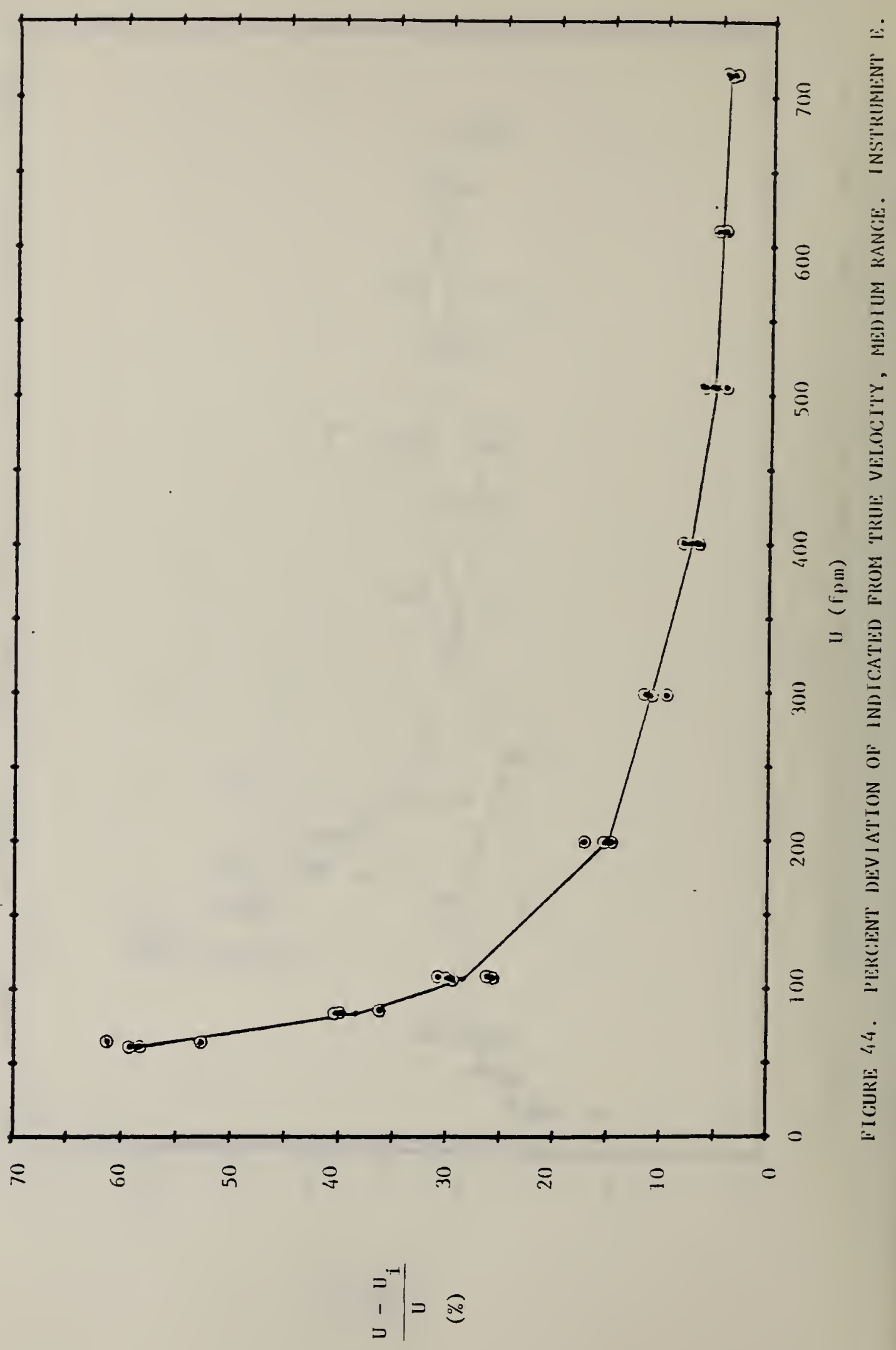




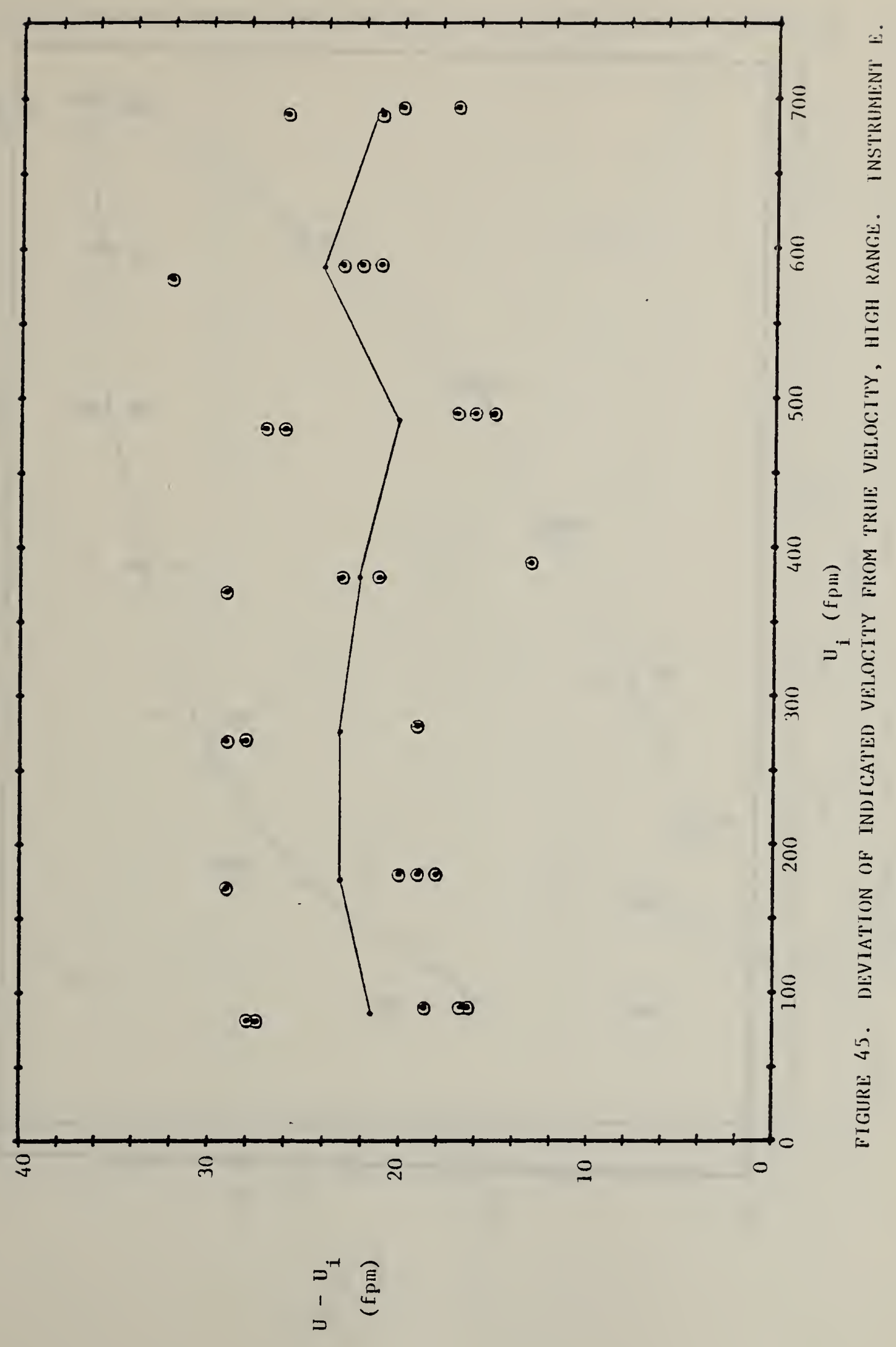




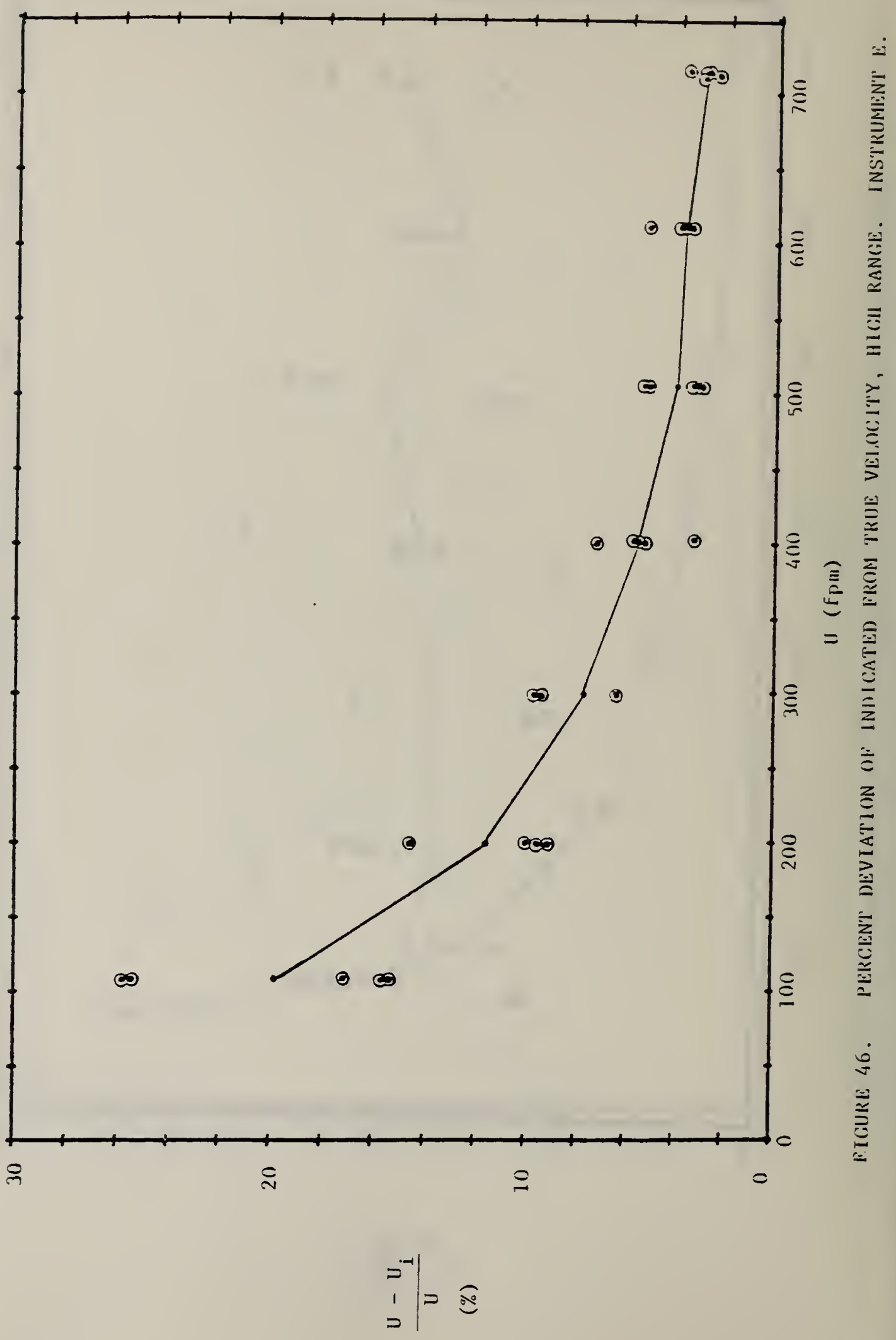




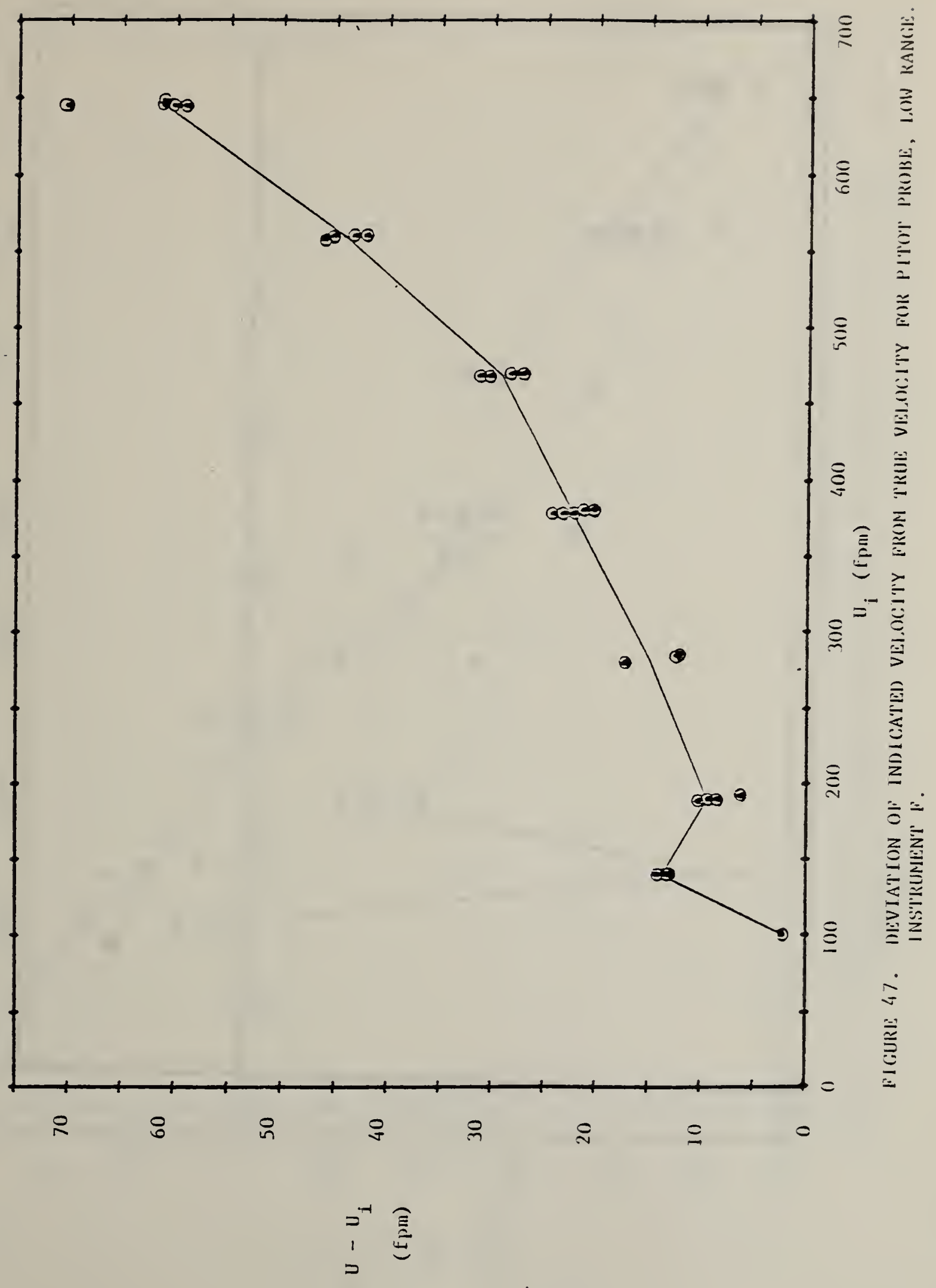




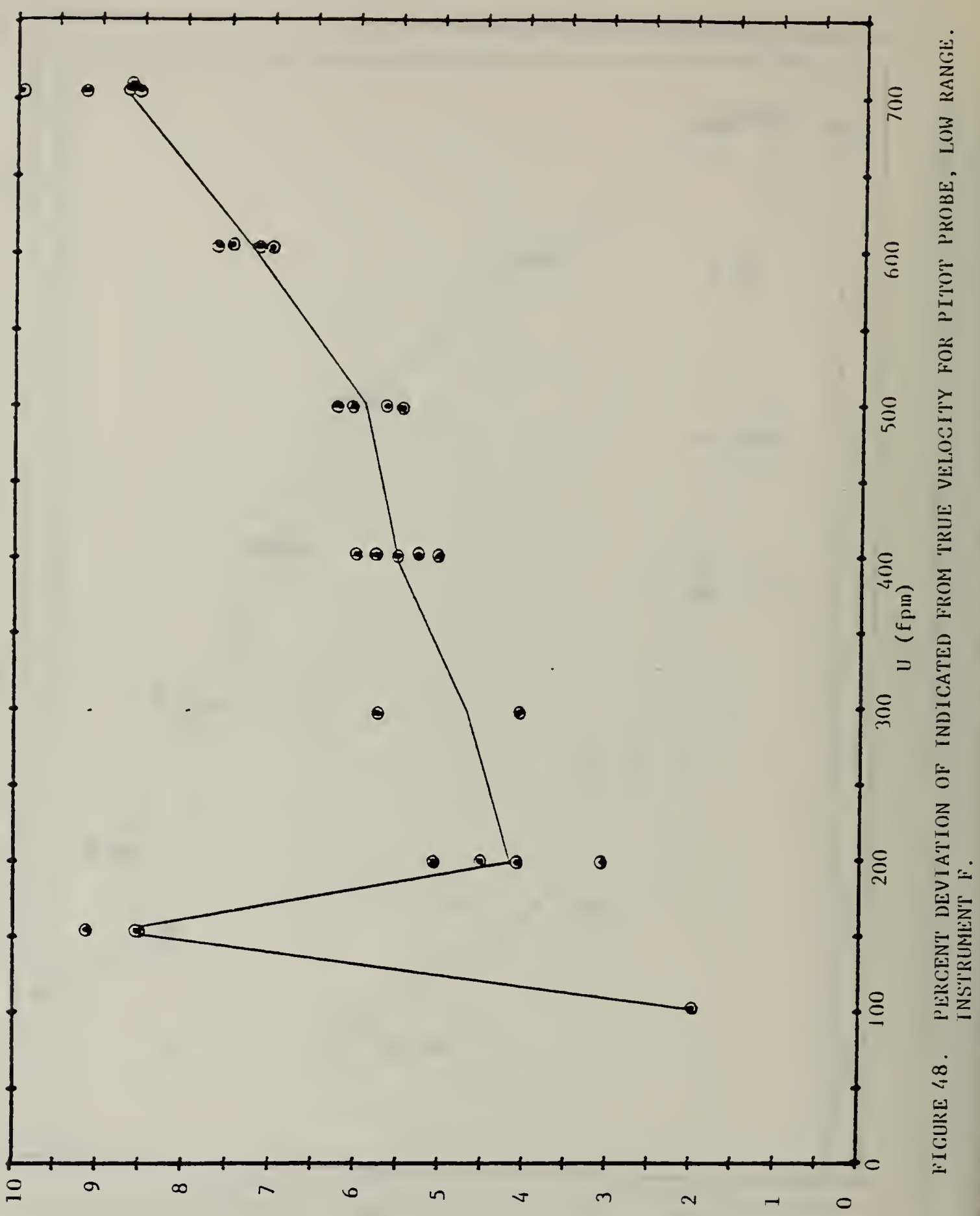

$$
\begin{gathered}
a^{-1} \\
1
\end{gathered} \mid=\widehat{x}
$$




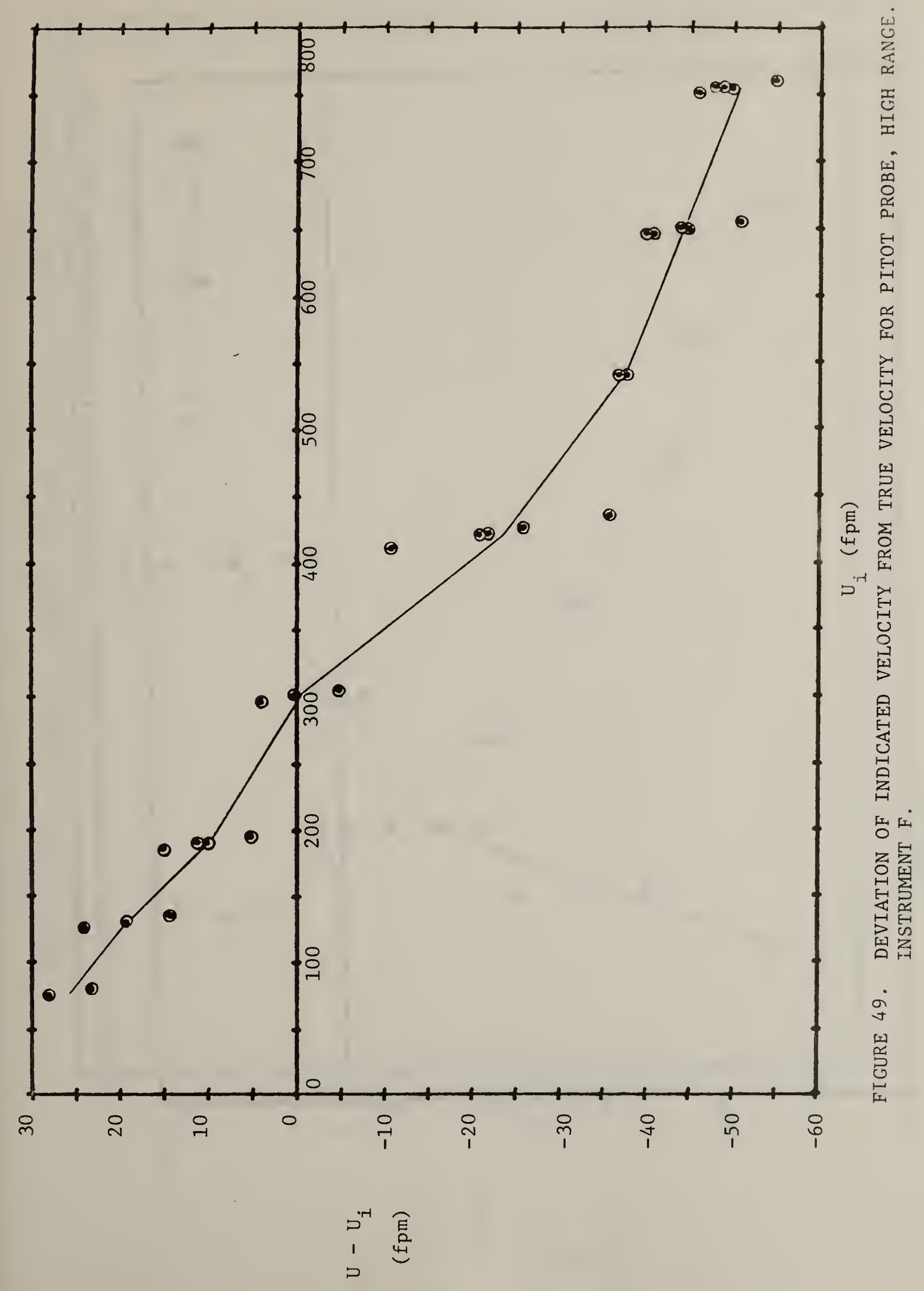




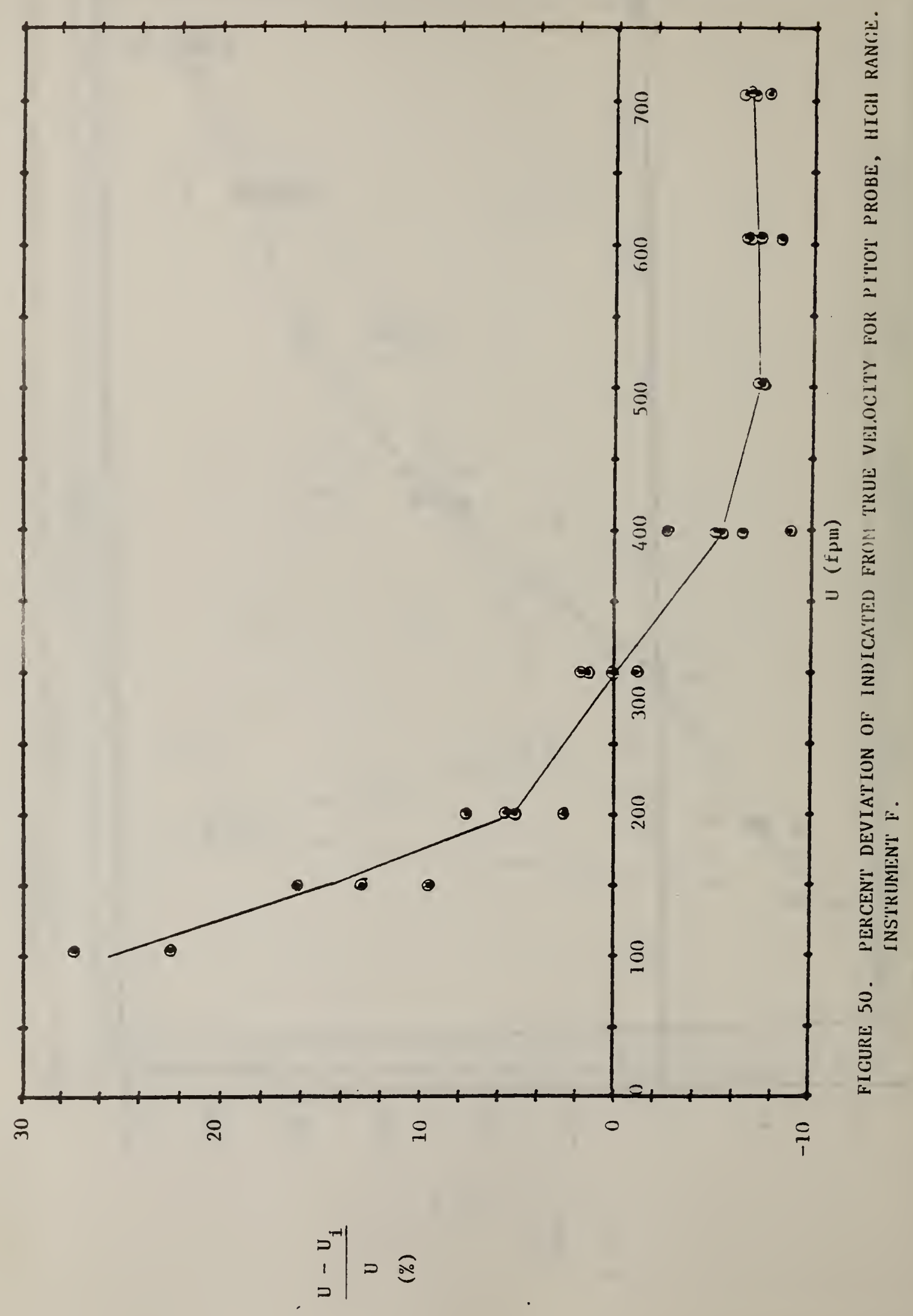




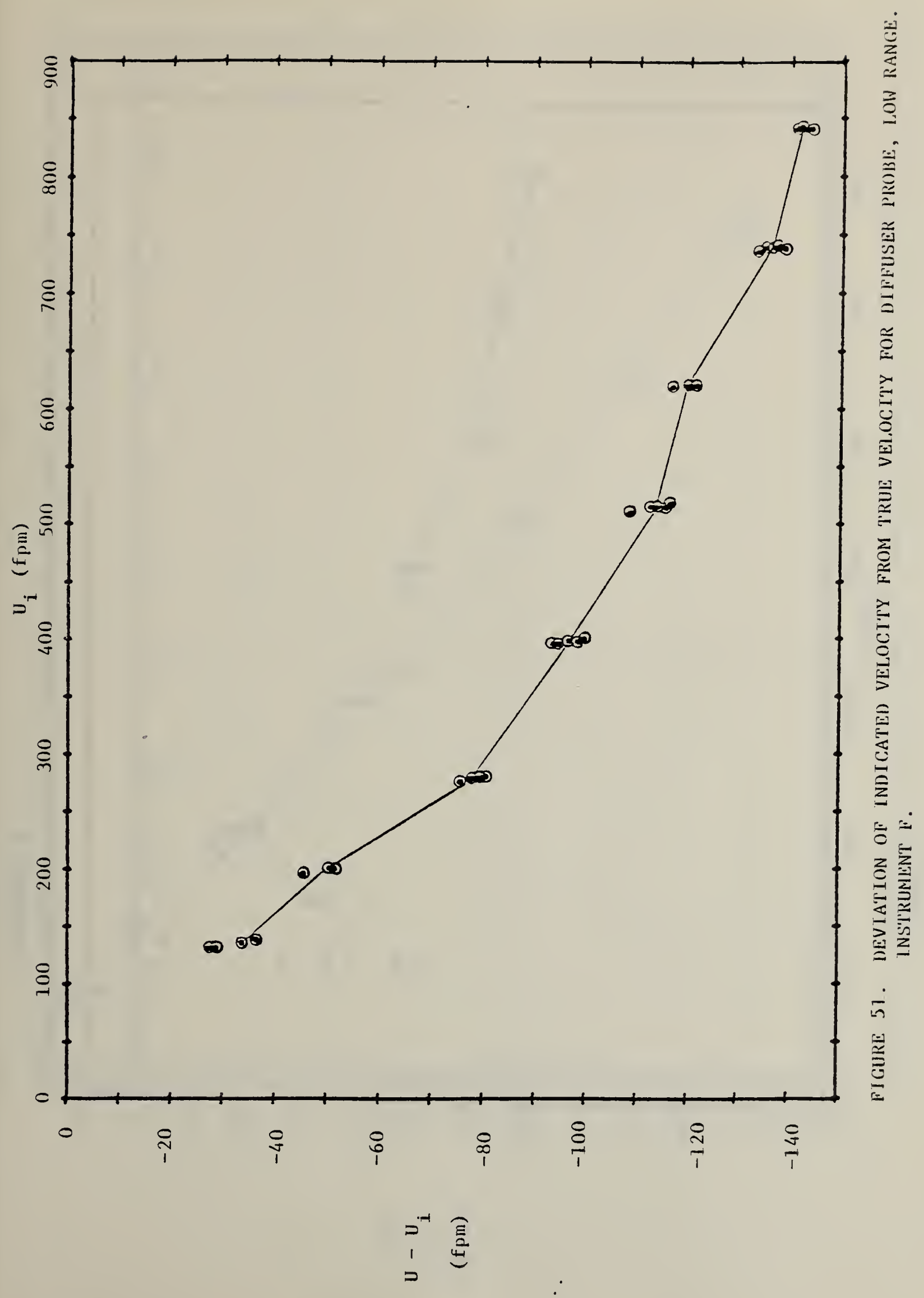




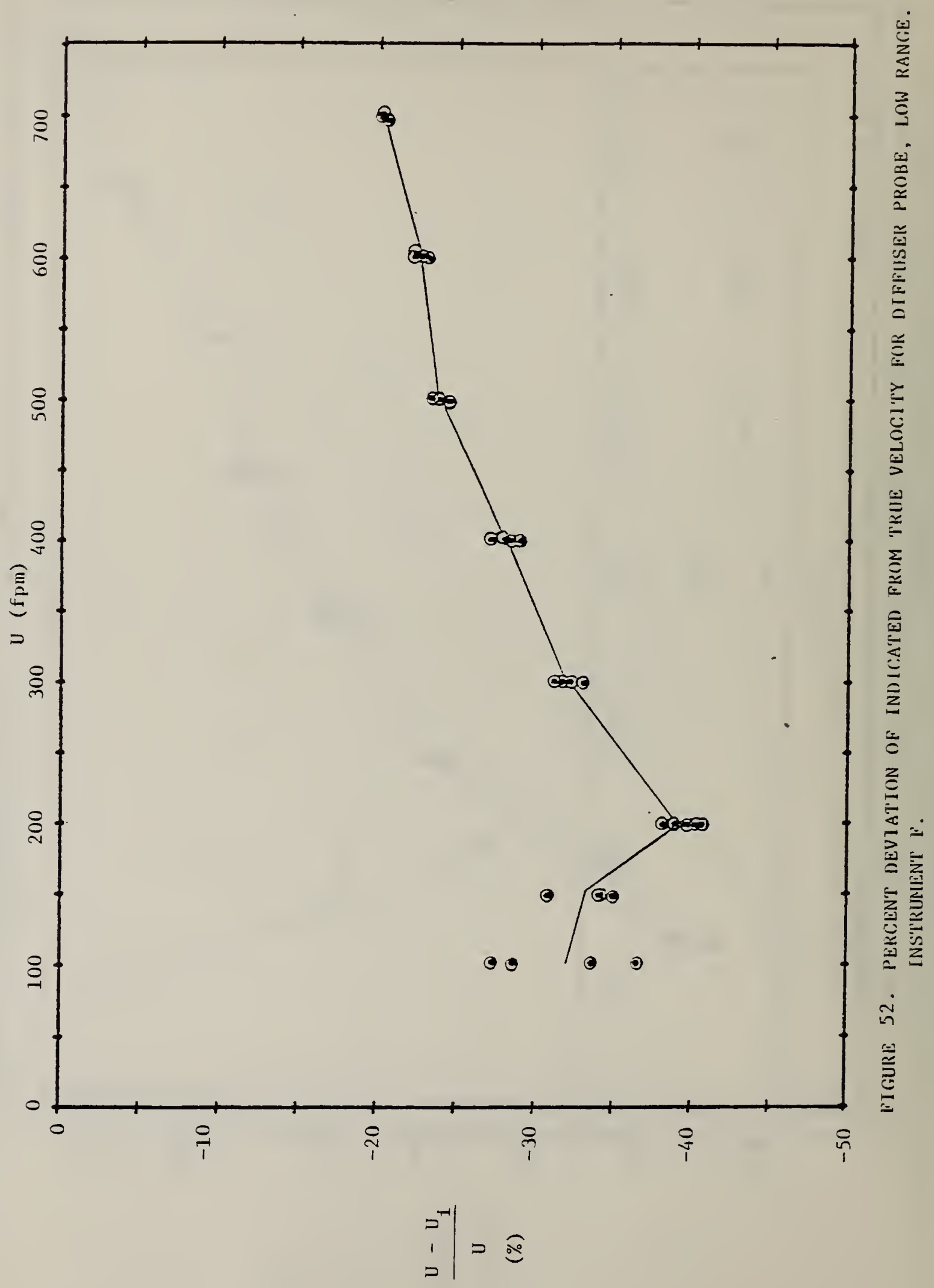




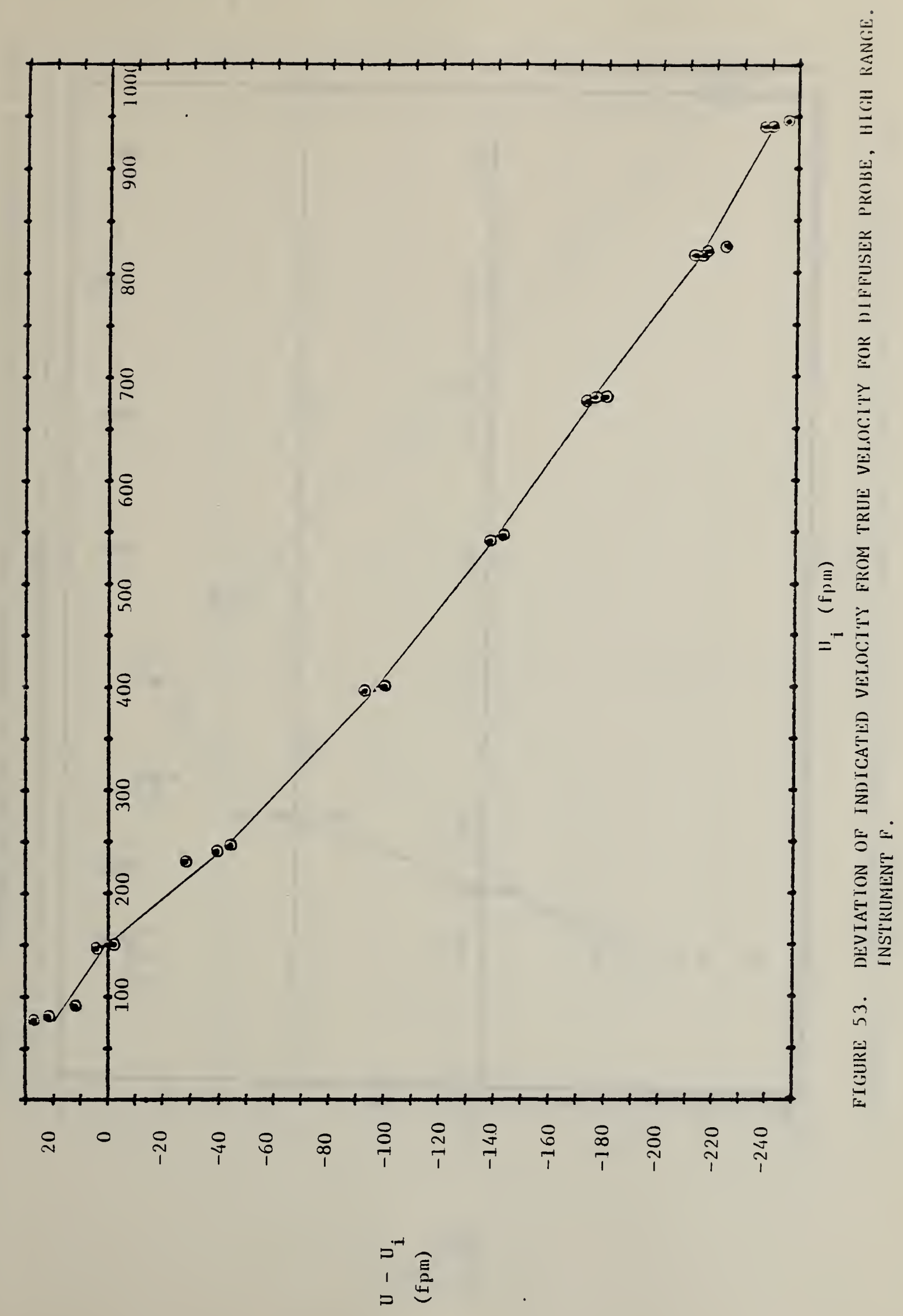




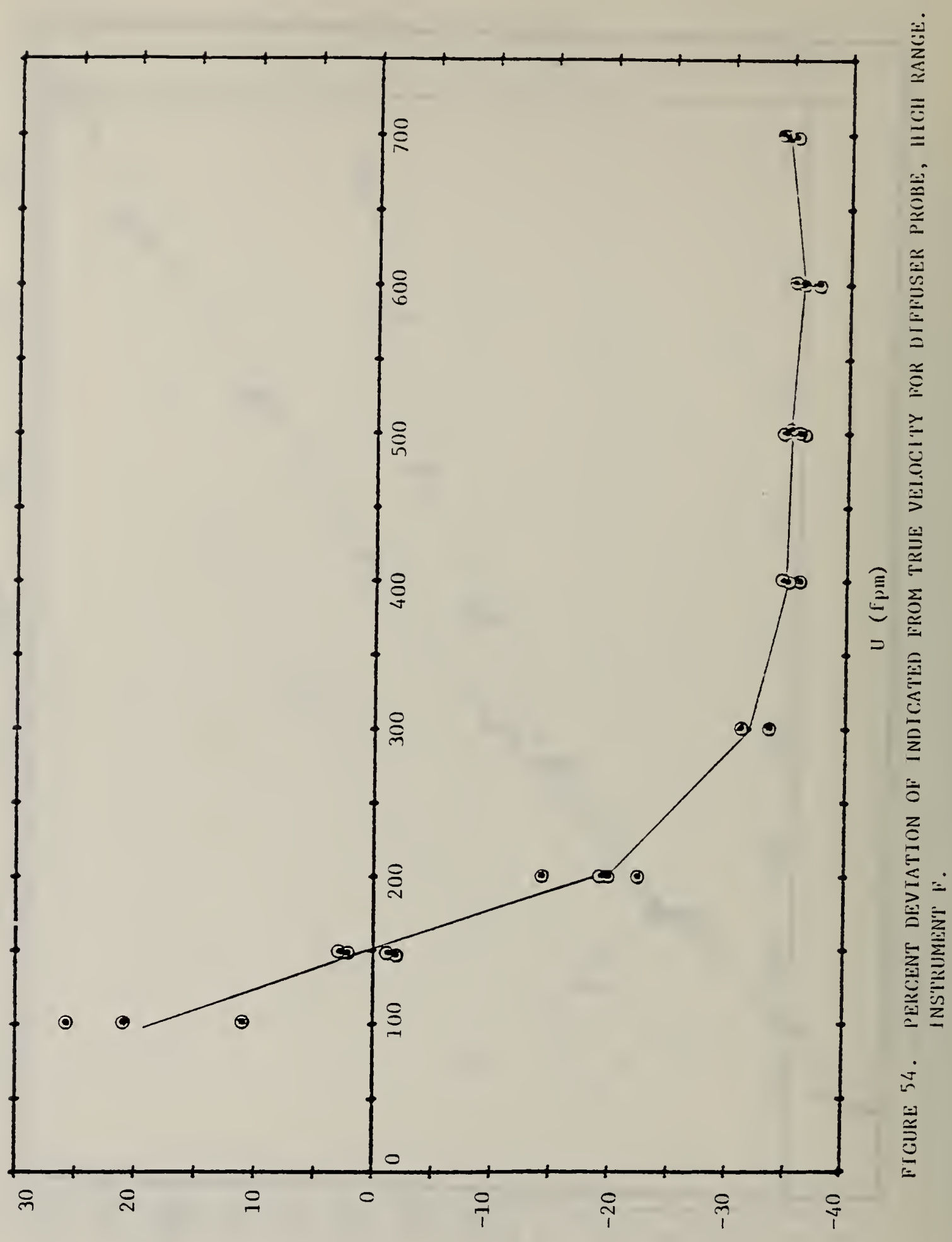

$$
\begin{aligned}
& 0 \\
& \vdots \\
& y
\end{aligned} \mid=\widehat{A}
$$




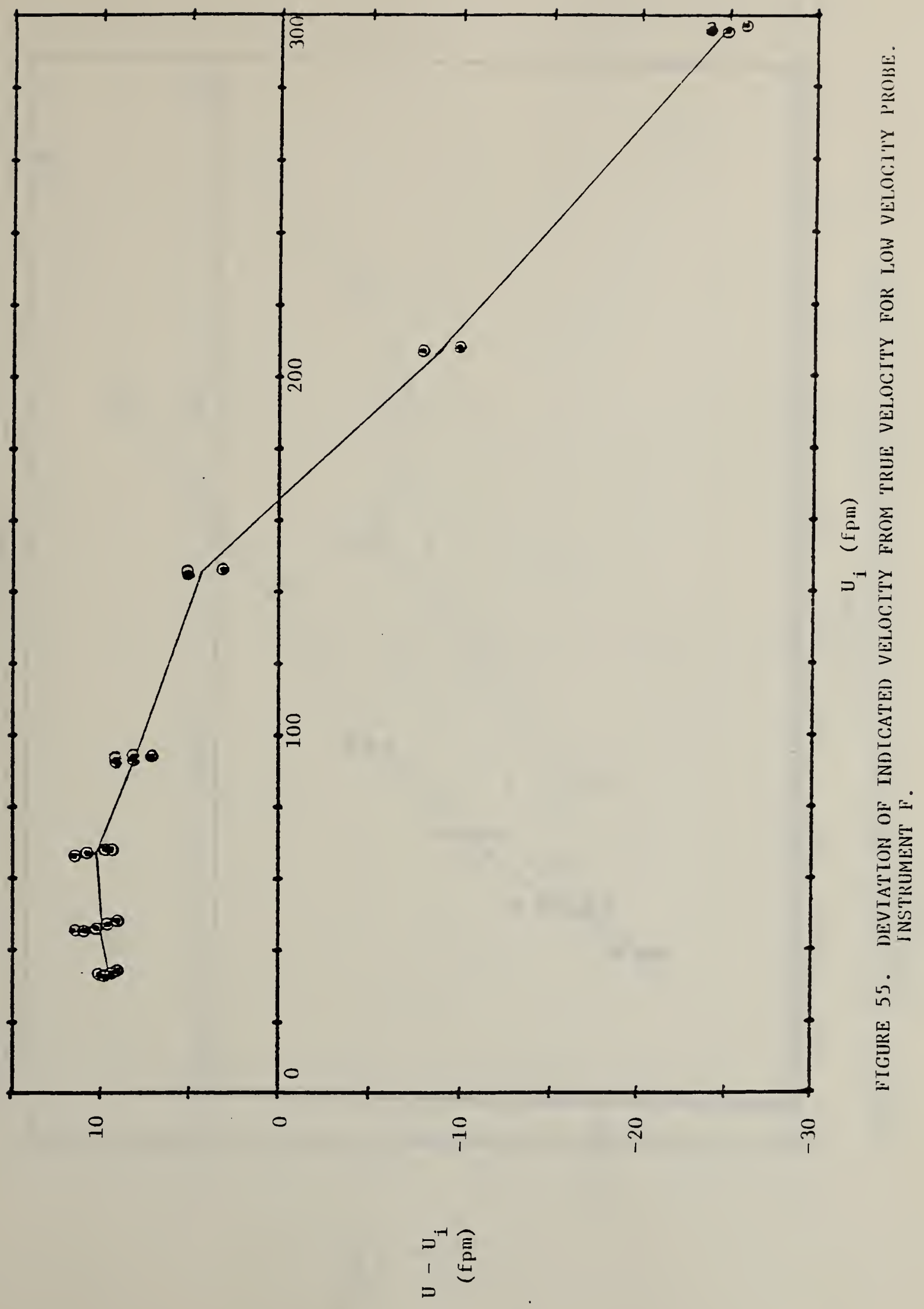




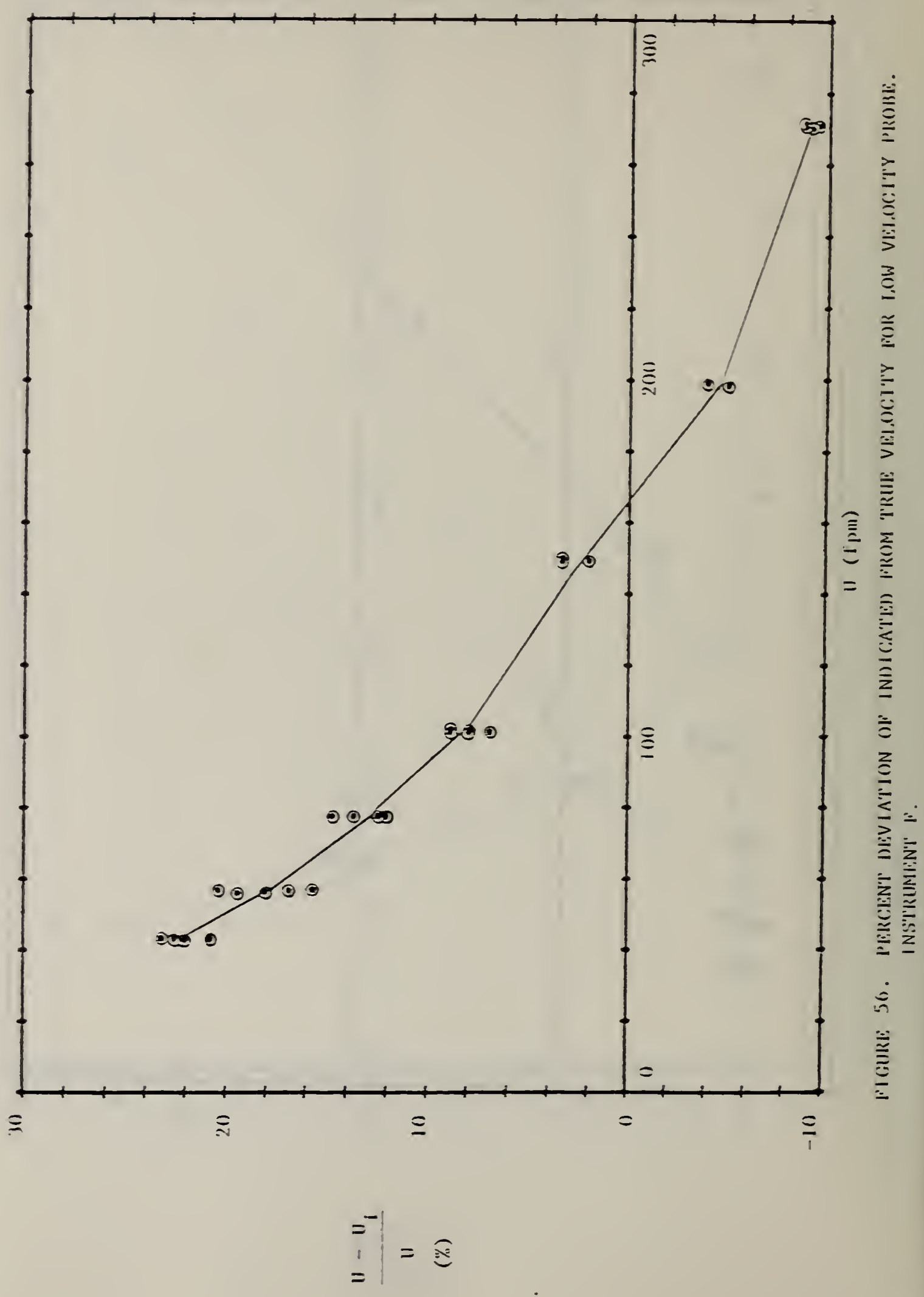




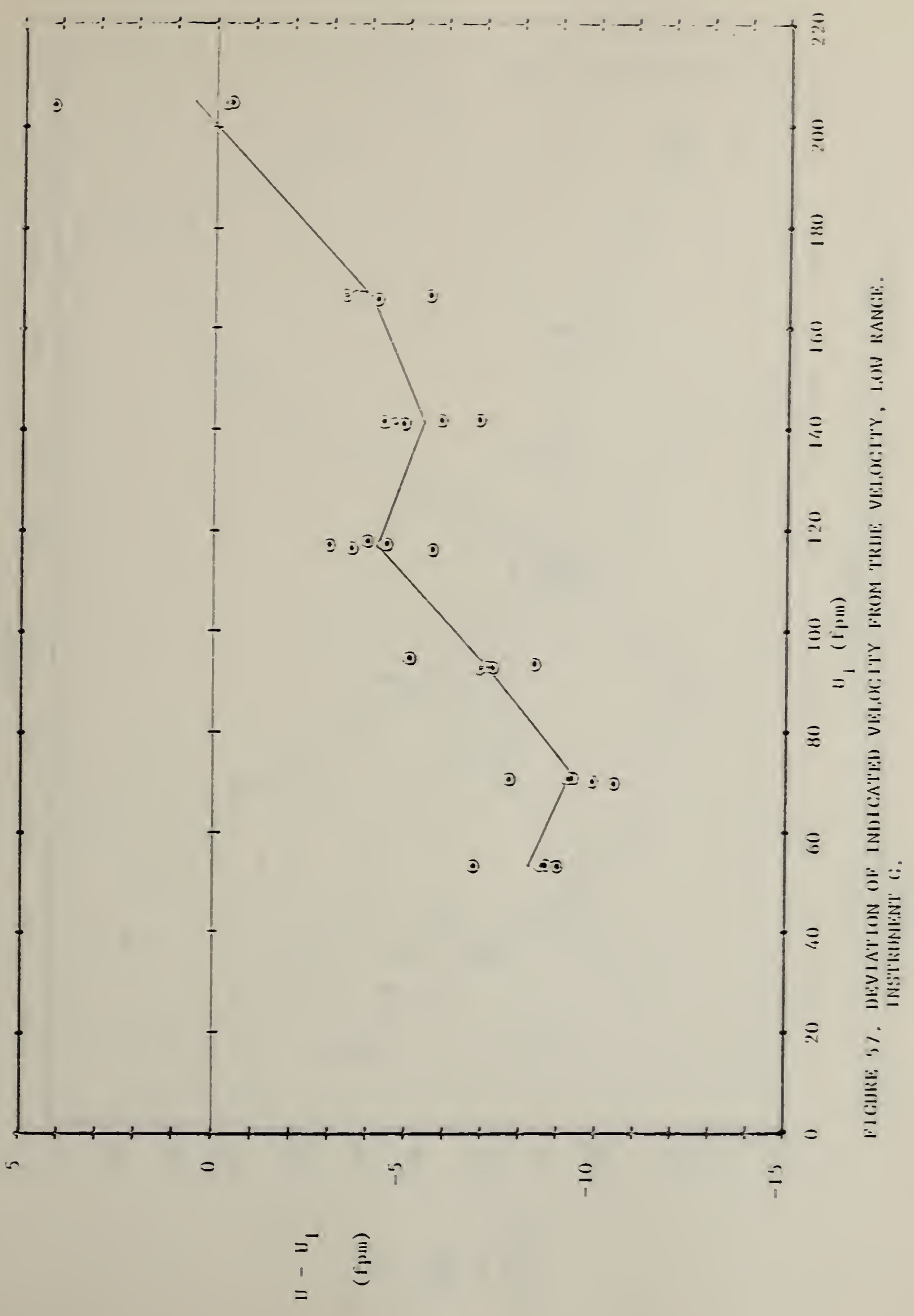




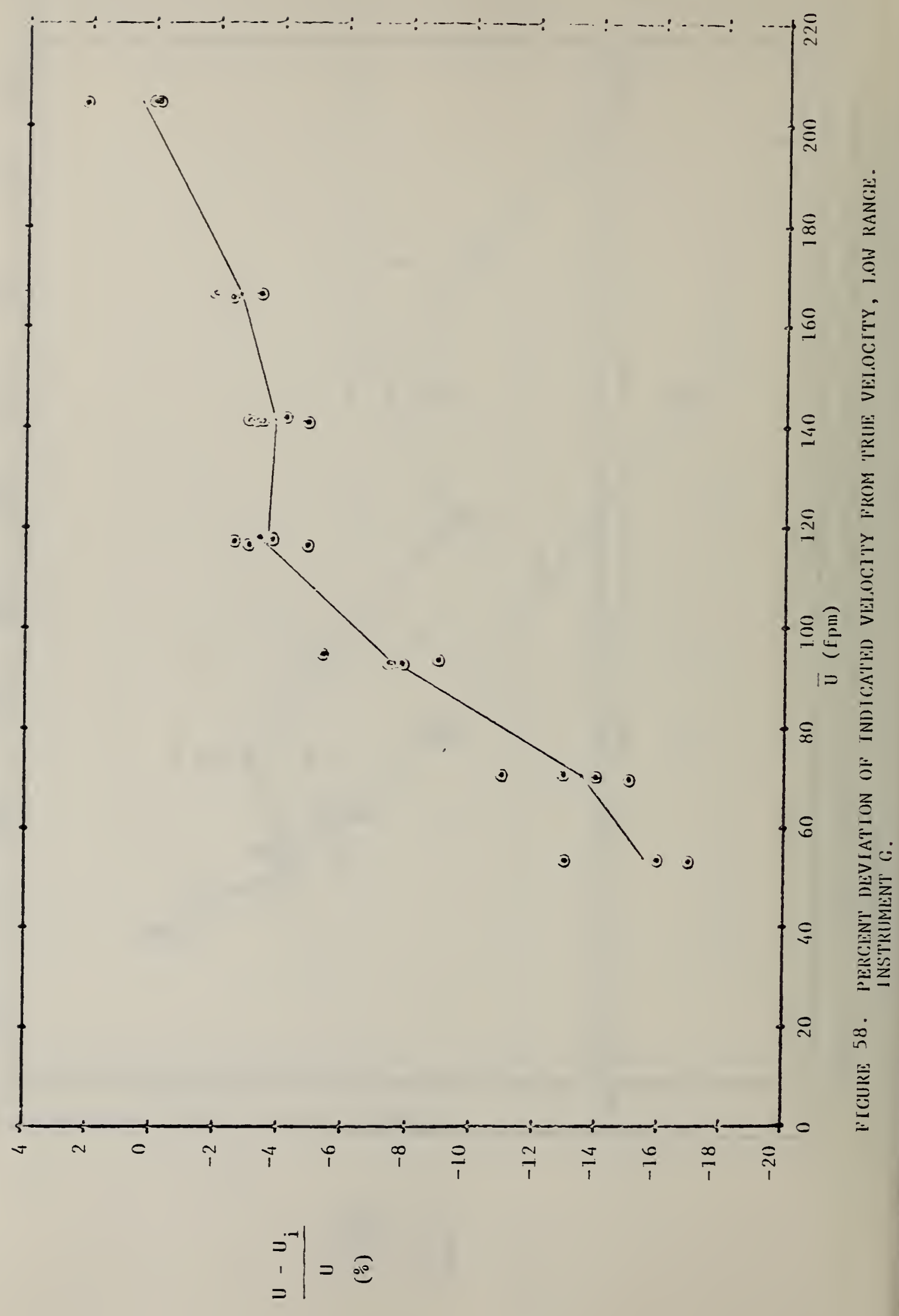




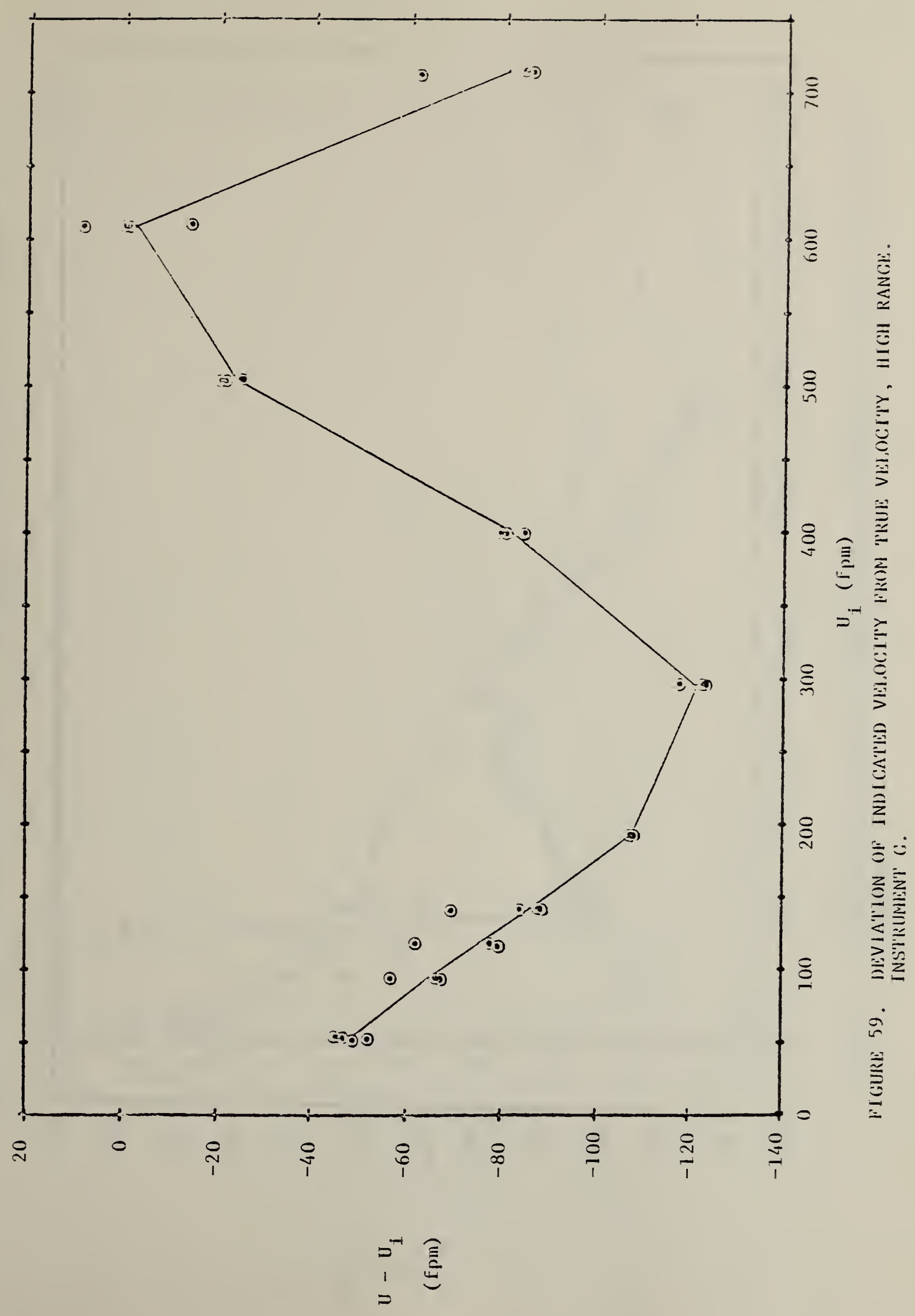




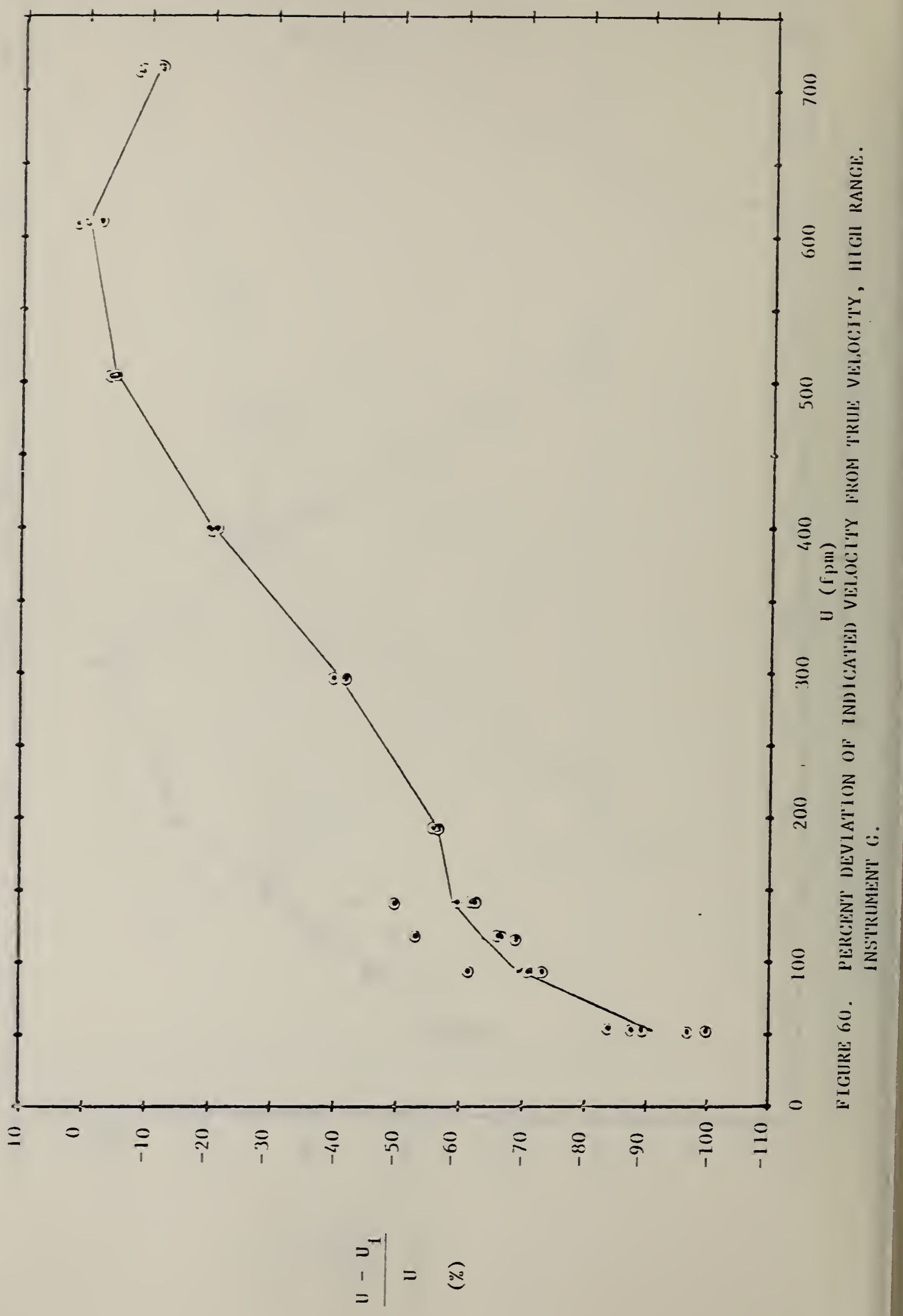




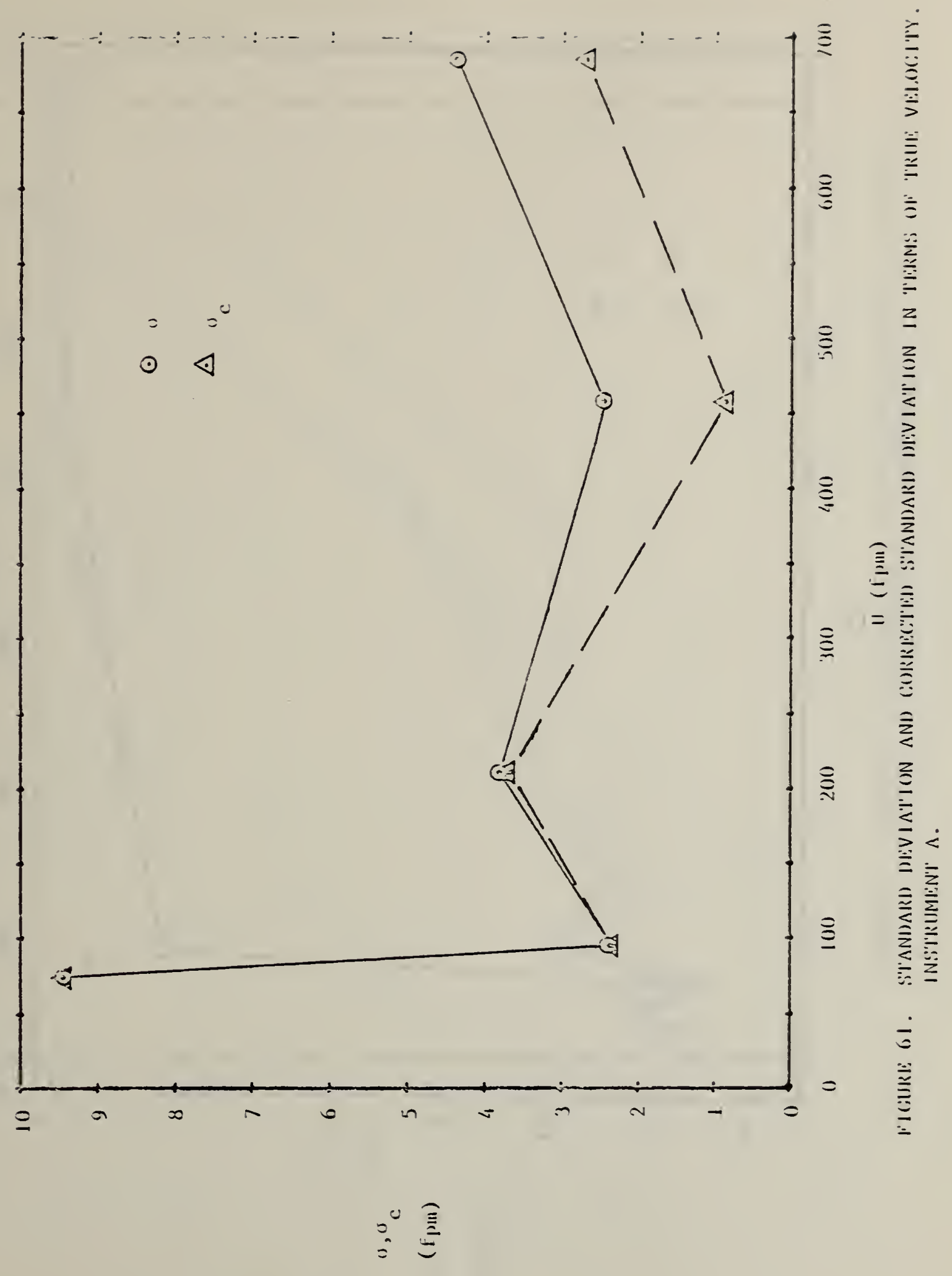




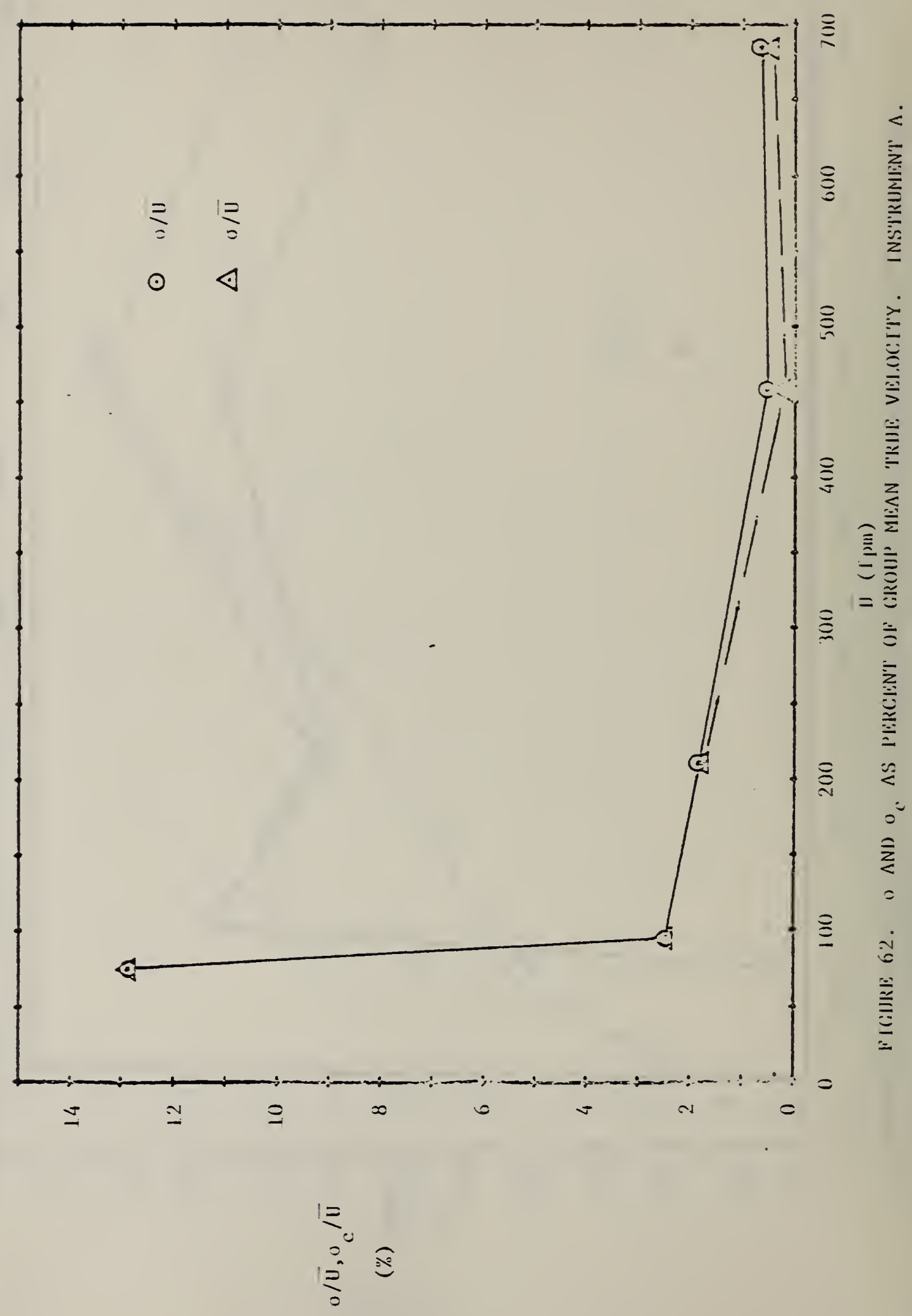




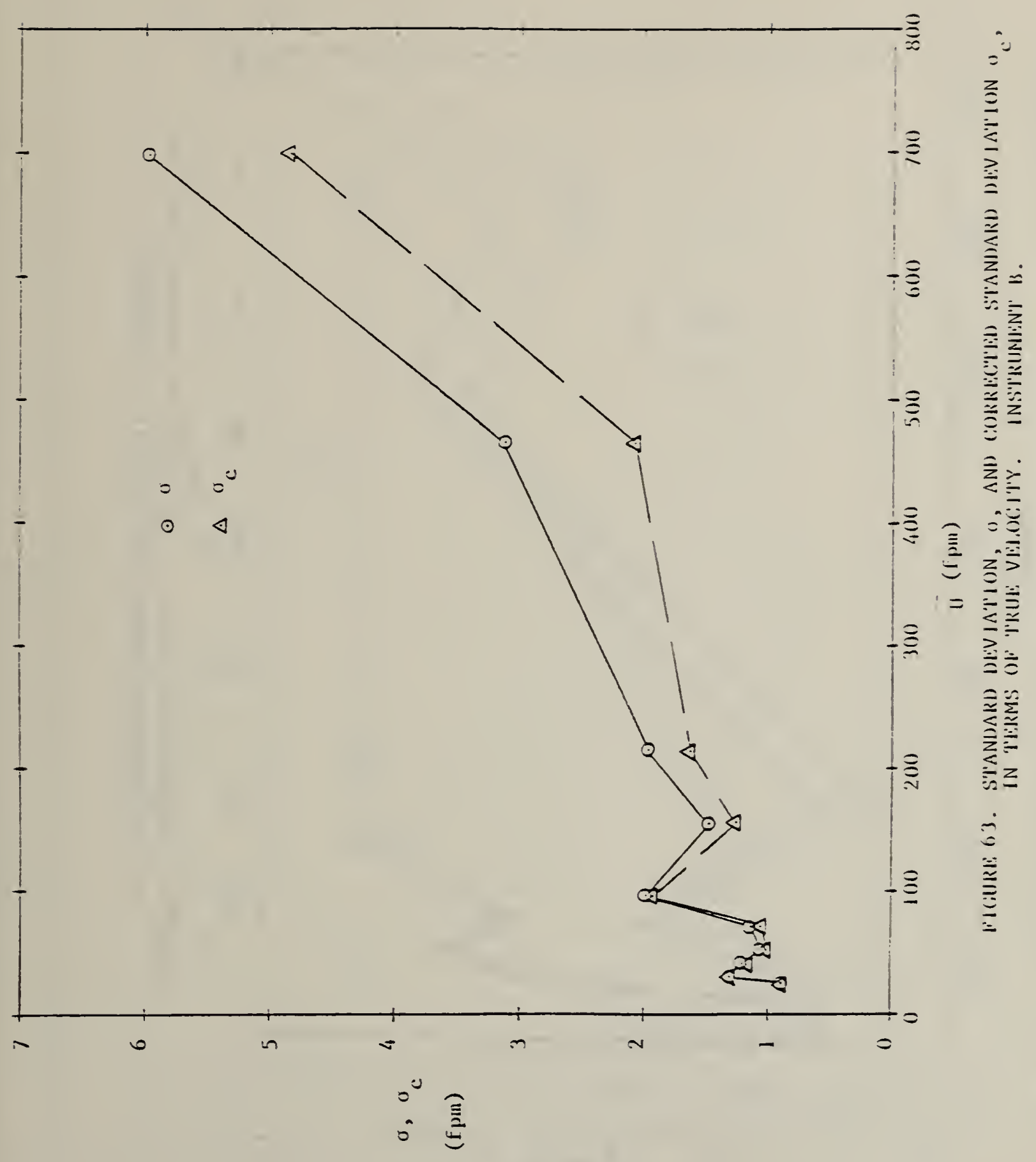




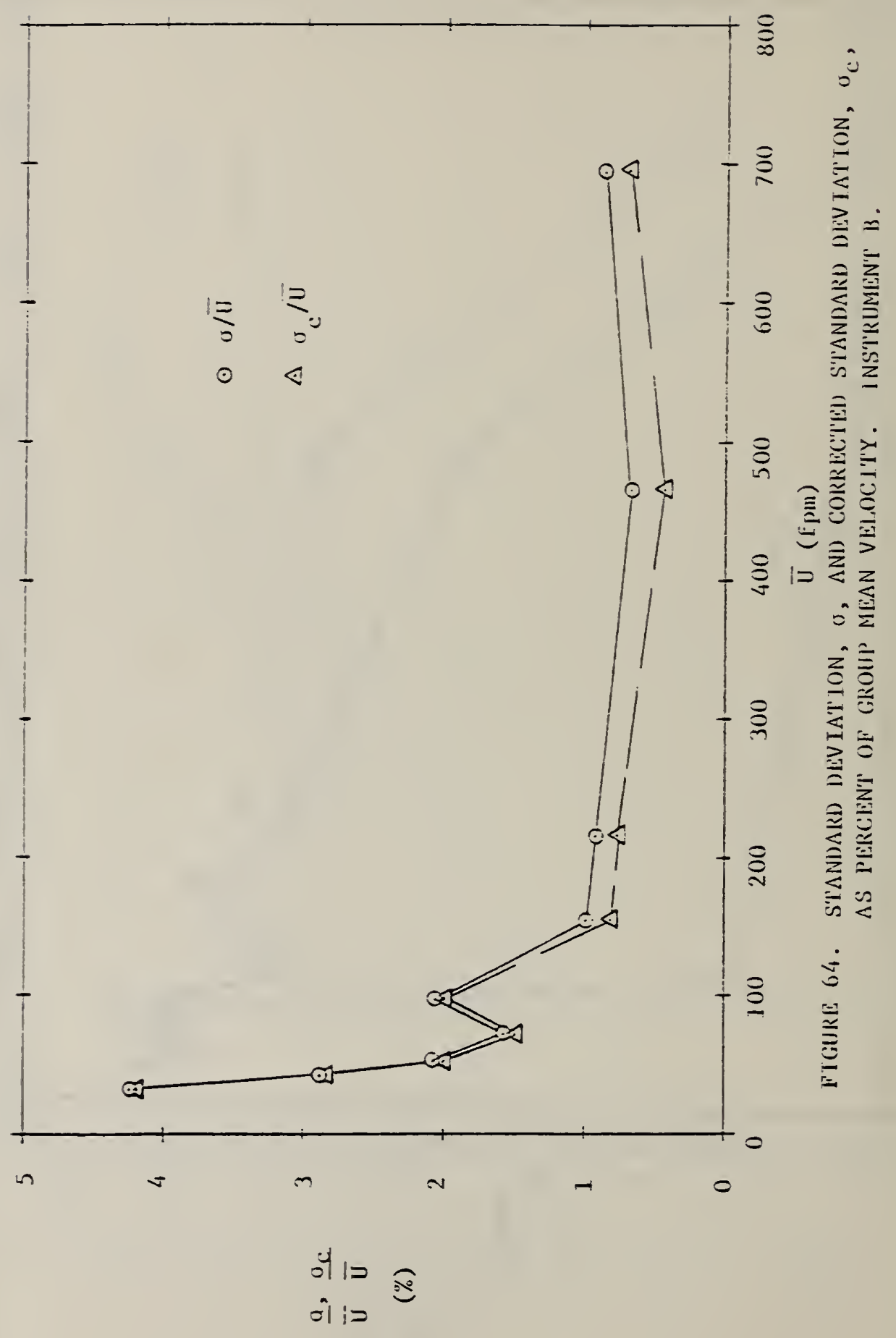




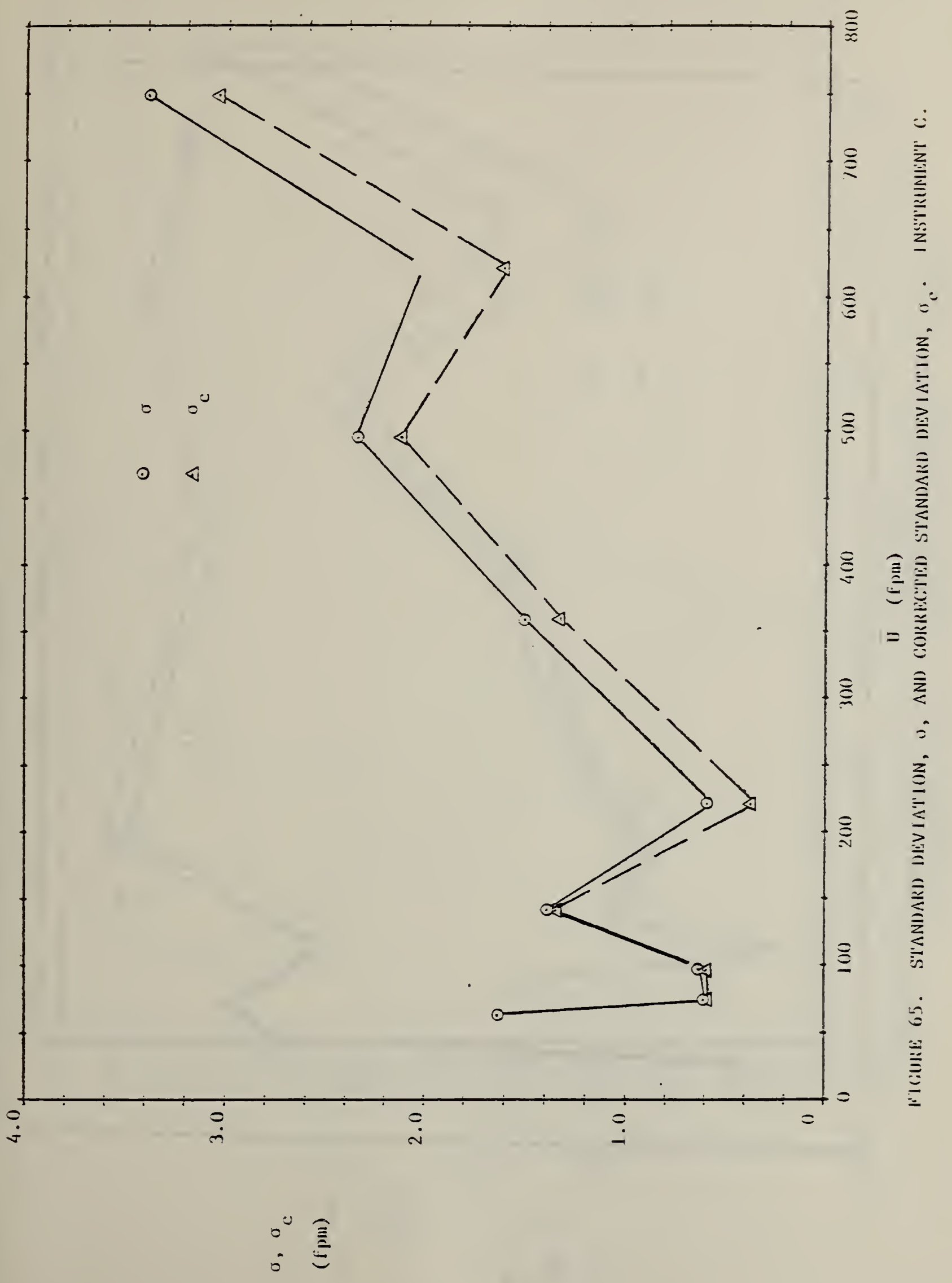




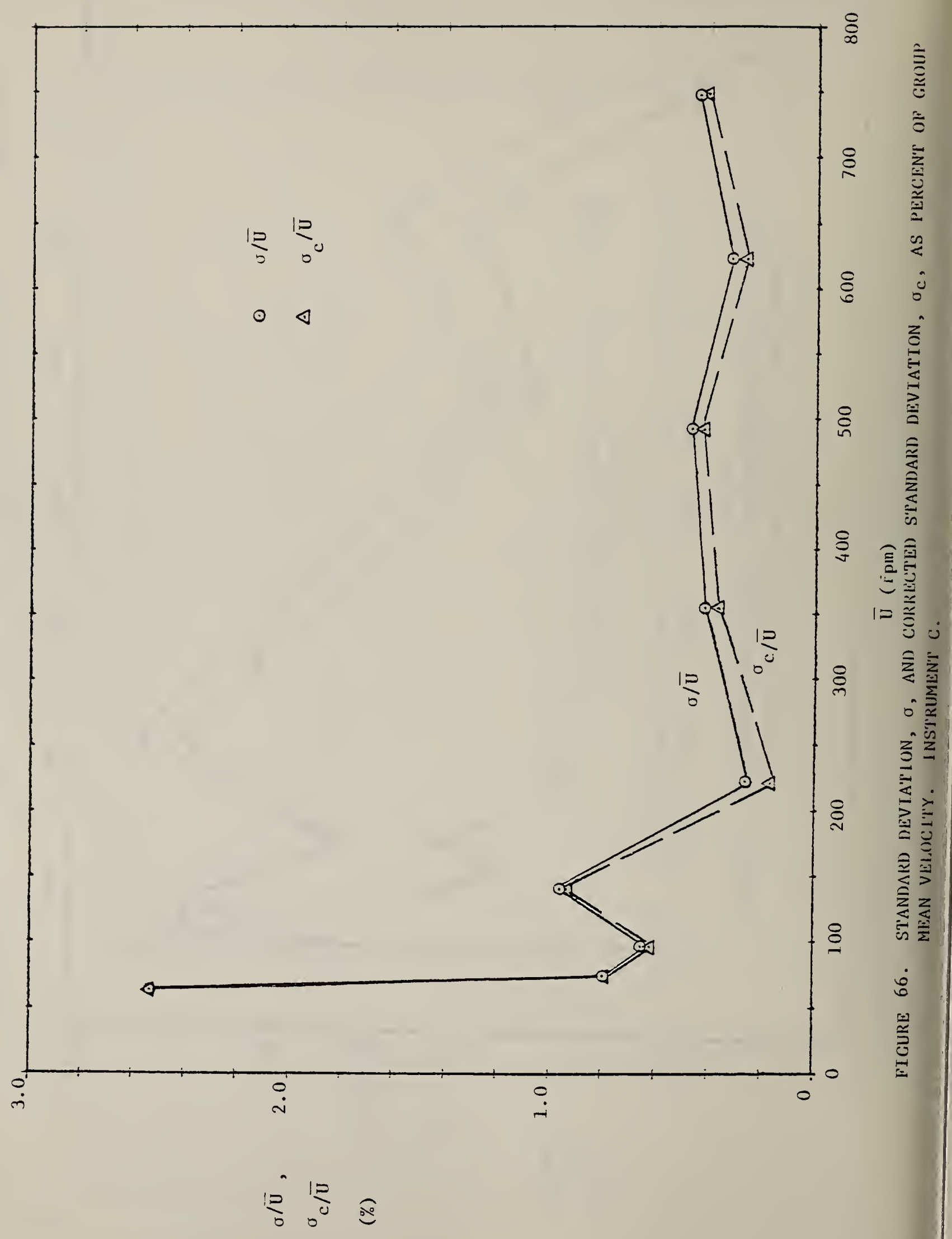




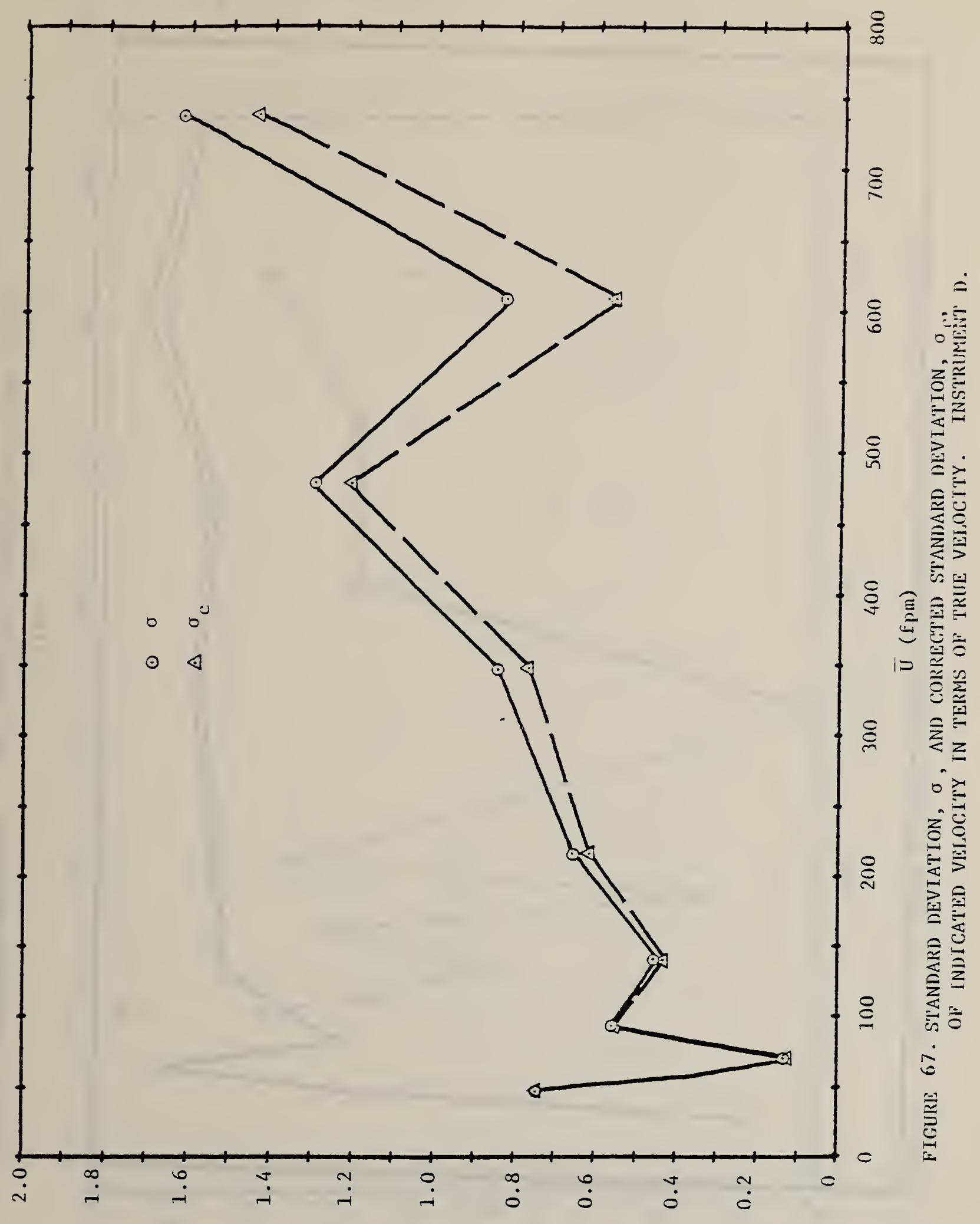

०. 


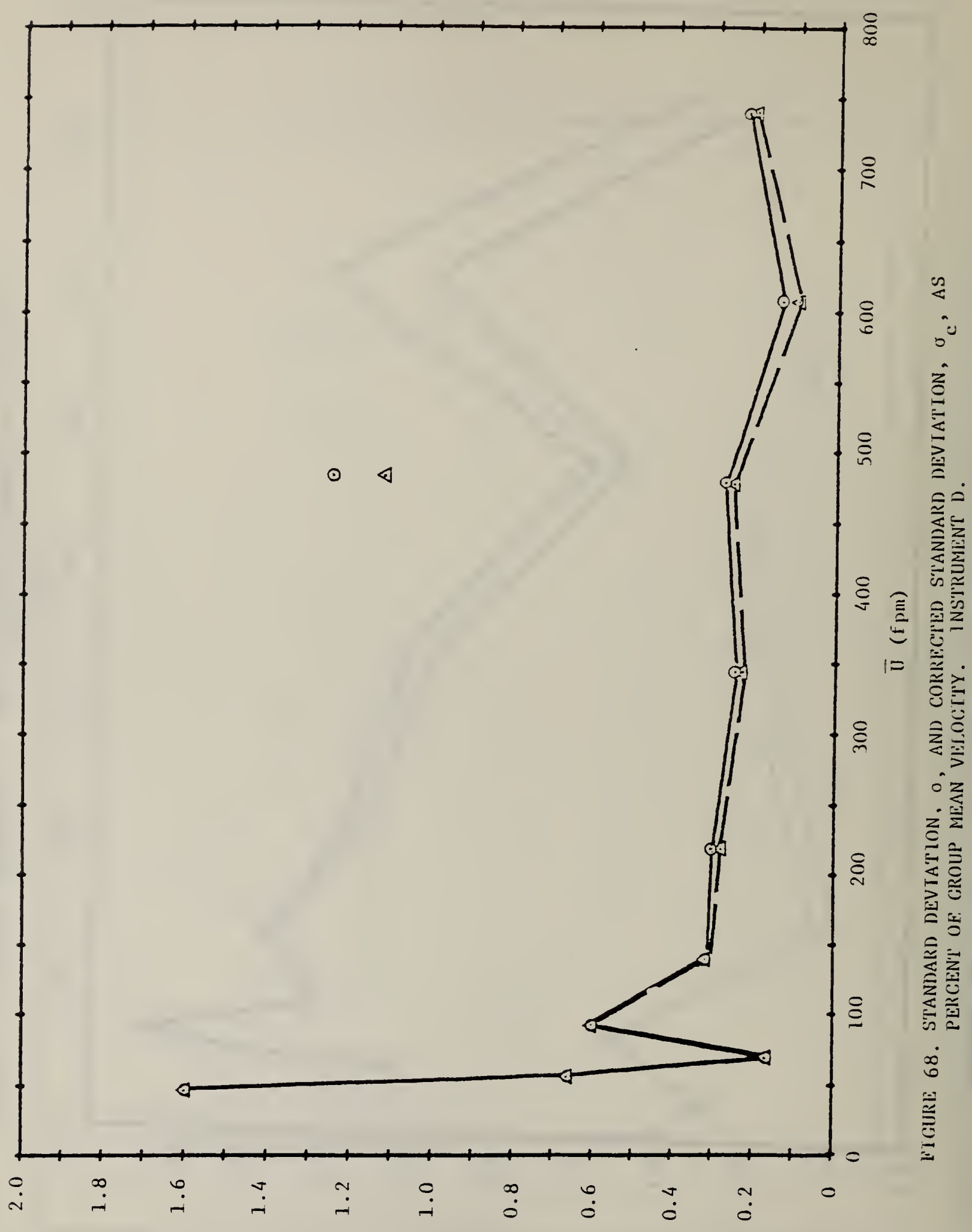

$$
\begin{aligned}
& \text { c I } \\
& 0 \hat{110}
\end{aligned}
$$




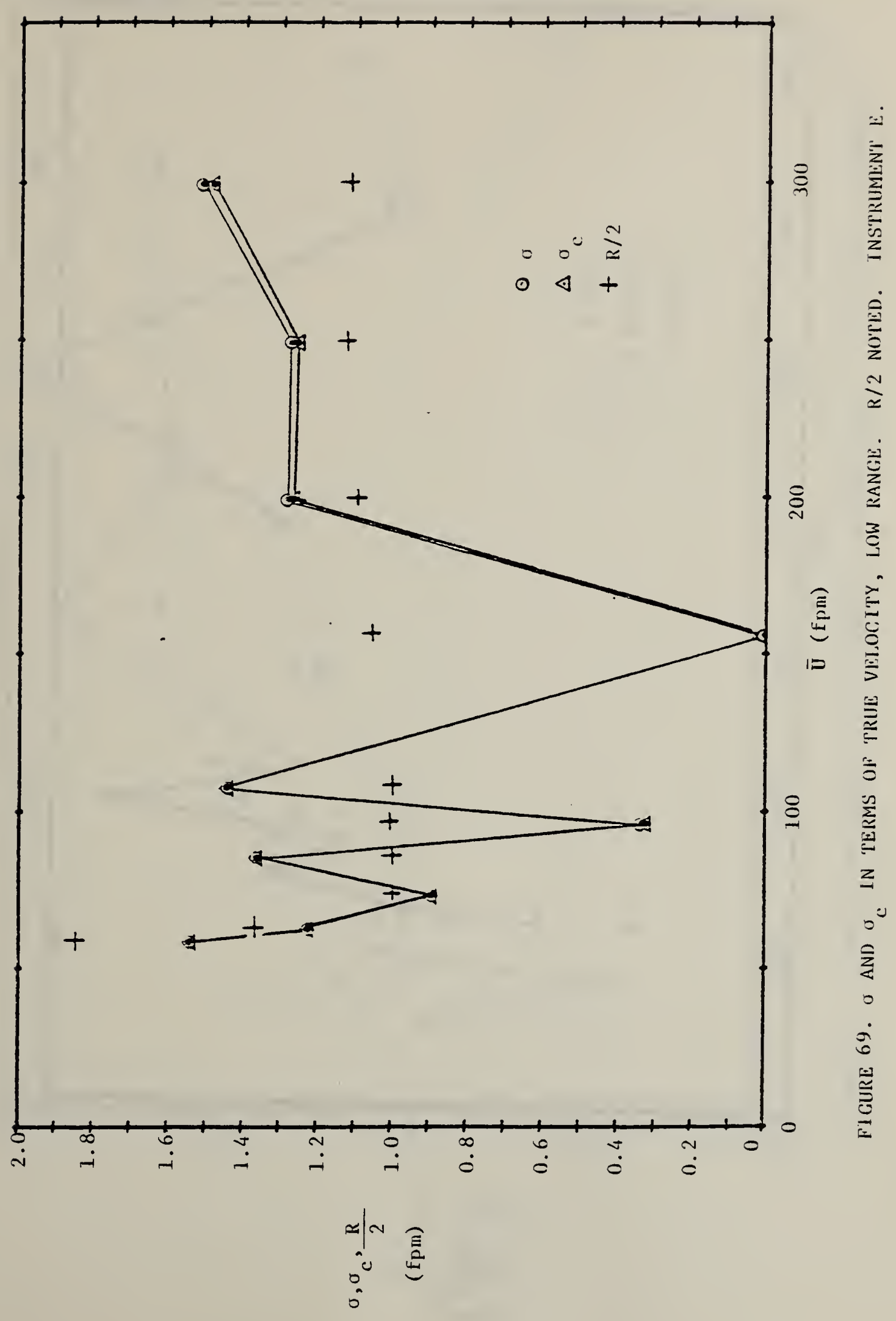




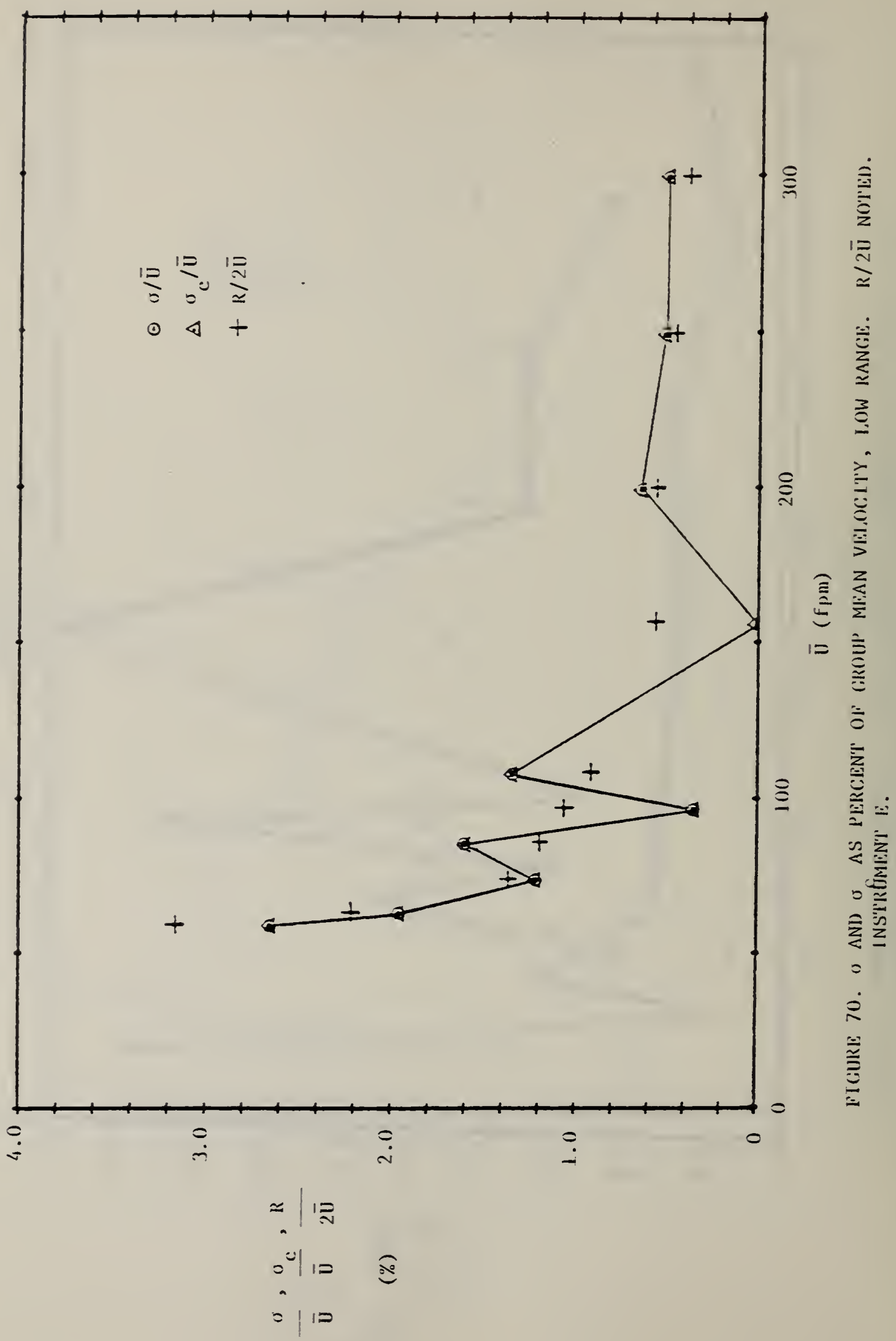




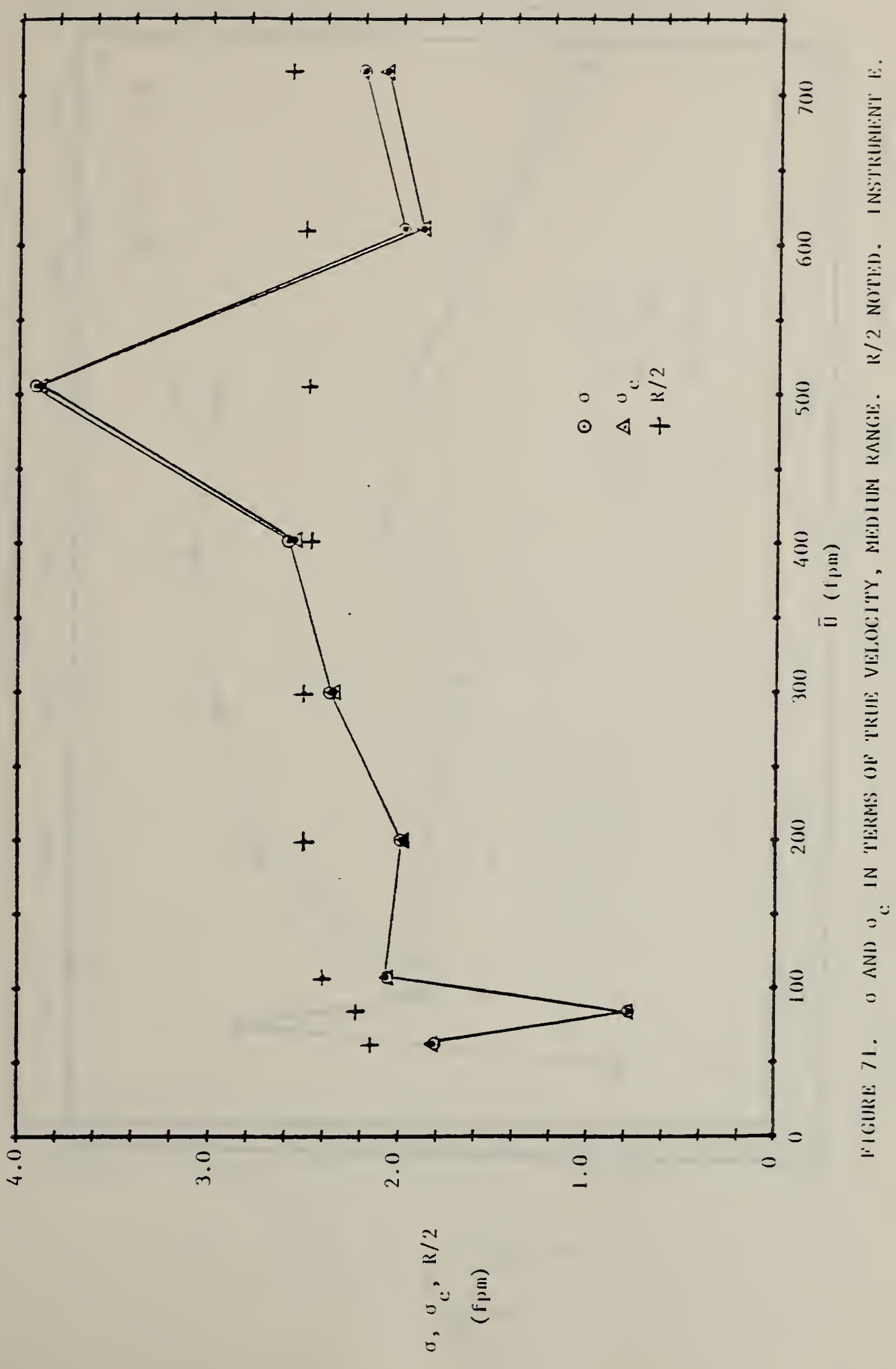




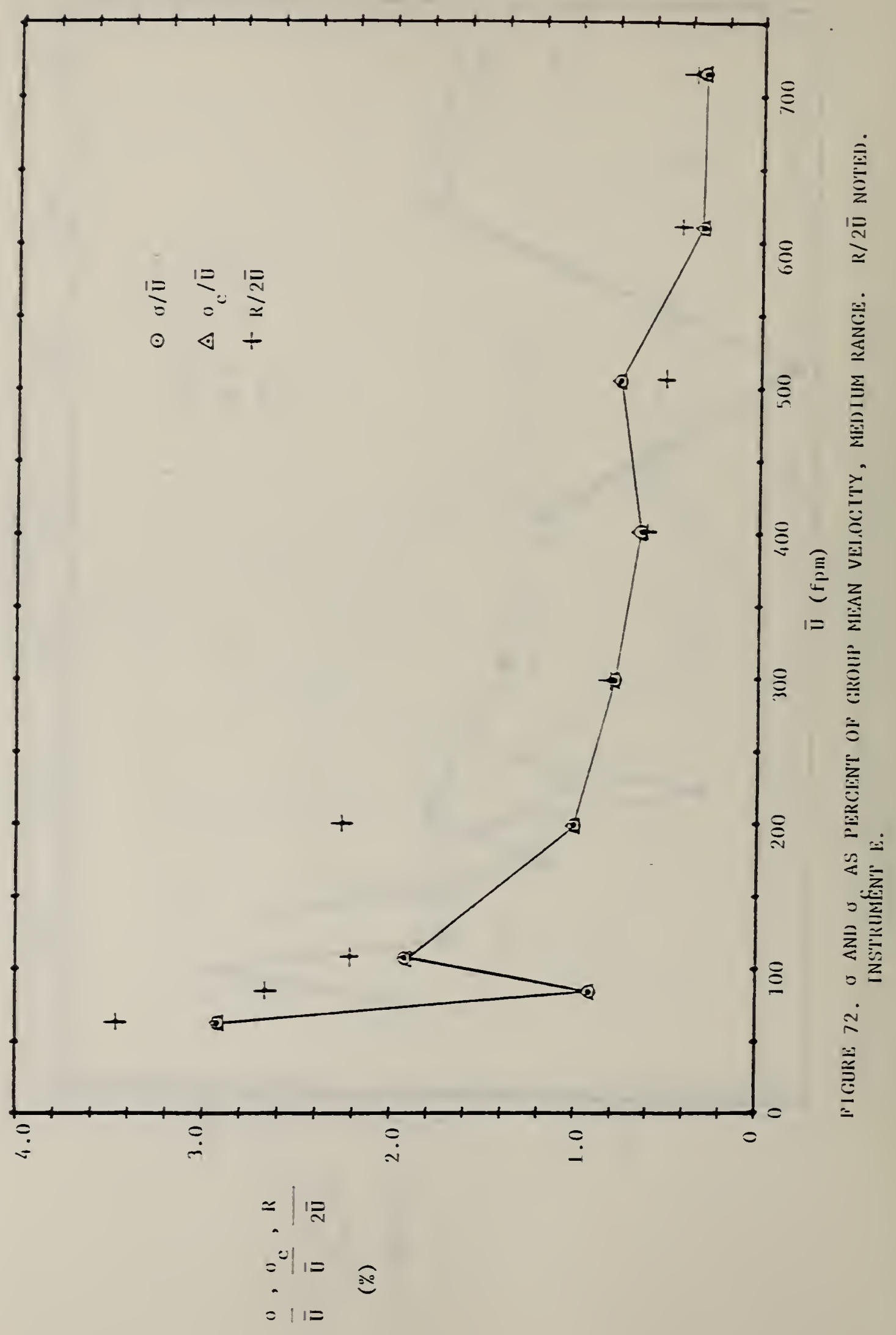




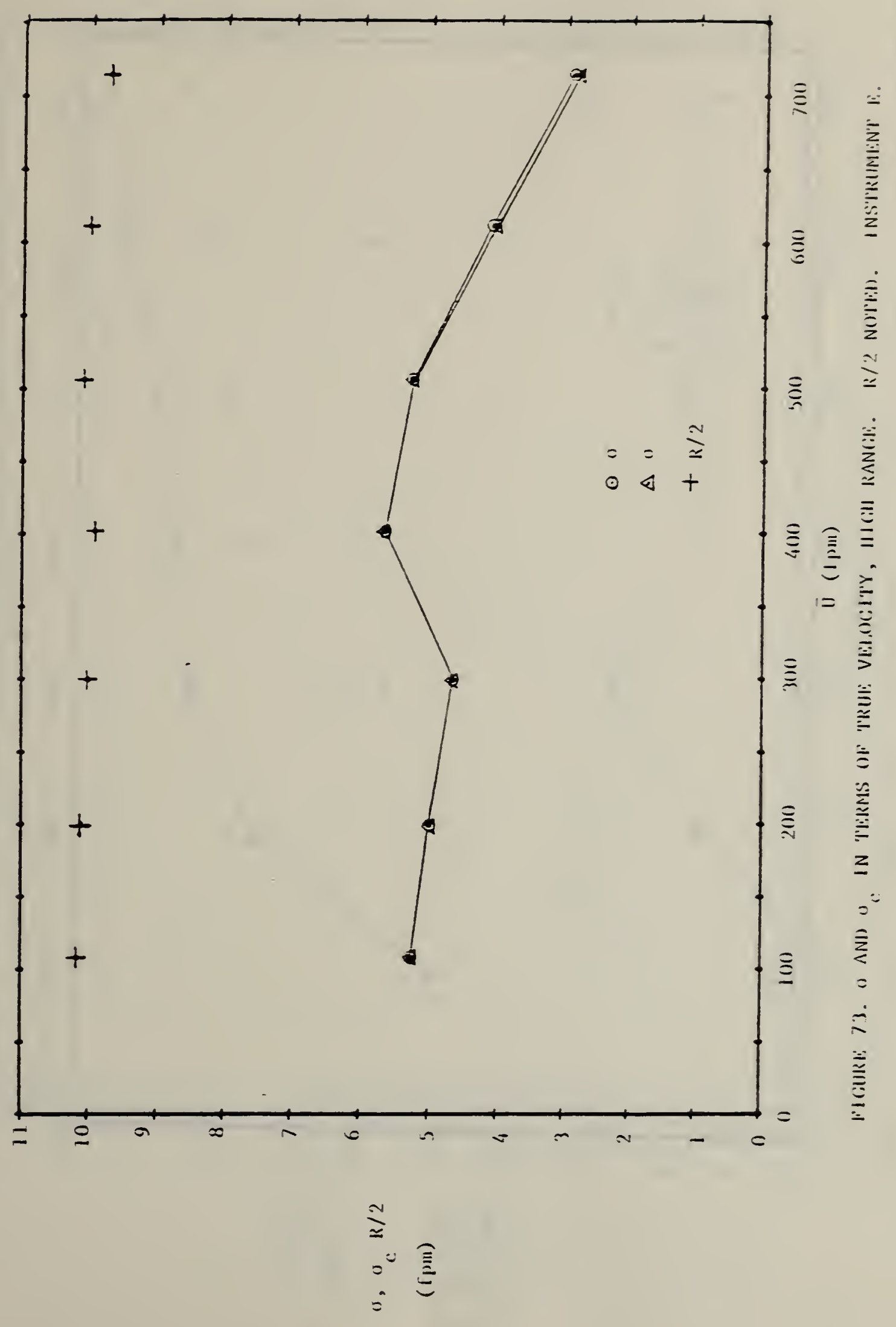




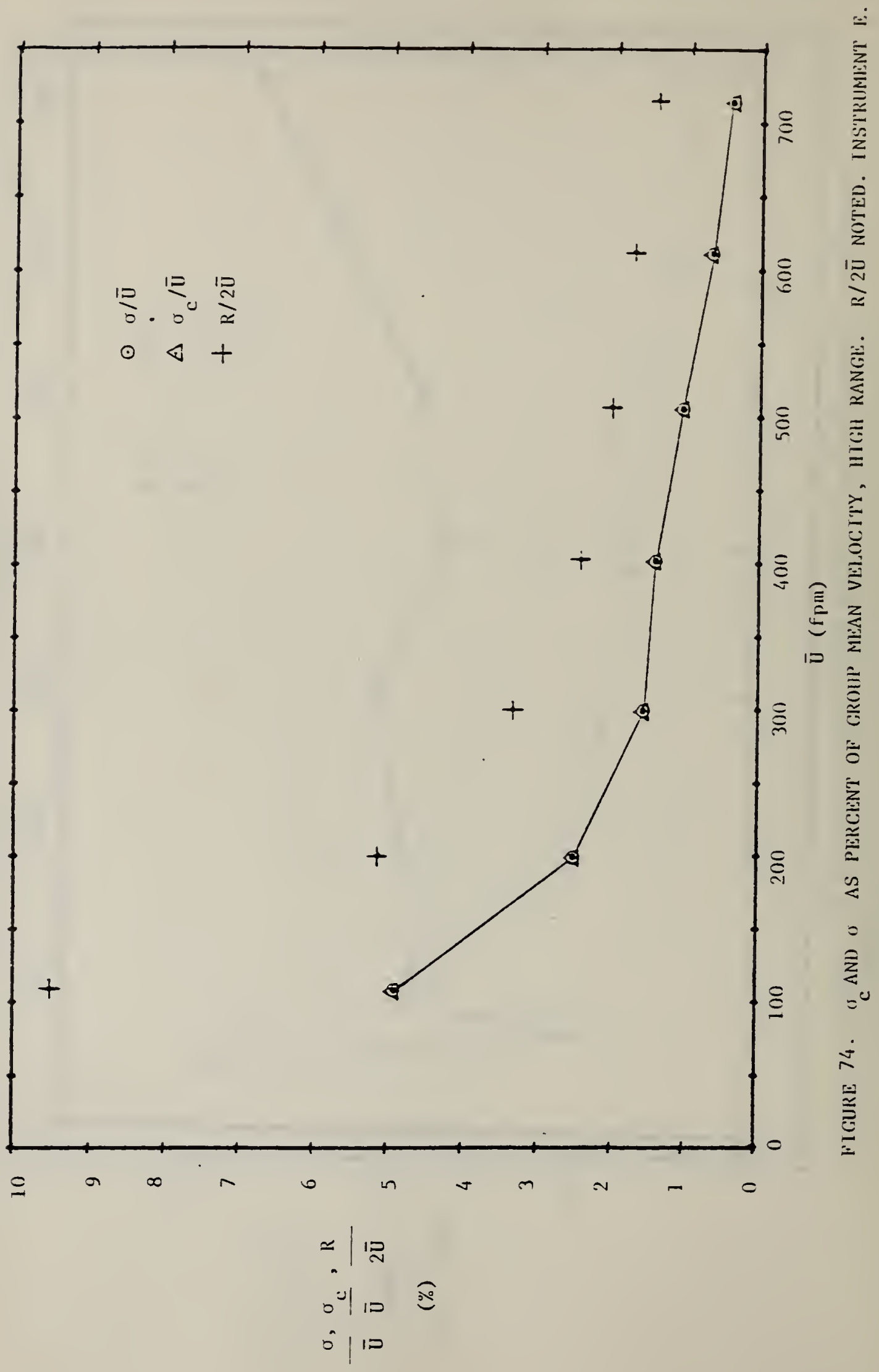




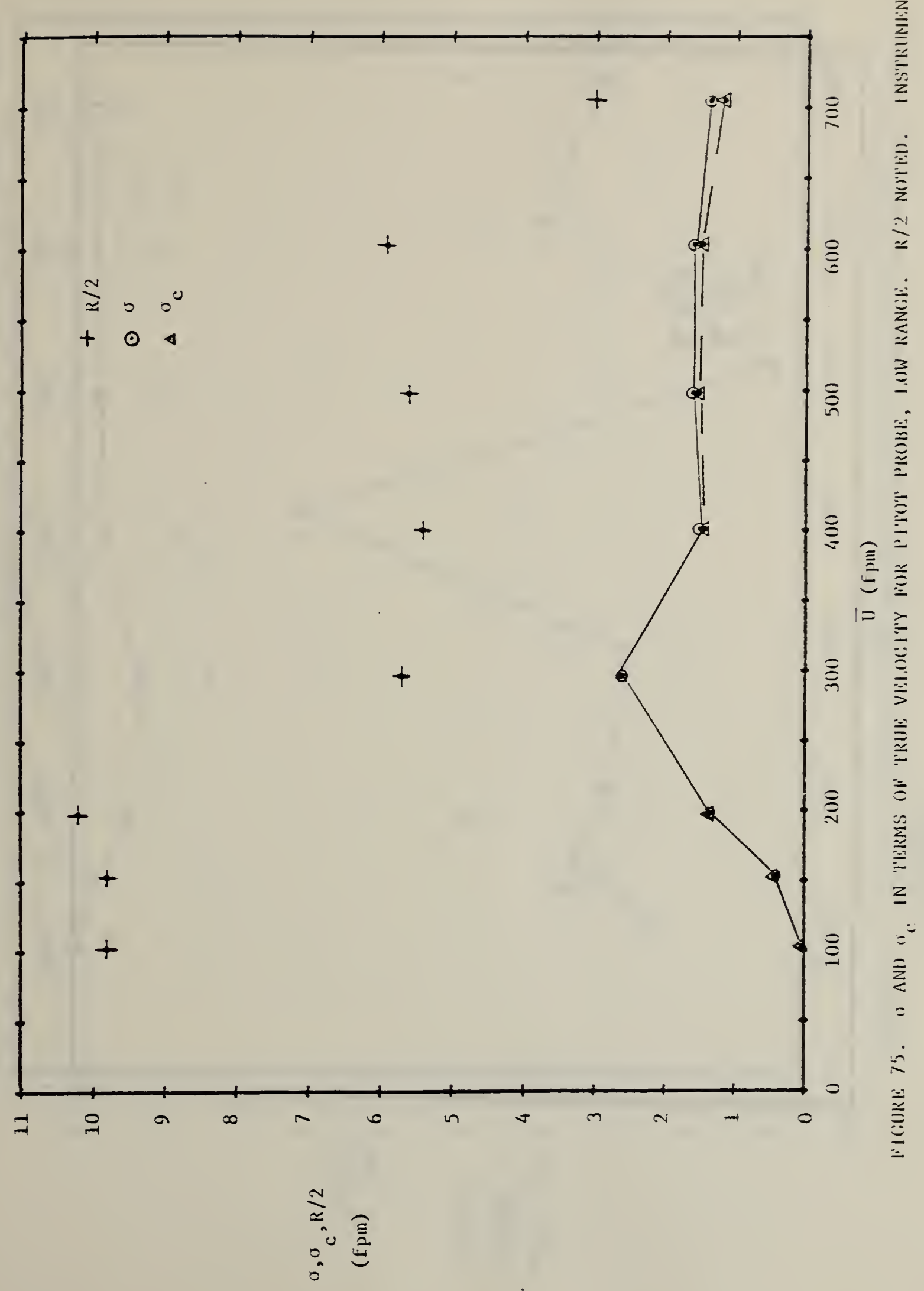




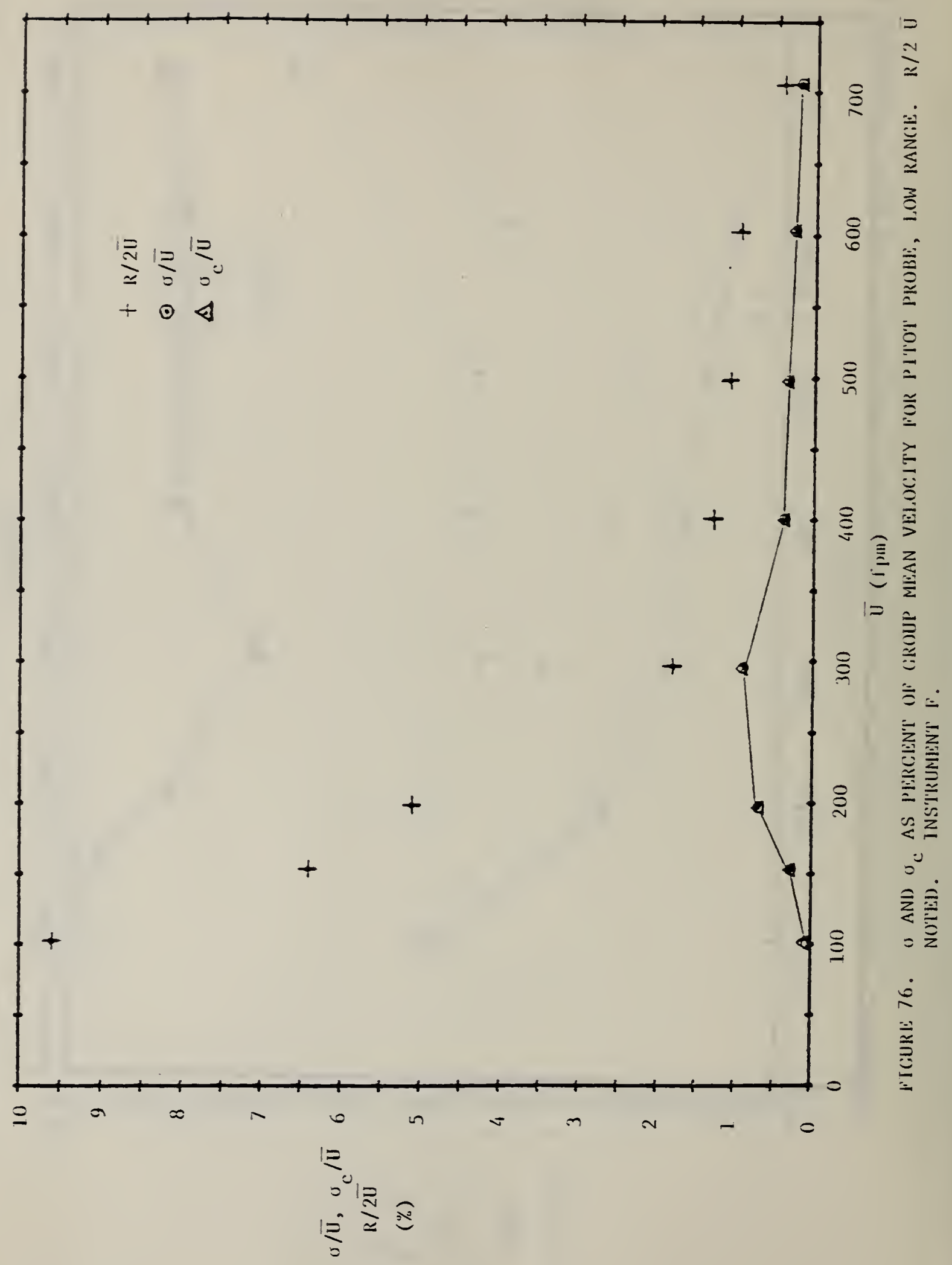




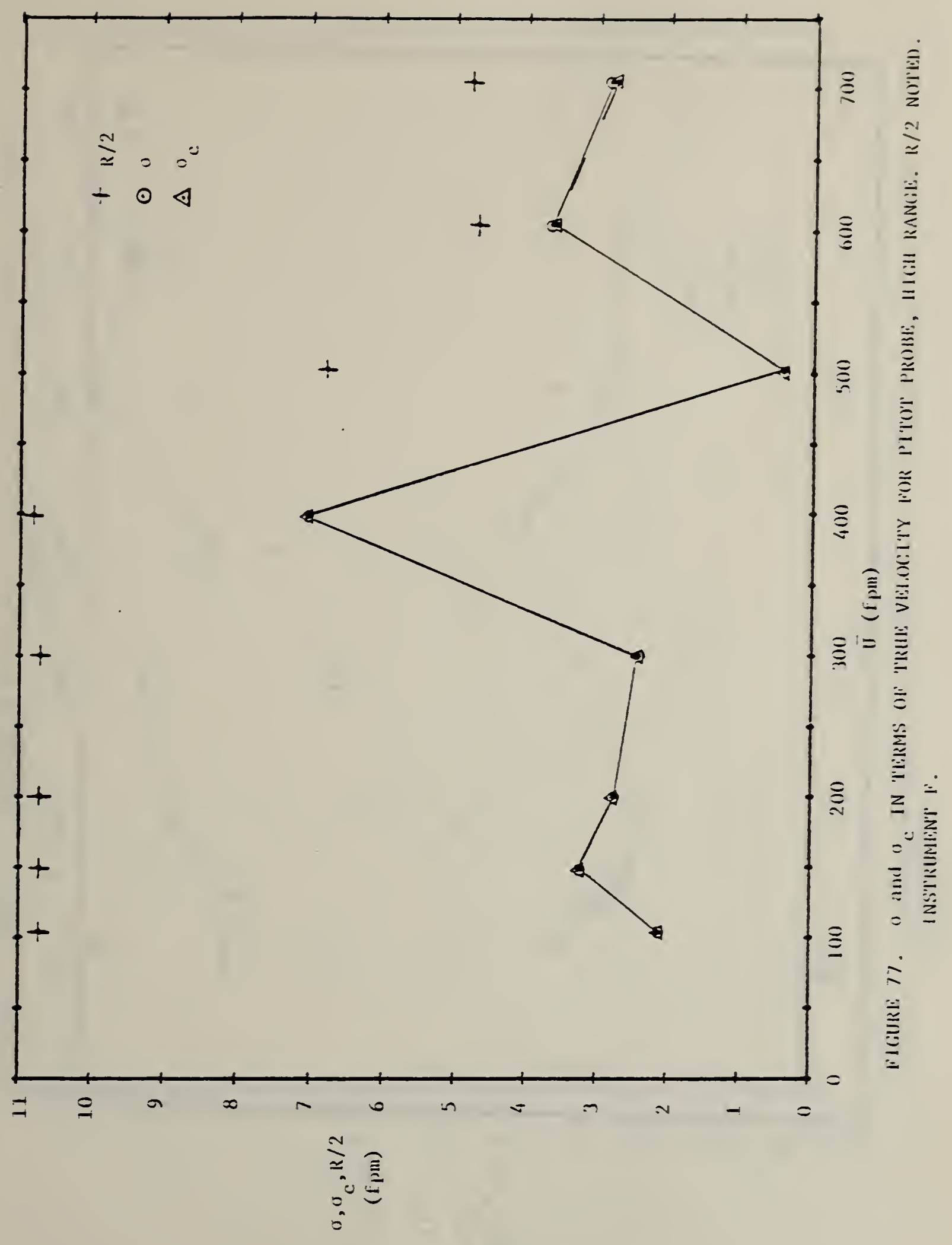




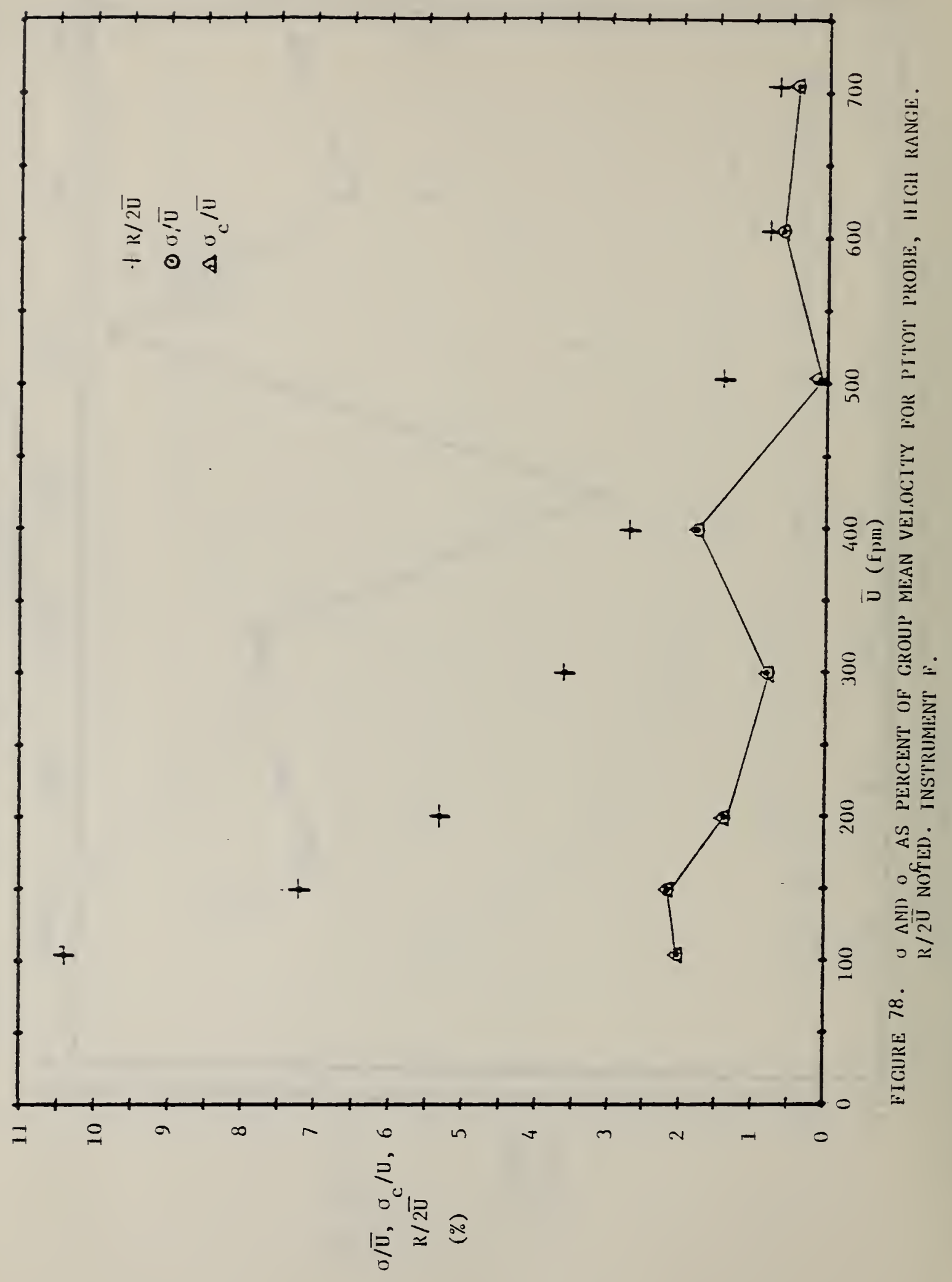




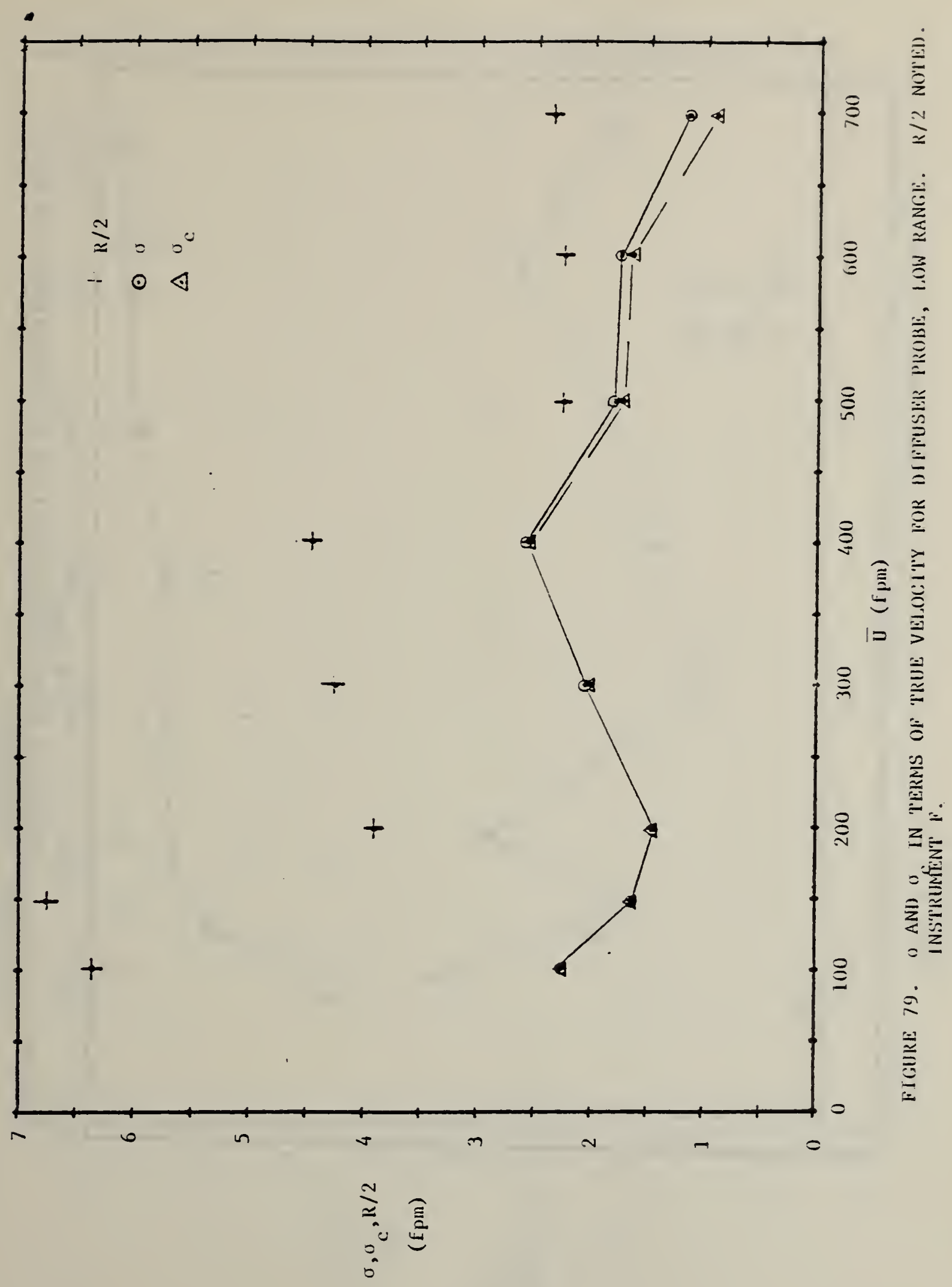




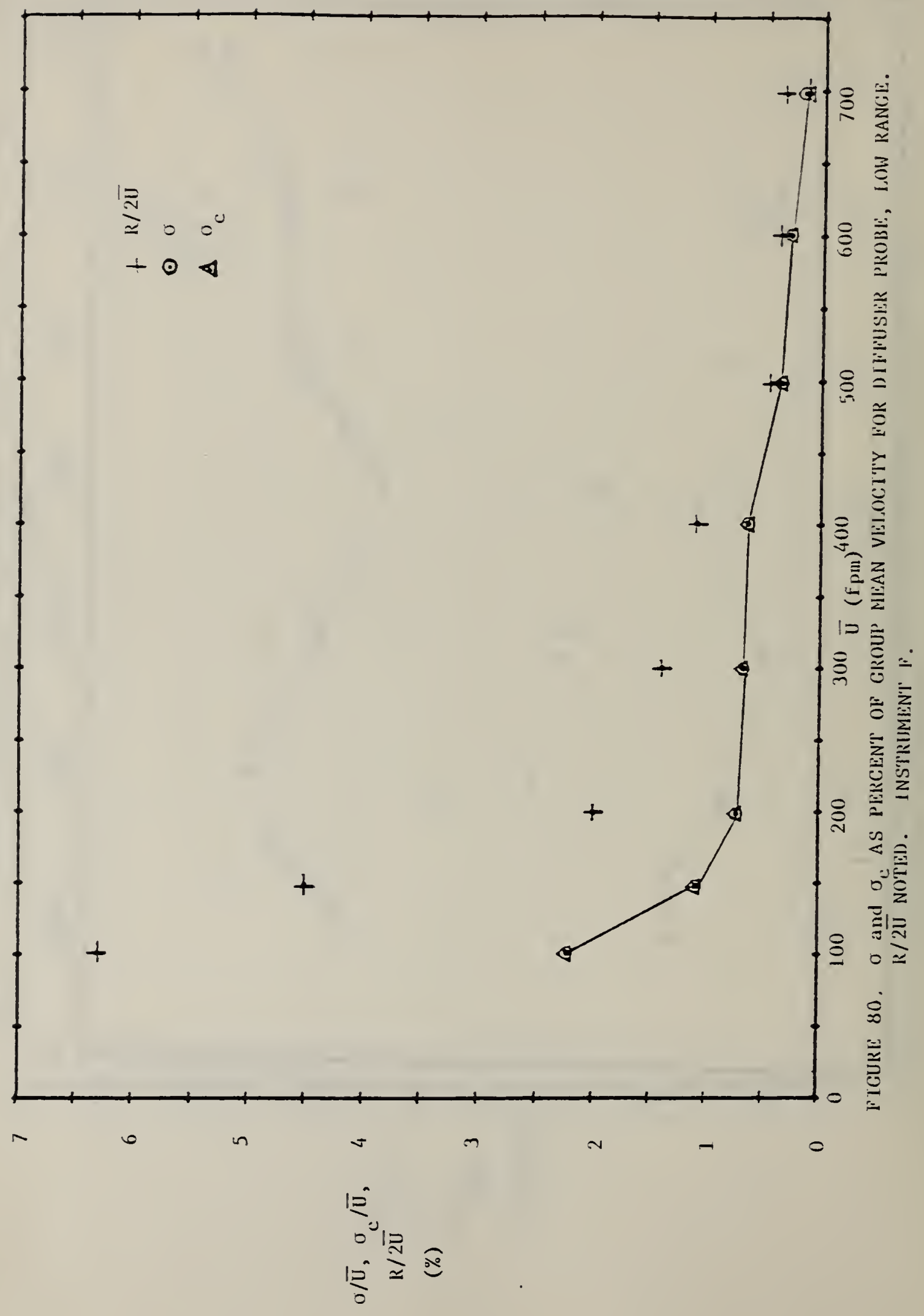




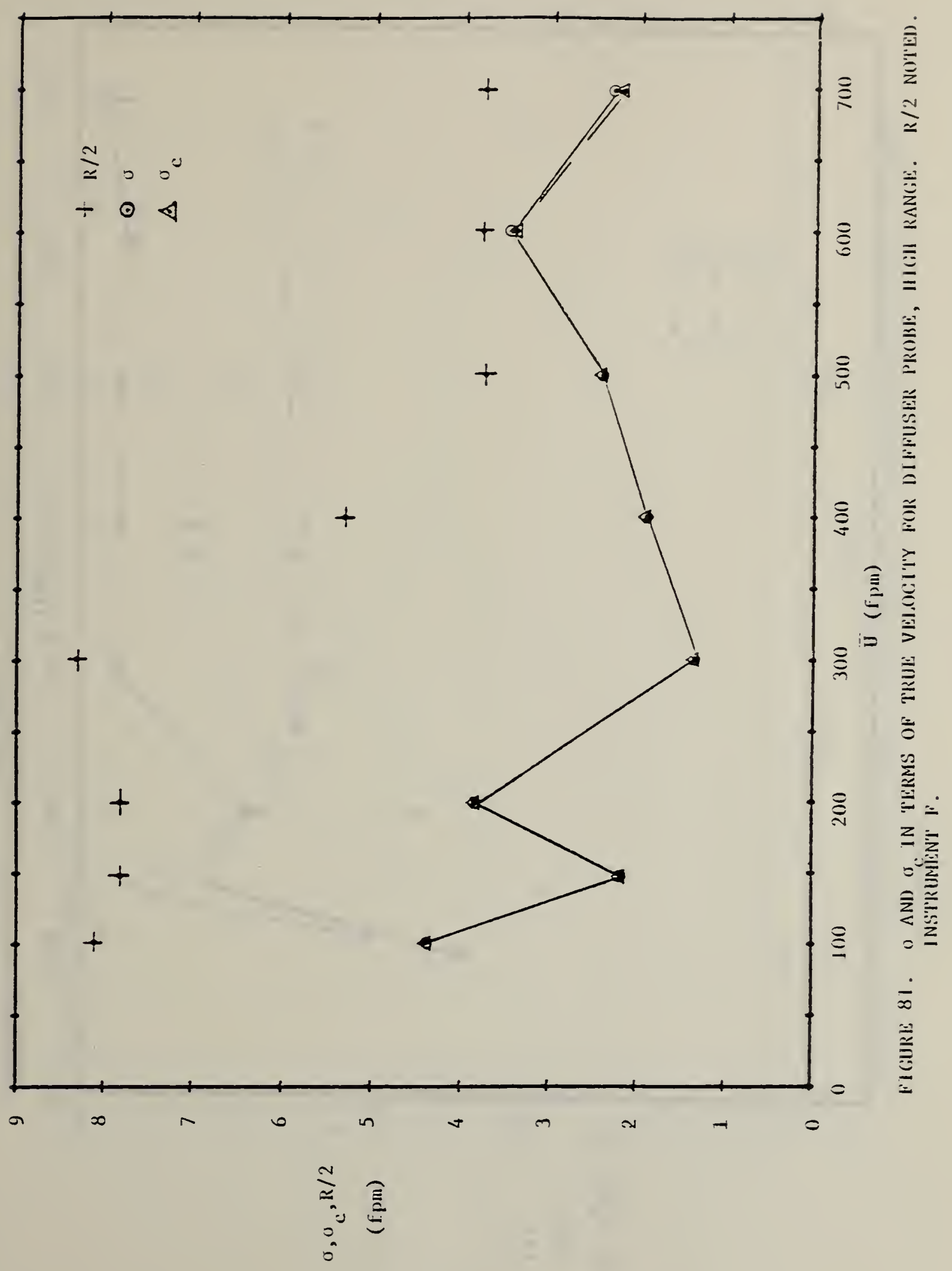




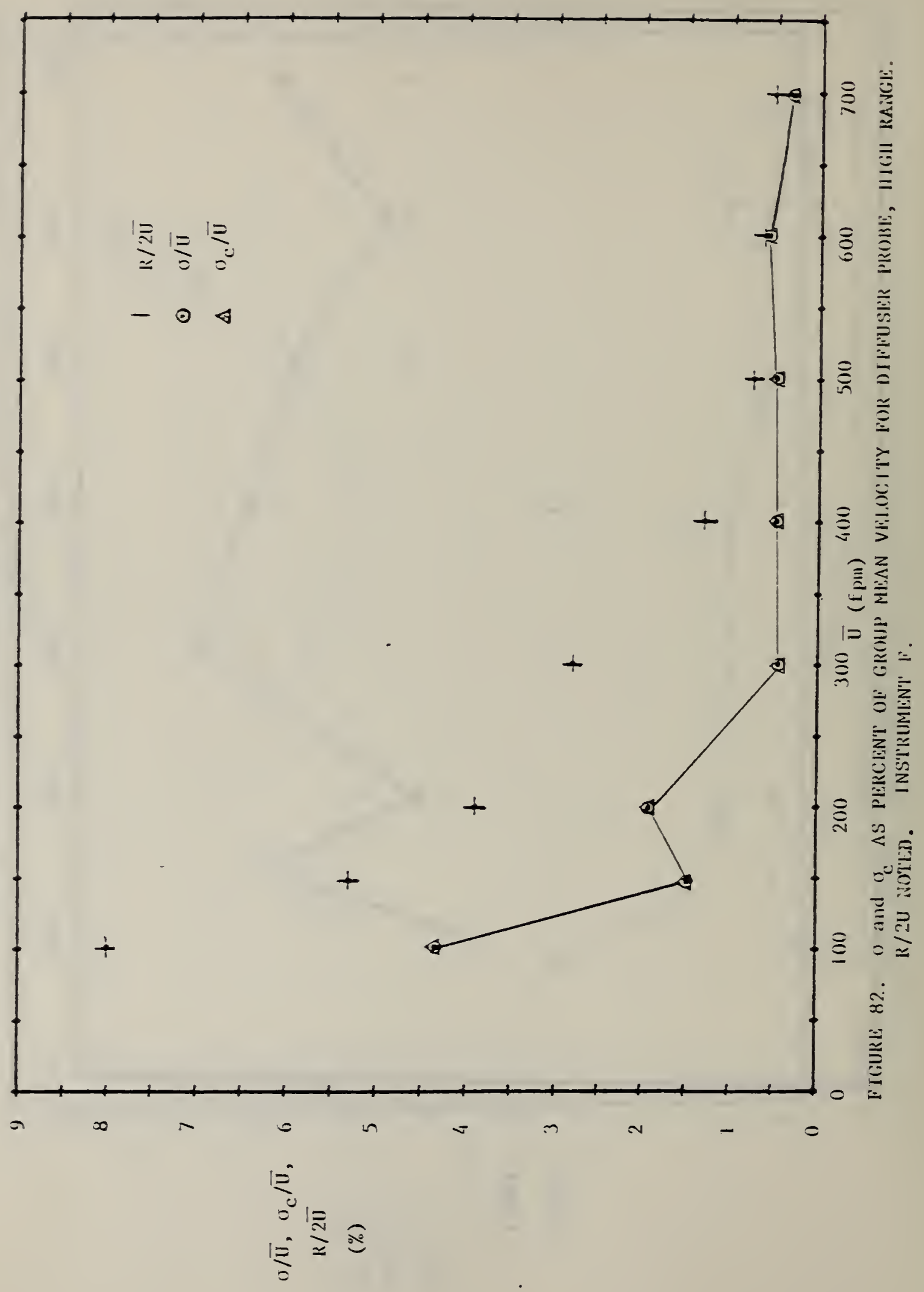




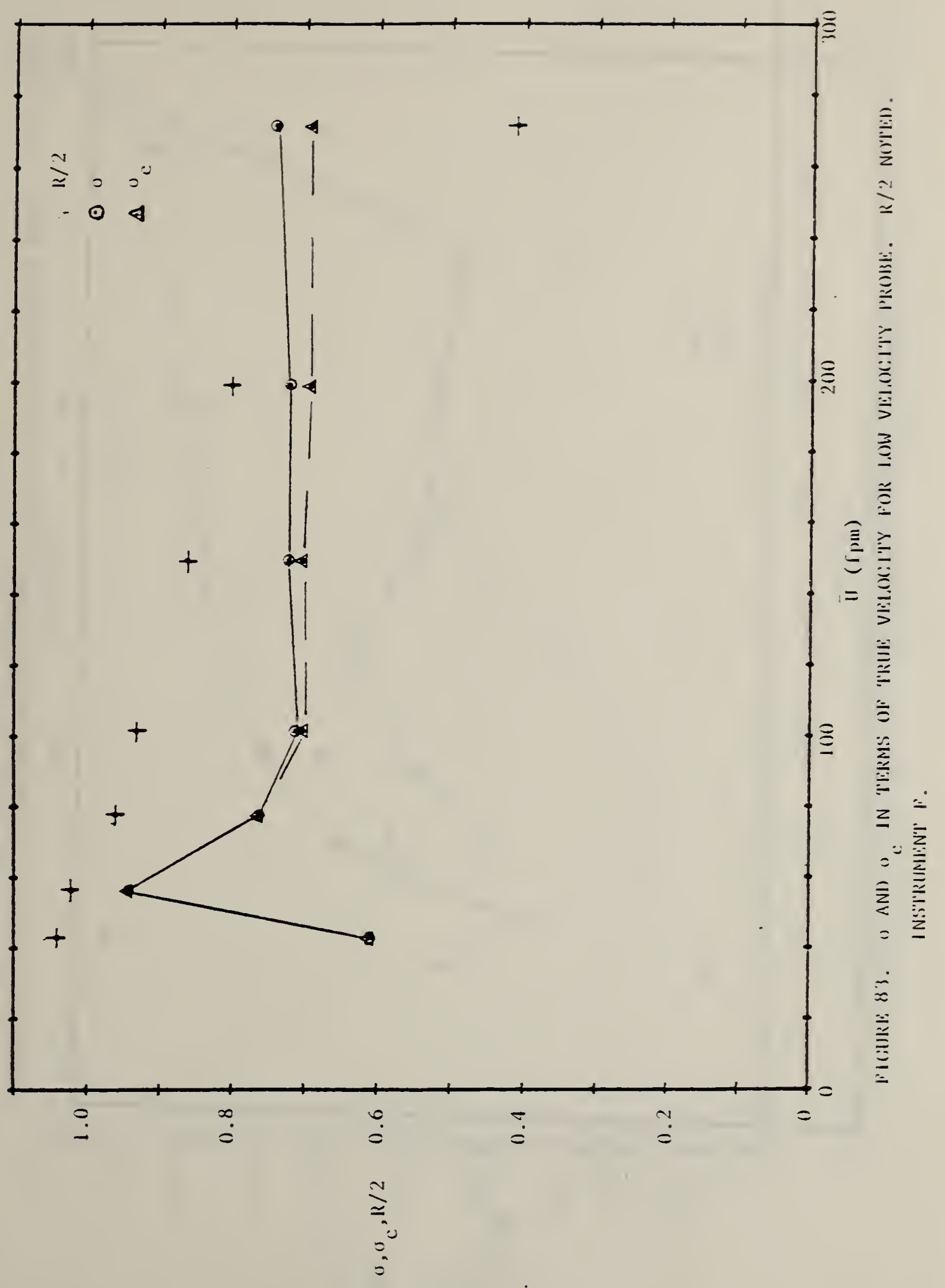




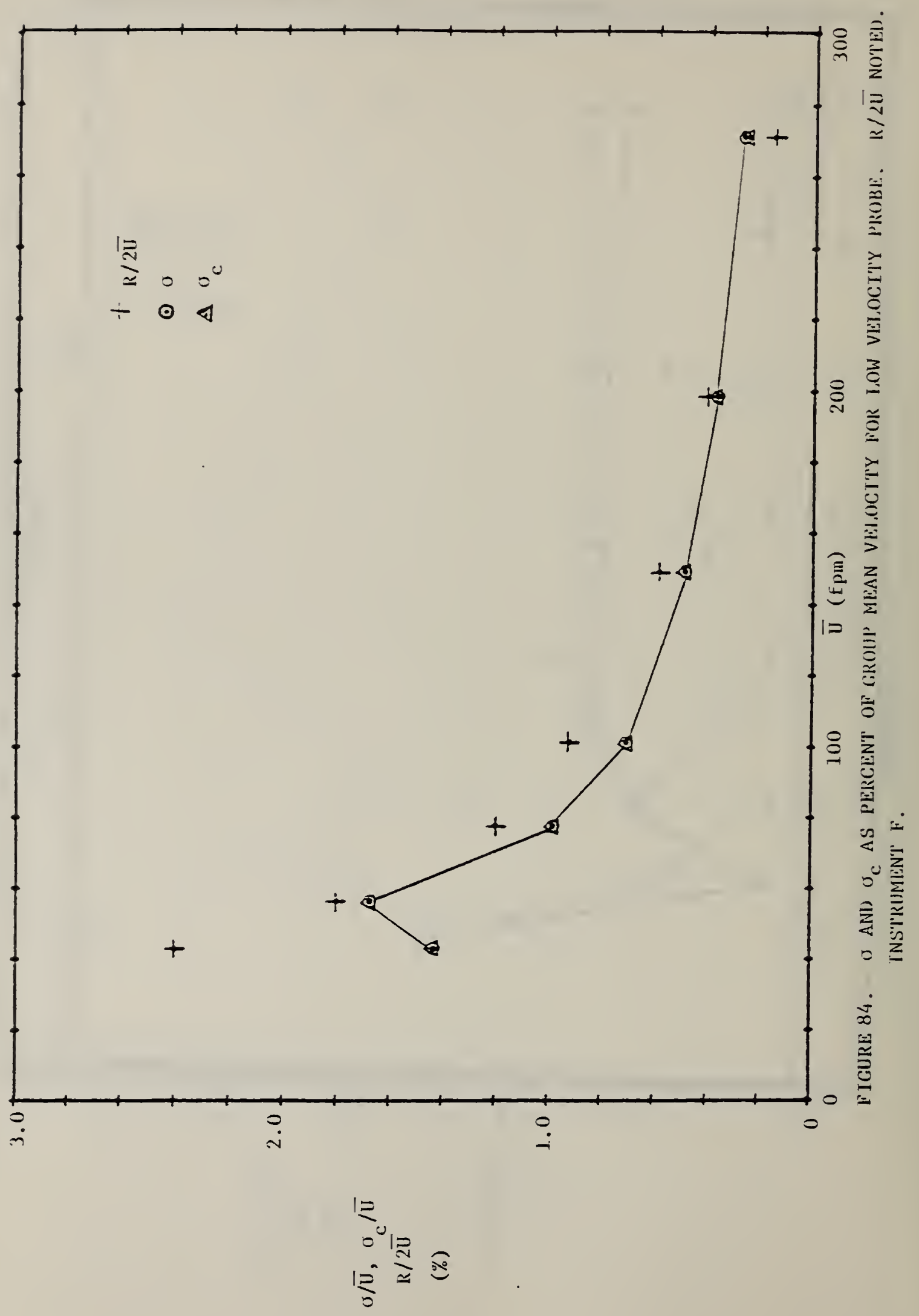




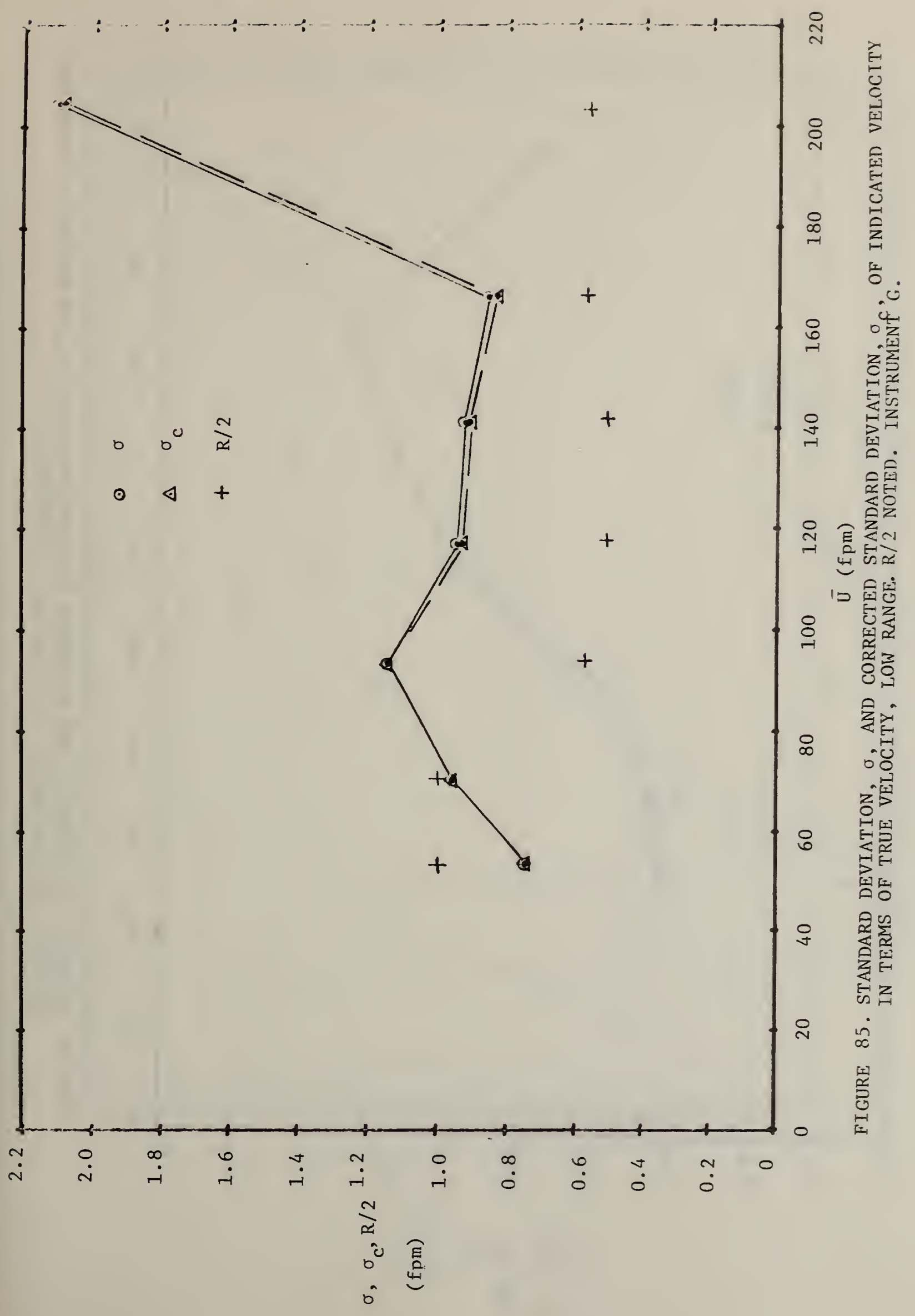




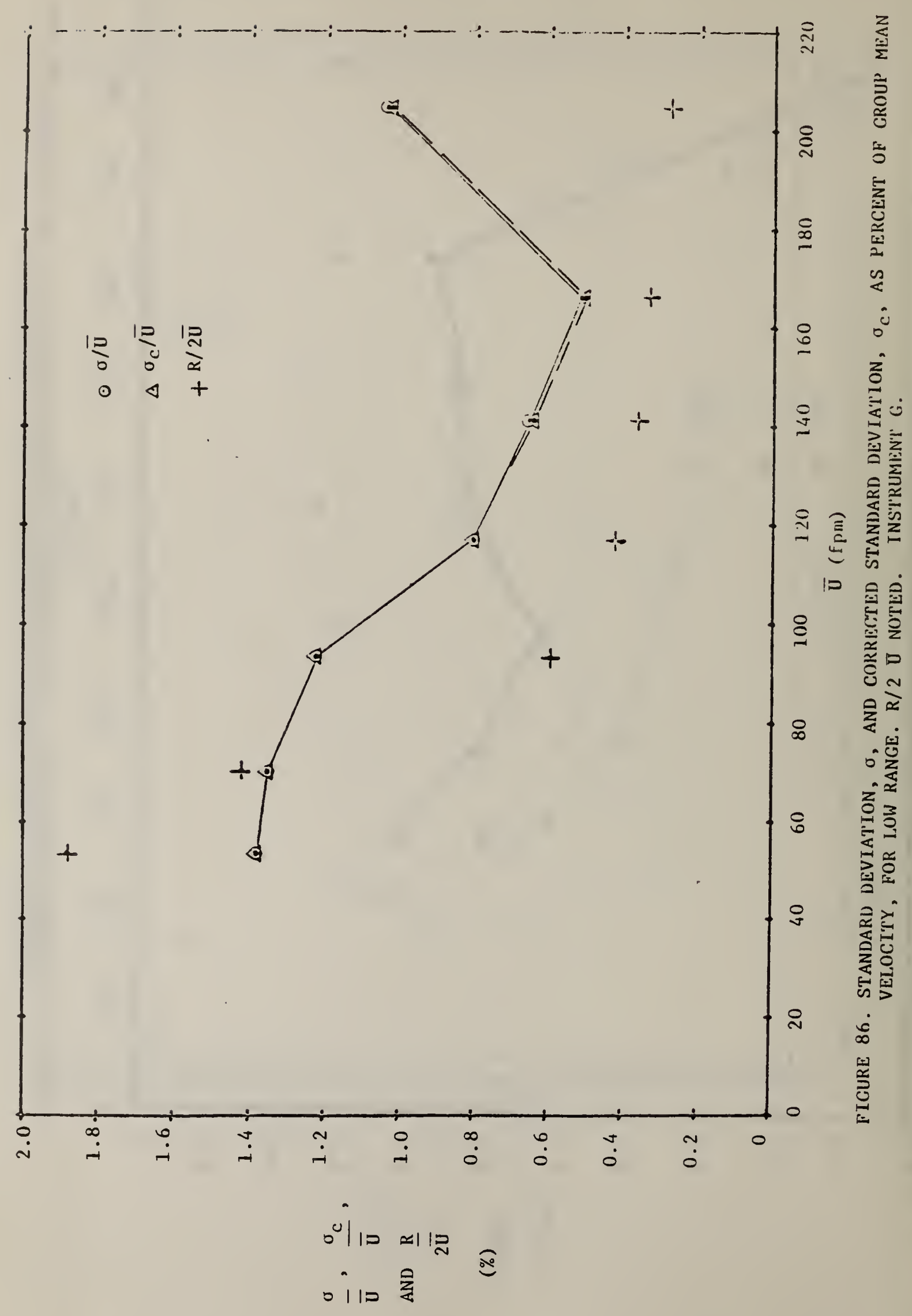




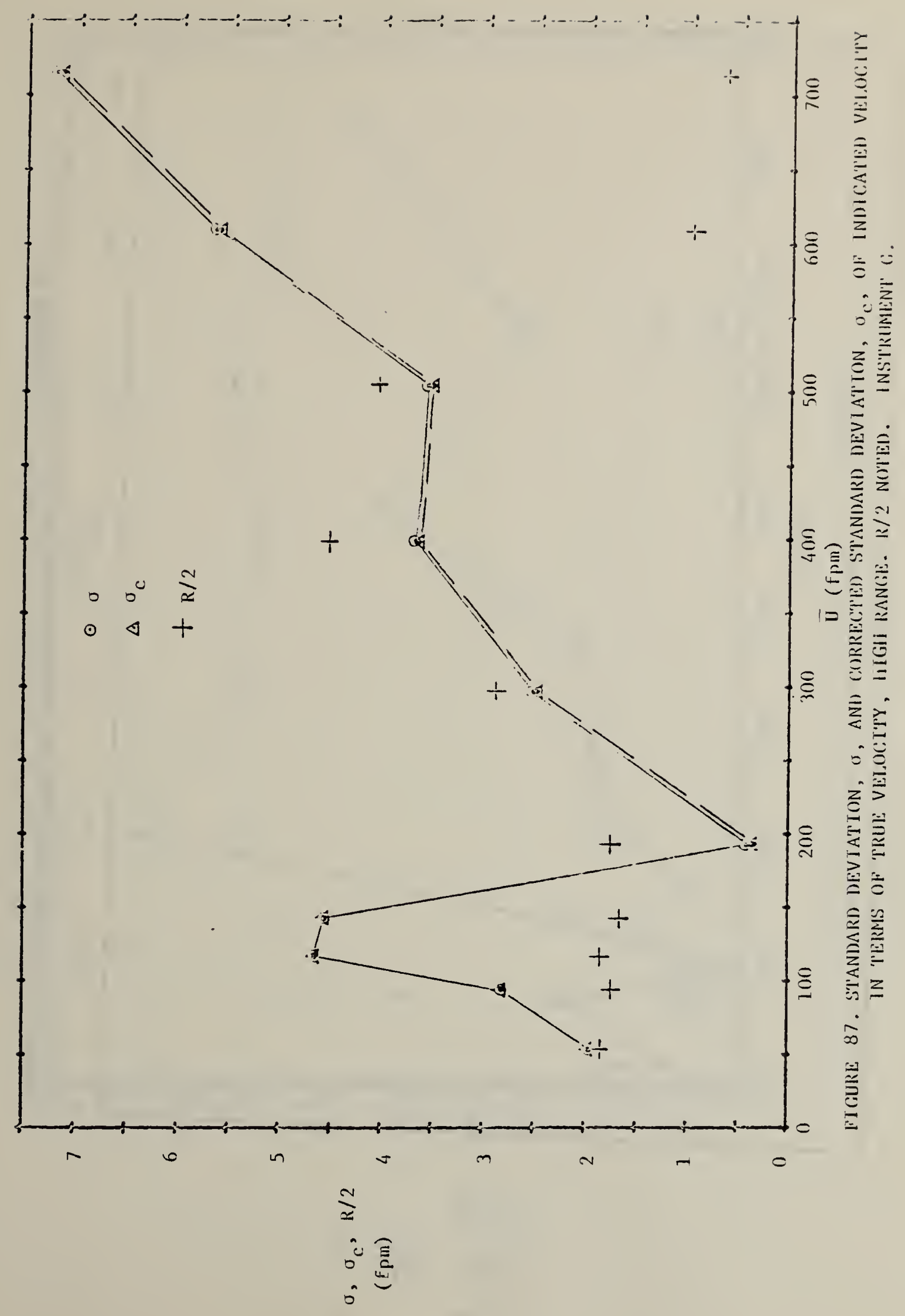




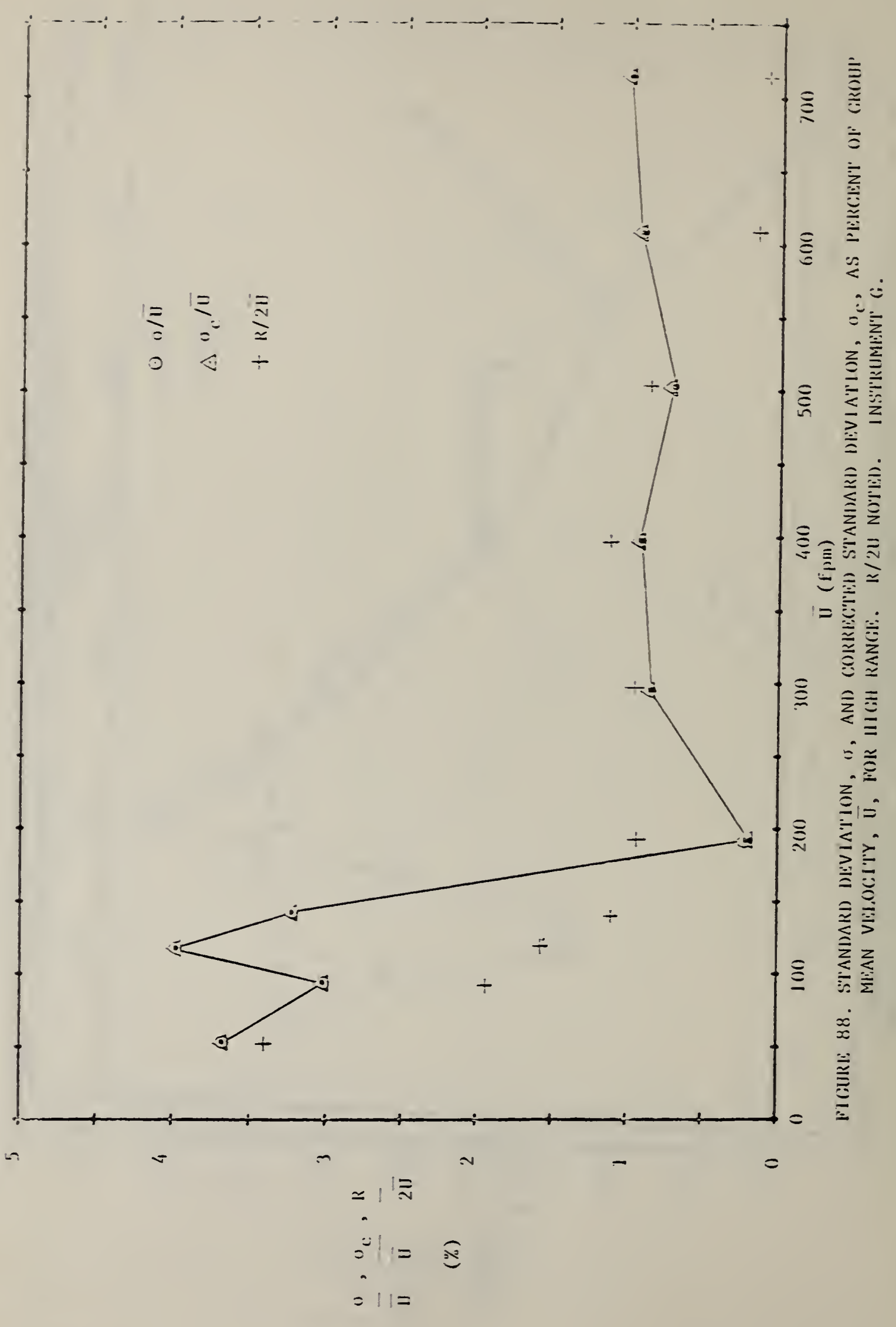




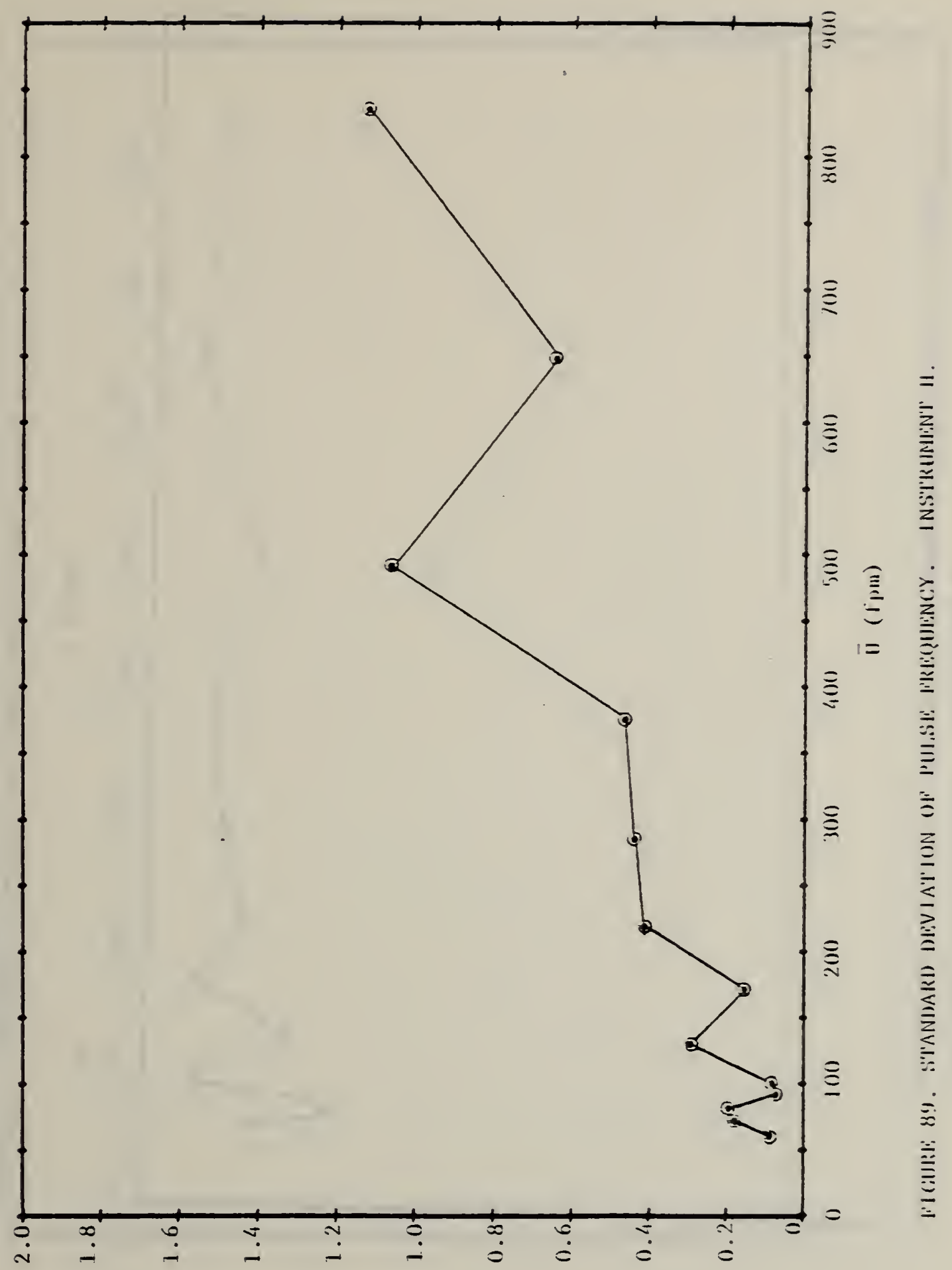

$$
0 \text { - }
$$




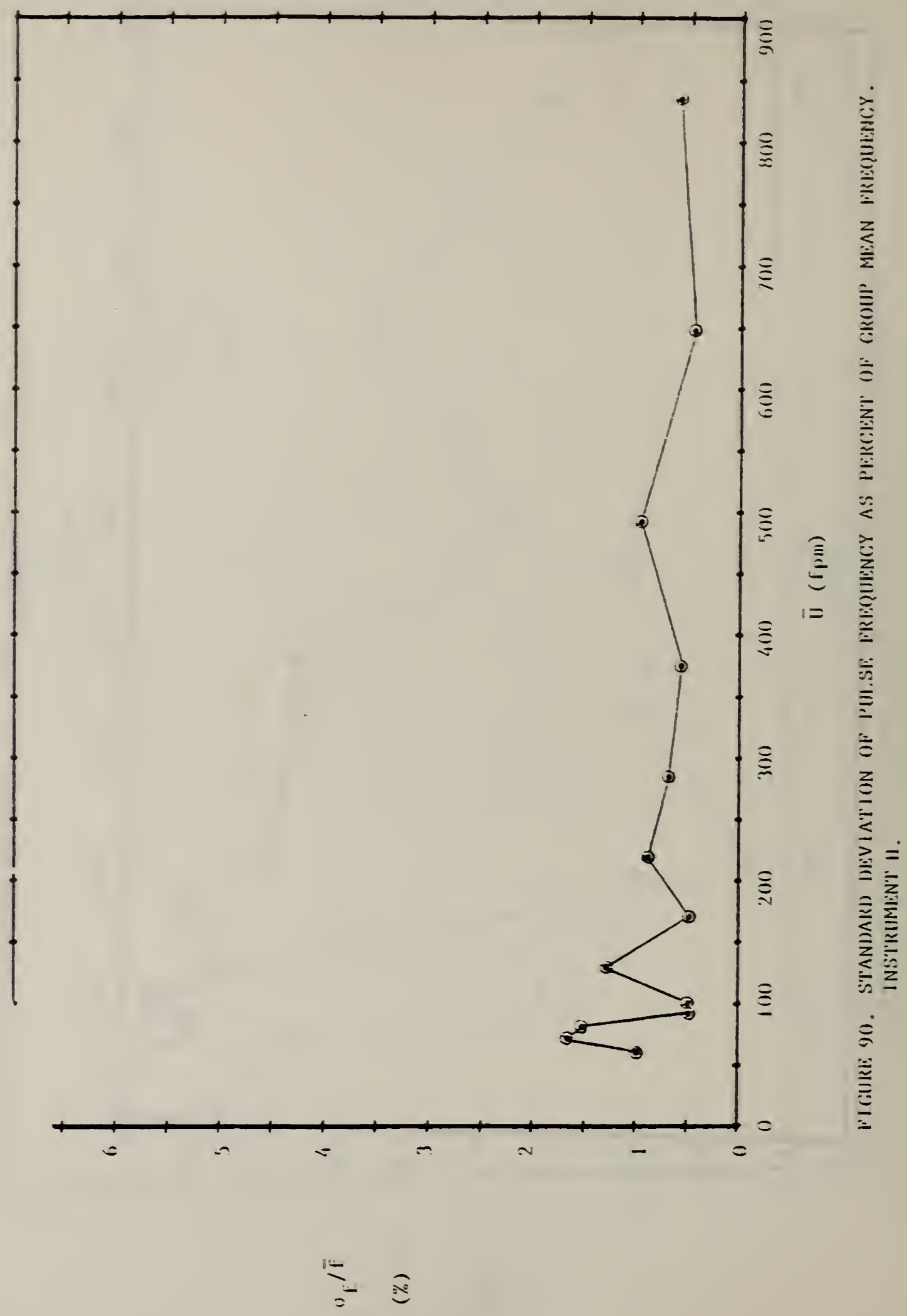




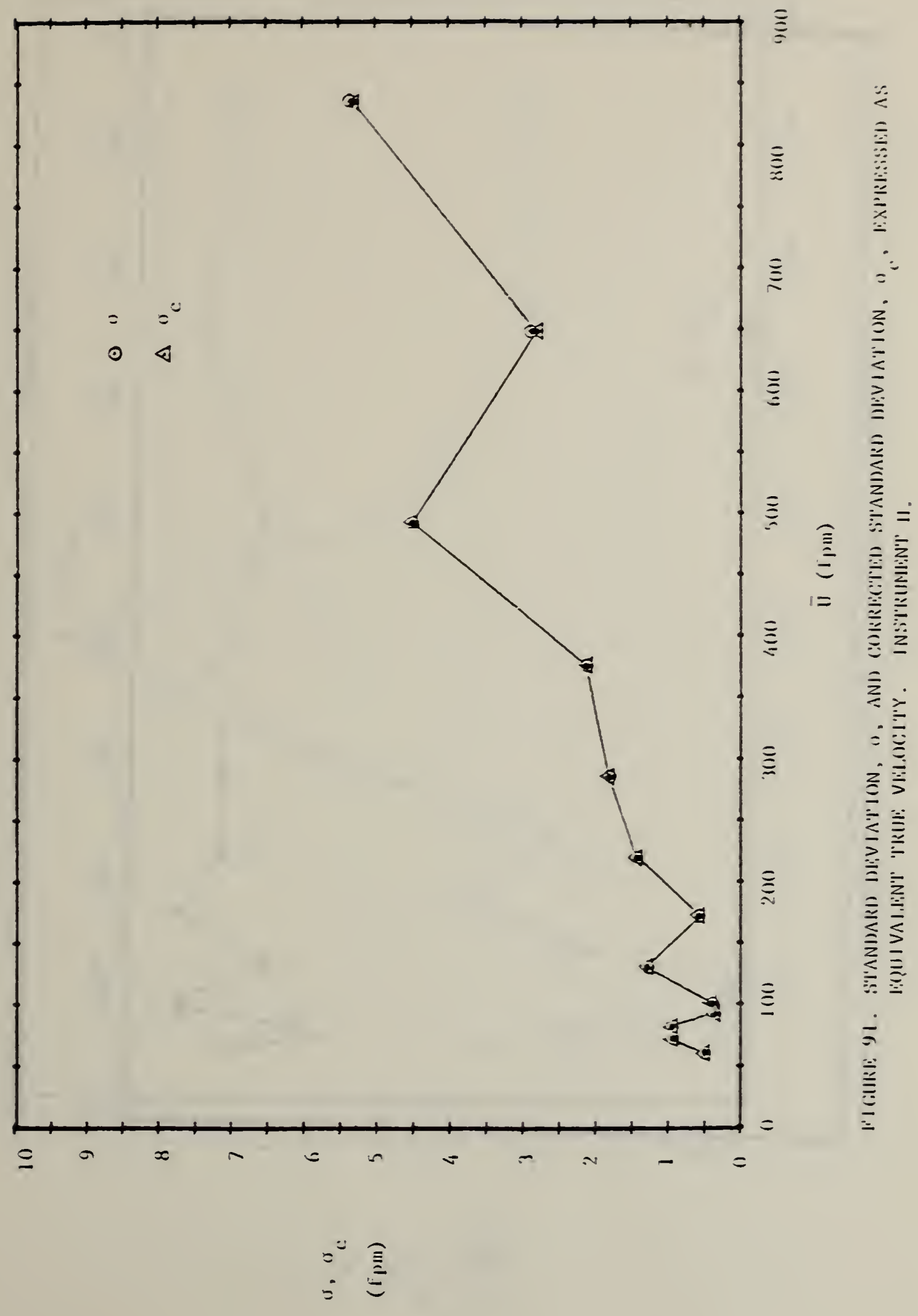




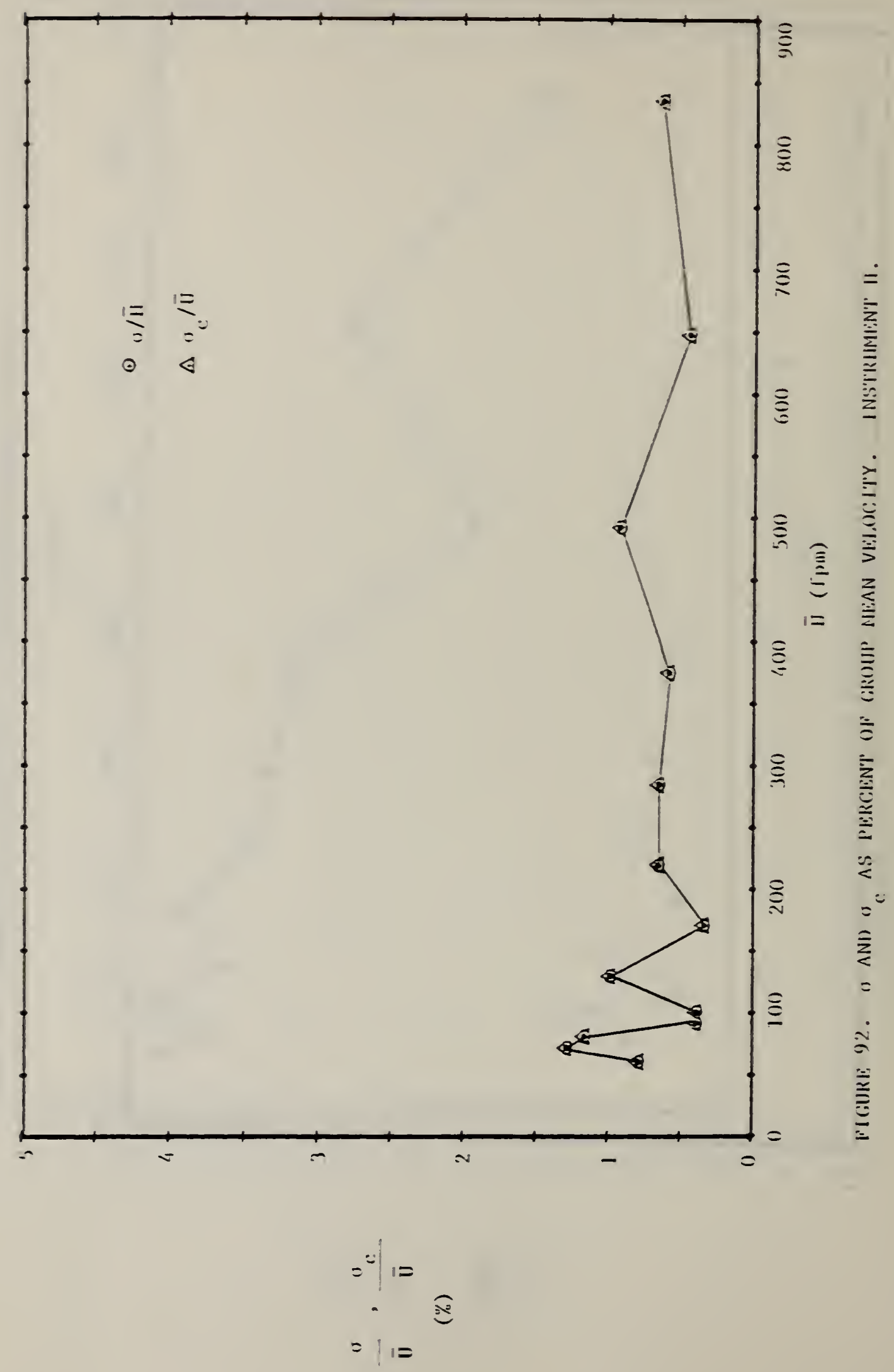




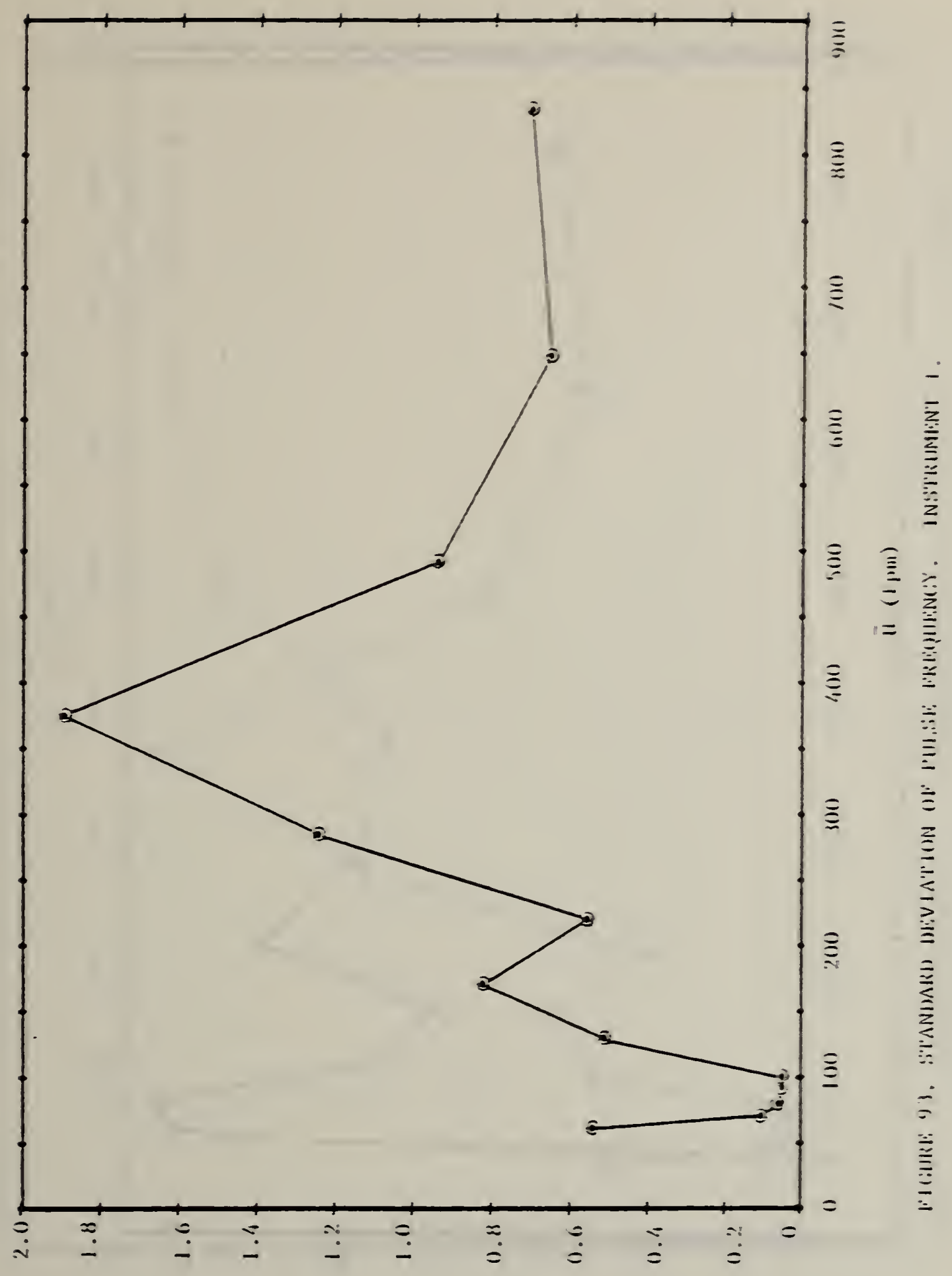

$$
=-\frac{\text { 童 }}{2}
$$




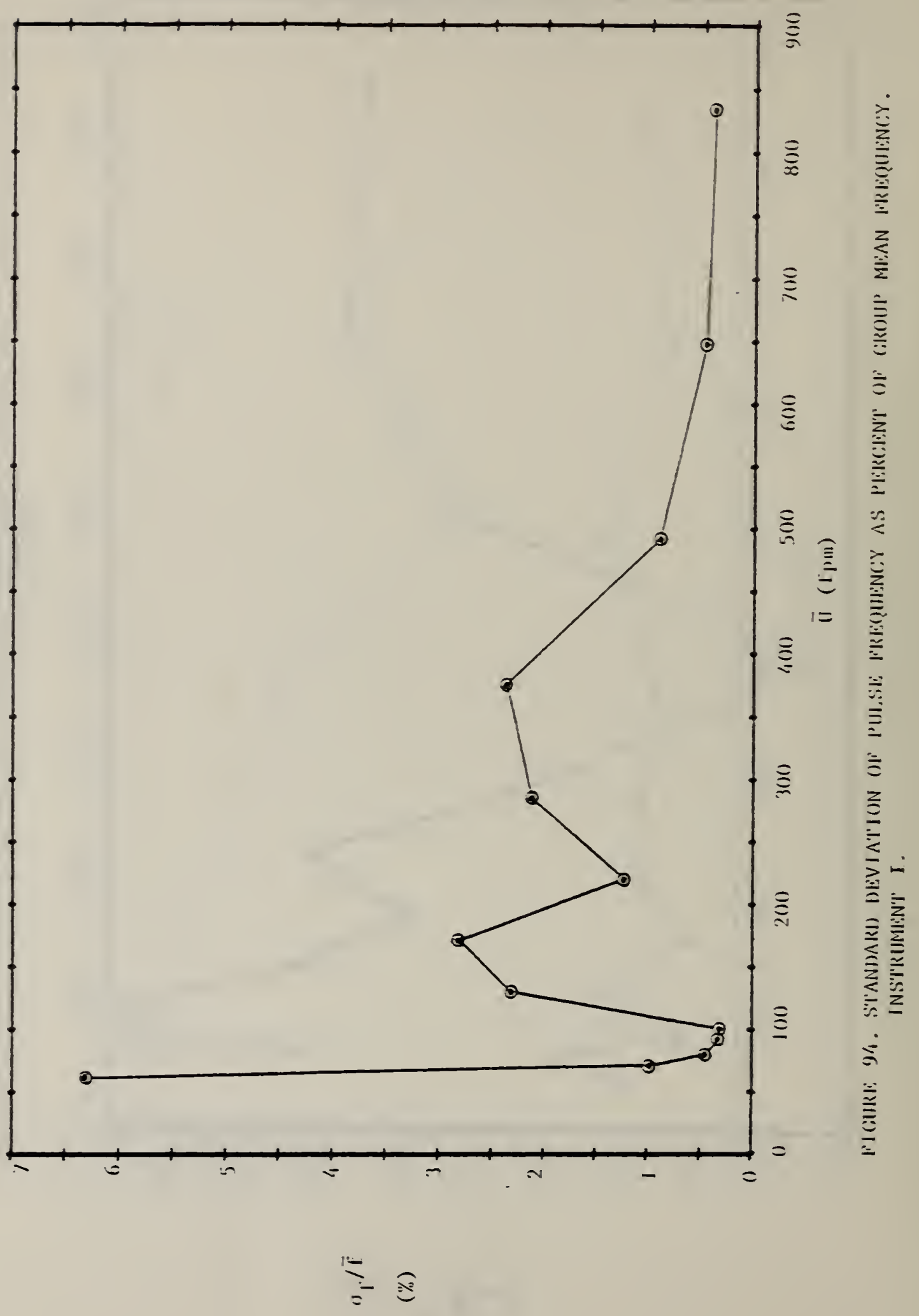




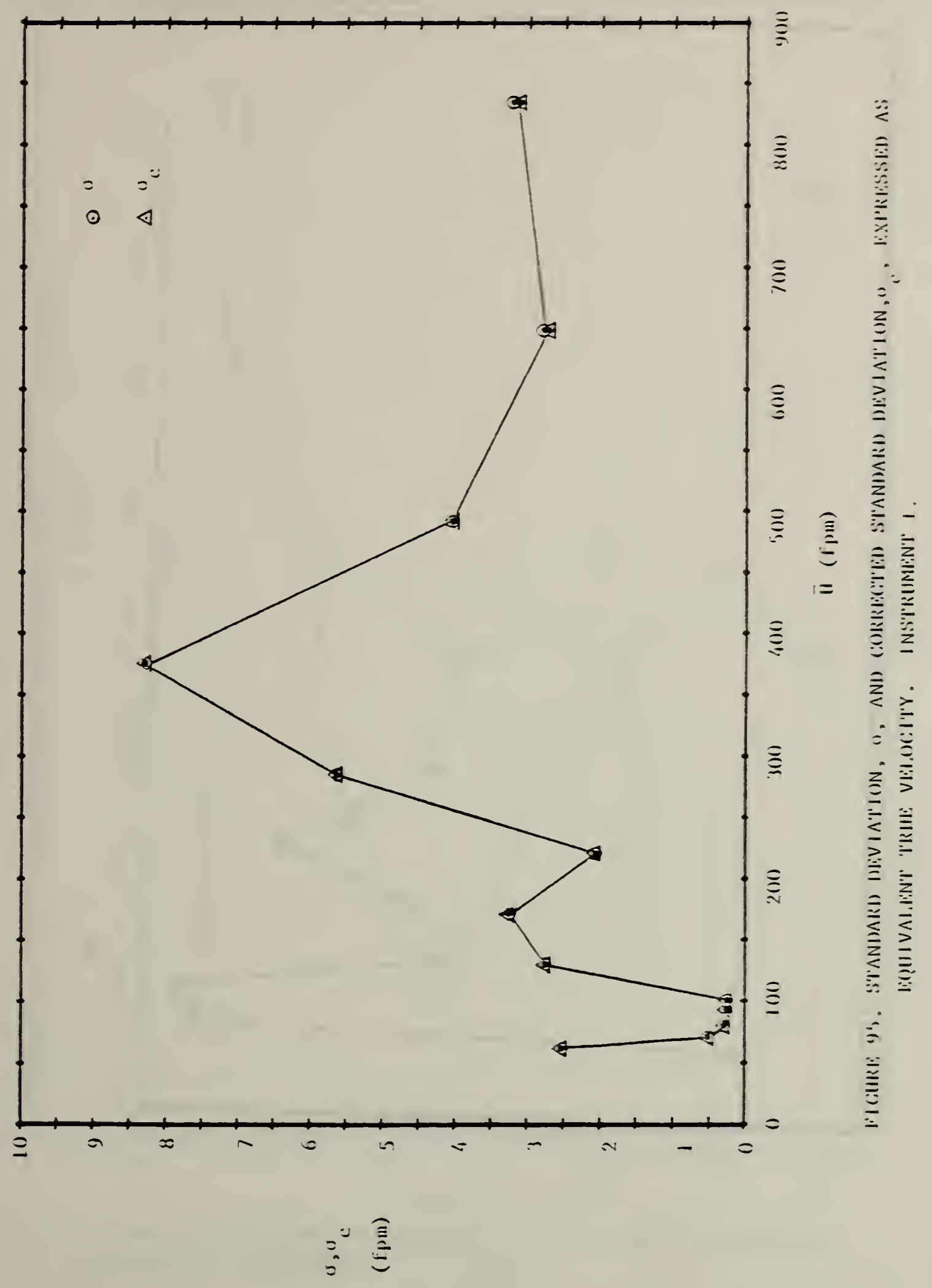




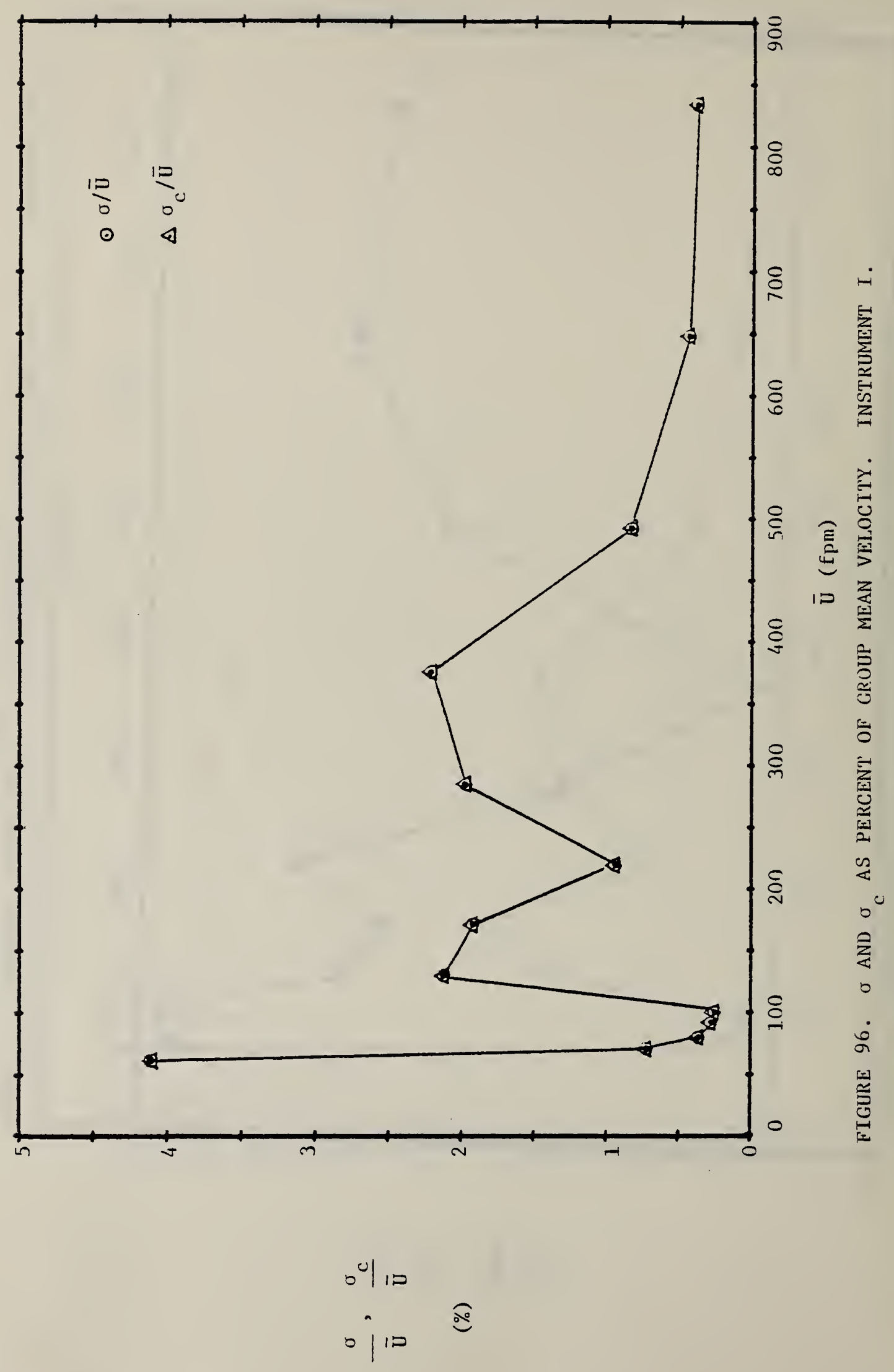




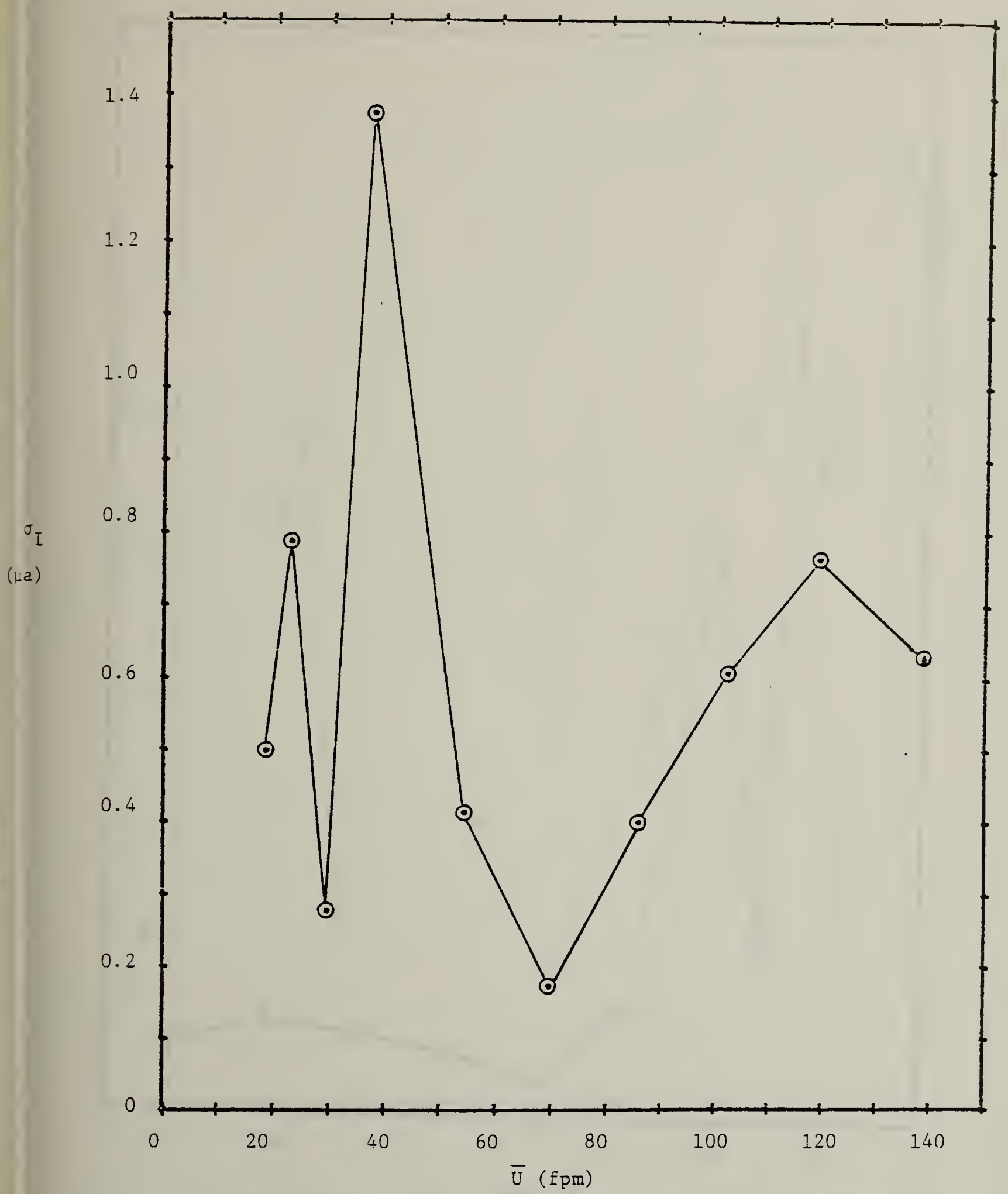

FIGURE 97. STANDARD DEVIATION OF INSTRUMENT OUTPUT AGAINST GROUP MEAN VELOCITY. INSTRUMENT J. 


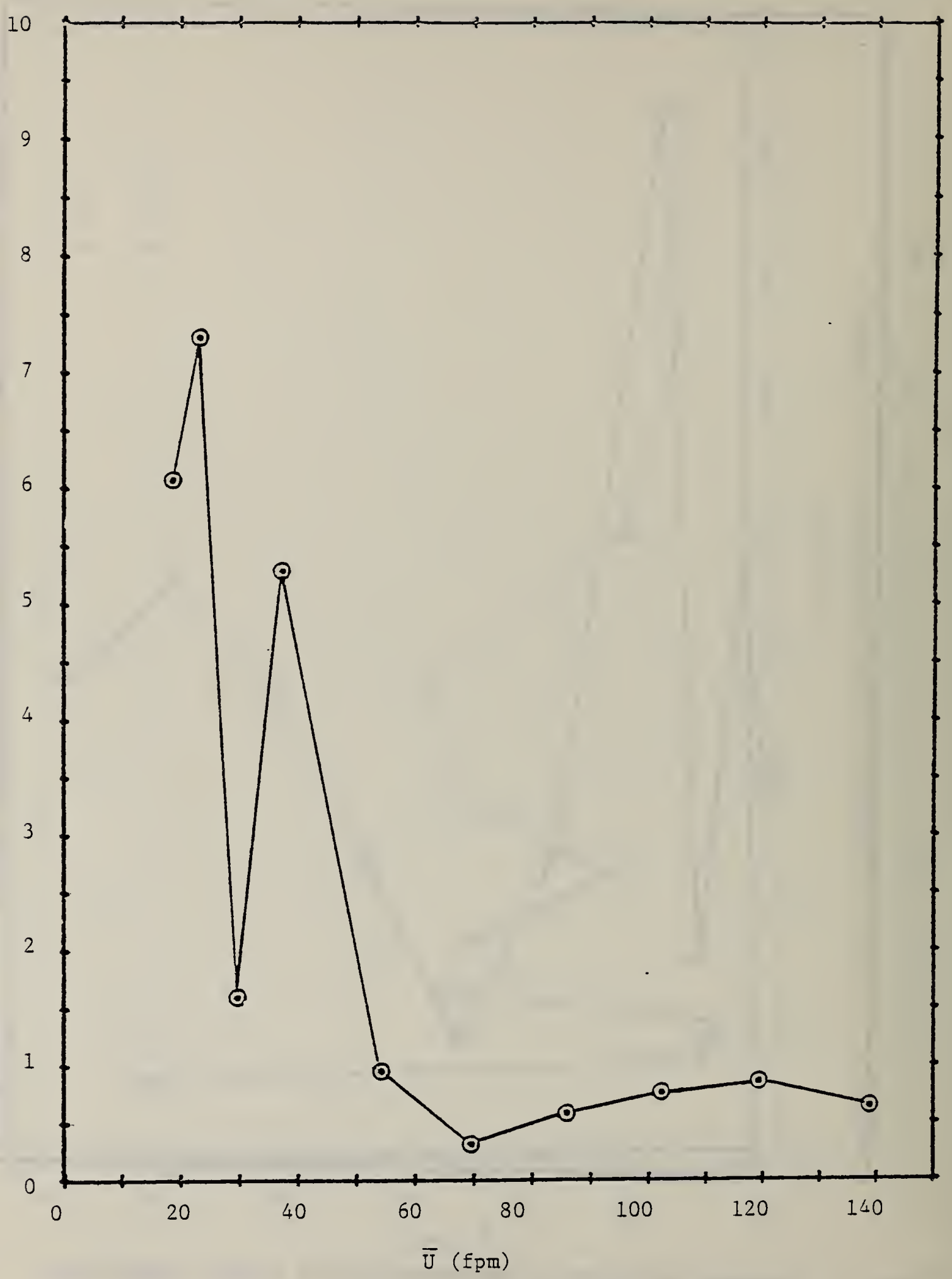

FIGURE 98. STANDARD DEVIATION OF INSTRUMENT OUTPUT AS PERCENT OF INSTRUMENT OUTPUT. INSTRUMENT J. 


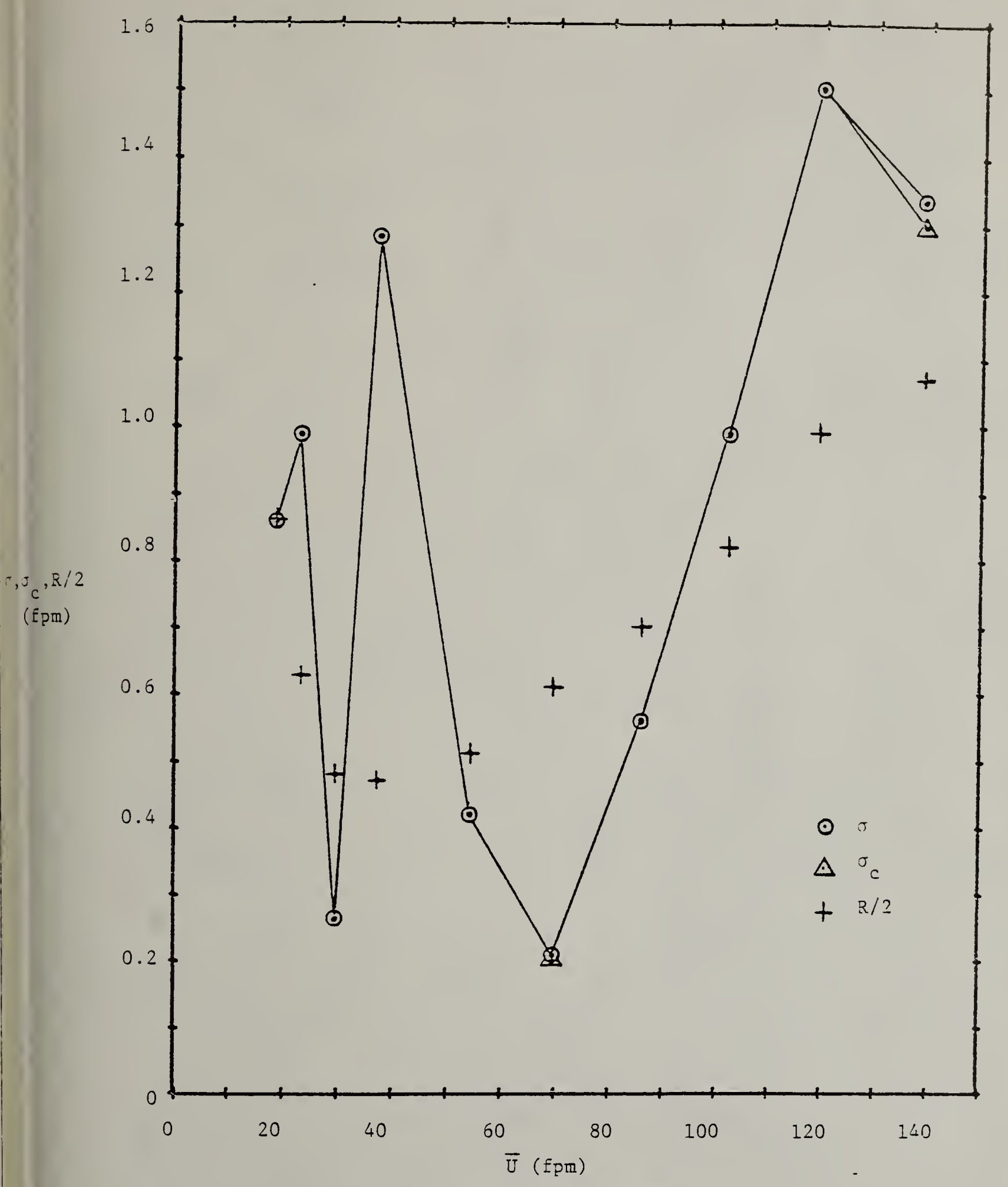

FIGURE 99. STANDARD DEVIATION AND CORRECTED STANDARD DEVIATION IN TERMS OF VELOCITY. R/2 NOTED. INSTRUMENT J. 


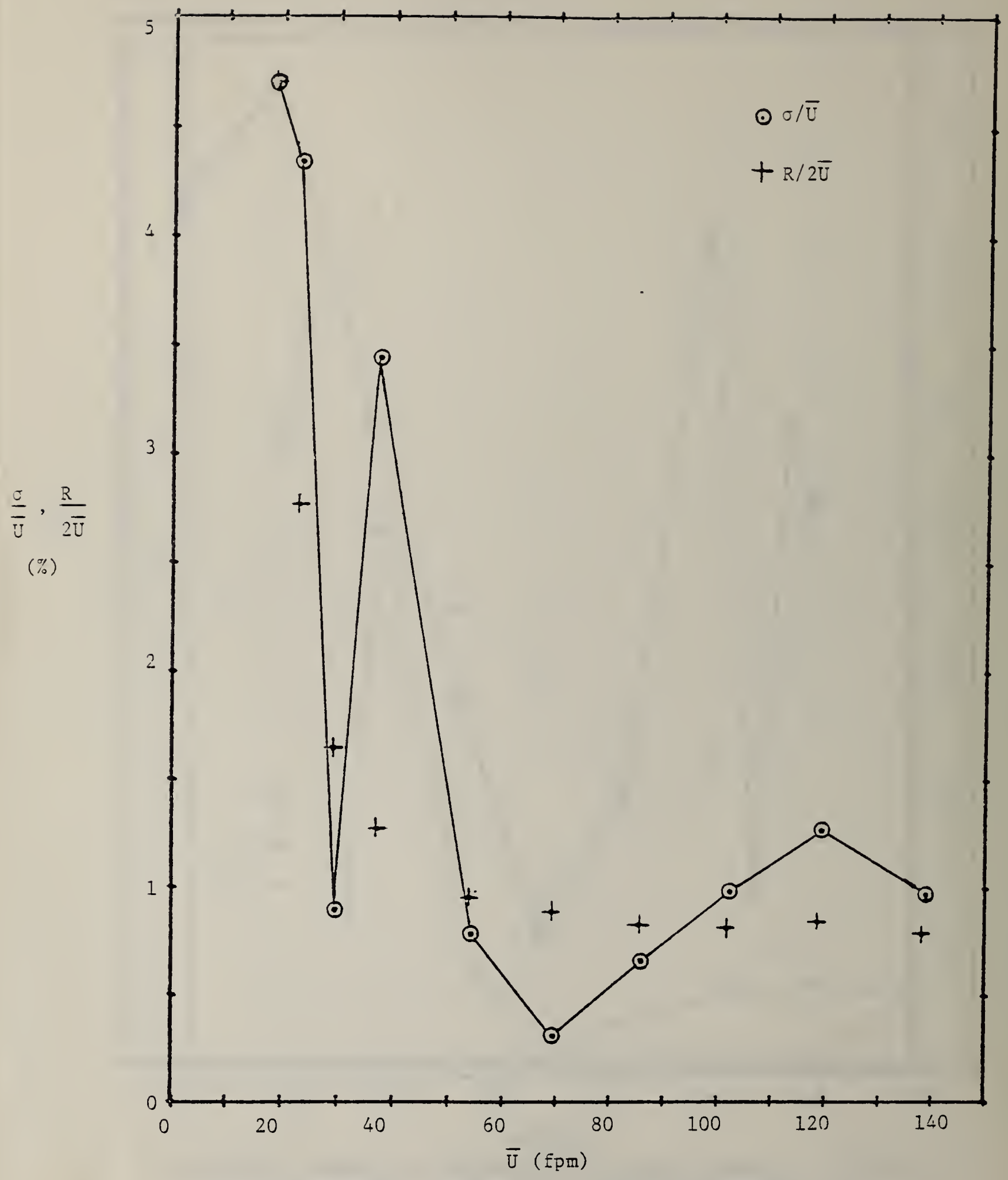

FIGURE 100. STANDARD DEVIATION IN TERMS OF VELOCITY AS PERCENT

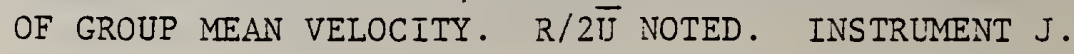

